Erster Beratungsgegenstand:

\title{
Parlament und Regierung im modernen Staat
}

\author{
1. Bericht von Professor Dr. Ernst Friesenhahn, \\ Bonn - Karlsruhe.
}

Vorbemerkung:

Als unser Vorstand mich bat, auf der diesjährigen Tagung ein Referat zu übernehmen, da habe ich es als eine Art Standespflicht angesehen, dieser Aufforderung zu entsprechen. Leider mußte ich dann später einsehen, daß die Zeit, die ich für die Vorbereitung des Referates erübrigen ksonnte, nicht ausreichte, um dieses Thema zu bewältigen. Ich habe allerdings auch Zweifel, ob $z u$ einem so umfassenden Thema in einem Referat von einer guten Stunde überhaupt jemand die Grundlagen für eine umfassende Diskussion ersch öpfend ausbreiten könnte. Immerhin wäre ein Referent, der über umfangreiche Vorarbeiten verfügt oder als Minister, Abgeordter oder Ministerialbeamter reiche praktische Erfahrungen gesammelt hat, eher in der Lage gewesen, dem Thema neue Seiten abzugewinnen und aus souveräner Stoffbeherrschung einen Querschnitt zu legen. Je mehr ich in die unübersehbare Literatur ${ }^{1}$ ) zu unserem Thema eindrang, - was nur zu einem

1) Aus der unübersehbaren Literatur kann ich nur einiges hervorheben, wobei ich mich im wesentlichen auf die neueste Literatur beschränke. - Von älteren Schriften seien erwähnt: M a x W e ber, Gesammelte politische Schriften, 1921, darin S. 126: Parlament und Regierung im neugeordneten Deutschland (1917); S. 277: Wahlrecht und Demokratie in Deutschland (1917); Ca r 1 $\mathrm{S}$ ch $\mathrm{m}$ it $t$, Die geistesgeschichtliche Lage des heutigen Parlamentarismus, 1. Aufl. 1923, 2. Aufl. (mit einer Vorbemerkung "Uber den Gegensatz von Parlamentarismus und Demokratie“) 1926; dazu: $R$ i chard Thoma, Zur Ideologie des Parlamentarismus und der Diktatur, ArchSozWiss. Bd. 53 (1925), S. 212 und $R$ i c h a r d Tönnies, Demokratie und Parlamentarismus, Schmollers Jb. Jg. 51 (1927) S. 173. - Allgemeine und rechtsvergleichende Werke: Georges Burdeau, Traité de Science Politique, T. V: L'état liberal et les techniques politiques de la démocratie gouvernée, 1953; T. VI: La démocratie gouvernante, son assise sociale et sa philosophie politique, 1956; Herman Finer, The Theory and Practice of Modern Government, 2 Bde, London 1932, in deutscher tbersetzung (hsg. von Siegfried Landshut) „Der moderne Staat", 3 Bde, 1958; C a rl J. Fri e d ri c h, Der Verfassungsstaat der Neu- 
kleinen Teil gelingen konnte -, um so mehr mußte ich erkennen, daß ich keine neuen Einsichten bieten kann, weil alles schon einmal und vieles besser und klüger gesagt worden ist, als ich es zu sagen vermag. Ich kann also nur den Versuch machen, Ihnen zur Einleitung der Diskussion einige mir wichtig erscheinende Aspekte des Themas in die Erinnerung zu rufen. Die Stoffülle hat es mir unmöglich gemacht, in den engen zeitlichen Rahmen ein in sich geschlossenes Referat zu fügen, das alle mir wichtig erscheinenden Punkte umgreifen

zeit 1953; F r i edri c h G l u m, Das parlamentarische Regierungssystem in Deutschland, Großbritannien und Frankreich, 1950; O t to $\mathrm{K}$ i r c h h e i mer, Vom Wandel der politischen Opposition, ArchRSozPh. XLIII, 1957, S. 59; K a r l L ö wenstein, The balance between legislative and executive power, Chicago Law Review Vol. 5 (1938) S. 566; ders., Verfassungsrecht und Verfassungsrealität, ArchOffR 77, 1952, S. 387; B or i s M i rkin e-Gu e t z évitch, Les Constitutions Européennes, T. I: „Essai Synthétique“, Paris 1951; A x e I V u lpi us, Die Allparteienregierung, Frankfurt 1957; Le régime parlementaire au milieu du XXe siècle, Revue internationale d'histoire politique et constitutionelle, Nouv. série Nr. 14, 1954 (Beiträge von B. Mirkine-Guetzévicht, G. Burdeau, C. J. Friedrich, K. Heckscher, P. Bastid, R. Capitant, F. Goguel); Le Travail parlementaire en France, en Grande-Bretagne, aux Etats-Unis et en Suisse. Rev. Française de Sc. politique Vol. IV Nr. 4, 1954 (Beiträge von Georges Galichon, Dorothy Pickles, Murray S. Stedman, P.-H. Coeytaux et François Goguel); Lord Campion and D. W. S. Lidderdale, European parliamentary procedure. A Comparative Handbook. London 1953; franz. Ausgabe unter dem Titel "La procédure parlementaire en Europe. Etude comparée, Paris 1955 (Cahiers de la Fondation Nationale de Sc. politique Nr. 73). - Für Deutschland: F r an z B 1 ü c h e r, Bundesregierung und Parlament, Presse- und Informationsamt der Bundesregierung 1955; H o r s t Ehmke, Militärischer Oberbefehl und parlamentarische Kontrolle, ZfPol. NF 1, 1954, S. 337; Ernst Forsth off, Verfassungsprobleme des Sozialstaats, 1954; der s., Hat der Staat noch Autorität? in "Christ und Welt" Nr. 46 v. 17. November 1955; Friedrich Glum, Kritische Bemerkungen zu Art. 63, 67, 68, 81 des Bonner Grundgesetzes, in Festgabe für Erich Kaufmann, 1950, S. 47; Wilhel m Hennis, Parlamentarische Opposition und Industriegesellschaft, in "Gesellschaft, Staat, Erziehung" 1956 S. 205; d e r s., Meinungsforschung und repräsentative Demokratie, 1957; A rnold Kött ge n, Abgeordnete und Minister als StatusInhaber, Gedächtnisschrift für Walter Jellinek, 1955, S. 195; G e r h a rd L e i b h o I z, Der Parteienstaat des Bonner Grundgesetzes, in Recht, Staat, Wirtschaft, Bd. III, 1951, S. 99; d e r s., Parteienstaat und repräsentative Demokratie, DVBl. 1951, S. 1; d e r s., Der Strukturwandel der modernen Demokratie, 1952; Herman n v. M a n goldt, Das Verhältnis von Regierung und Parlament, und: Das Verhältnis von Staatschef und Regierung, in Dt. Landesreferate z. III. Internat. Kongreß für Rechtsvergl. 1950, S. 819, 834; Fritz Münch, Die Bundesregierung 1954; Hans Peters, Neuere Entwicklungen des Parlamentarismus, in GegenwartsFrobleme des Rechts, Paderborn 1950 (Görresgesellschaft), S. 89; 
würde. Ich wollte auf der einen Seite nicht nur im Allgemeinen verharren, sondern auch einige aktuelle Streitfragen des deutschen Bundes- und Landesverfassungsrechts berühren, konnte aber andererseits nicht darauf verzichten, gewisse allgemeine Grundlagen zu entwickeln. Ich habe mir dann schließlich so geholfen, daß ich das Referat an einem bestimmten Punkt, der zeitlich geboten ist, abbreche, Ihnen aber auch noch einige Leitsätze aus dem an sich geplanten Besonderen Teil

H e l m u t R i d d e r, Parlamentarische Demokratie und autoritärer Staat, in "Diskus" (Frankfurter Studentenzeitung) 1956 Heft 1 und 2; Ulrich Scheuner, Grundlagen des modernen Staats, in Recht, Staat, Wirtschaft, Bd. 3, 1951, S. 126; de r S., Der Bereich der Regierung, in Festgabe für Rudolf Smend, 1952, S. 253; d e r s., Das parlamentarische Regierungssystem in der Bundesrepublik, DOV 1957, S. 633; K a r I S c h m id, Regierung und Parlament, in Recht, Staat, Wirtschaft, Bd. III, 1950 S. 86; Dolf Sternberger, Lebende Verfassung. Studien über Koalition und Opposition, 1956; W e r ner W e ber, Spannungen und Kräfte im westdeutschen Verfassungssystem, 1951; ders., Das politische Kräftesystem in der wohlfahrtsstaatlichen Massendemokratie, in: Zum Problem des Gleichgewichts zwischen Wirtschaftspolitik und Staatspolitik, Heft 39 der Schriftenreihe des Industrie- und Handelstages, 1956, de r s., Die Verfassung der Bundesrepublik in der Bewährung, 1957; - Für England: I vor J e n n ing s, Cabinet Government, 2nd ed., 1951; d e r s., Parliament, 1948; E I d o n G. Johnson, The Accountability of the British nationalized industries, in AmPolScReview Vol. 48, 1954, S. 316; Her b e r t Morrison, Government and Parliament, A Survey, 1954, deutsch unter dem Titel „Regierung und Parlament in England“ 1956; Parliament, A Survey, London 1952 (Beiträge von Lord Campion, L. S. Amery, D. W. Brogan, J. J. Craik Henderson, Sir Arthur Salter, H. E. Dale, Ivor Thomas, F. W. Lascelles, E. G. S. Wade, Sir Cecil Carr, A. L. Goodhart, G. M. Young). - Für Frankreich: $E \mathrm{mile} B \mathrm{lam}$ on $t$, Les conditions du contrôle parlementaire, in Revue du droit public et de la Science politique, T.66, 1950, S. 387; Friedrich August Frhr. v. d. Heydte, Parlamentarismus in Deutschland und Frankreich, in Festschrift für Hans Nawiasky, 1956, S. 323; We r n e r L u d w i g, Regierung und Parlament im Frankreich der IV. Republik, 1956; P h il i p Williams, Politics in Post-War France. Parties and the Constitution in the Fourth Republic, London 1953; Georges Ve de l, Manuel élémentaire de droit constitutionnel, Paris 1949. Für Belgien: Carl Henrik Höjer, Le Régime parlementaire belge de 1918 à 1940, Uppsala och Stockholm 1946; Aspects du Régime parlementaire Belge (Bibliothèque de l'Institut belge des Sciences Politiques Nr. 1), Bruxelles 1957 (Beiträge von G. Ciselet, H. Fayat, W.-J. Ganshof van der Meersch, M.-L. Gérard, M. Grégoire, P. Harmel, H. Rolin et P. Wigny); Le Contrôle parlementaire de l'action gouvernementale (wie vor Nr. 2), Colloque du 17 Mars 1956, Bruxelles 1957. - Für Schweden: D a n kw a r t A. Rus tow, The Politics of Compromise. A Study of Parties and Cabinet Government in Sweden, Princeton 1955. 
des Referats als Material für die Diskussion vorlege ${ }^{\mathrm{ta}}$ ). Die Weite des Themas, das unser Vorstand gestellt hat, hat jedenfalls den Vorzug, daß sie es Referenten und Diskussionsrednern überläBt, aus der Fülle des Stoffes diejenigen Fragen herauszugreifen, die ihnen bedeutsam erscheinen.

I.

1. Jeder Staat muß eine Regierung haben. Nicht jeder Staat braucht aber ein Parlament. Wenn also das Thema „Parlament und Regierung im modernen Staat" behandelt werden soll, so kann nur ein Staat gemeint sein, in dem ein echtes Parlament als ein aus allgemeinen und freien Wahlen hervorgehendes, an der Staatswillensbildung zumindest als gesetzgebende Körperschaft maßgebend beteiligtes Verfassungsorgan besteht. Autoritäre Staaten aller Spielarten scheiden also aus unseren Betrachtungen aus. Es gehört weder zu den Aufgaben dieses Referates, den Gründen für die antiparlamentarischen Tendenzen in der Gegenwart nachzuspüren, noch die Typen der autoritären Staaten herauszuarbeiten oder den quasi-parlamentarischen Einrichtungen autoritärer Staaten Aufmerksamkeit zu schenken. Wir beschränken uns auf jene Staaten, in denen es als eine Grundfreiheit anerkannt ist, "in angemessenen Zeitabständen freie und geheime Wahlen unter Bedingungen ${ }^{2}$ ) abzuhalten, welche die freie Äußrung der Meinung des Volkes bei der Wahl der gesetzgebenden Körper$\mathrm{s}$ c h a f t gewährleisten", wie es in Artikel 3 des Zusatzprotokolls zur Europäischen Konvention zum Schutz der Menschenrechte und Grundfreiheiten heißt.

2. Unser Thema lautet nicht „Parlament und Regierung in der Bundesrepublik Deutschland“, sondern „Parlament und Regierung im modernen Staat". Damit ist die rechtsvergleichende Betrachtung nahegelegt. $\mathrm{Da}$ wir aber eine Vereinigung von deutschen Staatsrechtslehrern sind, dürften wohl doch die einschlägigen Fragen des deutschen Bundesund Landesverfassungsrechts im Vordergrund stehen. Schon aus Zeitgründen kann nur gelegentlich ein Blick auf fremde Staaten geworfen werden, wenn auch zunächst die verschiedenen Regierungssysteme unterschieden werden müssen, die

1a) Ich hoffe, den zweiten Teil zusammen mit dem überarbeiteten und erweiterten ersten Teil später als Sonderschrift vorlegen zu können.

2) Das setzt also Freiheit der Parteigründung, Mehrparteiensystem, Recht zur verfassungsmäßigen Bildung und Ausübung einer parlamentarischen Opposition, Freiheit der Meinungsäußerung, Vereins- und Versammlungsfreiheit voraus. 
in den der freiheitlichen Demokratie zugewandten Staaten entwickelt worden sind, um unser parlamentarisches System einzuordnen. Im übrigen kann man Rechtsvergleichung nur mit größter Vorsicht betreiben, da die Gestalt des Regierungssystems ebenso stark von außerrechtlichen - psychologischen, historischen, soziologischen, ökonomischen - Voraussetzungen wie von verfassungsrechtlichen Normen ${ }^{3}$ ) bestimmt wird. Bei gleichem Wortlaut der einschlägigen Verfassungsbestimmungen kann die Verfassungswirklichkeit gänzlich verschieden aussehen. Insbesondere die vom Volikscharakter bestimmte Parteistruktur und die Reaktion des Volkes in politischen und ökonomischen Krisenzeiten spielen dabei eine entscheidende Rolle. Heil und Unheil liegen nicht in den verfassungsrechtlichen Institutionent), sonderndarin, wiedas Volk von ihnen Gebrauch zu machenverstehts). Ich glaube daher nicht, daß das Scheitern der Weimarer Republik auf Mängel der Weimarer Reichsverfassung zurückzuführen ist'), wie ich auch in den mit so großer Sorgfalt ausgeklügel-

3) Nicht nur das englische Kabinettsystem hat sich ohne verfassungsgesetzliche Normierung entwickelt, auch die Verfassungsurkunden von Belgien, Norwegen und Schweden z. B. enthalten keine Regeln über parlamentarische Regierung; nach dem Wortlaut ihrer Bestimmungen könnten die Monarchen "ihre" Minister nach Belieben ernennen und entlassen. - Vgl. auch Löwens te i n , Arch OffR 75, 159 f.: „Der Parlamentarismus ist im wesentlichen eine pragmatische und nicht eine dogmatische Erscheinungsform der politischen Ordnung. Er stellt keinen eindeutigen und in sich geschlossenen Regierungstyp dar."

4) Ihr Wert soll nicht bestritten werden: sie können zur Sichtbarmachung des Bruchs mit der alten Ordnung zwingen, wenn revolutionäre Bewegungen die Macht ergreifen wollen (vgl. als etwa einerseits Art. 150 Hess. Vfsg., andererseits Hitlers Weg der "Legalität").

s) Werner Kägi (Stadien im Prozeß der Demokratie, Schweizer Monatshefte Mai 1957 S. 99) bezeichnet als die Grundrichtung des von ihm unterschiedenen dritten Stadiums des demokratischen Denkens, zu dem unsere Zeit aufgerufen sei "die klare Erkenntnis, daß nicht die Institutionen die Demokratie ausmachen, sondern die geistige Verfassung der Bürger oder doch der großen Mehrheit der Bürger." Auch nach Ulrich Sch eu ner (DOV 1957, 637) hängt die Zukunft des deutschen Staates nicht nur von der Leistungsfähigkeit seiner Organisation ab, „sondern vor allem auch von der lebendigen Erfüllung der geistigen Anschauungen, die ihn tragen und seinen Einrichtungen ihre Legitimation geben ${ }^{\text {“. }}$

6) Ebenso Sche uner, DOV 1957, 633 unter Verweisung aut die Darstellung von B r a cher, Die Auflösung der Weimarer Republik, (2. Aufl. 1957), der die Ursache für den Weg „Von der parlamentarischen Demokratie zum Präsidialstaat" (S. 28 fi.) mit Recht in der "Schwäche und Unsicherheit der parlamentarischen Regierungs $\mathrm{p} r \mathrm{ax}$ i s" sieht. 
ten Neuerungen des Grundgesetzes für das Verhältnis von Parlament und Regierung keine Garantie für das Funktionieren des intendierten Regierungssystems finden kann. Es kommt auf die Menschen an, die die Verfassung handhaben.

Man wird sich darum auch vor übereilten Deutungen und Prognosen hüten müssen, die gerade in unserem Problemkreis so oft anzutreffen sind. Oft wird man feststellen können, daß das, was erste Sachkenner mit Sicherheit als Ziel einer Entwicklung vorausgesagt haben, in der Wirklichlkeit nicht eingetreten ist. In der Politik ereignet sich eben immer wieder das Unerwartete und wirft alle Prognosen über den Haufe $n^{7}$ ).

3. Wenn das Thema gestellt ist „Parlament und Regierung im modernen Sta a t", so ist darin bereits die These beschlossen, daß die Stellung von Regierung und Parlament und das System ihrer gegenseitigen Beziehungen sich gegenüber früheren staatlichen Epochen gewandelt haben. Bevor wir versuchen, die heutige Funktion dieser beiden obersten Staatsorgane und ihr Verhältnis zueinander in der einen oder anderen Richtung zu klären, müssen wir zunächst fragen, was denn die für unseren Zusammenhang bedeutsamen Merkmale des "modernen Staates" sind.

Vielleicht kann man in aller Kürze vier wesentliche Unterschiede gegenüber der klassischen liberalen repräsentativen Demokratie herausheben:

7) Vgl. z. B. Englands Rückkehr zum Zweiparteiensystem, die ein so ausgezeichneter Sachkenner wie Karl Löwenstein (JbOffR 20, 254) für unwahrscheinlich hielt (dazu A r is JbÖftR NF 2, 109), oder den Wahlsieg der Konservativen in Canada im Juni 1957, die die Liberalen nach 22jähriger Herrschaft ablösten und ihre zunächst schwache Mehrheit bei den Neuwahlen im März 1958 auf $80 \%$ der Sitze erhöhten. Auch konnte 1919 niemand voraussehen, daß sich die Weimarer Republik entgegen der von der Verfassung intendierten parlamentarischen Regierungsweise zu einem reinen Präsidialstaat entwickeln würde. Andererseits erscheint mir die negative Prognose, die heute manche Autoren (etwa Werner W e ber in den Anm. 1 erwähnten Schriften oder Winfried Martini, Das Ende aller Sicherheit, 1954) der repräsentativen Demokratie stellen, verfrüht und übertrieben. In diesem Sinn bekenne ich mich durchaus zu meinem "unbekümmert zuversichtlichen Ton" (B a r ing im Bericht über diese Tagung DVBl. 1958, 13); mit Peter Schneider (Vortrag im Nachtprogramm des Senders Freies Berlin am 25. Oktober 1957) halte ich dafür, daß „unser parlamentarisches System im Zeitalter der sogenannten Massengesellschaft noch sinnvoll “ ist, und zwar gerade als Gegengewicht gegen die nicht zu bestreitenden Gefahren der Vermassung. 
a) Der Grundsatz der politischen Gleichheit aller Staatsangehörigen schließt die Staatsführung durch privilegierte Schichten aus.

b) Die Notwendigkeit, diese Masse der Staatsbürger durch politische Parteien zu organisieren, hat aus den liberalen Honoratiorenparteien die bürokratisierten Massenparteien werden lassen.

c) Die Parlamente haben sich aus der liberalen Repräsentativversammlung zur demokratischen Volksvertretung entwickelt.

d) Die Staatsaufgaben sind im Zeitalter des Wohlfahrtsstaates ungeheuer angewachsen.

Das Zeitalter der Masse und der ihm entsprechende demokratische Massenstaat führen große Gefahren herauf; sie bieten aber auch große Chancen ${ }^{8}$ ). Entscheidend für die Behandlung der Fragen von Parlament und Regierung ist die grundsätzliche Einstellung zur „Masse“. Wer nur mehr Masse sieht, den Einzelnen im politischen Raum nicht mehr als Persönlichkeit wertet'), wer den Wähler als dumm verkauft, der Wählerschaft jede Fähigkeit zu vernünftiger Entscheidung aberkennt, wird die Einrichtung eines aus allgemeinen Wahlen hervorgehenden Parlaments für sinnlos erklären. Er wird für die autoritäre Führung der Masse durch eine starke Regierung ohne entscheidende Mitwirkung eines Parlaments ein-

8) Vgl. etwa den Sammelband „Masse und Demokratie“ hsg. von A l be r t H u n o l d, Erlenbach-Zürich und Stuttgart 1957. Gegenüber der im Negativen verharrenden Diagnose des Massenmenschen als "Anti-Individium" in dem Beitrag von $\mathrm{M}$ i chael Oakeshot t ("Die Massen in der repräsentativen Demokratie") erscheint mir der Beitrag von W e r n e r $\mathrm{K}$ ä g i („Das Massenproblem in der direkten Demokratie") besonders wichtig, weil er auch die „Frage der Therapie“ stellt, ausgehend von der Uberlegung, daß zwar nur auf Grund einer rückhaltlos offenen Diagnose eine klare Therapie möglich ist, daß aber „nur derjenige, der helfen will, zur Diagnose berufen und befähigt ist". Wesentlich für die „Politik der Entmassung" ist nach ihm "die Erweckung und Festigung neuer personhafter Gemeinschaft". In der Uberzeugung, daß die Vermassung noch nicht so total ist, wie sie vielfach dargestellt wird, und daß Heilkräfte vorhanden sind und aktiviert werden können, weiß ich mich mit Kägi einig. Nur in dieser Haltung, die vielleicht von mancher.Seite als naiver Optimismus gescholten oder belächelt wird, kann man m. E. an die Interpretation einer Verfassung herangehen, die am Idealbild der repräsentativen Demokratie festhält.

9) In zwei eindrucksvollen Schriften haben uns deutsche Parlamentarier gezeigt, wie sie über die Persönlichkeit im heutigen Parteien- und Verbändegetriebe denken: Adolf Arndt, Die Persönlichkeit in der parlamentarischen Demokratie, Berlin 1958, und Hermann Ehlers, Führer und Funktionär in der deutschen Politik, Berlin 1956. 
treten. Wer aber auch heute noch das personale Element in der Masse sieht - im Verhältnis des Wählers zu den Parteien und den Wahlkandidaten, des Wahlkandidaten zu den Wählern, des Abgeordneten und des Ministers zu seiner Partei und zum Volk -, der wird es auch heute noch für sinnvoll und möglich halten, ein "offenes Regime" des Kompromisses und des Ausgleichs zu installieren, wie es die parlamentarisch-demokratische Regierungsweise darstellt, und anerkennen, daB das Parlament auch heute noch eine Integrationsaufgabe erfüllt. Uber diese durch das Menschenbild ${ }^{10}$ ) bestimmte Grundhaltung muß man sich klar sein, wenn man über Parlament und Regierung im modernen Staat sprechen will.

II.

1. Demokratie bedeutet Herrschaft der Mehrheit. In der freiheitlichen Demokratie ist aber die Herrschaft der Mehrheit durch die rechtsstaatlichen Grundsätze beschränkt. $\mathrm{Zu}$ den wesentlichen politischen Freiheiten gehört der freie Wettbewerb der politischen Parteien. Die Minderheit kann zur Mehrheit, die Mehrheit kann zur Minderheit werden. Demokratie kann nur bestehen, wenn das Volk in seiner groBen Mehrheit die Grundlagender Verfassung bejaht, und wenn es die Fähigkeit zur Mehrheitsbildung in Parlament und Regierung besitzti1). Ist diese Voraussetzung gegeben, so erhebt sich die Frage, wie es mit den politischen Parteien steht, die sich zwar aller rechtsstaatlichen Freiheiten im Kampf um die Mehrheit bedienen, dabei aber das Ziel verfolgen, diese Freiheiten $z u$ beseitigen und die eigene Macht autoritär zu befestigen, sobald sie die Mehrheit errungen haben. $\mathrm{MuB}$ der freiheitliche demokratische Staat eine solche Opposition a s Prinzip dulden oder ist er befugt, sie auf verfassungsrechtlichem Wege auszuschalten?

10) Vgl. dazu auch $S \mathrm{c} h$ e u n e r, DOV 1957, S. $637 \mathrm{r}$ unten.

11) $\mathrm{Kägi} \mathrm{,} \mathrm{Schweizer} \mathrm{Monatshefte} \mathrm{aaO.,} \mathrm{S.} \mathrm{104.} \mathrm{-} \mathrm{Daran,} \mathrm{daß}$ diese Fähigkeit fehlte, ist die Weimarer Demokratie zugrundegegangen, nicht an Mängeln der verfassungsrechtlichen Ordnung. Die Gestaltung des Wahlrechts (Mehrheits- oder Verhältniswahl? Sperrklauseln gegen kleine Parteien bei der Verhälniswahl?) kann mithelfen, die Fähigkeit zur Mehrheitsbildung zu entwickeln. Das Bundesverfassungsgericht hat unter diesem Aspekt die Sperrklauseln in den deutschen Wahlgesetzen anerkannt und betont, daB auch im Rahmen des Grundgesetzes die Regierung trotz des konstruktiven Mißtrauenvotums - und, wie hinzugefügt werden muß, trotz des $\mathrm{m}$. E. irrealen Gesetzgebungsnotstandes - einer sicheren Mehrheit bedarf (vgl. insbes. die Entscheidung vom 23. Januar 1957, BVerfGE 6, 90 ff.). 
Die zum demokratisch-parlamentarischen System gehörende echte Opposition ${ }^{12}$ ) weiß sich mit der regierenden Mehrheit in der Anerkennung der Grundlagen der Verfassung einig ${ }^{13}$ ); ihr alternatives Regierungsprogramm läßt die Verfassungsgrundlagen unangetastet. Die Opposition aus Prinzip hingegen lehnt die Verfassung selbst ab und möchte ein auf entgegengesetzten Grundlagen aufbauendes Staatswesen an ihrer Stelle aufrichten.

Dieses Phänomen bestimmt da, wo die Verfassung keine Handhabe bietet, solche verfassungsfeindlichen Parteien auszuschalten, das politische Kampffeld in der Weise, daB die verfassungstreue Opposition im gemeinsamen Kampf gegen die verfassungsfeindlichen Parteien an die Seite der Regierungsparteien gedrängt wird und die Entscheidung der

12) Zur Entstehungsgeschichte der loyalen Opposition in England: Kurt Kluxen, Das Problem der politischen Opposition. Entwicklung und Wesen des englischen Zweiparteiensystems im 18. Jahrhundert, 1956; dazu Ernst Fraenkel in ZfPol. NF IV (1957) S. 90. - Die Jahrestagung der Vereinigung für die Wissenschaft von der Politik 1954 hatte "Formen und Funktionen der Opposition" zum Gegenstand. Eugen Kog on berichtet in ZfPol. NF I (1954) S. 365 über diese Tagung. Die Referate von Siegfried Landshut und Dolf Sternbergersind in der Festschrift $f$. A. Rüstow (Wirtschaft und Kultursysteme, 1955) S. 214 und S. 301 abgedruckt. - „Vom Wandel der politischen Opposition handelt Ot to Kirchheimer in ArchRSozPhil. XLIII (1957) S. 59. - \$88 Abs. 2 Nr. 3 StGB zähIt ,das Recht auf verfassungsmäBige Bildung und Ausübung einer parlamentarischen Opposition“ zu den strafrechtlich geschützten Verfassungsgrundsätzen. Nach dem SRP- und dem KPD-Urteil des Bundesverfassungsgerichts gehört es zu den obersten Grundsätzen der freiheitlichen Demokratie, die das Grundgesetz unter dem Begriff der freiheitlichen demokratischen Grundordnung zusammengefaßt (BVerfGE 2,13 und 5, 140). - Schleswig-Holstein gewährt dem Führer der Opposition eine besondere Aufwandsentschädigung (\$ 2 II c des Ges. über die Entschädigung der Abgeordneten v. 31. 5. 1955 [GVBl. S. 125], urspr. Beschluß des Landtages v. 5. 8. 1947). Das Bayerische Gesetz über die Errichtung einer Akademie für politische Bildung vom 27. Mai 1957 (GVBl. S. 103) geht von der Opposition in dem Sinne als einer verfassungsrechtlichen Institution aus, als die Mitglieder des Kuratoriums auf Grund einstimmiger Beschlüsse des Ministerpräsidenten, des "Landesvorsitzenden der nach der Zahl ihrer Mandate stärksten Oppositionspartei mit Fraktionsstärke" und einer von der bayerischen Rektorenkonferenz benannten Persönlichkeit berufen werden.

13) Das Bundesverfassungsgericht spricht von den „elementaren Verfassungsgrundsätzen, die die Verfassungsordnung $\mathrm{zu}$ einer freiheitlichen demokratischen machen, Grundsätzen, über die sich mindestens alle Parteien einig sein müssen, wenn dieser Typus der Demokratie überhaupt sinnvoll funktionieren soll“ (BVerfGE 5 , 141). 
Wähler primär nach dieser großen Zweiteilung erfolgt ${ }^{14}$ ). Das bedingt eine Modifikation in dem herkömmlichen Verhältnis der Opposition zur Regierungsmehrheit im Sinne einer gewissen Verschleifung der Gegensätze, um den gemeinsamen Kampf gegen die Feinde der Freiheit führen zu können. Ich verweise in diesem Zusammenhang darauf, daB sowohl in Osterreich wie in Frankreich ${ }^{15}$ ) und Italien die Kommunisten, die in den ersten Jahren nach dem Krieg aus leicht erklärlichen Gründen in die Regierung aufgenommen worden waren, wieder ausgeschieden worden sind. In der französischen Verfassung ist die Bestimmung, die vorsah, daß der im Fall der Parlamentsauflösung an die Spitze der Regierung tretende Präsident der Nationalversammlung zusätzlich Minister aus allen den Gruppen ernennen sollte, die in der Regierung nicht vertreten waren, 1954 wieder gestrichen worden, um $z u$ verhindern, da $B$ auf diese Weise Kommunisten Einblick in die Regierungsgeschäfte erhalten $\left.{ }^{16}\right)$.

Ausgehend von der Grundauffassung, daß die freiheitliche Demokratie einen Wert verkörpert und nicht nur ein formales Verfahren darstellt, in dem jede beliebige politische Meinung an die Macht kommen kann, ist es durchaus konsequent, wenn Artikel 21 Abs. 2 GG vorsieht, daß verfassungsfeindliche Parteien aus dem politischen Wettkampf durch Verbot ausgeschlossen werden können ${ }^{17}$ ). Uber die politische Zweckmäßigkeit eines solchen Verbotes kann man streiten. Es kann zu einer Verfälschung des innerpolitischen Kräfte-

14) Kirchheimer, aaO. S. 74.

15) Zur Entwicklung in Frankreich: Philip Williams, Politics in Post-War France. Parties and the Constitution in the Fourth Republic, London 1954.

16) Art. 52 der Verfassung von 1946 wurde durch das Gesetz vom 7. Dezember 1954 geändert. Uber die durch dieses Gesetz vorgenommene Verfassungsreform berichtet Georges Berlia in RevDroitPublicSciencePol. T. 61 (1955) S. 164. Sein skeptisches Gesamturteil: „II reste qu'elle ne s' est pas attaquée à l'essentiel et qu'il était impossible qu'elle le fît. Les principales difficultés constitutionnelles et politiques françaises tiennent à des mœurs et à des pratiques" (S. 164 f.).

17) Zum KPD-Urteil des Bundesverfassungsgerichts vom 17. August 1956 (BVerfGE 5, $85 \mathrm{ff}$.), das sich eingehend mit dem Begriff der verfassungsfeindlichen Partei auseinandersetzt: Abendroth in ZfPol. NF 3 (1956) $S$. 305 und $R$ idder in NeuePollit. 1957 S. 351. Unter Berufung auf Art. 17 der Europ. Konvention zum Schutz der Menschenrechte, der "das Aufkommen von Bewegungen verhindern will, die sich auf die Grundrechte berufen, um sie um so leichter zu vernichten", hat die Europ. Menschenrechtskommission die Beschwerde der KPD gegen den Verbotsantrag der Bundesregierung durch Beschluß vom 20. Juli 1957 für unzulässig erklärt (NJW 1957 S. 1350). 
spiels und zu einer Aufwertung der übrigen Parteien führen, wenn ein Teil der Wähler überhaupt nicht mehr mitzählt. Aber man wird nicht bestreiten können, daß diese Möglichkeit in der freiheitlichen Demokratie durchaus systemgerecht ist, indem sie die Beteiligung an dem Wettkampf um die Stimmen der Wähler nach dem Sinn der Wahl, - Verfassungsorgane im Rahmen der geltenden wertbetonten Verfassung zu bilden, - auf die Gruppen beschränkt, die dieses System selbst anerkennen ${ }^{18}$ ).

Dagegen ist es verfassungsrechtlich unzulässig, durch die Geschäftsordnung nicht verbotene Parteien wegen Verfassungsfeindlichkeit von der effektiven Teilnahme an den Geschäften des Parlamentes auszuschließen, indem ihnen die Anerkennung als Fraktion versagt wird (so die Geschäftsordnung des Landtags von Nordrhein-Westfalen vom 6. April 1948).

2. Der moderne massendemokratische Staat kann ohne die modernen straff organisierten massendemokratischen Parteien nicht existieren ${ }^{19}$ ). Ihre Existenz und ihr Wirken haben manche Autoren zu Folgerungen gebracht, die ich - etwas zugespitzt - auf die Formel bringen möchte: Regierung und Parlament sind im modernen massendemokratischen Staat nur noch Fassade; in Wahrheit üben die politischen Parteien, genauer gesagt die Parteibürokratien, die Macht aus ${ }^{20}$ ).

18) Dürig, HdwbSozWiss. IX (1956) S. 751 spricht in diesem Zusammenhang von der „abwehrbereiten“ im Gegensatz zur "relativistischen“ Demokratie und findet, daß „die Maxime ,Keine Freiheit den Feinden der Freiheit' auch noch vor dem traditionellen Demokratiebegriff mit dem legitimen demokratischen Streben nach einer minimalen Homogenität gerechtfertigt werden kann“. Kritisch gegenüber dem Parteiverbot $\mathrm{Stam} \mathrm{p} \mathrm{fer}$ in Hess. Hochschulwochen für staatswiss. Fortbildung V (1954) S. $156 \mathrm{ff}$. Daß „aufrechter Bürgersinn und menschenwürdiges Dasein für alle die Stützen einer freiheitlichen Staatsordnung sind" und "ohne sie auch kein Artikel 21 des Grundgesetzes hilft", ist sicher wahr, spricht aber nicht unbedingt gegen den Versuch der legalen Unterdrückung.

19) Zum Parteienstaat insbes. die Schriften von Leibholz (Anm. 1), die Verhandlungen der Staatsrechtlichen Abteilung des 38. DJT (1950): „Verfassungsrechtliche Stellung und innere Ordnung der Parteien" mit Referaten von Gerhard Leibholz und $\mathrm{H}$ a $\mathrm{n}$ s $\mathrm{R}$ e if, sowie der Bericht der vom BMdI eingesetzten Parteienrechtskommission: „Rechtliche Ordnung des Parteiwesens", 1957; dort S. 235 ff. Literaturverzeichnis. Das Bundesverfassungsgericht hat die politischen Parteien als verfassungsrechtliche Institution anerkannt (zusammenfassend BVerfGE 4, 27).

20) Repräsentativ etwa W er $n$ e $r W$ $W$ e $r$ (Anm. 1) oder $W \vdots:=$ f ried M a r tini (Anm. 7). Vgl. auch Götz R oth, Fraktion und Regierungsbildung, 1956. L, e ibholz tritt für die Demokratisierung der Parteien selbst ein, "damit die Parteien nicht als diktatoriale Körperschaften in Erscheinung treten" (38. DJT S. C 12). 
Ich glaube nun, die Wirklichkeit ebenso nüchtern zu betrachten wie jene Autoren, wenn ich feststelle, daB auch heute noch durchaus Persönlichkeiten auf der politischen Szene mitspielen, ja sie in gewissem Sinne beherrschen, und daß der Einzelne noch nicht so völlig von der Masse und den Massenorganisationen verschlungen ist, wie vielfach behauptet wird. Auch heute stoßen wir auf das Wirken von Persönlichlkeiten im nicht organisierten Staatsvolk, in den Parteien, in den Fraktionen, im Parlament, in der Regierung ${ }^{21}$ ). Ich muß mich hier mit wenigen Hinweisen begnügen. So wird vielfach geradezu beklagt, daB der Bundeskanzler sich zu stark als Persönlichkeit durchsetze. In unseren Parlamentsfraktionen finden wir nicht nur jene Klischee-Parteigänger, die uns meist vorgestellt werden. Ich brauche nur an so eigenwillige Persönlichkeiten wie Carlo Schmid oder August Dresbach zu erinnern ${ }^{22}$ ). Gerade diese beiden Abgeordneten haben aber bei der Bundestagswahl fünf- bis sechstausend Stimmen mehr auf ihre Person vereinigt, als ihre Parteien Zweitstimmen erhielten. Auch der Wähler scheint demnach doch nicht das dumpfe Herdentier zu sein, als das er so oft charakterisiert wird. Wahrscheinlich würde eine genaue Analyse der Erst- und Zweitstimmen bei der Bundestagswahl ergeben, daß eine große Anzahl von Wählern sich ihre Stimmenabgabe sehr genau überlegt und eine bewußte Entscheidung trifft ${ }^{23}$ ).

21) Sicher ist es richtig, daß heute die politische Persönlichkeit nur mehr im Rahmen einer Partei wirken kann, aber auch heute noch dürfte in gewisser Beziehung das Parlament die Auslesestätte der Führerpersönlichkeiten im Konkurrenzkampf der politischen Temperamente und politischen. Begabungen im Sinne $M a x$ W e bers sein, und zwar auch über das Ringen um die Führung in der eigenen Partei hinaus. Ernst Reuter etwa wurde 1951 auch mit Stimmen der „bürgerlichen“ Fraktionen zum Regierenden Bürgermeister von Berlin gewählt und konnte es wagen, im Frühjahr 1952 die Vertrauensfrage zu stellen, obwohl seine Partei nicht die Mehrheit hatte; nach seinem Tode wählte dann dasselbe Abgeordnetenhaus den CDU-Abg. Schreiber zum Reg.Bgm.

22) $\mathrm{DaB}$ ich nur diese beiden Namen nenne, beruht darauf, daB gerade während der Vorbereitung dieses Referates die Wahlergebnisse bekannt wurden. Man könnte natürlich noch viele Abgeordneten nennen, die wegen ihrer persönlichen Gaben hohes Ansehen auch bei den anderen Fraktionen und in weiten Volkskreisen genießen.

23) Die Mehrzahl der Wähler allerdings wird ihre Stimmabgabe für einen Kandidaten als Mittel betrachten, für eine Parteirichtung zu stimmen oder für die Persönlichkeit, die eine Partei als künftigen Regierungschef präsentiert. Aber jene Ausnahmen zeigen eben, da $B$ es auch heute noch auf die Persönlichkeit des Kandidaten ankommen kann. Die Wahlergebnisse der Bundestagswahl 1953 sind analysiert in dem von Wolfgang $\mathrm{Hirsch}-\mathrm{Weber}$ und 
Bei der Aufstellung der Kandidaten haben sich die örtlichen Parteigremien keineswegs immer den Wünschen der Parteizentralen gefügt. Manche Abgeordneten pflegen durchaus die Beziehung zu ihrem Wahlkreis, nicht nur zu ihrer ParteiBürokratie ${ }^{24}$ ). Man kann auch nicht behaupten, daß auf der Tribüne des Bundestages immer nur die Parteiwalze gedreht wird; wir haben große Debatten erlebt, die durch die Rednerpersönlichkeiten geprägt waren ${ }^{25}$ ) und deren Einfluß auf die Abstimmung in gewissem Umfange nicht bestritten werden kann. Zwei Beispiele sind mir in der Erinnerung haften geblieben: aus dem ersten Bundestag die großartige Rede Thomas Dehlers über die Todesstrafe und die danach unter dem Eindruck seiner Argumente erfolgte Abstimmung quer durch die Parteilager hindurch ${ }^{26}$ ); ferner die mit so großer Anteilnahme von den Abgeordneten, der Presse und den Bürdern am Radio aufgenommene nonkonformistische Rede des jungen CDU-Abgeordneten Nellen über die Kriegsdienstverweigerung im zweiten Bundestag ${ }^{27}$ ). In der Wehrpolitik- und Atomrüstungsfrage hat es starke Spannungen auch zwischen der Regierung und den Mehrheitsfraktionen im Bundestag

K l a u s S ch ü t z herausgegebenen Buch „Wähler und Gewählte", Berlin 1957; dazu Ot to K i r ch h e i mer Neue Pollit. 1957, 646. Die Wahlergebnisse in der Bundesrepublik, in den deutschen Bundesländern, im Saarland und in der Sowjetzone (DDR) 1946 bis 1956 hat zusammengestellt $R$ ichard $S c h a c h t n e r$, Die deutschen Nachkriegswahlen, München 1956; dort $\mathrm{S}$. $79 \mathrm{ff}$. auch eine Ubersicht über die Zusammensetzung der Regierungen in Bund und Ländern bis 1956.

24) Scheuner, DOV 1957 S. $637 \mathrm{f}$. betont mit Recht, daß die Verbindung des Parlaments mit der Wählerschaft eine Lebensfrage der Demokratie ist. Es dürfte auch zutreffen, daß dem Wahlsystem für das Verhältnis des Abgeordneten zu seinen Wählern und für seine Unabhängigkeit gegenüber der Partei keine entscheidende Bedeutung zukommt. Der Vorzug der Mehrheitswahl und der personalisierten Verhältniswahl unter diesem Aspekt sollte aber nicht übersehen werden.

25) So negativ die große außenpolitische Debatte im Bundestag vom 20.-25. März 1958 in einigen Auswüchsen zu bewerten sein mag - daß sie auf weiten Strecken große parlamentarische Beredsamkeit bewies, wird niemand bestreiten können. Wie weit sie nicht nur außerhalb, sondern - trotz der nach Fraktionen erfolgten Abstimmung - auch innerhalb des Bundestags meinungsbildend gewirkt hat, läßt sich in diesem Augenblick noch nicht übersehen.

26) 232. Sitzung des I. Bundestages v. 2. 10. 1952 StenBer. S. $10610 \mathrm{ff}$.

27) 159. Sitzung des II. Bundestages vom 6. Juli 1956, StenBer. S. 8841 ff. 
gegeben, wobei etwa der der Regierungs-Koalition angehörende Vorsitzende des Verteidigungsausschusses keineswegs immer Ordre parierte. Trotz der Gefahr, nicht wieder aufgestellt zu werden, sind einige Abgeordnete im ersten und zweiten Bundestag aus ihrer Fraktion ausgetreten ${ }^{28}$ ). Auch haben die Fraktionen keineswegs immer einheitlich abgestimmt'29).

So völlig glatt im Sinne einer bloßen Parteiregistrierungsmaschine scheinen also doch Parlament und Regierung bei uns nicht zu arbeiten. Ich vermag daher nicht allen Thesen beizustimmen, die über den heutigen Parteienstaat aufgestellt worden sind, und möchte als für unseren Zusammenhang wesentlich nur noch die Kontroverse zu Artikel 38 GG herausgreifen.

Ich leugne natürlich nicht, daß die Vorstellung des Abgeordneten als des frei abstimmenden Vertreters des ganzen Volkes ihren geistigen Urgrund in der liberalen Repräsentationsidee hat. Aber ich bestreite, daß der Wandel vom klassischen Parlament zur modernen Volksvertretung und die Erhebung der politischen Parteien zu Verfassungsrang durch Artikel $21 \mathrm{GG}$ dem Grundsatz des Artikels 38 Abs. 1 Satz 2 den Boden entzogen hat, so daß ein unlösbarer Widerspruch zwischen Artikel 38 Absatz 1 Satz 2 und Artikel 21 Absatz 1 GG besteht ${ }^{30}$ ).

Verfassungen brauchen sich nicht an Schemata zu halten, die von Theoretikern als "folgerichtig“ entwickelt worden sind. Es ist nicht einzusehen, wieso aus der verfassungsrechtlichen Anerkennung des $\mathrm{F}$ a $\mathrm{k} \mathrm{t} \mathrm{u} \mathrm{m} \mathrm{s,} \mathrm{daß} \mathrm{Wahlen} \mathrm{im} \mathrm{modernen}$ Massenstaat ohne politische Parteien nicht vor sich gehen können, zwangsläufig die rechtliche Konsequenz gezogen werden muß, daß die Abgeordneten Träger eines imperativen Mandates ihrer Partei sind. Durch Artikel 38 GG wird die Freiheit der Abgeordneten von Aufträgen und Weisungen ver-

28) Die Zahlenangaben schwanken; nach meinen Berechnungen haben im Ersten Bundestag 57 von 406 Abg., im Zweiten Bundestag 34 von 487 Abg. die Fraktion gewechselt. - Vgl. auch E $\mathrm{m}$ i 1 $\mathrm{Ob}$ ermanns, Alter und Konstanz von Fraktionen. Veränderungen in deutschen Parlamentsfraktionen seit dem Jahre 1920, Meisenheim 1956.

29) Dazu die Untersuchungen von $\mathrm{H}$ ein $\mathrm{z}$ Markmann, Das Abstimmungsverhalten der Parteifraktionen in deutschen Parlamenten, Meisenheim 1955; Bedenken gegen sein Verfahren äußert Gerhard Schulz, NeuePolLit. 1956 Sp. 354.

30) So im Anschluß an Le ibholz (38. DJT S. C 19) BVerfGE 2, $72 \mathrm{ff}$. 
fassungsrechtlich verbürgt, der Abgeordnete an sein Gewissen und an das Wohl des ganzen Volkes als Richtschnur seines Handelns verwiesen ${ }^{31}$ ). Dies ist der unseren Parlamentarismus auch heute noch beherrschende verfassungsrechtliche Obersatz. Es erscheint durchaus sinnvoll, gerade im Rahmen der modernen Massenparteien die Persönlichkeit des Abgeordneten und seine freie Gewissensentscheidung zu sichern. Artikel 38 Abs. 1 Satz 2 ist nicht eine aus Trägheit weiter mitgeschleppte sinnentleerte Formel, sondern die bewußte Entscheidung für die freie Abgeordnetenpersönlichkeit auch im modernen Massenstaat ${ }^{32}$ ).

Die politischen Parteien sind damit gehalten, in Erfüllung der ihnen durch Artikel 21 zugewiesenen dienenden Funktion nur solche Kandidaten zur Wahl zu stellen, die den Anforderungen des Artikels 38 genügen ${ }^{33}$ ), und sie haben rechtlich über die Abgeordneten nicht mehr Macht als ihre Vorläufer in den liberalen Repräsentationsversammlungen. Aus diesen grundsätzlichen Erwägungen zu Artikel 38 GG kann ich Bedenken gegen das SRP-Urteil des Bundesverfassungsgerichts, das ohne besondere gesetzliche Grundlage an das Parteiverbot den Mandatsverlust geknüpft hat ${ }^{34}$ ), nicht unterdrücken.

s1) Zu dem Parallelartikel 91 der Schweizer Bundesverfassung: Werner Kägi im Jahrbuch „Die Schweiz“ 1952 S. 8.

32) Auch Han s S ch n eid er DVBl. 1953 S. 440 meint: „In der Tat muB die parlamentarische Demokratie an dem Gedanken, daB der Abgeordnete nicht nur seine Wähler, nicht seinen Wahlkreis und erst recht nicht seine Partei vertritt, sondern für das ganze Volk handelt, wie an einem Glaubenssatz festhalten." Zum freien Mandat auch WPrGericht Rheinland-Pfalz in AS 3, 407.

3s) $\mathrm{Kä} \mathrm{g} \mathrm{i} \mathrm{,} \mathrm{Schweizer} \mathrm{Monatshefte} 1957$ S. 408: „Es ist eine Schicksalsfrage der Demokratie, daß ob der Loyalität gegenüber dem Verband und der Partei die Loyalität gegenüber dem Ganzen nicht verkümmert. Diese Auseinandersetzung ist jedem einzelnen Verbands- und Parteimitglied als Bürger aufgegeben; sie stellt aber die führenden Personen vor eine ganz besondere - beispielgebende - Verantwortung. In der schärfsten Zuspitzung finden wir diesen Konflikt dort, wo der Partei- und Verbandsvertreter zugleich Volksvertreter ist."

34) Urteil vom 23. Oktober 1952, BVerfGE 2, 1 ff. Der Bremische StGH hat sich in der Entscheidung vom 5. Jaunar 1957 dieser Auffassung angeschlossen; Bedenken dagegen unter Anführung der einschlägigen Literatur in der abw. Meinung von drei Mitgliedern des StGH (Urteil, abw. Meinung und Niederschrift über die mündliche Verhandlung sind in einem Sonderdruck der Brem. Bürgerschaft veröffentlicht). Der Niedersächs. StGH hat durch Beschluß vom 28. März 1958 die Entscheiđung über den Mandatsverlust der zwei KPD-Abg. im Nds. LT ausgesetzt und die Rechtsfrage erneut dem BVerfG vorgelegt. 
3. In diesem Zusammenhang noch ein Wort über den sog. „Fraktionszwang “"35). Ohne Fraktionsdisziplin ${ }^{36}$ ) können stabile parlamentarische Regierungen nicht gebildet werden und an der Macht bleiben. Dafür ist Frankreich das klassische Beispiel. Es gehört also durchaus zu den legitimen Gründen der Gewissensentscheidung eines Abgeordneten, wenn er bei seiner Stimmabgabe nicht nur das aktuelle Objekt der Abstimmung beurteilt, sondern auch die Auswirkung der Abstimmung auf die Regierungsposition seiner Partei abwägt. Dabei wird ihn oft ein Beschluß seiner Fraktion leiten ${ }^{37}$ ). Wesentlich ist aber, daß dieser Beschluß unter seiner Beteiligung zustandegekommen ist. Selbst wenn von der Tribüne des Parlaments nur mehr eine Parteientscheidung proklamiert werden sollte, so ist diese doch in der Fraktion unter freier Mitwirkung a ll er Mitglieder gefallen. Diese Rolle des einzelnen Abgeordneten in d er F r a $\mathrm{k}$ ti o $\mathrm{n}$, die als verfassungsrechtlich anerkannte Gliederung zum Parlament gehört, wird oft übersehen. Die Mitarbeit in der Fraktion gehört zur Ausübung des Mandats. Stellungnahme und Abstimmung in der Fraktion stehen also unter dem Gebot des Art. 38 Albs. 1 Satz 2. In der Gesamtwürdigung unseres Parlamentarismus darf diese innerparteiliche Demokratie mit echter Diskussion und Abstimmung nicht außer Acht gelassen werden. Je größer die Partei ist, je mehr soziale Schichten und Interessen in ihr vertreten sind, um so wichtiger wird der Ausgleich bereits in der

95) Zum Fraktionszwang: D r e her NJW 1950, 661; G r e we ArchठffR 75 (1949) S. 468; K ü s t e r ArchOffR 75, (1949) S. 399; L a u n, Gedächtnisschrift für Walter Jellinek, 1955, S. 175; v. M a n goldt SJZ 1950 S. 336. Der Brem. StGH hat am 13. Mai 1953 die „Entscheidung“ getroffen: „Aus § 83 Abs. 1 Satz 3 der Landesverfassung der Freien Hansestadt Bremen, wonach die Mitglieder der Bürgerschaft „nur ihrem Gewissen unterworfen sind", folgt, daß ein Abgeordneter nicht gezwungen werden kann, gemäß dem Mehrheitsbeschluß einer Fraktion abzustimmen und daß es insbesondere auch unzulässig ist, ihn mit rechtlich unerlaubten Mitteln dazu anzuhalten." (DVBl. 1953 S. 437 mit Anm. von $\mathrm{H}$ ans $\mathrm{Sch}$ eider).

36) Vgl. auch Kremer, Der Abgeordnete zwischen Entscheidungsfreiheit und Fraktionsdisziplin, 1953, und $L$ ö we n s te in, Uber die parlamentarische Parteidisziplin im Ausland, in: Die politischen Parteien im Verfassungsrecht, Tüb. 1950.

37) Aus Art. 38 Abs. 1 Satz 2 GG kann weder abgeleitet werden, daß Beratung und Abstimmung in der Fraktion verfassungswidrig sind, noch daB der Abg. seine Pflicht verletzt, wenn er bei seiner Abstimmung im Plenum auch den Beschluß seiner Fraktion in Rücksicht zieht. Selbstverständlich aber kann ein Abg. nie gehindert werden, entgegen dem Fraktionsbeschluß abzustimmen. Die Zahl der Fälle, in denen wirklich das "Gewissen“ des Abg. engagiert ist, dürfte übrigens verhältnismäßig gering sein. 
Fraktion. Darin liegt der große Vorzug des Zweiparteiensystems. In einer großen, durch Flügel und Außenseiter gekennzeichneten Partei kann es schon wegen der Vielfalt der in ihr vertretenen Volksschichten und Interessen nicht jene Diktatur der Parteibürokratie geben, die so oft als unausweichliches Schicksal behauptet wird. Zugleich mindern diese innerparteilichen Spannungen die politische Gefahr der Einparteienregierung im Zweiparteiensystem.

4. Im Wesen des parlamentarischen Systems liegt die Bereitschaft zum KompromiB ${ }^{38}$ ). Das macht dieses Regierungssystem zwar den Verfechtern autoritärer Regierungsformen bereits verdächtig, aber gerade darin dürfte seine Stärke in der gegenwärtigen gesellschaftlichen Situation liegen. Der moderne Staat wird seine Ordnungsfunktion nur erfüllen und ein friedliches Zusammenleben der im Staat vereinten Menschen nur sichern können, wenn er den Weg des Kompromisses geht. Die widerstreitenden Interessen lassen sich nicht durch Diskussionen auflösen und vereinigen. So ist Verhandeln und Kompromiß das Zeichen der gegenwärtigen parlamentarischen Arbeit: KompromiB innerhalb der Fraktion, KompromiB innerhalb der Regierungsparteien, Kompromi $B$ auch zwischen Regierungsmehrheit und Opposition. Denn das parlamentarische Regime muß ein Regime der Toleranz sein. Darum sind auch ständige Fühlungnahmen zwischen dem Regierungschef und dem Führer der Opposition angebracht. Zwar ist die Majorisierung der Minorität grundsätzlich möglich. Aber da es keine dauernde Festlegung der staatlichen Politik gibt, vielmehr jederzeit mit dem Wandel von Mehrheit zu Minderheit gerechnet wenden muß, wird die Mehrheit sich hüten, irreparable Maßnahmen zu treffen, die der Opposition die Verfolgung ihrer Politik unmöglich machen würde, wenn sie die Regierungsmacht ergreift. Das Beispiel der englischen Sozialisierung hat hier die Grenzen gezeigt.

5. Wenn die Regierung vom Parlament getragen werden soll, so müssen die Parteien bei den Wahlen zum Parlament mit einem Programm und einer Regierungsmannschaft hervortreten. Die Regierungspartei oder -koalition kämpft unter Hinweis auf das Erreichte und das in dieser Linie weiter Ge-

s9) Zum Kompromiß als wesensgemäßer und unvermeidbarer Eigenschaft des demokrat. Parteienstaates: $R$ i chard Th o ma, Uber Wesen und Erscheinungsformen der modernen Demokratie, Bonn 1948, S. $21 \mathrm{ff}$; vgl. auch $\mathrm{K}$ i r ch heimer, Opposition (Anm. 1) und ders. Changes in the structure of political compromise, in: Studies in Philosophy and Social Science, Vol. IX, New York 1941, S. $264 \mathrm{ff}$., und $\mathrm{R}$ u s tow, The Politics of Compromise (Schweden), 1955. 
plante um die Erneuerung des Mandats; die Opposition erstrebt unter Kritik der Regierungspolitik die Mehrheit für ihr Alternativprogramm ${ }^{39}$ ), um die Regierungsmacht $\mathrm{zu}$ ergreifen. In klassischer Form ist dieses System in „Her Majestys loyal opposition" mit dem Schattenkabinett und dem aus Staatsmitteln besoldeten Oppositionsführer verkörpert ${ }^{40}$ ).

Im Gegensatz zum englischen Verfassungsbrauch ${ }^{\text {(1) }}$ halte ich allerdings dafür, daß bei uns das Mandat der Mehrheit nicht auf die Fragen begrenzt ist, die im Wahlkampf eine Rolle gespielt haben ${ }^{42}$ ). Parlament und Regierung müssen alle Fragen aufgreifen können, die sich im Lauf der Wahlperiode stellen.

In dem plebiszitären Charakter der Parlamentswahlen als Entscheidung für eine Partei und ihr Programm und möglichst auch für eine bestimmte Regierungsmannschaft ${ }^{43}$ ) liegt nichts, was dem Wesen der Wahl widerspricht. Es bleibt eine Wahl, weil alle Gruppen unter gleichen Wettbewerbsbedingungen antreten, in voller Freiheit die öffentliche Meinung beeinflussen können, und weil die Stimmen, die den in die Opposition verwiesenen Parteien gegeben werden, nicht ins Leere fallen. Auch die Parteien, die nicht in die regierende Mehrheit gelangen, sind im Parlament vertreten und können dort in der vollen Offentlichkeit des Parlaments mit allen Mitteln parlamentarischer Kontrolle eine fortlaufende Kritik an der Regierung und der sie tragenden Mehrheit üben. Die Kontrollmittel, die ursprünglich dem

39) F or s th of $f$, Christ und Welt v. 17. November 1955, allerdings ist der Meinung: „Es gibt heute keine Parteiprogramme, keine grundsätzlichen Parteiziele, es gibt auch keine grundsätzlichen Differenzen mehr." Nach ihm ist auch die alte Regel außer Kraft gesetzt, daß eine Partei sich in der Regierung verbraucht und dann von der Opposition abgelöst wird. Der richtige Kern dieser Ansicht bedürfte noch eingehender Untersuchung und Differenzierung. Hinter die Unbedingtheit der Diagnose und Prognose möchte ich ein Fragezeichen setzen (vgl. Anm. 7)

40) Vgl. dazu die Darstellung aus der jüngsten Praxis von $\mathrm{H}$ er bert Morris on, Regierung und Parlament in England, 1956 (engl. Original 1954).

41) $\mathrm{J}$ e $\mathrm{n} \mathrm{n}$ in $\mathrm{g} \mathrm{s}$, Cabinet Gov., 1951, S. $467 \mathrm{ff}$.

42) So die These der Antragsteller in dem Verfahren vor dem Bundesverfassungsgericht betr. den EVG-Vertrag usw. (s. Der Kampf um den Wehrbeitrag, Band I S. 309, $315 \mathrm{ff}$., $324 \mathrm{ff}$. , Band II S. $624 \mathrm{ff}$., Band II S. 135 f.).

43) $\mathrm{DaB}$ bei der Parlamentswahl die Persönlichkeit des an der Macht befindlichen oder von der Opposition präsentierten Regierungschefs in den Vordergrund tritt, ist nach allem durchaus konsequent und widerlegt im übrigen die These von der Alleinherrschaft des Parteiapparats und der ausschließlichen Orientierung der Wählerschaft an den Parteien. 
Parlament gegen die von ihm unabhängige Exekutive gegeben worden waren, sind heute weitgehend zu Waffen der Opposition gegen die Regierung und ihre Mehrheit geworden ${ }^{44}$ ). Entscheidend ist weiter, daß die regierenden Parteien die Verantwortung nur auf Zeit tragen, auch außerhalb des Parlaments der Kritik der öffentlichen Meinung ausgesetzt sind ${ }^{45}$ ) und sich nach Ablauf der Wahlperiode dem Volke wieder stellen müssen. Jedes Regierungsmandat bleibt befristet, und jede Opposition kann darauf rechnen, eines Tages, und sei es wie 1957 in Canada erst nach 22 Jahren an die Regierung zu kommen.

Das von jeder politischen Partei zu verfolgende Ziel, die Regierungsmacht zu erlangen, erfordert allerdings einen bestimmten Parteityp. Parteien, die sich nur auf einzelne Schichten des Volkes stützen, haben weniger Chancen, die Mehrheit zu erringen, als solche, die breite und verschieden strukturierte gesellschaftliche Schichten ansprechen. Gerade die letzten Bundestagswahlen zeigen im deutschen Parteiwesen eine Auflockerung der überkommenen weltanschaulichen Verhärtung. Der Einbruch der Unionsparteien in die Arbeiterschaft und die Offnung der SPD nach rechts liegen in dieser Linie.

6. Ein Wort endlich noch zu den Verbände ${ }^{46}$ ). So wie einige Autoren den modernen Staat als Parteienstaat

44) Beide Linien laufen nebeneinander; auch die Spannung zwischen Parlament und Regierung besteht weiter, wie unten noch ausgeführt wird, und damit die Kontrolle der Regierung durch das Parlament als Ganzes. Aber das Zusammenspiel von Regierung und der sie tragenden Parlamentsmehrheit macht es erforderlich, die Kontrollmittel des Parlaments zu stärken und sie teilweise als Minderheitsrecht zu gestalten, damit die Opposition davon Gebrauch machen kann. Eine besondere Rolle spielen insofern die Untersuchungsausschüsse, die nach deutschem - nicht nach ausländischem - Verfassungsrecht in der Regel (nicht nach der Berliner und Bremer Verfassung) schon auf Antrag von 1/5 bis $1 / \mathrm{s}$ der gesetzlichen Mitgliederzahl eingesetzt werden müssen.

45) Uber die Gefahren einer Degeneration der repräsentativen Demokratie durch die Meinungsforschung vgl. Wilh elm Hen $n$ is, Meinungsforschung und repräsentative Demokratie, 1957, dazu R o m a n S ch n r, DVBl. 1957, S. 511.

46) Literaturbericht von $S t r i c k r o d t$, Gruppeninteressen und Staatsgewalt, NeuePolLit. 1957 S. 320; Legitime Interessenvertretung in der mod. Gesellschaft (Referate von U. Scheuner, H. Kr üger, O. A. Friedrich, W. Stra u B) Ev. Akademie Loccum 1956; Der Staat und die Verbände, hsg. von $W$ ilh e $1 \mathrm{~m}$ Beutler, Gustav Stein, Hellmuth Wagner, Ge spräch veranstaltet vom Bundesverband der Deutschen Industrie in Köln am 27. März 1957 (Referate von U. S ch e uner und W. Weber und Diskussion), Heidelberg 1957; Th. E schen- 
charakterisieren, in dem alle Macht bei den Parteibürokratien ruht, so bezeichnen ihn andere als Verbändestaat, in dem die Interessenverbände die Parteien, das Parlament und die Regierung durchdringen und die Verbandsbürokratien die politische Führung an sich gerissen haben, oder vielleicht besser gesagt, in dem die politische Führung dem zwischen den Verbänden entbrannten Interessenkampf zum Opfer gefallen ist.

Auch hier möchte ich nur vor Utbertreibungen warnen, ohne das Problem in seinem ganzen Umfang anzuschneiden ${ }^{47}$ ). Die Verbände sind im modernen Staat genauso wie die politischen Parteien nicht nur Gegebenheiten, sondern auch Notwendigkeiten. Es gibt eine durchaus legitime Interessenvertretung, die von den Verbänden wahrgenommen wird und wahrgenommen werden muß, auch durch Einwirkung auf Parteien, Parlament und Regierung. Aber ich glaube nicht, da $B$ die Mitentscheidung der Parteien bei der Willensbildung des Staates vielfach nur noch formal ist ${ }^{48}$ ). Die großen Parteien sind vielmehr genötigt, in sich die verschiedensten Interessen auszugleichen. Im Schoße der Parteien und ihrer Fraktionen stoßen die verschiedenen Interessenvertreter aufeinander, und da sicher nicht alle Abgeordneten verbandshörig sind, wird auch das Gemeinwohl in diesem Kreis noch kräftig zu Wort kommen. Innerparteiliche Demokratie und personalisierte Verhältniswahl dürften übrigens auch ein Gegengewicht dagegen bilden, daß sich hinter der Fassade der politischen Parteien ausschließlich oder auch nur überwiegend Interessen-

b u r g, Der Staat und die Verbände, 1955; J o s e p h H. K a is e r, Die Repräsentation organisierter Interessen, 1956; H e r b e r t $\mathrm{K} \mathbf{r}$ üger, Die Stellung der Interessenverbände in der Verfassungswirklichkeit, NJW 1956, S. $1217 \mathrm{ff}$; Ulrich Sche uner, Stellung und Einfluß der Verbände im heutigen Staat, Der Güterverkehr, 1956, S. 289; W e r n e r W e ber (Anm. 1); Parteien und Verbände, Eine Artikelreihe der "Neuen Züricher Zeitung“ (o. J.); der Beitrag von $\mathrm{H}$ a n $\mathbf{s} \mathrm{H}$ u e r, Die Umwälzung im Staatsgefüge durch die Verbände, auch in "Ordo" Bd. VII (1955) S. 189; G a n s h of van der Meers ch in Aspects... belge (Anm. 1) S. 129.

47) Die Gefahren für das Funktionieren der parlamentarischen Demokratie leugne ich nicht. Nur scheint mir auch hier, daß vielfach Möglichkeiten mit Realitäten gleichgesetzt werden. DaB die Bäume der Interessenverbände nicht in den Himmel wachsen, hat sich etwa darin gezeigt, daß die Bauernverbände die Wiederernennung des Bundeslandwirtschaftsministers Dr. Lübke im Oktober 1957, und der Bundesverband der Deutschen Industrie die Ernennung des ersten Kartellamtspräsidenten Dr. Günther im Januar 1958 nicht haben verhindern können.

48) So $\mathrm{Hans} \mathrm{Huber} \mathrm{aaO.} 47$. 
vertreter verbergen ${ }^{49}$ ). Der Vorteil des demokratischparlamentarischen Regimes liegt gerade darin, da $B$ Parteien, Fraktionen, Parlament und Regierung als Clearing der miteinander ringenden Interessen dienen. Durch die politische Führung von Parlament und Regierung wird die Verbandsmacht mediatisiert und nicht umgekehrt. Die Gesamtverantwortung, die Regierung und Opposition vor dem. ganzen Volke tragen, zwingt sie, über die Einzelinteressen dem Gemeinwohl Geltung zu verschaffen. Das Parlament bleibt bei der Gesetzgebung, die Regierung bleibt bei Regierungsmaßnahmen der Schiedsrichter des allgemeinen Interesses. Aber Parlament und Regierung müssen sich angesichts der unübersehbar gewachsenen Aufgaben des Staates auch bei den Gruppen und Verbänden orientieren, deren Wünsche und Darlegungen entgegennehmen und mit ihnen verhandeln, um das allgemeine Interesse den engeren Verbands- und Gruppeninteressen gegenüber geltend zu machen. Auch hier handelt es sich umeine Frageder Menschenund nicht um eine Frageder Statistik.

$\mathrm{Ob}$ und in welcher Weise die Geltendmachung der Interessen in der Regierungssphäre (Beiräte bei den Ministerien?) und beim Parlament (öffentliche Hearings?) organisiert werden kann und soll, oder ob die Verbände in den Staatsaufbau institutionell eingefügt werden sollen (Wirtschaftsrat?), ist eine Frage, die hier nicht weiter verfolgt werden kann ${ }^{50}$ ). Jedenfalls dürfte ein solcher Einbau nur unter Beachtung des bestehenden Bezugssystems Parlament-Regierung erfolgen, um Verantwortung und Kontrolle klar und ungeschwächt zu erhalten.

7. Nur kurz erwähnt sei schließlich das Problem der B ü r ok ratia ${ }^{51}$ ). Auch hier beschränike ich mich darauf, vor der

49) Der Bericht der Parteienrechtskommission (Anm. 19) betont S. 71 die wichtige Aufgabe der Parteien angesichts des Machtanstiegs der Interessenverbände. Es liege ihnen ob, „nicht nur in ihren eigenen Reihen bereits einen vermittelnden Ausgleich der Interessen vorzunehmen, sondern sich über partikulare Interessen hinaus am Wohle der Gesamtheit zu orientieren und von dieser Grundlage aus, gleich ob Regierung oder Opposition, ihre Entschließungen zu fassen".

so) Dazu etwa $\mathrm{K}$ u r t Uh Imann, Institutionelle Formen der Zusammenarbeit zwischen Staat, Wirtschaft und Verbänden, in „Der Staat und die Verbände" (Anm. 46) S. $56 \mathrm{ff} . ;$ Gü n th er M. R e m m ling, Die Interessenverbände in der westlichen Welt. Zur Frage der gesetzlichen Regelung des Verbändeeinflusses in einzelnen Ländern, ZfPol. NF IV (1957) S. $169 \mathrm{ff}$.

61) Grundlegend $M$ a $x$ W e b e r (Anm. 1) und d ers. Wirtschaft und Gesellschaft (Grundriß der Sozialökonomik III. Abt), 1922, Kap. VI S. 650; ff.; Th. E s chenbu rg, Bemerkungen zur deut- 
Úbertreibung zu warnen, die Macht der Bürokratie sei derart stark, da $B$ sie Parlament und Regierung überspiele ${ }^{55}$ ). Solange sich klare Mehrheiten im Parlament bilden und Mehrheit und Opposition gemeinsam den politischen Führungsanspruch gegenüber der Bürokratie verfechten, wird sich die Bürokratie nicht zu einer eigenständigen Macht im Staate entwickeln können, sondern die ihr zukommende dienende Rolle behalten.

Es kommt auf die Persönlichkeit der Minister an, ob es ihnen gelingt, der Bürokratie von der Spitze her die politischen Impulse zu geben und den Apparat in die Hand zu bekommen. $\mathrm{Da} \beta$ und wie dies einem Parlamentarier möglich ist, hat Henbert Morrison im 14. Kapitel seines interessanten Buches "Regierung und Parlament in England" aus umfassender praktischer Erfahrung beschrieben. Sicher wird der Minister einer durch große und sichere parlamentarische Mehrheit gestützten starken Regierung dazu eher in der Lage sein als der Minister einer schwachen und immer gefährdeten Koalition, der leicht zum Aushängeschild der Ministerialbürokratie werden kann. $\mathrm{Zu}$ schnelle Regierungswechsel stärken naturgemäß den Einfluß der Bürokratie.

Die Bedeutung der Bürokratie ${ }^{53}$ ) soll im übrigen nicht geringgeschätzt werden; es ist schon oft betont worden ${ }^{54}$ ), daß etwa Frankreich seine vielen Regierungskrisen nur deshalb ohne schweren Schaden für Staat und Volk überstehen kann, weil die ausgezeichnete Administration im Kommen und Gehen der Minister der ruhende $\mathrm{Pol}$ ist ${ }^{55}$ ).

schen Bürokratie, 1955; H ans $\mathrm{Hu}$ b er, Demokratie und Bürokratie, Schweizer Monatshefte Mai 1957 S. $130 \mathrm{ff}$; W e r n e r W eber (Anm. 1).

5:) Auf eine Affinität zwischen Bürokratie und Verbandswesen weist $\mathrm{H}$ a n s Huber (Anm. 46) S. 43 hin.

53) Dazu als einer ihrer Vertreter: $\mathrm{K}$ le in $\mathrm{r}$ a h $\mathrm{m}$, ArchOffR 79 (1953) S. $153 \mathrm{f}$.

54) Etwa v. d. H e y d t e, Festschrift Nawiasky S. $332 \mathrm{f}$.

55) Nur anmerkungsweise sei hingewiesen auf die Rolle des von Parteien, Verbänden und Bürokratie unabhängigen Sachverstandes, wie er in den wissenschaftlichen Beiräten der Bundesministerien zu Wort kommt. Es wird sich kaum bestreiten lassen, da deren Gutachten nicht nur von Bedeutung für Regierung und Parlament sind, sondern auch faktischen Einfluß auf die Gesetzgebungsarbeit gewinnen. Sie vermögen also einseitiger Parteiund Interessenpolitik entgegenzuwirken. Eine Ubbersicht über diese Einrichtungen in dem Aufsatz von $\mathrm{Hein} \mathbf{r} \mathrm{ch} \mathrm{Kipp,} \mathrm{Ent-}$ stehung, Aufgaben und Rechtsstellung von Hilfseinrichtungen von Regierung und Parlament, DOUV 1957 S. 513. „Die Problematik des Sachverständigenrats in politischen Angelegenheiten und die Funktion der wissenschaftlichen Beiräte bei den Bundesministerien" erörtert G e r h a r d.W e is s er in „Ratgeber von Parlament und Regierung“, Vortragsreihe des Instituts zur Förderung öffentl. Angelegenheiten, Frankfurt 1951. 
III.

1. Das Parlament ist heute nicht mehr - wenn es dies überhaupt im 19. Jahrhundert wirklich gewesen sein sollte ${ }^{56}$ ) eine Versammlung weiser, als Einzelpersönlichkeiten von privilegierten Schichten gewählter Männer, die sich in öffentlicher Diskussion durch Argumente zu überzeugen suchen in der Annahme, da $B$ die dann von der Mehrheit getroffene Entscheidung das Wahre und Richtige für das Volkswohl sei. Das Parlament hat heute eine andere, nicht minder legitime Funktion, mit der die überkommene repräsentative Stellung der Abgeordneten und die überkommenen Privilegien des Parlaments durchaus vereinbar sind. Es ist die öffentliche Tribüne geworden, auf der vor dem ganzen Volk, das durch Rundfunk und Fernsehen in besonderer Weise an dieser Offentlichkeit teilnimmt, die Regierung und die sie stützenden Parteien ihre Politik dem Volke darlegen und verteidigen, die Opposition aber diese Politik in der gleichen Offentlichkeit angreift und ihre Alternativpolitik entwickelt. Die Opposition zwingt so die Regierung und ihre Mehrheit, bei jedem Akt der Legislative und der großen Politik ihre Gründe vor dem Volke darzulegen, das ihnen nur auf Zeit die Regierungsmacht übertragen hat und vor dem sie sich bei der nächsten Wahl verantworten müssen.

Die Entscheidungen, die im Parlament gefällt werden, sind nicht das Erzeugnis dunkler anonymer Kräfte, sondern unter der Kontrolle der Offentlichkeit getroffene Entscheidungen des $\mathrm{Parl}$ aments, die von den Abgeordneten, die zustimmen, getragen und verantwortet werden. Im Ernst wird niemand behaupten können, daß unsere Parlamentsfraktionen nicht über bedeutende, kraftvolle und redegewandte Persönlichkeiten verfügen. Auf die führenden Persönlichkeiten, nicht auf die Hinterbänkler, kam und kommt es aber immer an. S i e formen das Bild der Institution. Die Abgeordneten geben als frei gewählte Repräsentanten des Volks den Willen des Volkes kund und wirken wieder zurück auf die Meinungsbildung im Volk. Sie stehen als Mittler zwischen Volk und Regierung, stützen und kritisieren die Regierung und sorgen dafür, daß die Regierung in der demokratischen Verantwortung gehalten wird.

56) So die bekannte These von $\mathrm{Carl} \mathrm{S} \mathrm{ch} \mathrm{mitt,} \mathrm{Parlamentaris-}$ mus (Anm. 1) S. 45 ff. Gegen das Weiterschleppen überholter Deutungen, die eine zeit- und landesgebundene Phase der liberalen Theorie für allein maßgeblich halten, unter Hinweis auf die älteren englischen Wurzeln auch S cheuner, Dơv 1957 S. 634. 
Auch heute noch ist das Parlament der Brennpunkt der öffentlichen Meinungsbildung, die repräsentative Stätte der Umformung öffentlicher Meinung in politischen Gesamtwillen ${ }^{57}$ ). Ich brauche nur an die großen Debatten des Bundestages über die Außenpolitik und die Wehrpolitik zu erinnern.

Die im Parlament gehaltenen Reden mögen „zum Fenster hinaus" gehalten werden. Das ist durchaus legitim, denn vor dem Fenster steht das souveräne Volk und erwartet die Rechtfertigung der von den Parteien getroffenen Entscheidungen. Diese Reden haben also durchaus eine integrierende Wirkung auf die Nation, ja man kann sogar sagen, daß ihnen auch eine gewisse Uberzeugungstendenz innewohnt, da die Parteien die Wähler für oder gegen eine bestimmte Politik gewinnen wollen.

Kein Einwand gegen die Institution des Parlaments kann daraus abgeleitet werden, daß die Arbeit zu einem großen, vielleicht zum wesentlichen Teil in den Ausschüssen geleistet wird. Auch die Ausschüsse gehören zum Parlament; es ist nur eine Frage der besten Arbeitstechnilk, inwieweit die Arbeit vor Plenum in die Ausschüsse verlagert wird. Im Interesse sachlicher Arbeit kann die Ausschußarbeit nur begrüßt werden, und die verschlossenen Türen kommen der Qualität der von den Ausschüssen geleisteten Arbeit nur zugute. Aber die Ausschußarbeit macht die Plenarsitzungen nicht überflüssig, da nur von den Plenarsitzungen die integrierende Wirkung ausgeht, und da dort die Entscheidungen in voller Offentlichkeit registriert werden oder auch erst fallen. Eine genaue Analyse der von dem Parlament und seinen A uss chüss en geleisteten Arbeit dürfte die vielfach vertretene These von der tberflüssigkeit und Sinnlosigkeit des Parlaments widerlegen.

57) Das Grundgesetz enthält keine plebiszitären Elemente und stellt damit das Parlament als alleinige Instanz politischer Willensbildung heraus. Volksbegehren und Volksentscheid wurden vom Parlamentarischen Rat wegen leicht möglichen demagogischen Mißbrauchs abgelehnt. Ob „das Volk“ wirklich in der Lage ist, über Sachfragen zu entscheiden, kann in der Tat zweifelhaft sein (über die Schweizer Erfahrungen: W e r n e r K ä g i , An den Grenzen der direkten Demokratie, Jahrbuch „Die Schweiz" 1951 S. $1 \mathrm{ff}$,). Eine starke Bewegung zugunsten „konsultativer Volksbefragung" wurde nach dem Bundestagsbeschluß vom 25. März 1958 betr. Atomrüstung entfacht (SPD.-Antrag im Bundestag; Vorhaben von Landesregierungen und Stadtvertretungen, in denen die Oppositionsparteien die Mehrheit haben, solche Befragungen im Land oder sogar in der Stadt durchzuführen). Es bleibt abzuwarten, ob sich daraus grundsätzliche Wandlungen unserer parlamentarischen Demokratie ergeben. 
2. Wenn auch im parlamentarischen Regierungssystem die Regierung von den gleichen politischen Kräften getragen wird, die die Mehrheit im Parlament innehaben, so ist doch nicht die notwendige Folge, da $\beta$ die Regierung zu einem Vollzugsausschuß des Parlaments herabsinkt. Das mag auf weiten Strecken das Signum der französischen Entwicklung sein, trifft aber für andere Staaten, insbesondere für die Bundesrepublik, nicht $\mathrm{zu}^{58}$ ). Auch innerhalb des parlamentarischen Systems kann die Selbständigkeit der Regierung als des politisch leitenden Exekutivorgans erhalten bleiben. Sie muß erhalten bleiben, wenn dieses System seine besonderen Vorzüge entfalten soll ${ }^{50}$ ). Die Regierung steht zwar in politischer Abhängigkeit vom Parlament, wirkt aber doch auch ihrerseits führend auf das Parlament ein, entfaltet eigene Initiative, gibt politische Impulse $\left.{ }^{00}\right)$. Die meisten Verfassungen überlassen es dem Chef der Regierung, die Richtlinien der Politik aufzustellen $^{(1)}$ ), was bei aller politischen Abhängigkeit vom Parlament doch die Initiative der Regierung verbürgt ${ }^{62}$ ).

58) Uber den "naturnotwendig" bestehenden Widerstreit zwischen Parlament und Regierung: A do 1 f A r ndt SJZ 1946 S. 83; zum Spannungsverhältnis zwischen Parlament und Regierung auch bei parl. Regierungsweise: K.l e i n r a h m, ArchOffR 79 (1953) S. 152 ff.

50) Ebenso für England und die Bundesrepublik: $S \mathrm{ch}$ e uner DOV 1957 S. 637.

B0) Uber die Regierung als einheitliche Zusammenfassung und Oberleitung der gesamten Staatstätigkeit: $S$ c h e u n e r, SmendFestgabe S. 261 ff. Diese Abhandlung über den „Bereich der Regierung" leidet aber m. E. darunter, daß Regierung als Funktion und Regierung als Organ nicht immer klar genug unterschieden sind.

61) Nach der Bremer Verfassung (Art. 118) führt der Senat die Verwaltung nach den Gesetzen und den von der Bürgerschaft gegebenen Richtlinien. Nach der Berliner Verfassung (Art. 43 II) bedürfen die vom Reg. Bgm im Einvernehmen mit dem Senat bestimmten Richtlinien der Regierungspolitik der Billigung des $\mathrm{Ab}-$ geordnetenhauses. Die Richtlinienkompetenz des Regierungschefs schließst nicht aus, daß das Parlament Beschlüsse über die Führung der Politik faßt. Darüber hinaus führt die Aufweichung des Gesetzesbegriffs dazu, daß auch in der Form des Gesetzes Richtlinien gegeben, Pläne aufgestellt werden. Vgl. z. B. das zwar aus einem Initiativentwurf entstandene, aber von der Bundesregierung akzeptierte Landwirtschaftsgesetz vom 5. 9. 1955 (BGBl. I S. 565). Auch wenn man solche Gesetze als Einwirkung des Parlaments auf die Regierung im Sinne der weiter im Text folgenden Ausführungen für zulässig hält, folgt daraus nicht, daß derartige "Ge-

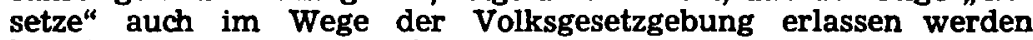
könnten (zum Streit um das Volksbegehren „Freiheitsgesetz“, das in diesem Sinne Richtlinien für die Außenpolitik geben wollte, vgl. Poetzsch-Hefter JbOffR 21, S. 199 ff.).

62) Verfassungsrechtlich hat jedenfalls das Parlament den Vorrang, da die Regierung in Bildung und Abberufung vom Parlament 
Regieren kann immer nur ein kleiner Kreis von Personen, nicht ein ganzes Parlament. Aber im parlamentarischen System soll die Regierung getragen sein von dem Vertrauen des Parlaments, damit die Regierung ihr Programm leichter durchführen kann und über das Medium der politischen Parteien Verständnis und Billigung im Volke findet. Kraftvolles und wirksames Handeln der Exekutive ist gerade im madernen Massen- und Sozialstaat erforderlich. Die parlamentarische Regierungsweise führt keineswegs notwendig zu einer schwachen Regierung, sondern sie will nur die Mitwirkung des Parlaments bei der Regierung (als Funktion) und die Kontrolle der Regierung (als Organ) durch das Parlament sichern. Das parlamentarische Regierungssystem steht, wie die Erfahrung zeigt, dem Wirken großer Staatsmänner und Politiker nicht entgegen, die die Nation führen und ihren politischen Willen bilden. Die Verankerung im Parlament verleiht der potestas, die jede Regierung haben muß, die erforderliche auctoritas. Zugleich dient es in besonderem Maße der Sicherung der Freiheit, daß die Regierung immer unter der Kontrolle einer in kurzen Intervallen gewählten Volksvertretung bleibt.

Obwohl die Mitglieder einer parlamentarischen Regierung nicht Abgeordnete sein müssen ${ }^{63}$ ), ja gelegentlich sogar Inkompatibilität vorgeschrieben ${ }^{64}$ ) oder dem Minister das Recht einabhängig ist, von ihm kontrolliert wird und zur Durchführung ihrer Politik der vom Parlament zu erlassenden Gesetze bedarf. Das Parlament hingegen ist in seiner Tätigkeit von der Regierung unabhängig. $\mathrm{Ob}$ im Zeitalter des Verwaltungsstaats der Regierung politisch die Vormachtstellung zukommt (so S c h e u n e r, Grundfragen des mod. Staates (Anm. 1) S. 149; zur Frage der Balance oder Vormacht vor allem L ö we n s te i n, ChicLawR (Anm. 1) und ArchOffR 75, 160), erscheint mir nicht unbedingt sicher; die Umstände des Verwaltungsstaates haben zwangsläufig dazu geführt, daß das Parlament durch "Maßnahmegesetze" (dazu die Verhandlungen der VrgDStRL 1956, Veröfftl. Heft 15, und B a ll er s t e d t in Festschrift Schmidt-Rimpler, 1956) stärker in die Exekutive hineinwirkt. Die Politik wird heute maßgebend durch Gesetze bestimmt, wenn auch wahr bleibt, daß sich nicht alle Bereiche der Politik zur Verrechtlichung in Form des Gesetzes eignen. Einer absoluten Gewalt des Parlaments wirken im übrigen die rechtsstaatlichen Hemmungen entgegen.

63) Verfassungsrechtlich vorgeschrieben nur in Nordrhein-Westfalen für den Ministerpräsidenten (Art. 52 Abs. 1).

64) Bremen Art. 108 Abs. 1; vorgeschlagen im Gutachten der Arbeitsgemeinschaft für Staatsvereinfachung: „Staatsvereinfachung in Bayern“, Erster Teil, 1955, S. $53 \mathrm{f}$.; von Th. E s chen bu r g für die Landesregierung in "Verfassung und Verwaltungsaufbau des Südweststaates", 1952, S. 68. Für Landesregierung auch tragbar, da mehr Verwaltungskollegium. Die Inkompatibilitätsvorschrift der Schweizer Bundesverfassung (Art. 77) gehört in das besondere politische Kräftesystem dieser Verfassung (unten bei Anm. 112). 
geräumt "ist, sein Mandat ruhen zu lassen ${ }^{65}$ ), erscheint die Mitgliedschaft der Minister im Parlament doch notwendig, damit sie eine politische Rolle gegenüber der Bürokratie und ihren Ministerkollegen spielen können. Die Einrichtung von Sonderministern mit dem speziellen Auftrag, die Verbindung zwischen Regierung und Mehrheitsfraktionen zu pflegen, hat sich übrigens nach einer Enklärung des Bundeskanzlers im Bundestag nicht bewährt ${ }^{68}$ ).

Die Tatsache, daß die Mehrheitsparteien das Bindeglied zwischen Regierung und Parlamentsmehrheit darstellen, fördert die Zusammenarbeit, muß aber nicht dazu führen, daß die Spannung zwischen Regierung und Parlament verschwindet ${ }^{67}$ ), da jede Institution ihr eigenes Gewicht und ihre besondere Funktion bei der Formung des Gesamtwillens hat ${ }^{68}$ ). So wenig

65) Rheinland-Pfalz Art. 81 Abs. 2.

68) 124. Sitzung des II. Bundestages v. 19. 1. 1956, StenBer. S. 6532.

67) We rner We ber, Festschrift für Hans Niedermeyer, 1953, S 267, allerdings meint: "Die maßgebende Parlamentsmehrheit ist politisch identisch mit dem Regierungskollegium." Auch nach Scheu ner DÓV 1957, 635, geht es im Grunde nur noch um Regierung und Parlamentsmehrheit auf der einen und Opposition auf der anderen Seite. Mir scheint aber, daß gerade in Deutschland die alte Spannung zwischen Parlament und Bürokratie immer noch stark nachwirkt und auch das Verhältnis von Mehrheit und Regierung beeinflußt. Ubrigens hat MinPr. Gebhard Müller nach Zeitungsmeldungen vor kurzem festgestellt, daß sich selbst [oder gerade?] die bd.-wttbg. Allparteienregierung einer oft recht wirksam werdenden Opposition des ganzen Parlaments gegenübersähe (Bad. Neueste Nachr. 21. Dez. 1957). Wenn die Regierungen über Eingriffe des Parlaments und der Abgeordneten in die Exekutive, wenn die Parlamente über mangelnde Unterrichtung durch die Regierung klagen, wenn auch Fraktionen der Mehrheit Initiativentwürfe ohne vorherige Abstimmung mit der Regierung oder Mitwirkung der Ministerialbürokratie einbringen, so dürfte das gegen die behauptete völlige Harmonisierung sprechen. In dem Konflikt mit der Regierung um die Ernennung der Mitglieder des nds. Rechnungshofes haben alle Parteien gemeinsam sofort die Verfassung durch Abs. 3 des Art. 53 ergänzt (Gesetz v. 29. 2. 1956). Gegen die vom Parlament einmütig beschlossenen Bestimmungen der GO, die Regierungsvertreter von der Teilnahme an den Sitzungen gewisser Ausschüsse ausschließen wollten, hat die nds. Landesregierung den StGH angerufen und das obsiegende Urteil vom 12. Dezember 1957 erreicht. Der sozialdemokratisch geführte Bremer Senat hat im Wege der abstrakten Normenkontrolle das Bundesverfassungsgericht gegen das von der sozialdemokratischen Mehrheit beschlossene Personalvertretungsgesetz vom 3. Dez. 1957 (GBl. S. 161) angerufen, dessen umstrittene Bestimmungen der Brem. StGH in der Entscheidung vom 3. Mai 1957 bereits für zulässig erkJärt hatte (abgedruckt mit der abw. Meinung von drei Mitgliedern des Gerichts und Anm. von $\mathrm{H}$ a $\mathrm{ns} \mathrm{Sch}$ neider in ZfBR 1957 S. 239).

68) Der Parteimann in der Regierung wird notwendig manches anders sehen als der reine Parlamentarier. 
wie die Regierung ein Vollzugsausschuß des Parlaments zu sein braucht, so wenig muß das Parlament zu einem bloßen Instrument werden, dessen sich die Regierung bedient, wenn es ihr notwendig erscheint. Parlament und Regierung leben in ständiger Durchdringung und gegenseitiger Abhängigkeit, und gerade diese fortdauernde $Z$ us ammenarbeit, die sich einer genauen Analyse entzieht, und in der die Akzente von Mal zu Mal anders gesetzt sein können, ermöglicht eine gute „Staatsführung“. Es mag Fälle geben, in denen das Parlament nur bestätigt, was die Regierung ihm vorschlägt $\left.{ }^{68}\right)$. Aber es gibt Fälle genug, in denen das Parlament an den Vorschlägen der Regierung eingreifende Änderungen vornimmt oder sie gar in vollem Umfang ablehnt. Und es gibt endlich Fälle, in denen die Initiative aus dem Parlament heraus ergriffen wird. Für den Normalfall wird man davon ausgehen können, daß das Parlament die Politik akzeptiert, die von der Regierung erarbeitet worden ist, und sie approbiert, soweit dies verfassungsrechtlich notwendig ist, sie z. B. nur in einem Gesetz Ausdruck finden kann. In Lebensfragen der Nation jedoch wird das Parlament selbst die führende Rolle übernehmen und den Willen für eine bestimmte Politik bekunden, dem sich die Regiemung schwerlich versagen kann ${ }^{70}$ ).

60) Einen scharfen Protest gegen die Behandlung des Wehrpflichtgesetzes im Bundestag erhebt $\mathrm{Helmut} \mathrm{R}$ idder in DOV 1957 S. 511.

70) Selbstverständlich kann das Parlament die Regierungspolitik "ändern" nur durch das konstruktive Mißtrauensvotum (so B l ü c h e r [Anm. 1] S. 2), aber es fragt sich, wie weit sie nicht nur durch Gesetze (Anm. 21 und 62), sondern auch durch schlichte Parlamentsbeschlüsse beeinflußt werden kann. Solche Manifestationen des politischen Willens des Parlaments, wie wir sie immer wieder erleben, mögen keine verfassungsrechtliche, justiziable Pflicht zur Befolgung durch die Regierung auslösen, man kann sie aber auch nicht als unbeachtliche, in tberschreitung des Funktionsbereichs und darum eigentlich unzulässige - , Meinungsäußerungen betrachten. In den Beziehungen zwischen den Verfassungsorganen gibt es neben den "einklagbaren" Rechten auch politische Pflichten. $\mathrm{Ob}$ und welche Folgen an deren Nichtbefolgung geknüpft werden, ist eine andere Frage. $\mathrm{Zu}$ den schlichten Parlamentsbeschlüssen vgl. etwa: $\mathrm{K}$ er $\mathrm{n}$, MDR 1950 S. 655; A rend DRZ 1949 S. 29 (behandelt die Praxis des Wirtschaftsrates), Bayer. Gutachten (Anm. 64) S. $47 \mathrm{ff}$. Selbstverständlich darf das Parlament nicht versuchen, durch Einzelweisungen in die $\mathrm{Verwaltu} \mathbf{\mathrm { ng }}$ einzugreifen. Das spielt eine Rolle bei der Erledigung der Petitionen, die übungsgemäB der Regierung z. T. „zur Berücksichtigung" überwiesen werden. Vgl. das Kurzprotokoll der 122. Sitzung des Pet.-Ausschusses des II. BT. v. 12. 9. 1956, in der auch über die Kontroverse aus dem Ersten Bundestag berichtet wird, und schriftl. Bericht des PetA, Anlage 2, zur BT-Sitzung vom 6. 12. 1956; weiter das auf Anfrage des Großen Rates von Genf erstattete 
Die Zuständigkeitsabgrenzung zwischen Parlament und Regierung kann weder nach dem Grundsatz der strengen Gewaltenteilung, noch auch nur unter dem Aspekt einer Balance vorgenommen werden ${ }^{71}$ ). Zwar dürfen sich Parlament und Regierung gleichermaßen nicht in die den Gerichten vorbehaltene Rechtsprechung einmischen. Zwar ist die Rechtsetzung unter Vorbehalt der Delegation - ein Reservat des Parlaments. Aber es gibt nicht ein gleichermaßen verfassungskräftiges Vorbehaltsgebiet für die Regierung. Das Parlament darf sich zwar nicht in die laufende Verwal tung einmischen, da dies dem Rechtsstaatsgrundsatz widersprechen würde. Die

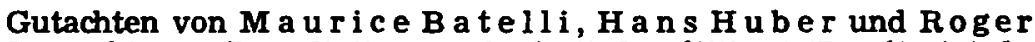
S e créta n „Consultation sur le droit de pétition“ (Secrétariat du Grand Conseil Nr. 1712). - Besondere Bedeutung hat die Frage der parlamentarischen Weisungen im Haushaltsrecht. Heckel bejaht in seinen grundsätzlichen Ausführungen (HdbDStR II, 406) die Existenz politisch betonter Ausgabebewilligungen und die "staatsrechtliche Pflicht" der Regierung, sie zu bewirken. Für unseren Zusammenhang auch heute noch lehrreich die Diskussion um den Panzerkreuzer- A (Literatur bei Heckel aaO. S. 406 Anm. 74). Streitig geworden ist die Frage heute bei den Subventionen; vgl. dazu I p s e $n$, Offentliche Subventionierung Privater, 1956, S. 41 f.; $\mathrm{K}$ e r $\mathrm{n}$ aaO. S. 655. Es ist eine andere Frage, die in einigen Ländern akut geworden ist, ob das Parlament sich selbst oder einem Ausschuß eine Mitwirkung beim Vollzug des Etats vorbehalten kann. Das würde in der Tat den auch im parl. System bestehenbleibenden Eigenbereich der Regierung verletzen. - Selbst die Kompetenz des Parlaments zur Aufstellung verbindlicher Grundsätze für die Verwaltungsführung findet sich in Verfassungen, die vorgeben, an dem Prinzip der Teilung der Gewalten festzuhalten (zu Art. 29 der Preuß. Vfg. 1920, vgl. T h o m a, HdbDStR II S. 158; zur Bremer Verfassung, die nicht nur den bereits erwähnten Art. 118 [Anm. 61] enthält, sondern der Bürgerschaft in Art. 101 zahlreiche Zuständigkeiten im Bereich der Verwaltung zuweist: $K$ rets chmann, Verwaltungsbefugnisse des Bremischen Landesparlaments, Heid. Diss. 1957; dort auch Hinweise auf die zahlreichen vom StGH entschiedenen Streitfragen).

71) Zur Gewaltenteilung: Martin Drath, Die Gewaltenteilung im heutigen deutschen Staatsrecht, in „Faktoren der Machtbildung “ 1952 S. 99 ff.; W e r n e r Käg i , Zur Entstehung, Wandlung und Problematik des Gewaltenteilungsprinzips, Zürich 1932; O t t o $\mathbf{K}$ üst e r, Das Gewaltenteilungsproblem im modernen Staat, ArchOffR 75, 1949, S. 397 ff.; H an s Peters, Die Gewaltentrennung in moderner Sicht, Köln und Opladen 1954, P e ter Schneider, Zur Problematik der Gewaltenteilung im Rechtsstaat der Gegenwart, ArchOffR 82 (1957) S. 1 ff.; W e r n e r W e b e r, Spannungen (Anm. 1). - Man wird die Feststellung von Werner W e ber schwerlich bestreiten können: „Exekutive und Legislative gehen . . heute, unter den Bedingungen der parteienstaatlichen Massendemokratie und des Verwaltungsstaates, sowohl ihrem politischen Träger nach als auch ihren Funktionen nach ineinander uber" (Festschrift Niedermeyer S. 267). Dann ist es aber nicht mehr möglich, das Prinzip der Gewaltenteilung so 
Sta ts leit ùng aber steht Regierung und Parlament gewissermaßen zur gesamten Hand $\mathrm{zu}^{72}$ ). $\mathrm{Zu}$ Unrecht wird in diesem Bereich vielfach der Rechtsstaatsgrundsatz bemüht, um eine verfassungswidrige Einmischung des Parlaments in die Regierung oder eine unzulässige Ausdehnung der Verordnungsgewalt der Regierung zu behaupten. Nur da, wo eine Kompetenz absolut eindeutig durch spezielle Verfassungsvorschrift der Regierung zugewiesen ist, ist es ausgeschlossen, daß das Parlament durch Beschlüsse außerhalb des Gesetzgebungsverfahrens Einfluß nimmt oder durch einfaches Gesetz sich ein Mitwirkungsrecht bei Regierungsakten vorbehält ${ }^{73}$ ).

selbstverständlich als eine starre Verfassungsregel zur Entscheidung von Kompetenzstreitigkeiten zwischen Regierung und Parlament zu benutzen, wie es vielfach geschieht. Eine Verfassung, die parlamentarische Regierungsweise einführt, beruht nicht auf der "Trennung der gesetzgebenden, rechtsprechenden und vollziehenden Gewalt", auch wenn sie das Gegenteil ausdrücklich versichert, wie Rheinland-Pfalz Art. 77. Dieses Prinzip kann nur als "staatliches Ordnungsprinzip einer freiheitlichen Staatsform" zugrundegelegt werden, so daB nicht jede Abweichung von diesem System strenger Funktionenunterscheidung zwischen Regierung und Parlament als Verletzung verfassungrechtlicher Grundsätze gebrandmarkt werden kann (so $S \mathrm{c}$ h e u n e r DOV $1957 \mathrm{~S}$. 635 unter Hinweis auf $H$. Peters und $P$. Schneider). Helmut Ridder (Anm. 1) bestreitet, daß in Art. 20 Abs. 2 GG die Gewaltentrennung ,verankert" sei, geht aber in der Betonung des Parlaments als „Führungsorgan“ (vgl. auch DOV 1957, 511) zu weit.

72) Johannes Heckels Gedanke der demokratischen im Unterschied zur rechtsstaatlichen Gewaltenteilung (HdbDStR II, $386 \mathrm{ff}$.) dürfte auch über den Bereich des Haushaltsrechts hinaus fruchtbare Ansätze geben, insbes. für die Ausw. Gewalt und die Militärgewalt.

73) Schon bei der Gesetzgebung handelt es sich um ein Zusammenwirken von Parlament und Regierung, nicht nur wegen des Initiativrechts der Regierung und der Teilnahme der Regierungsvertreter an den Beratungen im Ausschuß und Plenum, sondern auch wegen der ihr etwa weiter eingeräumten Rechte wie Einspruch oder Anrufung des Volksentscheids, erst recht wenn der Regierung mit der herrschenden Meinung, die ich ablehne, ein materielles Prüfungsrecht bei der Ausfertigung und Verkündung der Gesetze eingeräumt wird. Aber man darf den Blick überhaupt nicht so starr auf die Aufgabe des Parlaments als Gesetzgeber und der Regierung als Exekutive richten. Die zahlreichen Bestimmungen, die schon von Verfassungs wegen eine Mitwirkung des Parlaments bei Regierungsakten vorsehen (Vertragsschluß, Entscheidung über Krieg und Frieden, Haushaltsplan, Organisationsgesetze) brauchen nicht notwendig als Ausnahmen angesehen zu werden, sondern können ebensogut als Ausflüsse eines allgemeinen Prinzips gelten. Dann aber dürfte es auch zulässig sein, daß das Parlament sich in Gesetzen, wie z. B. Personalgutachterausschuß-Gesetz vom 23. 7. 1955 (BGBI. I S. 451) oder Rechnungshofgesetz ein Mitwirkungsrecht bei der Ernennung der Träger politischer Funktionen vorbehält, oder nach Art des $\S 7$ des Freiwilligengesetzes vom 23 . 7 . 
„Mitwirkung“ bedeutet nicht, daß das Parlament exekutive Befugnisse in vollem Umfang an sich reißt. Der Gefahr eines Parlamentsabsolutismus beugt im übrigen der richtig verstande Rechtsstaatsgrundsatz vor.

Umgekehrt brauchte man nicht so ängstlich mit der Delegation von Rechtsetzungsbefugnissen an die Regierung $\mathrm{zu}$ sein, wenn nur eine starke Kontrolle durch das Parlament gesichert ist $\left.{ }^{74}\right)$. Nachdem das Budgetrecht des Parlaments seine alte Bedeutung verloren hat, nachdem die Rechtsetzungsaufgabe des Parlaments unter Zeitmangel, Arbeitsdruck und DetailUnkenntnis leidet und von der Delegation in weitem Umfang Gebrauch gemacht werden muß, erscheint es notwendig, zur Kompensation die Kontrollrechte des Parlaments ${ }^{75}$ ) zu ver-

1955 (BGBl. I S. 449) einen Gesetzesvorbehalt für organisatorische Regelungen anbringt. Die Grenzen liegen darin, daß das Parlament einerseits nicht in die eigentliche Verwaltung eingreifen darf, andererseits etwas übrig bleiben muß, was funktionell als Regierung bezeichnet werden kann. - Grundsätzlich a. M. der österr. Verf.GH. Die Osterr. Verfassung enthält einen besonderen $\mathrm{Ab}$ schnitt "Mitwirkung des Nationalrats und des Bundesrats an der Vollziehung des Bundes". Der VerfGH betrachtet diese Aufzählung als erschöpfend und hat daraus in dem Erkenntnis Nr. 1454 den Schluß gezogen, daß eine neue Aufgabe der Mitwirkung an der Vollziehung, wie z. B. die Bestellung von Organen durch den Nationalrat, die im Bundesverfassungsgesetz nicht vorgesehen ist, nur durch ein Bundesverfassungsgesetz übertragen werden kann. (Adamovich, Die Rspr. des VerfGH, 1952, S. 75 f.)

74) Zur „Ubertragung rechtsetzender Gewalt im Rechtsstaat", vgl. den Bericht über die Weinheimer Tagung des Instituts zur Förderung öffentlicher Angelegenheiten, Frankfurt 1952. Ich würde mit $\mathrm{N}$ a w i a sky, Grundfragen S. 121, für eine weite Auslegung des Art. 80 Abs. 1 Satz 2 GG eintreten; das Bundesverfassungsgericht hat sich mit der Entscheidung vom 5. März 1958 (BVerfGE Bd. 7 S. 282 wohl endgültig der engen Auslegung zugewandt. Ein geeignetes Mittel parlamentarischer Kontrolle würden Vorlage an das Parlament und Aufhebungsverlangen bzw. Zustimmung des Parlaments oder eines Ausschusses sein, die ich mit Peter S c h n eider, JZ 1952, S. 93, für zulässig halte. Richtig gehandhabte Delegationspraxis könnte dem Parlament die dringend notwendige Entlastung bringen. Sie dürfte ein besseres Mittel sein als die Verlagerung des Gesetzesbeschlusses in die Ausschüsse, die nach Italien. Verfassungsrecht zulässig ist (darüber $\mathrm{G} \mathrm{og} \mathrm{u} \mathrm{el} \mathrm{in} \mathrm{Travail}$ Parlementaire [Anm. 1] S. 836).

75) Ein System dieser Kontrollmittel und der Einwirkungsmittel der Regierung auf die Tätigkeit des Parlaments kann hier nicht gegeben werden. Nur ein paar Hinweise auf interessante neuere Entwicklungen: Die Verfassungsgerichtsbarkeit in ihren beiden Erscheinungsformen des Organstreits und der abstrakten Normenkontrolle dient als Mittel rechtlicher Kontrolle nach beiden Richtungen und entschärft den Gegensatz zwischen Parlament und Regierung; besonders wichtig das Klagerecht der Fraktion an Stelle des Bundestags nach $\$ \S 63,64$, Abs. 1 BVerfGG. - Mit dem Wehr- 
stärken und dem Parlament stärkeren Einfluß auf die Führung der Regierungsgeschäfte einzuräumen. Dies ist in größerem Umfang möglich, als es die Verfechter eines allzu eng gefaßten Gewaltenteilungsgrundsatzes wahrhaben wollen. Einzelheiten kann ich nicht weiter ausführen. Einiges zu diesem Punkt findet sich im Zweiten Teil meiner Thesen.

beauftragten als Hilfsorgan des Bundestages erscheint ein neuartiges Kontrollorgan im deutschen Verfassungsrecht, das Vorbilder im skandinavischen Recht hat; dazu insbes. Ule in "Von den Grundrechten des Soldaten“, Isar-Bücherei, Band 1, München 1957, S. $109 \mathrm{ff}$. und die Diskussionsrede von $\mathrm{K}$ ö $\mathrm{t} \mathrm{tg}$ e n ebenda $\mathrm{S}$. $137 \mathrm{f}$;; U le, JZ 1957, S. 422 ff.; K i p p, DOV 1957, S. 515; G r o B, DVBl. 1956, 261 und 1957, S. 342. - U le rechnet den WB zu keiner der drei herkömmlich unterschiedenen „Gewalten“, ebensowenig wie die Rechnungshöfe. Auch bei diesen zeigt sich die Tendenz, ihre Eigenschaft als Hilfsorgan des Parlaments (so auch I p s e n, Hamburgs Verfassung und Verwaltung, 1956, S. $467 \mathrm{f}$.) schärfer herauszubilden durch Mitwirkung des Parlaments bei der Ernennung der Mitglieder und durch die direkte Ubersendung der Prüfungsergebnisse an das Parlament (vgl. darüber Härtig, DVBl. 1955, S. 174 ff., W e i c h m a n n DVBl. 1953, S. 745; K or t e JZ 1956, S. 684). - Aus der parlamentarischen Verantwortung der Regierung haben L oe $n$ ing, DVBl. 1954, S. 173 ff., und andere geschlossen, daß es grundsätzlich in der Verwaltung keinen "ministerialfreien Raum" geben dürfe, daß also das Parlament nicht befugt sei, durch einfaches Gesetz exekutive Aufgaben an eine ministerieller Leitung nicht unterstehende Stelle zu übertragen (so auch $\mathrm{S}$ c h e u n e r DÖV $1953 \mathrm{~S}$. 521). Besonders pointiert die abw. Meinung (Raschhofer, Rohwer-Kahlmann und Werner Weber) zu der Entsch. des Bremer StGH. über das Personalvertretungsgesetz vom 3. Mai 1957 (Anm. 67): „Nach der Verfassung ist nicht gestattet, $\mathrm{da} B$ wesentliche Entscheidungen der staatlichen Exekutive in einen verantwortungsfreien Raum fallen. Auch um der unverzichtbaren Kontrollrechte der Bürgerschaft willen kann es deshalb in der Exekutive keine Entscheidungsinstanz geben, die der Bürgerschaft nicht in vollem Umfang verantwortlich ist." Nun ist es aber eine petitio principii, wenn daraus, daß die Fachminister für die Entscheidungen, die sie oder die ihnen nachgeordneten Dienststellen im Rahmen ihrer gesetzlichen Zuständigkeit treffen, dem Parlament verantwortlich sind, gefolgert wird, daB durch Gesetz nicht einer Instanz Entscheidungsbefugnisse übertragen werden können, die nicht ministerieller Leitung unterstellt wird. Gegen die These spricht insbesondere auch, daß das deutsche Verwaltungsrecht seit jeher unabhängig entscheidende Ausschüsse kennt. So einfach dürfte das Problem also nicht zu lösen sein; es bedarf genauer Differenzierung. Vgl. dazu noch Dep pich, DOV 1954 S. 241, B a c h of, Wehrpflichtgesetz und Rechtsschutz, $1957 \mathrm{~S}$. $47 \mathrm{f}$. und Gros s, JZ 1958 S. 71. - Völlig neue Probleme wirft die Kontrolle des Parlaments über nationalisierte Industriezweige auf, insbes. auch die Frage der zweckmäßigsten Organisationsform; vgl. darüber Morrison, Regierung und Parlament in England, S. 327 ff.; J o hns on, The Accountability of the British nationalized industries, in AmPolitical Science Review Vol 48 (1954) S. $366 \mathrm{ff}$. 
IV.

1. Das Verhältnis von Parlament und Regierung ist grundsätzlich verschieden gestaltet, je nachdem, ob die Verfassung auf dem streng durchgeführten Grundsatz der Gewaltenteilung aufbaut und dem Parlament auf Bildung und Amtsdauer der Regierung überhaupt keinen und auf die Führung der Regierungsgeschäfte nur einen verfassungsrechtlich erschöpfend bestimmten und eng begrenzten Einfluß gewährt, oder ob unter Nichtachtung des Dogmas der Gewaltenteilung dem Parlament eine mehr oder weniger große Einwirkungsmöglichkeit auf die Regierung - im Sinne des Organs und der Funktion - eröffnet ist ${ }^{70}$ ).

Die Unabhängigkeit der Regierung vom Parlament nach Art der amerikanischen Präsidentschaftsdemokratie hat zur Voraussetzung, daß die Regierung ihrerseits eine vorm Parlament unabhängige plebiszitäre Legitimation besitzt.

Aber nicht überall, wo ein mit eigener Autorität umkleidetes Staatsoberhaupt als konstitutioneller Monarch oder als volksgewählter Präsident an der Spitze des Staates steht, ist die Regierung auf ihn ausgerichtet und vom Parlament unabhängig. Immer aber schafft die Existenz eines solch en Staatsoberhaupts77) die Möglichkeit, Einsetzung und Amtsdauer der Regierung nach beiden Seiten hin zu orientieren. Die Erfahrungen mit der Weimarer Verfassung ${ }^{78}$ ) dürften allerdings dagegen sprechen, die Regierung gleichermaßen vom Vertrauen des Staatsoberhaupts und des Parlaments abhängig $\mathrm{zu}$ machen. Ein starkes Parlament wird sich eine eigene Regierungspolitik des Staatsoberhaupts nicht gefallen lassen; bei einem schwachen Parlament können die Grundlagen der Regierungsform gestört werden.

Hat das Staatsoberhaupt die Befugnis, den Chef und die Mitglieder der Regierung nach seinem Ermessen zu ernennen und ist der Bestand der Regierung nur von der Bestätigung durch das Parlament oder gar nur davon abhängig, da $B$ das Parlament der Regierung nicht ausdrücklich das Mißtrauen

76) Ka r 1 Lö we nste i n, ArchơffR 75 (1949) S. 129 ff. unterscheidet im AnschluB an Bryce die präsidentielle, parlamentarische und direktoriale Regierungsform.

77) Die Stellung des Staatspräsidenten im Verhältnis zu Regierung und Parlament kann hier nicht im vollen Umfang erörtert werden. Vgl. dazu etwa außer der in Anm. 76 erwähnten Abhanlung von Lö we n s t e i n "Der Staatspräsident“ noch P a u 1 K e h l en beck, Der Staatsprä́sident, Forschungsstelle für Völkerrecht und ausl. öfftl. Recht a. d. Universität Hamburg, 1955.

78) Vgl. dazu die Schilderung von B r a cher (Anm. 6). 
ausspricht ${ }^{79}$ ), so kann die Regierung gegebenenfalls in Verbindung mit anderen Institutionen der Verfassung, etwa dem Auflösungsrech $t^{\circ 0}$ ), eine stärkere Stellung gegenüber dem Parlament einnehmen als da, wo sie nur als Geschöpf des Parlaments ins Leben tritt.

Ein solches eigenes politisches Gewicht dürfte dem Ernennungsrecht der heute noch regierenden konstitutionellen Monarchen nicht zukommen, wenn auch nicht verkannt werden soll, daß es in Krisenzeiten vielleicht Bedeutung gewinnen und die Machtakzente verschieben könnte.

Der volksgewählte österreichische Bundespräsident dürfte nach der Entwicklung, die das österreichische parlamentarische System seit dem Krieg genommen hat, die im Wortlaut der Weimarer Reichsverfassung entsprechenden Vorschriften der Bundesverfassung ${ }^{81}$ ) über die Bestellung der Regierung nicht im Sinne einer eigenen Politik der Regierungsbildung ausnützen können.

Die Eigenwilligkeit des italienischen Staatspräsidenten bei der Regierungskrise im Frühjahr 1957 hat zu dem Vorwurf einer verfassungswidrigen Einwirkung geführt, obwohl ihm die Verfassung das Recht einräumt, den Ministerpräsidenten zu ernennen, der dann erst das Vertrauensvotum der Kammern einholen $m u \beta^{82}$ ).

In der Bundesrepublik Deutschland haben die Erfahrungen mit der Weimarer Präsidialregierung dazu geführt, daß alle konstitutionellen Reste aus der Verfassung beseitigit sind und

79) So die Weimarer Reichsverfassung.

80) Die Begrenzung der Auflösung des BT auf zwei Ausnahmefälle (Art. 63 Abs. 4 Satz 3 und Art. 68 Abs. 1 GG) kann man nur auf dem Hintergrund des Auflösungsrechts und der Auflösungspraxis der Weimarer Verfassung verstehen; vgl. dazu die Berichte über das „Staatsleben unter der Weimarer Verfassung“ im JböffR, insbesondere den letzten Bericht in Bd. $21 \mathrm{~S}$. $68 \mathrm{ff}$. über die Reichstagsauflösung vom 12. 9. 1932; nicht nur die vom RPr. eingesetzte, noch nicht vom RT bestätigte RReg., sondern selbst die durch Mißtrauensvotum gestürzte RReg. konnte das Auflösungsdekret gegenzeichnen; es konnte sogar während der Abstimmung über ein Mißtrauensvotum verkündet werden!

81) Art. 70 Abs. 1 in der Fassung der Novelle vom 7. Dezember 1929; vorher wurden die Mitglieder der Bundesregierung vom Nationalrat gewählt:

82) Art. 92 Abs. 2, 94 Abs. 3. Die Verfassungspraxis wird letztlich uiber das $\mathrm{MaB}$ von Selbständigkeit entscheiden, das der StPr. entwickeln kann. Ein wesentlicher Unterschied zur WRV besteht darin, daß die Regierung des innerhalb von zehn Tagen zu gewährenden Vertrauens zum Amtsantritt bedarf, und daß der StPr. nicht die Regierung nach seinem Ermessen entlassen kann (was der österr. BPr. dem Wortlaut des Art. 70 Abs. 1 Satz 2 der Bundesverfassung gemäß könnte). 
der Bundespräsident keinen entscheidenden Einfluß auf die Regierungsbildung nehmen kann. Zwar schlägt er dem Bundestag einen Bundeskanzler zur Wahl vor ${ }^{83}$ ), aber das Parlament ist in seiner Entscheidung frei, und zwar der deutsche Bundestag noch mehr als die französische Nationalversammlung, weil er auch einen nicht vom Bundespräsidenten vorgeschlagenen Bundeskanzler wählen kann $^{84}$ ).

Nomination durch das Staatsoberhaupt setzt voraus, daß sich bereits eine Regierungsmehrheit zusammengefunden und über die Person des Regierungschefs, das Regierungsprogramm ${ }^{85}$ ) und vielleicht auch bereits über das ganze Kabinett geeinigt hat $\left.{ }^{86}\right)$. Immerhin soll nicht verkannt werden, da $B$ dem Nominationsrecht eine gewisse politische Bedeutung ${ }^{87}$ ) insofern zugemessen werden kann, als bei nicht eindeutiger parlamentarischer Situation das Staatsoberhaupt durch vorherige Sondierung ${ }^{88}$ ) und ausgleichendes Bemühen der Wahl eine bestimmte Richtung zu geben vermag.

Ein Entlassungsrecht nach eigenem Ermessen entgegen dem Willen des Parlaments dürfte heute kein Staatsoberhaupt mehr ausüben können, auch wenn einzelne Verfassungen ihrem Wortlaute nach eine solche Möglichkeit eröffnen ${ }^{80}$ ).

2. Schreibt die Verfassung vor, da $\beta$ der Regierungschef vom Parlament gewählt wird, so ist die Amtsdauer der Regierung auf die Wahlperiode des Parlaments begrenzt ${ }^{90}$ ). Jedes neugewählte Parlament ist zur Regierungsbildung berufen. Das

83) Dazu W. Jell i n ek VDStRL 8, S. 9; H. S ch neider NJW 1953, S. 1331.

84) Zum Designationsrecht des französ. Staatspräsidenten vgl. Art. 45 der Verfassung, der durch die Novelle vom 7. Dezember 1954 geändert worden ist; zur urspr. Fassung: V e del (Anm. 1) S. 434 ff.; zur Reform B e r li a (Anm. 16) mit Hinweis auf frühere Berichte in dieser Zeitschrift.

85) Auf die darin liegende politische Beschränkung der nach der Verfassung dem Regierungschef eingeräumten Kompetenz, die Richtlinien der Politik zu bestimmen, wird immer wieder hingewiesen; vgl. z. B. Es chen burg, Die Richtlinien der Politik im Verfassungsrecht und in der Verfassungswirklichkeit, DVBl. 1954 S. $193 \mathrm{ff}$.

86) Das gilt insbesondere, wenn die Wahl des Regierungschefs "ohne Aussprache" erfolgen muß, wie es das GG in Art. 63 Abs. 1 vorschreibt.

87) H. S ch neider NJW 1953, 1331.

88) Die französ. Verfassung schreibt die „consultations d'usage“ in Art. 45 Abs. 1 ausdrücklich vor.

89) Z. B. österr. Bundesverfassung Art. 70 Abs. 1 Satz 2 idF von 1929.

90) So grundsätzlich für die parl. Regierung auch Dürig HdwbSozWiss. IX, 749; a. M.: Uh litz, Die Amtszeit der Landesregierungen, DOV 1956, 485. 
muß auch da gelten, wo es in der Verfassung nicht ausdrücklich bestimmt ist'1). Die entgegengesetzte Staatspraxis in Berlin, Hamburg und Schleswig-Holstein ${ }^{22}$ ) entspricht nicht den Grundlagien des durch Parlamentswahl akzentuierten parlamentarischen Regierungssystems.

Die Wahl, die sich in der Regel nur auf den Chef der Regierung, seltener auf die ganze Regierung ${ }^{\text {} 3}$ ) bezieht, erfolgt grundsätzlich mit absoluter Mehrheit, die entweder von der gesetzlichen Mitgliederzahl'4) oder von den abgegebenen Stimmen $^{95}$ ) berechnet wird. Einige Verfassungen, darunter das Grundgesetz lassen bei späteren Wahlgängen relative Mehrheit ${ }^{20}$ ) $\mathrm{zu}$, ermöglichen damit also die Bildung einer Minder-

01) In den Landesverfassungen von Berlin (wie hier L a n d s berg-Goetz, Verfassung von Berlin, 1951, S. 106) Hamburg (wie hier I p s e n, Hamburgs Verfassung und Verwaltung, S. 290 ff.; dort weitere Literatur in Anm. 18 für die Weimarer Zeit, in Anm. 21 für die Gegenwart), Rheinland-Pfalz (wie hier S üs te r he n n-Schäf er, Kommentar der Verfassung für RheinlandPfalz, S. 359), Saarland und Schleswig-Holstein (anders als hier La uritzen, Die Selbstverwaltung in Schleswig-Hostein, 1950, Anm. 5 zu Art. 21 LS und Ma nnzen, JböffR NF VI 271) fehlt eine Bestimmung darüber.

92) Uber sie Uh litz aaO. S. 486.

98) Bremen Art. 107, Hamburg Art. 34; in Berlin zunächst Wahl des RegBgm., dann auf dessen Vorschlag Wahl des Bgm. und der Senatoren (Art. 41).

94) Art. 63 GG, Baden-Württemberg (Art. 46), Hamburg (Art. 34), Hessen (Art. 101), Niedersachsen (Art. 20), Nordrhein-Westfalen (Art. 52), Rheinland-Pfalz (Art. 98), Saarland (Art. 88), SchleswigHolstein (Art. 22).

95) Berlin Art 41; Bremen Art 107. Die Bayerische Verfassung, Art. 44 Abs. 1, sagt nichts über die Mehrheit; also gilt der allgemeine Grundsatz des Art. 23, wonach der Landtag mit einfacher Mehrheit der abgegebenen Stimmen beschließt, soweit die Verfassung kein anderes Stimmenverhältnis vorschreibt. Hier fehlt der sonst allgemein übliche Vorbehalt, daß die GO für Wahlen etwas anderes vorschreiben kann (vgl. z. B. Art. 42 Abs. 2 Satz 2 GG). Zu dem Streit über die Anderung der GO des Preuß. IT durch Beschluß vom 12. 4. 1932 (Einführung der Stichwahl kurz vor der Neuwahl, um die Wahl eines ns. MinPr. zu verhindern) vgl. RStGH v. 20. 11. 1932 bei Lammers-Simons VI, S. $137 \mathrm{ff}$. Die Zulässigkeit dieser Anderung der GO spielte auch eine Rolle im Konflikt Preußen/Reich; vgl. Preußen contra Reich, S. 27, 467, 512.

96) Art. 63 IV GG: relative Mehrheit genügt, wenn Vorschlag der BPr. abgelehnt, Wahl mit absoluter Mehrheit innerhalb 14 Tagen nicht erfolgt, und BPr. nicht auflöst; Niedersachsen Art. 21: nach 21 Tagen Selbstauflösung durch Beschluß der Mehrheit der Abg. oder relative Mehrheit; Nordrhein-Westfalen Art. 52: beim 2. und 3. Wahlgang (innerhalb 14 Tagen) absolute Mehrheit der abgegebenen Stimmen, beim 4. Wahlgang Stichwahl zwischen den beiden Kandidaten, die die höchste Stimmenzahl erhalten haben; SchleswigHolstein Art. 22: relative Mehrheit genügt beim dritten Wahlgang. 
heitsregierung, die an sich dem Wesen des parlamentarischen Regierungssystems widerspricht. Andere Verfassungen lassen darum diesen Ausweg nicht zu, sondern zwingen entweder den Landtag, eine Regierung mit Mehrheit zu bestellen'7), oder sehen die Auflösung des Landtags vor, wenn ihm die Bildung einer Mehrheitsregierung nicht gelingt ${ }^{98}$ ).

Nach dem Grundgesetz und einigen Landesverfassungen ${ }^{09}$ ) liegt in der Wahl des Regierungschefs nicht nur die Bekundung des positiven Vertrauens ${ }^{100}$, sondern auch das Einverständnis des Parlaments mit der von ihm zu bestellenden Regierung. Diese Konzentration der Regierung auf die Person des Regierungschefs, die sich im Recht der Ernennung und Entlassung der Minister, in der Abhängigkeit des Bestandes der Regierung von seiner Person und in der Ausschließlichkeit des auf ihn abgestellten Mißtrauensvotums zeigt, ist allerdings in unterschiedlicher Weise ausgebaut. Einige deutsche Landesverfassungen verlangen zusätzlich die Bestätigung der ganzen Regierung ${ }^{101}$ ) bzw. die Zustimmung zur Ernennung der Minister ${ }^{102}$ ). Dabei geht der EinfluB des Parlaments auf die Regiemungsbildung gelegentlich so weit, daß nicht nur die Einteilung in Ressorts, sondern auch noch die Verteilung der Ressorts auf die Minister des parlamentarischen Jinverständnisses bedarf ${ }^{103}$ ), eine Einwirkungsmöglichkeit, die an sich dem System der parlamentarischen Regierung nicht innewohnt.

97) Berlin, Bremen, Hamburg, Hessen, Rheinland-Pfalz, Saarland.

08) Bayern Art. 44 Abs. 5: nach 4 Wochen Auflösung durch den LTPr.; Baden-Württemberg Art 46: automatische Auflösung nach drei Monaten.

09) Nordrhein-Westfalen und Schleswig-Holstein.

100) Auch der nur mit relativer, also von einer Minderheit gewählte Regierungschef gilt als im Besitz des Vertrauens des Parlaments, bis ihm dies ausdrücklich entzogen wird, was meist nur mit absoluter Mehrheit möglich ist. Interessanterweise sieht die französ. Verfassungsnovelle von 1954 für die Investitur des MPr. nur mehr einfache Mehrheit vor, während es für das Mißtrauensvotum bei der absoluten Mehrheit verbleibt (Art. 45 Abs. 3, Art. 49 Abs. 3).

101) Baden-Württemberg Art. 46 Abs. 3 (absolute Mehrheit der abgegebenen Stimmen); Hessen Art. 101 Abs. 4 (Form des positiven Vertrauensvotums; keine besondere Mehrheit vorgeschrieben); Niedersachsen Art. 20 Abs. 3 (keine besondere Mehrheit vorgeschrieben; entfällt bei Wahl des MPr. mit relativer Mehrheit [Anm. 96]); Rheinland-Pfalz Art. 98 Abs. 2 Satz 3 (keine besondere Mehrheit vorgeschrieben).

102) Bayern Art. 45; Saarland Art. 89.

103) Darüber, daß nach dem Grundgesetz der BK allein die Zahl der Bundesminister bestimmt, sie vergrößern und vermindern kann, auch allein (vorbehaltlich des Budgetrechts des Parlaments) über die Einrichtung von Ministerien und über die Abgrenzung der 
Nach der Stellung, die das Grundgesetz dem Bundeskanzler einräumt, kommt ihm allein die Verfügung über den Personalbestand der Regierung zu. Dem Bundestag sind verfassungsrechtlich keinerlei Befugnisse in dieser Richtung zugeteilt; das Ernennungs- und Entlassungsrecht des Bundespräsidenten ist nur formal und muß nach den Vorschlägen des Bundeskanzlers ausgeübt werden. Bei der Bildung der Regierung ist der Bundeskanzler politisch natürlich an Koalitionsabreden ${ }^{104}$ ) oder an den Ausgleich innerhalb der einen Mehrheitsfraktion gebunden. In der Frage der Entlassung kommt es darauf an, ob dem Bundeskanzler eine hinreichende parlamentarische Unterstützung verbleibt, wenn er sich dem Wunsch von Parteien oder Fraktionen nach Abberufung eines Ministers entzieht. $\mathrm{Da}$ die Minister nicht als Vertreter ihrer Partei dem Kabinett angehören, $\mathrm{k}$ a $\mathrm{n} \mathrm{n}$ der Bundeskanzler auch einen Minister im Kabinett behalten, der aus der Partei, von der er vorgeschlagen war, ausgetreten ist. Es kommt auf die jeweilige parteipolitische Situation an. Es han-

Geschäftsbereiche bestimmt: Eschen burg DOV 1954, S. 199. Aus dem, was ich oben in Anm. 73 ausgeführt habe, ergibt sich, daß ich es auch beim Schweigen des Grundgesetzes für zulässig halte, durch einfaches Gesetz Zahl und Geschäftsbereiche der Bundesminister festzulegen. - Die Geschäftsbereiche und damit grundsätzlich auch die Zahl der Minister (weil der Ministerpräsident nach Art. 50 Abs. 1 Satz 2 mehrere Geschäftsbereiche nur vorübergehend einem Minister zuweisen kann) sind in der Bayerischen Verfassung Art. 49 festgelegt; sie können auf Vorschlag des MPr. durch Beschluß des LT erhöht oder vermindert oder ihre Abgrenzung anders bestimmt werden; die Zuweisung der Geschäftsbereiche an die Minister liegt aber allein in der Hand des MPr. Eine Höchstzahl der Regierungsmitglieder legt die Berliner Verfassung in Art. 40 Abs. 2 fest. Die Zahl der Senatoren soll durch Gesetz bestimmt werden nach den Verfassungen von Bremen Art. 107 und Hamburg Art. 33. Die Verfassung von BadenWürttemberg verlangt ein Gesetz, das die Zahl der Minister und die Geschäftsbereiche der Ministerien bestimmt; im Sommer 1957 ist ein Versuch, dieses Gesetz zustande zu bringen, im LT von Baden-Württemberg gescheitert. Soweit die Verfassungen die Bestätigung der Landesregierung vorschreiben, ist darin auch die Mitbestimmung des Parlaments über die Verteilung der Ressorts enthalten. Nach den Verfassungen von Hessen (Art. 104) und Rheinland-Pfalz (Art. 105) beschließt die Regierung über die Zuständigkeit der einzelnen Minister; die Beschlüsse sind dem Landtag unverzüglich vorzulegen und auf sein Verlangen zu ändern oder außer Kraft zu setzen.

104) Hans Schneider NJW 1953 S. 1330; über die Bildung einer Koalitionsregierung auf Landesebene berichtet Göt z R ot h, Fraktion und Regierungsbildung. Eine Monographische Darstellung der Regierungsbildung in Niedersachsen im Jahre 1951, Meisenheim 1954. 
delt sich dabei um eine politische, nicht um eine verfassungsrechtliche Frage. Daß der Kanzler einem ernsthaften Entlassungsgesuch eines Ministers entsprechen muß, ist selbstverständlich; als merkwürdige Zwischenform hat sich das Rücktritts a ng e b ot herausgebildet, mit dem der Minister dem Kanzler die Entscheidung über das Verbleiben im Kabinett ermöglichen will, ohne die schroffe Entlassung ohne Antrag zu riskieren ${ }^{105}$ ).

Da der Bundeskanzler die Richtlinien der Politikk ${ }^{108}$ ) aufstellt, da ihn allein das Mißtrauensvotum treffen kann, muß er sich mit Ministern $s$ e in es Vertrauens umgeben können. Dem Bundespräsidenten, dessen Wunsch für die Wahl des Bundeskanzlers der Bundestag nicht einmal zu berücksichtigen braucht, kann unmöglich auf dem Umweg über eine Ermessensentscheidung bei der Ernennung und Entlassung der Bundesminister ein entscheidender Einfluß auf Bildung und Bestand der Bundesregierung zukommen. Er ist also verfassungsrechtlich verpflichtet, den Vorschlägen des Bundeskanzlers zu entsprechen ${ }^{107}$ ). Die Entlassung der Minister steht nach

105) Aus dem ersten Kabinett Adenauer schied der Bundesminister Dr. Heinemann im Konflikt mit dem BK auf seinen Wunsch aus. Im zweiten Kabinett Adenauer verblieben die Minister Kraft und Oberländer trotz des Austritts aus dem BHE, die Minister Blücher, Neumayer, Preusker und Schäfer trotz Ausscheidens aus der FDP; der Koalitionspakt der CDU/CSU mit der FDP und dem BHE zerfiel; die Regierung blieb, weil die CDU/CSU die absolute Mehrheit im II. BT hatte. Mehrere Ressortverschiebungen fanden statt. Die Sonderminister Kraft und Schäfer und der Bundesjustizminister Neumayer schieden aus. Uber die Vorgänge um die aus ihren Fraktionen ausgeschiedenen Minister vgl. Bulletin 1956 Nr. 11 S. 89, Nr. 15 S. 121, Nr. 196 S. 1865.

108) Dazu Es chen bu r g DÖV 1954 S. $193 \mathrm{ff}$.

107) ebenso: $D$ e $n$ n e w it $z-M$ ed e $r$, Bonner Kommentar Art. 64 Anm. II 1; D r e h e r NJW 1950, 130; W. J e 11 i n e k, VDStRL 8 S. 10f.; Kehlenbach, Staatspräsident S. $30 \mathrm{f}$.; L a f o r e t VDStRL 8 S. 56; v. M a ngoldt, Kommentar Art. 64 Anm. 2 S. $345 ; H$. P eter $\mathrm{s}$, Entwicklungstendenzen $\mathrm{S}$. 242; a. M.: E s c he n b u r g, DOV 1954, 198 f.; Gi es e, Grundgesetz, 4. Aufl., Art. 64 Anm. II 3 ; Herrfah rdt, VDStRL $8 \mathrm{~S}$. 61; M a u $\mathrm{z}$, Staatsrecht, 6. Aufl. S. 286; M e rk, VDStRL 8 S. 60; K o e llr e u ter, Staatsrecht S. 205; $\mathrm{N} \mathrm{a} \mathrm{w} \mathrm{i} \mathrm{a} \mathrm{s} \mathrm{k} \mathrm{y,} \mathrm{Grundgedanken} \mathrm{S.} \mathrm{97;}$ Han s S ch n e ide r, NJW 1953 S. 1332 und „Die Mitwirkung des BPr. bei der Regierungsbildung“, Festschrift Benedikt Kraft, 1955, S. 129 f.; vermittelnd: $M$ ü $n \mathrm{ch}$, Bundesregierung $S$. $149 \mathrm{ff}$. unter dem Beifall von S c h ü le ArchOffR 80 S. 382. - Der Wortlaut des Art. 64 Abs. 1 GG spricht jedenfalls nicht gegen die Bindung des $\mathrm{BPr}$. an die Vorschläge des BK. Daraus, daß in anderen Fällen das GG die Verpflichtung des BPr. ausdrücklich ausspricht (Art. 63 II 2; 63 IV 2, 3; 67 I 2), kann nicht gefolgert werden, daß die Verpflichtung im Fall des Art. 64 I nicht besteht; der Wortlaut des GG ist nicht so exakt durchgearbeitet, daß dieses arg. e contr. möglich 
den deutschen Landesverfassungen im allgemeinen dem Regiemungschef allein $\mathrm{zu}$, gelegentlich aber bedarf sie der $\mathrm{Zu}-$ stimmung des Parlaments ${ }^{108}$ ).

3. Grundsätzlich fordert das parlamentarische Regierungssystem eine Regierung mit einem Prog ra m m ${ }^{109}$ ), das von der $\mathrm{M} \mathrm{e} \mathrm{h} \mathrm{r} \mathrm{h} \mathrm{e} \mathrm{it} \mathrm{des} \mathrm{Parlaments} \mathrm{gebilligt} \mathrm{wird.} \mathrm{Da} \mathrm{"Regieren“}$ heute weitgehend "Gesetze geben“ bedeutet, ist die Regierung

wäre. (Die Fassung des Art. 69 Abs. 3 z. B. verschleiert eine zweifellos bestehende verfassungsrechtliche Pflicht des BPr.). Diese ausdrüicklich fixierten Fälle der Bindung des BPr. an anderwärts getroffene Entscheidungen zeigen aber jedenfalls, daß es. nicht gegen die Würde des Amts verstößt, den BPr. bei der Ausübung des ihm als Staatsoberhaupt zugewiesenen Ernennungsrechts an fremden Willen zu binden. Die Auslegung der entsprechenden Bestimmung der WRV (Art. 53) kann zur Auslegung des Art. 64 I nicht herangezogen werden, da dem BPr. im Regierungssystem des GG bewußt nicht die Stellung eingeräumt worden ist, die dem RPr. in der WRV zukam, und die letzten Endes dazu geführt hat, daß aus dem beabsichtigten Parlamentarismus der reine Präsidentialismus wurde. Das GG ordnet die parlamentarische Regierungsweise unter klarer Hervorkehrung der beherrschenden Stellung des BK. Dann aber wäre es systemwidrig, dem BPr., - dem der BT einen von ihm nicht gewünschten BK aufdrängen kann, der nicht in der Lage ist, von sich aus den BK zu entlassen oder an das Volk zu appellieren, dem jede Einflußnahme auf die Richtlinien der Politik verwehrt ist - , durch freies Veto gegen die Vorschläge des BK entscheidenden Einfluß auf die personelle Zusammensetzung der BReg. zu geben. Wie sehr die Konzentration der parlamentarischen Verantwortlichkeit (im Sinne des Vertrauensmechanismus) auf den Regierungschef gedanklich mit dem Recht der freien Auswahl seiner Mitarbeiter zusammenhängt, zeigt sich auch darin, daß A. R ü s to w s. Zt. seinen Vorschlag des konstruktiven Mißtrauensvotums für die WRV (unten Anm. 151) mit diesem Recht des RK koppelte (vgl. E s c h e n b u r g, DOV 1954 S. 198).

108) Die Senatoren in Berlin und Hamburg können gegen ihren Willen nur durch Mißtrauensvotum aus ihrem Amt entlassen werden. In Bremen kann der Senat bei der Bürgerschaft beantragen, einem Senator wegen Pflichtverletzung durch Beschluß die Mitgliedschaft im Senat zu entziehen (Art 110 Abs. 4). Der Ministerpräsident von Baden-Württemberg muß einen Minister entlassen, wenn es 2/3 der Mitglieder des Landtags beschließen (Ersatz für das fehlende Mißtrauensvotum gegen die Minister!). Der MPr. kann die Minister nach seinem Ermessen entlassen in Baden-Württemberg (Art. 46), Nordrhein-Westfalen (Art. 52) und Schleswig-Holstein (Art. 21). Er bedarf der Zustimmung des Landtags in Bayern (Art. 45), Hessen (Art. 112), Niedersachsen (Art. 20), RheinlandPfalz (Art. 98) und Saarland (Art. 89).

109) Die französ. Verfassung schreibt in Art. 45 Abs. 2 ausdrücklich vor, daß der vom Staatspräsidenten designierte Ministerpräsident sich der Nationalversammlung stellt "afin d'obtenir sa confance sur le programme et la politique qu'il compte poursuivre." 
auf das Parlament zur Durchführung ihres Programms angewiesen ${ }^{110}$ ).

Minderheitsregierungen, die sich von Fall zu Fall ihre Mehrheiten suchen müssen, können also nur ein Notbehelf sein und deuten auf einen Krisenzustand. Eine Minderheitsregierung kann auch in ihren reinen Regierungsmaßnahmen keine starke Initiative entfalten.

Im Mehrparteienstaat kann sich nun zeigen, daß die Mehrheitsbildungen auf den verschiedenen Gebieten der Politik, etwa in der Außenpolitik, Wirtschaftspolitik, Sozialpolitik, Kulturpolitik unterschiedliche Parteigruppierungen umfassen. Daraus kann dann die Folgerung gezogen werden, daß es nicht zweckmäßig erscheint, eine Regierungskoalition mit festem, umfassendem Programm zu bilden, die sich gegen eine ebenso fest formierte Opposition abhebt, sondern den Vollzug der jeweiligen Parlamentsentscheidung einem Regierungskollegium zu übertragen, an dem alle Parteien quotenmäßig beteiligt werden. Auch eine „Geschäftsregierung" von Fachleuten ließe sich so rechtfertigen. Solche Regierungen stehen natürlich in stärkerer Abhängigkeit vom Parlament und werden mehr zur ausführenden Behörde ${ }^{111}$ ).

Auch der Schweizer Bundesrat, der als Kollegium mit jährlich wechselndem Vorsitz die Regierungsgeschäfte führt, zeigt weniger Ambitionen politischer Führung als das Bestreben sorgsamer Verwaltungsführung. Es gibt keine „Koalition“ und kein Regierungsprogramm. Allerdings wird das Schweizer Regierungssystem entscheidend durch die Eigenart der Schweiz als Referendumsdemokratie geprägt. $\mathrm{Da}$ über das Schicksal der Gesetzesvorlagen letzten Endes nicht die Räte, sondern das Volk entscheidet, erscheint der Bundesrat mehr wie eine exekutive Behörde, die den Willen der Räte und des Volkes

110) Darin liegt die Problematik des so umständlich ausgeklügelten Gesetzgebungsnotstandes nach Art. 81 GG: selbst wenn die Krisensituation des BT nicht auf den BR übergegriffen hat und der Bundeskanzler BPr. und BR für seine Gesetzentwürfe gewinnt, ist er nach sechs Monaten am Ende. Er muß also demissionieren und der BT muB einen BK wählen, obwohl er gerade bei der Abstimmung über die Vertrauensfrage nach Art. 68 gezeigt hat, daß er nicht in der Lage ist, einen BK mit der gebotenen absoluten Mehrheit zu wählen. Das Spiel kann also nur von neuem beginnen, wenn der BPr. nicht jetzt zur Auflösung nach Art. 63 Abs. 4 Satz 3 schreitet. Wirklichen Krisensituationen, wie wir sie gegen Ende der Weimarer Zeit erlebt haben, kann mit solch komplizierten verfassungsrechtlichen Vorschriften nicht wirksam begegnet werden. Man kann nur hoffen, daß sie uns durch die Gestaltung des Wahlrechts und die Entwicklung der Parteien erspart bleiben.

11) Unter anderem Aspekt (unfähiges Parlament) behandelt S che u n er DOV 1957 S. 633 die Fachleute-Regierung. 
vollzieht. Das dürfte auch die Neigung erklären, die einmal gewählten Bundesräte wie Beamte immer wieder zu wählen, so lange sie nicht selbst auf das Amt verzichten. Weiter erklärt sich damit das Bestreben, im Rahmen der auf diese Weise freiwerdenden Sitze alle im Nationalrat vertretenen Parteien am Bundesrat $z u$ beteiligen, die dazu bereit sind, wobei allerdings Differenzen über das Ausmaß dieser $\mathrm{Be}-$ teiligung nicht ausbleiben ${ }^{112}$ ).

Andere Voraussetzungen und Gründe haben jenie Allparteienregierungen, die in Kriegs- oder Krisenzeiten gebildet werden, um unter Hintanstellung der Gegensätze alle Kräfte zur Uberwindung der Notzeit zusammenzufassen ${ }^{113}$ ).

Von einem anderen Ausgangspunkt her, nämlich von der Erkenntnis, daß die Gliedstaaten eines Bundesstaates doch im wesentlichen nur Verwaltungskörperschaften sind, hat sich der Gedanke der Allparteienregierung in diesen Gebilden vielfach durchgesetzt. In den Verfassungen der österreichischen Bundesländer ist die verhältnismäßige Beteiligung aller Parteien verfassungsrechtlich vorgesehen ${ }^{14}$ ); in der Schweiz beruht sie auf politischem Brauch, der allerdings zum Teil durch Verfassungsrichtlinien gesteuert ist $^{115}$ ); in Deutschland hingegen haben wir das Gebilde der Allparteienregierung in den Ländern nur vereinzelt ${ }^{116}$ ), wahrscheinlich wegen der Fehlkonstruktion unseres Bundesrates ${ }^{117}$ ). $\mathrm{Zu}$ den Grundsätzen

112) Uber die Allparteienregierung in der Schweizer Eidgenossenschaft: V u I p i u s, Allparteienregierung S. $44 \mathrm{ff}$.

113) Uber das engl. „National Government" s. Vulpius aaO. S. $83 \mathrm{ff}$. Uber die Bestrebungen zur Schaffung einer „permanent national coalition" in Schweden berichtet $\mathrm{R} u \mathrm{~s}$ to $\mathrm{w}$ aaO. (Anm. 1) S. $219 \mathrm{ff}$.

114) Uber die österr. Länderregierungen: Vulpius S. $60 \mathrm{ff}$.

115) Uber die Schweizer Kantone: Vulpiu s S. $31 \mathrm{ff}$.; vgl. auch die Entscheidung des Schweizer Bundesgerichts v. 26. 2. 1926 zu der Bestimmung der Luzerner Verfassung, daß vom Großen Rat bei der Bestellung der Magistrate „im allgemeinen auf Vertretung der Minderheit billige Rücksicht zu nehmen ist" aus Anlaß einer Richterwahl (Entsch. Bd. 52 I S. 14).

110) Berlin 1946-1953 (V u l p i u s S. 110 ff.); Württemberg-Baden 1946-1950 (V u 1 p i u s S. 124 ff.); Baden-Württemberg seit Oktober 1953.

117) Mit einer merkwürdigen Zähigkeit hat sich diese Struktur des föderalistischen Organs in der Bundesverfassung erhalten, obwohl der Bundesrat, den Bismarck, in unbewußter Genialität... unbekümmert um die Schablonen der Doktrin" geschaffen hatte, sinnvoll nur im Rahmen der eigentümlichen Bismarckschen Verfassung des monarchischen Bundesstaates war (darüber insbes. Erich $\mathrm{K}$ a u fmann, Bismarcks Erbe in der Reichsverfassung, 1917, S. 57 fi.; das Zitat auf S. 61). Nur seine Stellung als dem Reichstag koordiniertes Regierungskollegium des Reichs recht- 
des republikanischen, demokratischen und sozialen Rechtsstaates im Sinne des Grundgesetzes, an die Art. 28 Abs. 1 GG die verfassungsmäßige Ordnung in den Ländern bindet, gehört nicht die parlamentarische Regierung, so daß im Gegensatz zu Art. 17 WRV nicht von Bundes wegen vorgeschrieben ist, daß die Landesregierung des Vertrauens der Volksvertretung bedarf $\left.{ }^{118}\right)^{119}$ ).

fertigte seine Zusammensetzung aus Vertretern der Regierungen der Bundesstaaten. Die Konstruktion des Bundesrats zwingt den Bundeskanzler heute Einfluß $\mathrm{zu}$ nehmen auf die Regierungsbildung in den Ländern, (Baden-Württemberg, Bayern, Niedersachsen), wie umgekehrt die Opposition versucht, über die Landesregierungen im Bundesrat Einfluß auf die Bundespolitik zu gewinnen (Nordrhein-Westfalen). Auch $\mathrm{H}$ enn is, Opposition (Anm. 1) S. 215 spricht darum von der "unglücklichen grundgesetzlichen Konstruktion des Bundesrates". DaB die Landtagswahlen unter den Parolen der Bundespolitik ablaufen, dürfte mit darauf zurückzuführen sein. Von den Ländern als eigenständigen Gebilden her gesehen erscheint mir dieser Zustand nicht begrüßenswert. Man kann die Dinge natürlich auch so sehen wie $S \mathrm{ch}$ e u $\mathrm{n}$ e $\mathrm{r}$, der eine wichtige Funktion der parl. Länderregierungen - und wohl auch ihrer Mitwirkung im Bundesrat - darin sieht, daß dadurch der Opposition Möglichkeiten zur Teilnahme am Staatsleben eröffnet werden (DOV 1957 S. 636). Gl u m. (Anm. 1) S. 337 hat den Vorschlag gemacht, den Bundesrat als Legalitätsreserve bei der Regierungsbildung und beim Gesetzgebungsnotstand zu nutzen; Ehmke ZfPol. NF 1 (1954) S. 347 meint, man sollte eine Anderung des Grundgesetzes in dieser Richtung ernsthaft erwägen. Das setzt allerdings nicht notwendig die jetzige Struktur des Bundesrats voraus. Die Stellung des Bundesrats in dem Beziehungssystem Parlament und Regierung konnte in diesem Referat nicht behandelt werden. Wenn der BR auch an der Gesetzgebung teilnimmt, so ist er jedenfalls kein Parlament; andererseits ist er auch nicht ein Regierungskollegium des Bundes, als das Erich Ka u fmann zutreffend aaO. sein Urbild beschreibt.

118) E s c h e n b u r g, Südweststaat (Anm. 64) S. $61 \mathrm{ff}$. plädiert auf der Landesebene für Beseitigung der parlamentarischen Regierung; ebenso $\mathrm{H}$ en $\mathrm{n}$ is aaO. S. 217, der darauf hinweist, daB H u g o Preuss schon für die Länder der Weimarer Verfassung auf Zeit gewählte Regierungen nach Schweizer Vorbild vorgeschlagen habe, bei denen die Regierungsbildung - in der Regel unter Beteiligung aller Parteien - in erster Linie nach Amtsgesichtspunkten erfolgt.

119) Von den Blockregierungen der "Volksdemokratien“ (dazu Vulpius S. 141 ff., Han S Peters, Art. Blockregierung im Staatslexikon der Görresgesellschaft, 6. Aufl., Band 2, 1958; S t e i n i g e r, Das Blocksystem, Berlin 1949) ist hier nicht zu handeln, da es nur einen Mehrparteienstaat vortäuscht, wo es sich in Wahrheit um einen Einparteistaat handelt (so mit Recht L e ibholz, 38. DJT, S. C 17). H a n S Peters, Neuere Entwicklungen des Parlamentarismus, 1950, S. 80, dürfte das sowjetzonale Blocksystem und die westeuropäische Große Koalition bzw. Allparteienregierung nicht genügend auseinanderhalten, wenn er das Blocksystem „zu den ernsthaft zu diskutierenden Mitteln zur Überwindung der 
4. Nach dem Hinweis auf die Minderheitsregierung, die "Geschäftsregierung" und die Allparteienregierung wenden wir uns dem Normalfall der Mehrheitsregierung zu.

Wo sich das Zweiparteiensystem durchgesetzt hat oder in einem Mehrparteiensystem ein e Partei die absolute Mehrheit errungen hat, ist die Regierungsbildung insofern einfach, als der Führer der siegreichen Partei durch das Plebiszit der Wähler zum Chef einer stabilen Regierung designiert ist, die höchstens durch Zerfall der Mehrheitspartei selbst gefährdet werden könnte.

Aber auch dann noch kann die Regierungsbildung Schwierigkeiten machen, da die eine Mehrheitspartei regelmäßig viele Richtungen umfassen wird und der Parteiführer alle wesentlichen Strömungen berücksichtigen muß, um seiner Gefolgschaft sicher $\mathrm{zu}$ sein $^{120}$ ). Eine große Mehrheitspartei stellt gewissermaßen eine Koalition in sich dar.

Das spezifische Verhältnis der Regierung zur Mehrheitspartei im Unterhaus und damit zum Parlament selbst, wie es sich in England herausgebildet hat, dürfte allerdings auf andere Länder unübertragbar sein $\left.^{121}\right)$. In England ist die absolut führende Stellung der Regierung eindeutig. Der Premierminister dirigiert als Parteiführer zugleich die Geschäfte des Parlaments. Bei uns in Deutschland bleibt das Spannungsverhältnis zwischen Parlament und Regierung erhalten, selbst wenn die Regierung durch eine Partei gebildet wird, die die absolute Mehrheit errungen hat. Dabei dürfte die Frontstellung des Parlaments zum konstitutionellen Monarchen und seiner vom Parlament unabhängigen Regierung (Bürokratie) nachwirken. Auch die die Regierung tragende Mehrheitspartei wacht eifersüchtig über die Erhaltung der parlamentarischen Privilegien und läßt insbesondere an der Autonomie des Parlaments, selbst über seine Geschäftsführung zu bestimmen, nicht rütteln. Dieses Spannungsverhältnis bleibt bestehen, obwohl die Partei als Bindeglied zwischen Parlament und Regierung existiert.

Mißstände des Parlamentarismus" zählt. Utber den Unterschied zwischen der Trabantenpartei in einer freiheitlichen Demokratie und den Blockparteien in den "Volksdemokratien“, sowie über die Rolle der Opposition in der freiheitlichen Demokratie treffend Groß DVBl. 1957 S. 852.

120) Nach Zeitungsmeldungen hat sich Bundeskanzler Adenauer über die Schwierigkeiten der Regierungsbildung nach den Wahlen vom 6. 9. 1957, bei denen der CDU/CSU die Mehrheit der Mandate zugefallen war, bitter beklagt.

121) Vgl. darüber Morris on und Jennings (Anm. 1). 
5. Wo ein Mehrparteiensystem besteht und nicht eine Partei die absolute Mehrheit errungen hat, ergibt sich der Zwang zur Koalitionsbildung ${ }^{122}$ ). Sie wird schwieriger oder leichter sein, je nachdem wie weit einzelne Parteien in ihren Grundauffassungen harmonieren oder bereit sind, sich im Wege des Kompromisses auf eine gemeinsame Linie zu vereinigen, die unter Umständen auch durch die Abwehr eines gemeinsamen Gegners diktiert sein kann. Dabei mögen bestimmte Bereiche ausgespart werden; eine Koalition schließt aber aus, daß die beteiligten Parteien in wesentlichen politischen Fragen eine entgegengesetzte Politik, etwa in ihren Initiativentwürfen, verfolgen. Einer Hegemonialpartei kommt zwar bei der Regierungsbildung als Kristallisationspunkt große Bedeutung zu; es gibt aber kein demokratisches "Recht" der größten Partei, an der Regierungsbildung beteiligt $z u$ werden ${ }^{123}$ ).

Je nachdem, ob die parlamentarischen Gruppen Fraktionen festgefügter bürokratisch organisierter Parteien sind (Deutschland), oder sich nur loser um einzelne Persönlichkeiten scharen (Frankreich), wird die Regierungsbildung ein anderes Gesicht annehmen. Um sich den Unterschied klar zu machen, braucht man nur an die in ihrer Bedeutung von unserem Standpunkt aus vielfach überschätzten französischen Regierungskrisen zu denken und beachten, da $B$ immer derselbe Kreis von Ministrablen in verschiedenen Kombinationen erscheint, während bei uns der Regierungswechsel in der Regel eine Totalerneuerung bedeutet.

Als Konsequenz für das Verhältnis des Parlaments zur Regierung ergibt sich daraus, da $B$ angesichts der schwachen Koalitionsbildung im französischen Regierungssystem das Parlament absolut dominiert. Das französische Regierungssystem wird als "Gouvernement de l'Assemblée "124) bezeichnet, und für die französische Regierung mag die sonst meist zu

122) Uber „Bildung und Formen der Koalitionsregierung“ D olf St er n berger ZfPol. NF I, 1954, S. $47 \mathrm{ff}$. = Lebende Verfassung S. $101 \mathrm{ff}$.

123) Diesen Anspruch erhob die CDU in Baden-Württemberg, als sie bei der Regierungsbildung im April 1952 übergangen wurde (nach L e i b h o l z, Strukturwandel, S. 37, Anm. 29, hat damals die CDU-Führung die Bundesregierung gebeten, „demokratische $\mathrm{Zu}-$ stände im Südweststaat wieder herzustellen"), die CSU in Bayern bei der Regierungsbildung im Dezember 1954. In beiden Fällen kam es übrigens noch während der Wahlperiode zu einer Umbildung der Regierung (Baden-Württemberg Oktober 1953 nach der BT-Wahl; Bayern Oktober 1957 nach der BT-Wahl). In NordrheinWestfalen wurde die CDU als stärkste Partei im Februar 1956 ausgebootet. In Niedersachsen wurde 1955 die SPD in die Opposition versetzt, Ende 1957 aber in die Regierung aufgenommen.

124) Vgl. Ve d e l (Anm. 1) S. 583 ff. 
Unrecht gebrauchte Formel von der parlamentarischen Regierung als dem bloßen Vollzugsausschuß des Parlaments zutreffen ${ }^{125}$ ).

Dieses französische System, charakterisiert insbesondere auch durch die grundsätzliche Ablehnung des Referendums und die immer noch starke Scheu vor der Auflösung ${ }^{120}$ ), dürfte durch die Vorstellung bestimmt sein, daß das Volk die Ausübung der Staatsgewalt global an das Parlament übertragen hat und nur in den Intervallen der regulären Wahlen zu Wort kommen soll. Die Macht der Tradition hat in Frankreich die Abhängigkeit der Regierung vom Parlament auch unter der neuen Verfassung in einem Maße bestehen lassen, das von den Vätern der Verfassung nicht beabsichtigt war. Die Instabilität der französischen Regierungen ${ }^{127}$ ) mag auch psychologische Gründe ${ }^{128}$ ) haben, wie etwa ein französischer Beobachter gelegentlich als den Grund dafür die „absence de toute majorité dans l'esprit public français" bezeichnet hat ${ }^{129}$ ).

Trotz Mehrparteiensystem können sich starke Koalitionsregierungen bilden. Es kommt auf die besondere Parteistruktur und die jeweilige Konstellation an. Solche Regierungen stehen dann dem Parlament wesentlich stärker gegenüber als in Frankreich. Für die Bundesrepublik Deutschland jedenfalls trifft die Charakterisierung der parlamentarischen Regierung als eines Vollzugsausschusses des Parlamentes nicht $z u$, selbst wenn sie als eine Koalitionsregierung gebildet worden ist.

6. Wieder eine andere Nuance im Verhältnis des Parlaments zur Regierung finden wir da, wo die Wähler ihre Stimmen annähernd gleichmäßig auf zwei große Parteien verteilen und dritte Parteien nicht zu einer solchen Macht angewachsen sind, daB sie eine schiedsrichterliche Rolle spielen könnten, und wo dann diese beiden großen Parteien das Votum der Wähler dahin auslegen, daß diesen die gemeinsame Regierungsund Verwaltungsführung durch beide Parteien wichtiger erscheint als die Ausübung der traditionellen Oppositionsfunk-

125) v. d. Heydte, Parlamentarismus in Frankreich und Deutschland, Festschrift Nawiasky, 1956, S. 323; W e r n e r L u d wi g, Regierung und Parlament im Frankreich der IV. Republik, Würzburg 1956; dazu R o m a n S ch n u r, DVBl. 1957 S. 219; Literaturbericht von $R$ u dolf v. A I bertini, Probleme der Vierten Republik, NeuePolLit. 1957 S. 295.

126) V e d e $1 \mathrm{~S}$. $471 \mathrm{ff}$.

127) S c h n u r (Anm. 125) spricht von der „unstabilen Stabilität der Verfassungswirklichkeit Frankreichs".

128) Vgl. H e r b e r t L ü thy, Frankreichs Uhren gehen anders, Zürich-Stuttgart-Wien 1954.

129) Gog u l, zitiert bei v. A 1 bertin i (Anm. 125) S. 249.) 
tion. Ich meine das österreichische Beispiel der Koalition c̉er Österreichischen Volkspartei und der Sozialistischen Partei Osterreichs, die nun schon zum dritten Mal die politische Szene ('sterreichs beherrscht ${ }^{130}$ ). Erstaunlicherweise hat diese gemeinsame Regierungsführung, die auf einem Abkommen beruht, in dem diese in vielen Punkten so gegensätzlichen Parteien die Regierungs- und Verwaltungsmacht quotenmäßig aufteilen, den scharfen Wettbewerb der Parteien bei den Wahlen nicht beeinträchtigt und auch ein nicht geringes $\mathrm{MaB}$ gegenseitiger Kritik schon während der Wahlperiode bestehen gelassen. Für unseren Zusammenhang interessant ist, da $B$ der Koalitionspakt das Initiativrecht der Abgeordneten beschränkt, und daß ein Koalitionsausschuß die reibungslose Zusammenarbeit innerhalb der Regierung und innerhalb des Parlaments sichern soll. In diesem System ist jede Partei gleichzeitig Regierungs- und Oppositionspartei; jede Partei übt Opposition für den Bereich, in dem die andere regiert.

Dieses wohl ursprünglich aus der besonderen Lage des besetzten Nachkriegs-Osterreichs entstandene politische System dürfte nicht so auf besondere Landeseigentümlichkeiten zugeschnitten sein, wie das englische, das schweizerische oder das amerikanische Regierungssystem. Vielleicht ist es die Antwort auf die Gleichgewichtslage zwischen rechts und links, die sich in so vielen Staaten ausgependelt hat, und stellt es den Versuch dar, die Politik des Kompromisses, die in der heutigen gesellschaftlichen Situation allein noch den sozialen Frieden in der staatlichen Gemeinschaft erhalten kann, in der Regierungsbildung zu institutionalisieren ${ }^{131}$ ).

7. Bei parlamentarischer Regierungsweise ist die vom Parlament gewählte oder durch positives Vertrauensvotum investierte Regierung in der Regel auch in ihrem Bestande vom Willen des Parlaments abhängig's2). Die ohne aktive Teilnahme des Parlaments eingesetzte Regierung muß es sein, damit man überhaupt von parlamentarischer Regierung sprechen kann $^{138}$ ).

In der Schweizer Eidgenossenschaft wird der Bundesrat von den beiden Häusern des Parlaments auf die Dauer der Legislaturperiode des Nationalrates von vier Jahren bestellt, und er kann während dieser Zeit nicht abberufen werden. Hat die

130) Darüber eingehend Otto $\mathrm{Kirchheimer} \mathrm{ArchRSozPh.}$ XLIII (1957) S. 67 ff.; dort ist auch S. 69 Anm. 15 der Koalitionspakt vom Juni 1956 abgedruckt.

131) Vgl. die Bestrebungen in der Bundesrepublik zur Bildung "großer Koalitionen".

132) Typ des Grundgesetzes oder Frankreichs.

133) Typ der Weimarer Verfassung. 
absolute Unabhängigkeit der amerikanischen Regierung vom Kongre $\beta$ ihre Ursache in der eigenständigen plebiszitären Macht des Präsidenten, so dürfte die relative Unabhängigkeit des Schweizer Bundesrates von den Räten ${ }^{134}$ ) darauf beruhen, daß Regierung und Parlament gleichermaßen von dem im Referendum jederzeit gegenwärtigen Volk abhängig sind. Die Eigenart der Schweiz als Referendumsdemokratie dürfte auch andere Eigentümlichkeiten ihres Regierungssystems erklären ${ }^{135}$ ).

Mit dem Schweizer Beispiel wird vielfach die Regelung der Bayerischen Verfassung verglichen. M. E. zu Unrecht. Zwar bestimmt Art. 44, daß der Ministerpräsident auf die Dauer von vier Jahren gewählt wird. Wenn aber Abs. 3 Satz 2 hinzufügt, daß er zurücktreten $\mathrm{muB}$, wenn die politischen Verhältnisse ein vertrauensvolles Zusammenarbeiten zwischen ihm und dem Landtag unmöglich machen, so ist ihm damit eine verfassungsrechtliche Pflicht ${ }^{186}$ ) zum Rücktritt auferlegt, wenn die Vertrauensgrundlage geschwunden ist. Diese neue politische Situation kann aber nur der Landtag selbst in irgendeiner Form feststellen, die notwendigerweise einem Mißtrauensvotum gleichkommt. Für unmöglich halte ich es, daß der Verfassungsgerichtshof von sich aus diesen Wegfall der Vertrauensgrundlage feststellt, wie es im Kommentar von Nawiasky-Leusser vorgeschlagen wird ${ }^{137}$ ).

8. Man kann darüber streiten, ob und inwieweit es sinnvoll ist, das parlamentarische System in verfassungsrechtliche

134) Dazu auch Lö wen s te in, Arch OffR 75, $164 \mathrm{ff}$.

135) Vgl. oben bei Anm. 112.

136) So auch Nawiasky-Leusser, Die Verfassung des Freistaats Bayern, $S$. 121. Ha ns $P$ et ers dürfte das übersehen haben, wenn er diese Regelung (Neuere Entwicklungen des Parlamentarismus S. 77) "kaum noch als Parlamentarismus" ansprechen will. Im Grunde ist es genau so viel und so wenig Parlamentarismus wie das von Peters aaO. begrüßte „konstruktive Mißtrauensvotum" des Grundgesetzes.

137) aaO.: „Für den praktisch kaum denkbaren Fall, daß der Regierungschef seine Verpflichtung zum Rücktritt nicht erkennen oder ihr nicht entsprechen sollte, könnte er im Wege einer Verfassungsstreitigkeit nach Art. 64 oder auf Grund der Ministeranklage nach Art. 59, 61 durch den Verfassungsgerichtshof gezwungen werden." Das würde aber voraussetzen, daß der VerfGH aus einem unzweideutigen Verhalten des Landtags erkennen kann, daß das vertrauensvolle Zusammenarbeiten zwischen dem MPr. und dem LT unmöglich geworden ist. Nur ein klarer Beschluß des LT könnte diese Frage justiziabel machen. Dann aber handelt es sich in Bayern genau so viel und so wenig um eine Regierung auf Zeit wie in den Fällen des sog. konstruktiven Mißtrauensvotums. Auch das Mißtrauensvotum, das nicht in die Form der Neuwahl gekleidet ist, hat in der Regel nicht die automatische Amtsenthebung zur Folge, sondern begründet nur die Pflicht zum Rücktritt. 
Normen einzufangen ${ }^{138}$ ), oder ob es nicht besser ist, da $B$ es sich im Verfassungsbrauch entwickelt und den jeweils gegebenen Umständen anpaßt. Die Stabilität von parlamentarischen Regierungen hängt jedenfalls mehr von der Stabilität der politischen Parteien als von der verfassungsrechtlichen Konstruktion des Vertrauensmechanismus ab. Insbesondere verdanken wir die Stabilität der Regierungen in der Bundesrepublik der derzeitigen Struktur unseres Parteiensystems und nicht dem sogenanten konstruktiven Mißtrauensvotum des Grundgesetzes ${ }^{139}$ ). Regierungskrisen werden durch Zerfall der Mehrheitspartei oder durch Koalitionskrisen ${ }^{140}$ ) ausgelöst. Würde die Parteientwicklung den Weg der Weimarer Republik gehen, - was aber wohl wegen des Art. 21 Abs. 2 GG kaum möglich sein wird, - so würde auch das konstruktive Mißtrauensvotum die Verfassungskrise nicht verhüten.

Die Geltendmachung der parlamentarischen Verantwortung durch Abberufung der Regierung141) kann technisch verschieden gestaltet werden. In der herkömmlichen Form hat das aus der Initiative des Parlaments geborene Mißtrauensvotum oder die Ablehnung der von der Regierung gestellten Vertrauensfrage nur die negative Folge des Rücktritts der Regierung. Dabei können unterschiedliche Mehrheiten vorgesehen und besondere Verfahrensvorschriften, etwa Fristen

138) Dagegen Mirkine-Guetzévitch, L'échec du parlementarisme "rationalisé", in Le Régime Parlementaire, 1954 (Anm. 1) und in dem Essai synthétique in T. 1 seiner Sammlung „Les Constitutions Européennes, S. $29 \mathrm{ff}$. Er sieht das Wesen des "parlementarisme rationalisé", in dem Versuch, durch ausgeklügelte Verfassungsbestimmungen die Instabilität der Regierung zu bekämpfen.

159) Nach S c h e u n e r DOV 1957, 634, jedenfalls eine noch offene Frage.

140) Bayern September 1947 und Oktober 1957; Niedersachsen August 1950 und Oktober 1957; Nordrhein-Westfalen Februar 1956; Rheinland-Pfalz Oktober 1949; Schleswig-Holstein Juni 1952.

141) Gegen das Mißtrauensvotum überhaupt und für politische Unabsetzbarkeit der Regierung: Adolf Arndt in seinen interessanten Aufsatz "Grundfragen des Verfassungsrechts im Spiegel des französischen Entwurfs", SJZ 1946 S. 81 ff. Zentral der Satz, „daß die funktionsgerechte Kontrolle der Regierung nicht durch das juristische Instrument des Vertrauens- oder Mißtrauensvotums, sondern durch die metajuristische, nämlich rein politische Bindung der Regierungsmitglieder an ihre Parteien erfolgt.“ „Die Begrenzung der Regierung, ihre Kontrolle, erfolgt politisch durch die Parteibindung, rechtlich durch die Justiz, sowie dadurch, daß sie für Gesetze und Budget auf das Parlament angewiesen ist." Durch eine parlamentarisch abhängige Regierung werde dem Parlament „eine strukturwidrige thbermacht zugebilligt", die die Diktaturgefahr „bedrohlich erhöht, weil auch ein Parlament zum Diktator auszuarten in der Lage ist" 
zwischen Antragstellung und Abstimmung, eingebaut sein. $\mathrm{Ob}$ auch die Ablehnung eines von der Regierung für wichtig erklärten Gesetzes schlechthin oder nur bei ausdrücklicher Stellung der Vertrauensfrage zum Rücktritt zwingt, hängt von dem parlamentarischen Brauch in den verschiedenen Staaten $a b^{142}$ ).

Regelmäßig ist jedes Mitglied der Regierung dem Mißtrauensvotum ausgesetz ${ }^{143}$ ). Das Grundgesetz hat aber die Konzentration der Regierung auf den Bundeskanzler so weit getrieben, da $B$ sich das Mißtrauen nur gegen ihn und damit gegen die ganze Regierung wenden $\mathrm{kann}^{144}$ ). Trotzdem sind auch die Bundesminister dem Bundestag verantwortlich ${ }^{145}$ ). Die außer dem eigentlichen Mißtrauensvotum möglichen Un-

142) Ausdrücklich verneint in Art. 94 Abs. 4 der italienischen Verfassung. Uber die französische Praxis, in der die Entscheidung über eine Gesetzesvorlage mehr zu einer Entscheidung über die Existenz der vorlegenden Regierung als über das Gesetz selbst wird: v. d. H e y d t e aaO. unter Hinweis auf B l a m on t (Anm. 1).

143) In den deutschen Ländern noch: Berlin Art. 42, Bremen Art. 110, Hamburg Art. 35, Rheinland-Pfalz Art. 59, Saarland Art. 90, Baden-Württemberg in der Anm. 108 erwähnten, abgewandelten Form. Mißtrauensvoten hat es gegeben in Berlin (28. 10. 1954), Hamburg (23. 7. 1948) und Rheinland-Pfalz (9. 4. 1948).

144) Art. 67 GG; ebenso mit Bezug auf die Ministerpräsidenten die Landesverfassungen von Baden-Württemberg Art. 54, Hessen Art 114, Niedersachsen Art. 23, Nordrhein-Westfalen Art. 61, Schleswig-Holstein Art. 30. Das Mißtrauen wurde ausgesprochen der Regierung Arnold in Nordrhein-Westfalen am 20. 2. 1956 (echtes konstruktives Mißtrauensvotum), dem Senat Brauer in Hamburg am 2. 12. 1953, der Regierung Diekmann in Schleswig-Holstein am 5. September 1950 (beides keine echten Fälle, da nach Neuwahl, vgl. Anm. 90).

145) Ebenso: v. Wi $\mathbf{k}$, die Verantwortung der Bundesminister DOV 1956 S. 113 ; v. B r ünneck DOV 1951 S. 258; U l e JZ 1957 S. 426; a. M.: v. M a n g o ld t, Kommentar Art. 65 Anm. 4 S. 350; M e d e r im Bonner Kommentar Anm. II zu Art. 65; B lü c her (Anm. 1) S. 3; Eschenburg DOV 1953 S. 199; Scheuner DOV 1957 S. 634. Würden die Bundesminister nicht dem Bundestag verantwortlich sein, so wären sie zu bloßen Staatssekretären degradiert. Das dürfte nicht dem Sinn der Verfassung entsprechen bei aller Hervorkehrung des Kanzlerprinzips. Die Minister sollten sich darum auch selbst vor dem Parlament verteidigen, wenn sie wegen dienstlicher Handlungen oder außerdienstlicher Äußerungen im Parlament angegriffen werden. tbrigens zählt § 88 Abs. 2 Nr. 4 StGB "die parlamentarische Verantwortlichkeit der Regi e -

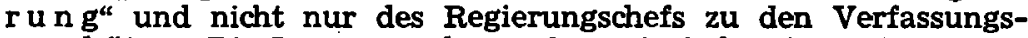
grundsätzen. Die Leugnung der parlamentarischen Verantwortlichkeit der Bundesminister dürtte vielfach darauf beruhen, daß sie gleichgesetzt wird mit der Möglichkeit des Sturzes durch Mißtrauensvotum. Es gibt aber auch andere Möglichkeiten, die Verantwortung geltend $\mathrm{zu}$ machen. $\mathrm{M} \ddot{\mathrm{u}} \mathrm{nch}$ aaO. übersteigert das Kanzlerprinzip allerdings so weit, daß er selbst Anträge auf Streichung des Ministergehalts nicht zulassen will. 
zufriedenheitserklärungen (Mißbilligung, Tadel usw.) sind auch gegen Bundesminister möglich, so daß die Abstimmung nicht wegen verfassungsrechtlicher Unzulässigkeit verweigert werden kann ${ }^{146}$ ). $\mathrm{DaB}$ auch da, wo Minister gegen förmliche Mißtrauensvoten gesichert sind, politischer Druck des Parlaments zur Abberufung eines Ministers führen kann, hat das Beispiel des bayerischen Justizministers Müller gelegentlich der Auerbach-Affäre gezeigt ${ }^{147}$ ).

Der deutschen Staatsrechtslehre der Weimarer Republik hatte nun das Mißtrauensvotum besondere Schwierigkeiten bereitet, das von einer heterogenen Mehrheit beschlossen wurde, die selbst nicht zur Regierungsbildung in der Lage war. Schon damals war die These aufgestellt worden, daß ein solches Mißtrauensvotum die verfassungsrechtliche Folge des Rücktritts der Reichsregierung nicht haben könne, da ein Parlament eine Regierung nur stürzen könne, wenn es fähig sei, eine neue Regierung $z u$ bilden ${ }^{148}$ ). Konsequenterweise lassen heute einige deutsche Landesverfassungen die Wirksamkeit eines Mißtrauensvotums davon abhängen, ob es dem Parlament gelingt, binnen bestimmter Frist eine neue Regierung zu bilden, oder sie knüpfen an die Unfähigkeit zur Bildung einer neuen Regierung die Auflösung des Landtags ${ }^{148}$ ). Das Grundgesetz kleidet das Mißtrauensvotum gegen die amtierende Regierung unmittelbar in die Form der Bestellung einer neuen Regierung ${ }^{150}$ ). Dieses sogenannte konstruktive

146) a. M. M ü $\mathrm{nch}$, Die Bundesregierung $S .179 \mathrm{f}$; dort Hinweise auf das Material aus der parlamentarischen Praxis. Für Zulässigkeit die Glossen imArchOffR 75 (1949) S. 346 und 76 (1950) S. 338; v. W i ck DOV 1956, 113; M a u n z, Deutsches Staatsrecht, 6. Aufl., S. 291; H a n s S c h n e i d e r VDStRL $8 \mathrm{~S}$. $28 \mathrm{f}$. Im Bundestag sind verschiedentlich Mißbilligungsanträge und Anträge gestellt worden, den Bundeskanzler zu ersuchen, beim BPr. die Entlassung eines Bundesministers zu beantragen.

147) BayerLT vom 7. Mai, 8. Mai und 5. Juni 1952; in Württemberg-Baden hat die SPD im April 1947 den Rücktritt des Ministers Simpfendörfer erzwungen.

148) Car 1 S c h m itt, Verfassungslehre S. 345.

140) In Bremen (Art. 110) wird es erst durch Neuwahl wirksam. In Berlin (Art. 42) verliert es seine Wirksamkeit, wenn nicht binnen 21 Tagen die Neuwahl erfolgt. Anders die Regelung in Hessen (Art. 114), Rheinland-Pfalz (Art. 99) und Saarland (Art. 71 II), wo der Landtag aufgelöst ist oder aufgelöst werden muß (Saarland), wenn die Neuwahl nicht binnen 12 Tagen (Hessen), oder vier Wochen (Rheinland-Pfalz und Saarland) gelingt.

150) Art. 67 GG. Ebenso die Landesverfassungen von BadenWürttemberg (Art. 54), Hamburg (Art. 35), Niedersachsen (Art. 23), Nordrhein-Westfalen (Art. 61) und Schleswig-Holstein (Art. 30). In allen Fällen (auch bei den Gestaltungen gemäß Anm. 149) wird die absolute Mehrheit der gesetzlichen Mitgliederzahl gefordert. 
Mißtrauensvotum ${ }^{151}$ ) wird im allgemeinen als eine der bedeutungsvollsten Neuerungen des Grundgesetzes gefeiert ${ }^{152}$ ). Mir scheint diese Regelung zu stark retrospektiv zu sein und nicht die politische Bedeutung $z u$ haben, die ihr vielfach beigemessen wird ${ }^{153}$ ).

Eine absolute Mehrheit, die grundsätzlich auch für die Regierungsbildung gefordert wird, kann jederzeit die Regierung stürzen. $\mathrm{DaB}$ auch heute noch Koalitionszerfall und Neubildung einer Koalition während der Wahlperiode möglich sind, hat uns das nordrhein-westfälische Beispiel ${ }^{154}$ ) gelehrt.

Gesichert ist die nur mit relativer Mehrheit gewählte und die ursprünglich auf eine absolute Mehrheit gestützte Regierung, die diese Mehrheit verloren hat, solange als sich nicht eine neue Koalition bildet, die über eine abs olu te Mehrheit verfügt.

Es ist also falsch, wenn behauptet wird, daß das konstruktive Mißtrauensvotum nur Schutz gegen „unechte parlamentarische Mehrheiten" gewähre, und daß es die Gewähr

Namentliche Abstimmung schreiben Berlin (Art. 42) und Hessen (Art. 114 Abs. 3) vor. Die Fristen zwischen Antragstellung und Abstimmung schwanken zwischen 48 Stunden (GG Art. 67 Abs. 2, Berlin Art. 42 Abs. 2 und Nordrhein-Westfalen Art. 61 Abs. 2), 2 Tagen (Hessen Art. 114 Abs. 2, Rheinland-Pfalz Art. 99 Abs. 3, Saarland Art. 90 Abs. 2), 3 Tagen (Baden-Württemberg Art. 54 Abs. 2), 1 Woche (Bremen Art. 110 Abs. 2 und Hamburg Art. 35 Abs. 2) und 21 Tagen (Niedersachsen Art. 23 Abs. 2).

151) Nach Eschen burg DOV 1954, 198 erstmals von A. R ü s tow in einem Vortrag vor der Hochschule für Politik in Berlin 1929 für die Weimarer Reichsverfassung vorgeschlagen.

152) Das Für und Wider wägt $H$ an $S \mathrm{Shneider}$ in seinem Bericht für die Heidelberger Staatsrechtslehrertagung 1949 ab (VDStRL Heft 8); vgl. ferner G 1 u m (Anm. 1) S. $298 \mathrm{ff}$. Sicherlich bedeutet das konstruktive Mißtrauensvotum eine Schwächung des herkömmlichen parlamentarischen Regierungssystems (so Leitsatz 1 von $\mathrm{H}$ ans S c h n eider aaO. S. 53; Hans Peters, Festschrift Giacometti, 1953, S. 241 hält es für die äußerste Grenze dessen, was noch mit dem Wesen der parlamentarischen Regierungsform vereinbar ist), aber man wird unmöglich mit U. M., ArchOffR 75 (1949) S. 370 f., von einem ,nicht-parlamentarischen System, wie das Bonner Grundgesetz es geschaffen hat, “ und nur von „gewissen parlamentarischen Einsprengungen" in das Bonner Regierungssystem sprechen können (U. M. folgert aus seiner These die Inkompatibilität von Ministeramt und Abgeordnetenmandat!).

153) Garantie des stetigen Vorhandenseins einer herrschaftsfähigen Regierung; Konstanz der Regierungspolitik; Unabhängigkeit der Regierung von parlamentarischen Krisen. Nach v. d. Heydte, Festschrift Nawiasky S. 331 f., fördert es eine Regierung der Mitte.

154) Mißtrauensvotum vom 20. 2. 1956. Vgl. auch die Neuwahl des MPr. in Bayern am 16. 10. 1957 nach Rücktritt des bisherigen MPr. wegen Zerfalls der Koalition. 
dafür biete, daß jederzeit eine von der Autorität des Bundestages getragene und nicht nur geschäftsführende Regierung vorhanden sei.

In dem ersten Punkt schießt es über das Ziel hinaus, da es auch eine Regierung, die sich nur auf eine relative Mehrheit stützen kann, dagegen sichert, daß eine andere Regierung mit relativer Mehrheit ans Ruder kommt. Hat sich eine andere relative, regierungsbereite Mehrheit gebildet, so ist sie genau so regierungsfähig wie die amtierende Regierung nach Verlust ihrer absoluten Mehrheit. Art. 67 gewährt nicht nur Schutz gegen die negative destruktive Mehrheit, sondern läßt eine Neuorientierung der Regierungspolitik erst $\mathrm{zu}_{0}$ wenn die Opposition die a b s olu te Mehrheit erlangt hat, selbst wenn die Regierung nicht mehr die absolute Mehrheit hat oder sie nie gehabt hat. Es ist natürlich vollkommen richtig, daß nur im Vertrauen einer a b s o l u t e n Mehrheit die sichere Grundlage für eine starke und kontinuierliche Regierungsführung liegt. Aber warum soll eine Regierung, die diese Vertrauensgrundlage nicht besitzt, unter allen Umständen im Amt bleiben, wenn eine andere gleich schwache oder gleich starke Regierung parlamentarisch gebildet werden kann? Die einzige Rechtfertigung für diese Regelung könnte vielleicht darin gefunden werden, daß das Erfordernis absoluter Mehrheit für Regierungssturz durch Regierungsneubildung schwankende Flügel der Regierungskoalition beieinander hält und so einen mittelbaren Druck auf Erhaltung der absoluten Mehrheit ausübt ${ }^{155}$ ).

Die mit absoluter Mehrheit gewählte Regierung, die diese Mehrheit verloren hat, wind ebensowenig wie die mit relativer Mehrheit gewählte Regierung von der Autorität des Bundestages getragen Die künstliche Behinderung des Regierungssturzes verschafft keine Autorität. Dadurch, daß sie nicht gestürzt werden kann, erlangt eine solche Regierung keine größere Stärke oder Autorität als die Regierung, die durch ein destruktives Mißtrauensvotum gestürzt worden ist, aber als geschäftsführende Regierung im Amt bleibt, bis eine neue Regierung geblidet wird. Besteht keine andere, an sich zur Regierungsbildung bereite relative Mehrheit, so ist der Unterschied zur Weimarer geschäftsführenden Regierung nur ein rein formaler. Die Regierung bleibt ja geschäftsführend auch da im Amt, wo die Verfassung nicht die Wirksamkeit des Mißtrauensvotums an die Neubildung der Regierung knüpft, sondern wo die Neubildung der Regierung faktisch nicht gelingt.

155) vgl. auch Glum, Festschrift E. Kaufmann S. 60 zur Vertrauensfrage der Art. 68. 
Man spricht dann zwar von einer nur geschäftsführenden Regierung, aber wie bereits der Staatsgerichtshof für das Deutsche Reich in mehreren Entscheidungen mit Recht ausgesprochen hat, hat die geschäftsführende Regierung grundsätzlich die gleichen Kompetenzen wie die Vollregierung $\left.{ }^{156}\right)$.

Was verbessert also die Stellung der Regierung, die sich nicht mehr auf das Vertrauen der Mehrheit des Parlamentes stützen kann, aber kraft des konstruktiven Mißtrauensvotums nicht gestürzt werden kann, gegenübber der Regierung, die sich dem destruktiven Mißtrauensvotum einer heterogenen Mehrheit gegenübersieht, also geschäftsführend im Amte bleibt ${ }^{157}$ )? Meines Erachtens sind beide Regierungen verfassungsrechtlich gleich stark und politisch gleich schwach. Regierungen können ebendurch noch so a usgeklügelte Bestimmungennichtronparlamentarischen Krisenunabhängig gemacht werden ${ }^{158}$ ).

Bewußt ist der Regierung nicht ein Notverordnungsrecht gegeben für den Fall, daß das Parlament nicht mehr seine eigentliche Aufgabe der Gesetzgebung erfüllen kann oder die Mehrheit aus Opposition die Vorschläge der Regierung ablehnt. Der Ausweg des Art. 81 GG, der die Regierung zudem an die Mitwirkung des Bundespräsidenten und des Bundesrates bindet, ist nur auf Zeit gegeben ${ }^{150}$ ).

Haben sich Regierung und Parlament soweit auseinandergelebt, da $B$ die Regierung keine zuverlässige Mehrheit mehr hat, daß aber auch eine andere Mehrheit zur Regierungsbildung sich nicht herausgebildet hat, dann muß das Volk durch Neuwahl den Konflikt entscheiden. Insofern ist die Möglichkeit der Auflösung des Parlamentes durch Initiative der

186) L a m mers - S i m o n s Bd. I S. 267; Bd. IV S. 372; Bd. VI S. 144; BayerVerfGH aaO. Bd. IV S. 372. Zur Unzulässigkeit des Mißtrauensvotums gegen eine gf. Regierung: RStGH aaO. Bd. V S. 186.

157) Zweifelnd auch D r e h er, NJW 1950 S. 132.

15e) a. M. v. M a ngoldt, Deutsche Landesreferate (Anm. 1) S. 820: „Man versucht, die Regierungen von parlamentarischen Krisen möglichst unabhängig zu machen und dadurch eine konstante Regierungspolitik zu gewährleisten.“ Eine „konstante Regierungspolitik" kann aber von einer Regierung, die die Mehrheit des Parlaments gegen sich hat, niemals geführt werden. Es kam mir nur darauf an, die politische Bedeutungslosigkeit für den extremen Fall der heterogenen Mehrheit, an dem sich das Problem entzündet hat, herauszustellen. Im übrigen mag das konstruktive Mißtrauensvotum heilsam und erzieherisch $\mathrm{zu}$ wirken vermögen.

150) Mit Recht von S c h e u n e r DOV $1957 \mathrm{~S}$. 634 als unrealistisch und den legistischen Stillstand nach 6 Monaten um so sicherer herbeiführend bezeichnet. 
Regierung nach Ablehnung eines Vertrauensvotums eine für das Funktionieren des parlamentarischen Regierungssystems überaus wichtige Einrichtung. Auch in diesem Punkt bin ich der Meinung, daß nach der vom Grundgesetz intendierten Ordnung des Verhältnisses von Parlament und Regierung der Bundespräsident dem Verlangen des Bundeskanzlers auf Auflösung des Bundestages entsprechen muß $\left.{ }^{180}\right)$. Der Bundeskanzler, der glaubt, mit dem Weg des Art. 81 GG nicht fertig werden zu können, kann vom Bundespräsidenten nicht genötigt werden, mit einem Bundestag weiter zu regieren, der ihm die Gefolgschaft versagt. Zwar könnte der Bundeskanzler seine Entlassung fordern, wenn der Bundespräsident seinem Wunsche nicht nachkommt, und dann würde nach Art. 63

160) Gegen diese Auffassung spricht freilich, daß ihr (im Gegensatz zu der in Anm. $107 \mathrm{zu}$ der Streitfrage um Art. 64 Abs. 1 vertretenen Auffassung) der Wortlaut des Art. 68 Abs. 1 Satz 1 entgegensteht. Sie wird auch, soweit ich sehe, nur von $L$ udwig Bergsträsser, Die Entwicklung des Parlamentarismus in Deutschland, 1954, S. 25, geteilt. Aber die allgemeine Meinung, daß es gerade in dieser Krisensituation dem BPr. zukomme, „die Weichen zu stellen", gibt ihm einen so entscheidenden politischen Einfluß, daß es kaum mit dem Amt vereinbar erscheint, das nach S ch euner (DOV 1957 S. 633) „ins Repräsentative allein orientiert" ist. Warum soll der BPr., dem alle anderen Einflußrechte genommen sind (Auflösung, Notstand, Oberbefehl, Ernennung und Entlassung des BK) gerade in der parlamentarischen Krisensituation dem BK das Heft aus der Hand nehmen können? Welche Weiche kann der BPr. überhaupt stellen? Das ganze Verfahren kann nur auf Initiative des BK in Gang kommen. Dieser wird das positive Vertrauensvotum nur fordern, wenn er glaubt, auf diese Weise die Parlamentsmehrheit, deren er zur Durchführung seines Gesetzgebungsprogramms bedarf, sammeln und binden zu können. Gelingt ihm das nicht, so kann wiederum nur er die Auflösung anregen. Er wird das nur tun, wenn er glaubt, mit seinem Programm die Wahlen gewinnen zu können, oder wenn er die Situation für so verfahren hält, daß sie nur noch durch den Appell von den Gewählten an die Wähler geklärt werden kann. Soll nun der BPr. das Recht haben, durch Verweigerung des Auflösungsdekrets den BK zum Rücktritt zu zwingen? Der BT hat ja gerade bewiesen, daß sich keine absolute Mehrheit für irgendeinen BK bildet (den geringen Einfluß, den der BPr. bei der Neuwahl des BK durch sein Nominationsrecht ausüben kann, würde er sicher auch üben können, wenn der BK die Vertrauensfrage gestellt hat!). Erreicht nun bei der Neuwahl des BK der zurückgetretene Kanzler die relative Mehrheit nach Art. 63 Abs. 4, so bleibt dem BPr. nichts anderes übrig, als nunmehr nach Art. 63 IV 2 aufzulösen. Erreicht ein anderer die relative Mehrheit und wird er vom BPr. ernannt, so würde dem BPr. die politische Entscheidung zustehen, einer anderen Minderheitsregierung ins Amt $\mathrm{zu}$ verhelfen. Mir will aber scheinen, als ob damit dem BPr. ein Einflußrecht gegeben würde, das nicht in das vom GG geordnete Regierungssystem hineinpaßt. Mir will auch nicht einleuchten, daß der BPr. durch Nichteingreifen nach abgelehntem Vertrauensvotum „die Partei der 
Abs. 4 die Wahl einer Regierung mit relativer Mehrheit möglich werden. Aber auch damit wäre die Krise ja nicht behoben, und es erscheint mir zweifelhaft, ob dem Bundespräsidenten ein so weitgehender Einfluß auf die Regierungsbildung eingeräumt sein soll.

Auf das Auflösungsrecht kann ich leider nicht weiter eingehen, so interessant insbesondere auch rechtsvergleichend seine Darstellung sein würde. Nur möchte ich aus der höchst komplizierten Regelung der französischen Verfassung die für die französische Auffassung vom Verhältnis des Parlaments zur Regierung so überaus charakteristische Bestimmung herausheben, da $B$ in dem Falle, in dem der Auflösung ein Mißtrauensvotum vorangegangen ist, der Staatspräsident den Präsidenten der Nationalversammlung zum Ministerpräsidenten und Innenminister ernennt ${ }^{161}$ ). Dort also erkennen wir das $\mathrm{Be}-$ streben, die amtierende Regierung aus dem Wahlkampf auszuschalten, während für unsere deutsche Auffassung gerade charakteristisch ist, daß wir in der Auflösung und in dem anschließenden Wahlkampf die Lösung des Konfliktes zwischen der Regierung und dem Parlament sehen, und da $B$ darum die auflösende Regierung weiterhin im Amt bleibt.

\section{SchluBbemerkung :}

An diesem Punkt muß ich mein Referat abbrechen, - ich habe Ihre Zeit schon über Gebühr in Anspruch genommen. Lassen Sie mich zum Schluß einen Gedanken aus der Einleitung wieder aufnehmen: es kommt a uf die Menschen an, nicht auf die Paragraphen!

Gerade die parlamentarische Demokratie kann nur gelingen, wenn diejenigen, die die Macht ausüben, von einer breiten

Volksvertretung ergreift" (so v. d. H e y d t e, Festschrift Nawiasky S. 328). Die relative Mehrheit, die dem BK, der die Vertrauensfrage gestellt hat, geblieben ist, ist doch genau so viel und so wenig die Volksvertretung wie eine andere relative Mehrheit, die einen neuen BK wählt. Die Frage wird durch das Fehlen eines Notverordnungsrechts und die eigenartig verklausulierte Regelung des zeitlich begrenzten und vom Zusammenwirken dreier Verfassungsorgane abhängigen Gesetzgebungsnotstandes noch komplizierter und kann hier nicht in ihrem ganzen Umfang aufgerollt werden. Es kam mir zunächst nur darauf an, auf die Ungereimtheiten hinzuweisen, die sich aus der $h$. L. ergeben.

161) Art. 52 in der Neufassung der Novelle vom 7. Dezember 1954. Bis dahin galt, daß der Staatspräsident in jedem Falle der Auflösung den Präsidenten der Nationalversammlung zum Ministerpräsidenten ernennen mußte, daß dieser im Einvernehmen mit dem Büro der Nationalversammlung den Innenminister bestimmen und außerdem Staatsminister aus den in der Regierung nicht vertretenen Parlamentsgruppen ernennen mußte. 
Schicht verantwortungsbewußter Bürger getragen werden, und wenn die Abgeordneten und Minister ihr Wirken ausschlieBlich am Gemeinwohl orientieren. Aber ich darf in diesem Kreise auch an die Verantwortung der deutschen Staatsrechtslehrer erinnern. Was aus der deutschen Demokratie wird, hängt a $\mathrm{u} \mathrm{ch}$ von dem ab, was von den deutschen Kathedern heruntertönt. Einseitige Hervorkehrung der unbezweifelbaren Mängel unserer Staatsform, ohne auch ihrer großen Chancen zu gedenken, könnte wieder einer verhängnisvollen Entwicklung den Weg bahnen helfen ${ }^{162}$ ).

Vielleicht wird auch der, der sich für die parlamentarische Demokratie nicht begeistern kann, sie nach den Erfahrungen, die wir gemacht haben, wenigstens als das kleinste Übel ansehen, im Sinne jener nüchternen Bemerkung, die ich von der Hand unseres kürzlich verstorbenen Seniors und Ehrenpräsidenten, meines verehrten Lehrers Richard Thoma unter dem bekannten Aufsatz von Erich Kaufmann über „Die Regierungsbildung in Preußen und im Reich"163) fand. Erich Kaufmann übte damals (1921) heftige Kritik an dem parlamentarischen Regierungsapparat, den er allenfalls als Notbehelf zur Rettung vor dem Abgrund des Bolschewismus gelten lassen wollte. Er meinte aber grundsätzlich, das deutsche Volk sei geistig zu reich und zu tief, um „in diesen vom angelsächsischen Geiste für seine Bedürfnisse geschaffenen Formen seine Mission erfüllen zu können“. Dazu vermerkte Richard Thoma: „Was soll es denn sonst machen? Minderheitsherrschaft an Stelle der Mehrheitsherrschaft setzen? Alle Verfassungen sind töricht. Das Problem ist: das $\mathrm{k} l \mathrm{l}$ in $\mathrm{ste}$ (tbel finden ${ }^{164}$ )."

102) Die gleiche Sorge bewegte den verstorbenen Bundestagspräsidenten Hermann Ehlers in seinem Vortrag "Führer und Funktionär in der deutschen Politik “ S. 15, 16, 19, 21.

183) „Die Westmark “ Bd. I, 1921, S. 205 ff.

104) Vgl. dazu auch seine Ausführungen über den „Demokratismus der Resignation" in "ther Wesen und Erscheinungsformen der modernen Demokratie ${ }^{\prime}$, 1948 S. 28 ff. - Hermann Ehlers spricht aaO. S. 19, 21, von der Demokratie als der „am wenigsten schlechten Staatsform ${ }^{*}$. 


\title{
Leitsātze des Berichterstatters über: Parlament und Regierung im modernen Staat
}

\author{
I.
}

1. Voraussetzung für das Funktionieren des parlamentarischen Systems ist die Fähigkeit des Volkes zur Mehrheitsbildung in Parlament und Regierung, $d$. h. die Existenz großer im Volk verwurzelter politischer Parteien, die sich in den Grundauffassungen von Staat und Verfassung einig sind und Opposition nur in Form einer Alternativpolitik unter Achtung der verfassungsrechtlichen Grundlagen betreiben.

2. Es widerspricht nicht den verfassungsrechtlichen Grundlagen der wertbetonten freiheitlichen Demokratie, wenn verfassungsfeindliche Parteien von dem Wettkampf der politischen Parteien ausgeschlossen werden. Dies ist aber nur auf Grund verfassungrechtlicher Vorschriften zulässig; parlamentarische Geschäftsordnungen dürfen nicht Ausnahmebestimmungen gegen Parteien enthalten, die das Parlament für verfassungsfeindlich erklärt.

3. Art. 38 Abs. 1 Satz 2 GG steht nicht in unlösbarem Widerspruch zu Art. 21 GG; er bedeutet vielmehr die bewußte Entscheidung für die freie Abgeordnetenpersönlichkeit auch in der ohne politische Parteien nicht existenzfähigen modernen Massendemokratie.

4. Ohne Fraktionsdisziplin können stabile parlamentarische Regierungen weder gebildet werden noch an der Macht bleiben. Da die Fraktionen verfassungsrechtlich anerkannte Gliederungen des Parlaments sind, gehört die Mitarbeit in der Fraktion zur Ausübung des Mandats; sie steht unter dem Gebot des Art. 38 I 2 GG. Ein Abgeordneter, der einer in freier Diskussion und Abstimmung getroffenen Fraktionsentscheidung im Plenum folgt, verletzt nicht das Gebot des Art. 38 I 2 GG.

5. Die Stärke des parlamentarischen Regierungssystems in der gegenwärtigen gesellschaftlichen Situation liegt in seiner Bereitschaft und Fähigkeit zum Kompromiß. 
6. Die Parlamentswahlen tragen heute zwar plebiszitären Charakter, sind aber nach wie vor echte Wahlen. Parlament und Regierung sind in ihrem Wirken nicht auf die Fragen begrenzt, die im Wahlkampf eine Rolle gespielt haben.

7. Die Macht im Staat steht weder bei den Parteien noch bei den Verbänden, sondern bei Parlament und Regierung, die die widerstreitenden Interessen zum Ausgleich bringen und ihre Entscheidungen nach den Forderungen des Gesamtwohls treffen.

8. Ein institutioneller Einbau der Verbände in die Verfassung (Wirtschaftsrat) müßte das Bezugssystem ParlamentRegierung beachten, um Verantwortung und Kontrolle klar und ungeschwächt $z u$ erhalten.

9. Die Bürokratie behält die ihr zukommende dienende Rolle, wenn sich klare Mehrheiten im Parlament bilden und Regierungsmehrheit wie Opposition gemeinsam den politischen Führungsanspruch verfechten.

10. Die Funktion des Parlaments besteht heute darin, daß die Regierung und die sie stützenden Parteien öffentlich ihre Politik dem Volk darlegen, die Opposition in der gleichen Offentlichkeit diese Politik bekämpft und ihre Alternativpolitik darlegt. Von der Arbeit des Parlaments geht damit eine integrierende. Wirkung auf das Volk aus.

11. Auch die Ausschüsse gehören zum Parlament. Die Aufteilung der Arbeit zwischen Ausschüssen und Plenum ist nur eine Frage der besten Arbeitstechnik.

12. Parlamentarische Regierungsweise bedingt weder, daß die Regierung zu einem Vollzugsausschu $\beta$ des Parlaments, noch daß das Parlament zu einem Instrument in der Hand der Regierung wird. Das System entfaltet seine besonderen Vorzüge, wenn eine gesunde Spannung erhalten bleibt.

13. Im parlamentarischen Regierungssystem sind die Grenzen der sogenannten Gewaltenteilung zugunsten des Parlaments verschoben. Parlament und Regierung sind gleichermaßen von der Rechtsprechung ausgeschlossen. Die Rechtsetzung ist ein Reservat des Parlaments. Aber es gibt kein verfassungskräftiges Vorbehaltsgebiet der Regierung. Die Staatsleitung steht Parlament und Regierung gemeinsam $z u$, so daß das Parlament auch auf Regierungsakte Einfluß 
nehmen kann. Verfassungsbestimmungen, die dem Parlament ausdrücklich eine Mitwirkung sichern, sind nicht eng auszulegende Ausnahmebestimmungen, sondern Ausdruck eines allgemeinen Prinzips. Wo nicht eindeutige Verfassungsbestimmungen entgegenstehen, kann das Parlament sich auch durch einfaches Gesetz weitere Mitwirkungsrechte sichern.

14. Von der Delegation der Rechtsetzungsbefugnis kann ausgiebig Gebrauch gemacht werden, wenn eine starke parlamentarische Kontrolle gesichert ist.

15. Unabhängigkeit der Regierung vom Parlament nach Art der amerikanischen Präsidentschaftsrepublik setzt voraus, daß die Regierung ihrerseits eine vom Parlament unabhängige plebiszitäre Legitimation besitzt.

16. Gleichzeitige Abhängigkeit der Regierung vom Vertrauen des Parlaments und eines plebiszitären Staatsoberhaupts (WRV) muß zu einer Krise des Regimes führen.

17. Schreibt die Verfassung vor, daß die Regierung vom Parlament gewählt wird, so ist die Amtsdauer der Regierung auf die Wahlperiode des Parlaments begrenzt, auch wenn dies in der Verfassung nicht ausdrücklich gesagt ist.

18. Der Bundespräsident ist verpflichtet, den Vorschlägen des Bundeskanzlers auf Ernennung und Entlassung von Bundesministern zu entsprechen.

19. Das parlamentarische Regierungssystem fordert grundsätzlich als Gegenspieler des Parlaments eine Regierung mit einem Programm, das von der Mehrheit des Parlaments gebilligt wird. Minderheitsregierungen und unpolitische Geschäftsregierungen sind Krisenerscheinungen. Allparteienregierungen verzichten auf eigene Politik und vollziehen nur die jeweiligen Parlamentsentscheidungen.

20. Allparteienregierungen sind für die Gliedstaaten eines Bundesstaates eine angemessene Lösung, weil diese im wesentlichen nur Verwaltungskörperschaften sind. Art. 28 Abs. 1 GG schreibt den deutschen Ländern das parlamentarische Regierungssystem nicht vor.

21. Mehrheitsregierungen können Einpartei- oder Koalitionsregierungen sein. Die Festigkeit einer Koalitionsregierung hängt von der Festigkeit der sie tragenden Parteigruppe ab (Gegensatz Deutschland-Frankreich). 
22. Das österreichische Experiment, das die beiden großen Parteien unter Aufrechterhaltung ihrer Gegensätzlichkeit und Aussparung einer Bereichsopposition zu einer Regierungskoalition zusammenführt, versucht die Politik des Kompromisses in der Regierungsbildung zu institutionalisieren.

23. Die Sicherung der Regierung in der Schweiz gegen Abberufung durch das Parlament findet ihre Erklärung in der Eigenart der Schweizer Referendums-Demokratie.

24. Da der Ministerpräsident zurücktreten $m u \beta$, wenn die politischen Verhältnisse ein vertrauensvolles Zusammenarbeiten zwischen ihm und dem Landtag unmöglich machen, ist die Regierung in Bayern nicht eine Regierung auf Zeit. Den Wegfall der Vertrauensgrundlage kann nur der Landtag in einer Form feststellen, die einem Mißtrauensvotum gleichkommt.

25. Auch die Bundesminister sind dem Bundestag verantwortlich. Der Bundestag kann nicht nur dem Bundeskanzler, sondern auch Bundesministern die Mißbilligung aussprechen. Anträge, den Bundeskanzler zu ersuchen, einen Bundesminister zu entlassen, sind geschäftsordnungsmäßig zulässig.

26. Das sogenannte konstruktive Mißtrauensvotum des Art. 67 GG hat nicht die politische Bedeutung, die ihm vielfach beigemessen wird. Eine Regierung, die ihre Mehrheit verloren hat, aber wegen des konstruktiven Mißtrauensvotums nicht gestürzt werden kann, ist verfassungsrechtlich gleich stark und politisch gleich schwach wie eine Regierung, die durch destruktives Mißtrauensvotum einer heterogenen Mehrheit gestürzt ist, aber geschäftsführend im Amt bleibt.

27. Der Bundespräsident muß dem vom Bundeskanzler nach Art. 68 GG gestellten Verlangen auf Auflösung des Bundestages nachkommen.

II.

(Die nachfolgenden Leitsätze werden nur als Material für die Diskussion vorgelegt; das Referat dazu kann aus Zeitmangel, nicht erstattet werden.)

1. Da parlamentarische Demokratie die Demokratisierung der Exekutive bedeutet, kann dem liberalen Prinzip der Gewaltenteilung für die Abmarkung der Funktionen des 
Parlaments von denen der Regierung nur eine sehr beschränkte Bedeutung zukommen. Das Kennzeichen der parlamentarischen Demokratie ist gerade das Hineinwirken des Parlaments in die Regierungsfunktion. Die Grenze für die Einflußnahme des Parlaments liegt da, wo der richtig verstandene Grundsatz des Rechtsstaates außer acht gelassen wird.

2. Das Parlament ist befugt, der Regierung durch Entschließungen Weisungen für die Führung der Regierungsgeschäfte zu erteilen. In diesem Sinne kann auch ein politisch akzentuierter Haushaltsansatz die Verpflichtung der Regierung begründen, den bewilligten Betrag für den vorgesehenen $\mathrm{Zweck}$ auszugeben. Solche Weisungen können allerdings nur mittelbar durch politischen Druck, äußerstenfalls durch Mißtrauensvotum durchgesetzt werden.

3. Die Ausdehnung des parlamentarischen Einflusses auf die Vertragsgewalt und auf das Recht über Krieg und Frieden mag der strengen Gewaltenteilung widersprechen; sie entspricht aber dem parlamentarischen Regierungssystem. Ausdehnende Auslegung des Art. 59 Abs. 2 GG ist darum geboten. Da die Kündigung von Verträgen in erheblichem Ausmaß die politischen Beziehungen des Bundes beeinflussen kann, kann aus Art. 59 Abs. 2 GG auch ein Zustimmungsrecht des Parlaments zur Kündigung gewisser Verträge abgeleitet werden.

4. Das Parlament kann durch einfaches Gesetz Aufgaben der Organisationsgewalt an sich ziehen oder einen Gesetzesvorbehalt in diesem Bereich schaffen.

5. Bei der noch ausstehenden Regelung des Notstandsrechts wird in besonderer Weise auf das Zusammenwirken von Regierung und Parlament Bedacht genommen werden müssen, um ausreichende Kompetenzen der Regierung mit einer effektiven Kontrolle des Parlaments zu koppeln.

6. Es ist zulässig, durch einfaches Gesetz die Ernennung der Mitglieder des Rechnungshofs, eines Personalgutachterausschusses, einer Kommission für Wirtschaftlichkeit in der Staatsverwaltung und dergleichen an die Zustimmung des Parlaments $z u$ binden. Die Ernennung von Beamten und Richtern kann vom Plazet eines Ausschusses abhängig gemacht werden, selbst wenn seine Mitglieder ganz oder zum Teil vom Parlament gewählt werden. Es bestehen keine Bedenken dagegen, daß der Vorsitzende der Schiedsstelle nach einem Personalvertretungsgesetz vom Präsi- 
denten des Parlaments bestellt wird, selbst wenn die Schiedsstelle bei Nichteinigung zwischen Behördenleiter und Personalrat in Personalfragen von Beamten entscheidet.

7. Es ist zulässig, daß das Parlament der Regierung Petitionen "zur Berücksichtigung" überweist. Der Regierung. bleibt allerdings vorbehalten, darüber $z u$ entscheiden, ob, in welchem Ausmaß und mit welchen Modalitäten sie dem Ersuchen Folge geben will. Die Landesregierungen sind nicht befugt, über Ersuchen der Bundesregierung die Auskunft über die Ausführung von Bundesgesetzen in den Ländern zu verweigern, wenn der Petitionsausschuß des Bundestages solche Auskünfte zu seiner Unterrichtung erbeten hat.

8. Die Möglichkeit, daß die Regierung gegen ein vom Parlament beschlossenes Gesetz den Volksentscheid anruft, hat im richtig funktionierenden parlamentarischen System keinen Platz; sie fehlt im geltenden deutschen Bundesund Landesverfassungsrecht. Das Referendum auf Antrag einer Parlamentsminderheit und das Volksbegehren wirken der Mediatisierung des Volkes durch die Parteien entgegen und erlauben es der Opposition, auch während der Wahlperiode eine Wandlung des politischen Klimas auszunutzen.

9. Die Ausfertigung der Gesetze durch die Regierung ist ein Uberbleibsel aus der Zeit der konstitutionellen Monarchie; in der parlamentarischen Demokratie gehört die Ausfertigung der Gesetze in die Hand des Parlamentspräsidenten.

10. Auch da, wo in der Verfassung keine Frist für die Verkündung der Gesetze vorgeschrieben ist, ist die Regierung verpflichtet, die Gesetze unverzüglich zu verkünden.

11. In der parlamentarischen Demokratie kommt es der Regierung nicht zu, die vom Parlament beschlossenen Gesetze auf ihre inhaltliche Ubereinstimmung mit der Verfassung zu prüfen. Das muß jedenfalls in der Bundesrepublik gelten, deren Verfassung das richterliche Prüfungsrecht anerkennt und die Verwerfungskompetenz beim Bundesverfassungsgericht konzentriert. Die beste Lösung würde sein, der Bundesregierung den Antrag auf abstrakte Normenkontrolle bereits vor Verkündung des Gesetzes zu gewähren und die Verkündung bis zur Entscheidung des Bundesverfassungsgerichts auszusetzen. 
12. Es dient der Entlastung des Parlaments, wenn es sich in den Gesetzen auf die allgemeinen und grundsätzlichen Regeln beschränkt, die nähere Ausgestaltung und die Anpassung an die wechselnden Umstände aber der Regierung im Wege der Verordnung überläßt. Art. 80 Abs. 1 Satz 2 GG ist daher großzügig auszulegen. Allerdings müßte die Kontrolle des Parlaments über die Verordnungsgebung der Regierung verstärkt werden. Alle Verordnungen sollten dem Parlament vorgelegt werden, das das Recht haben muß, die Aufhebung oder Außerkraftsetzung zu verlangen. Es ist auch zulässig, den Erlaß von Regierungsverordnungen an die Zustimmung des Parlaments oder eines Ausschusses zu binden. Abänderung einer Verordnung durch das Parlament hingegen bedeutet eine unzulässige Vermischung der beiden Rechtssetzungswege.

13. Da "die Länder" nach Art. 50 GG „durch den Bundesrat" bei der Gesetzgebung und Verwaltung des Bundes mitwirken und die Mitglieder des Bundesrats instruktionsgebundene Mitglieder der Landesregierung sind, ist es zulässig, daß ein Landtag der Landesregierung Weisungen gibt, wie sie im Bundesrat abstimmen soll. Der Bundesrat, der seine Berechtigung in der eigenartigen Verfassung des monarchischen Bundesstaates Bismarck'scher Prägung hatte, paßt aber überhaupt nicht in die Struktur einer parlamentarisch-demokratischen Verfassung. Die Senatslösung würde sich besser in das parlamentarische Regierungssystem des Bundes einpassen. Landtagswahlen unter den Parolen der Bundespolitik und Bildung der Landesregierungen unter dem Gesichtswinkel der Mehrheitsbildung im Bundesrat hindern zudem die Entfaltung eines eigenständigen Föderalismus in den Ländern.

14. Daraus, daß die Minister für ihren Geschäftsbereich dem Parlament verantwortlich sind, folgt nicht, daß für alle Bereiche, die nicht Rechtsetzung oder Rechtsprechung sind, eine ministerielle Weisungsbefugnis bestehen muß. Gegen den sogenannten ministerialfreien Raum bestehen von Verfassungswegen keine Bedenken.

15. Völlig neue Probleme für das Ausmaß der ministeriellen Leitung und damit für Möglichkeiten, Formen und Umfang der parlamentarischen Kontrolle ergeben sich aus der Nationalisierung von Wirtschaftszweigen. Nationalisierte Unternehmen können nicht wie Regiebetriebe durch Beamte unter ministerieller Weisungsbefugnis geführt werden. Für sie eignet sich besser die Form des selbständigen 
öffentlich-rechtlichen Unternehmens. Dies bedingt eine nur beschränkte ministerielle Aufsicht und begrenzt auch die Kontrolle des Parlaments über solche Unternehmen.

16. Hilfsorgane zur Effektuierung seiner Kontrolle nach Art des Wehrbeauftragten (skandin. Ombudsmänner) kann das Parlament auch ohne besondere verfassungsrechtliche Grundlage schaffen.

17. Da die Regierung die Arbeit der parlamentarischen Untersuchungsausschüsse nicht erschweren darf, muß ein Untersuchungsausschuß darüber entscheiden können, ob die Verweigerung der Aussagegenehmigung für einen Beamten berechtigt ist.

18. Das Recht des freien Zutritts und der jederzeitigen Anhörung ist den Regierungsvertretern in solchen vom Parlament gebildeten Ausschiissen nicht unbedingt gegeben, die durch Gesetz mit besonderen Aufgaben betraut sind (Wahlprïfungsausschuß, Richterwahlausschuß u. dgl.); auch bei Untersuchungsausschüssen kann dieses Recht Beschränkungen unterliegen. 


\section{Parlament und Regierung im modernen Staat}

\section{Mitbericht von Professor Dr. Karl J os ef Partsch, $\mathrm{Kiel}^{*}$ )}

Das Thema der heutigen Tagung ist in der deutschen Staatsrechtslehre am intensivsten vor fast genau 40 Jahren behandelt worden, als zur Diskussion stand, ob die Reichsregierung parlamentarisch verantwortlich gemacht werden solle $\left.{ }^{1}\right)$. Damals stand im Vordergrund, wie die unitarisch wirkende Parlamentarisierung mit dem Föderalismus, welcher die Struktur der Regierungsspitze bestimmte, in Einklang gebracht werden könne. Dieses Problem ist heute stark verblaßt. M a x W e b e r hat jedoch schon damals als eine Hauptfrage für die Beziehungen zwischen Regierung und Parlament angesehen, wie sich politisches und bürokratisches Denken miteinander vereinbaren lassen. Wenn ich mir den Zugang zu diesem auch heute noch hoch aktuellen Problem nicht verbauen will, kann ich mich daher nicht auf das Kabinett beschränken, sondern muß auch den ganzen hinter ihm stehenden Apparat der Ministerialbürokratie mit einbeziehen, ebenso wie es weltfremd wäre, als „Parlament" nur die auf unmittelbarer Volksrepräsentation beruhenden Beschlußkörperschaften anzusehen und Gebilde wie unseren Bundesrat oder den schweizerischen Ständerat völlig auszuschließen. Auch bei der Definition dessen, was hier als "moderner Staat" verstanden werden soll, ist Großzügigkeit geboten. Eine Einheitsform gibt es nicht. Um aber mit vergleichbaren Größen rechnen zu können, müssen zwei Mindestforderungen gestellt werden:

*) Die Nachweise in den Fußnoten geben kein ganz vollständiges Bild von den Quellen, die der Verfasser benützte. Zahlreiche Anregungen erhielt er durch die Beobachtung von Parlamentsarbeiten, durch Gespräche mit Parlamentariern und Fachleuten, welche Regierungen im Verkehr mit Parlamenten beraten, und auch mit Angehörigen der Stäbe parlamentarischer Hilfseinrichtungen. Ihnen hier zu danken, ist ihm eine angenehme Pflicht. Ganz besonders ist er der Leitung der Bibliothek des Deutschen Bundestages verpflichtet, die ihn großzügig mit Material unterstützt hat.

1) G. Anschütz: Parlament und Regierung im Deutschen Reich, 1918; $\mathrm{Max}$ W e ber : Parlament und Regierung im neugeordneten Deutschland, Die innere Politik hrsg. v. S. Hellmann, 1918; Le o Wittmayer: Deutscher Reichstag und Reichsregierung, 1918. 
1. daß die Repräsentation des Volkswillens durch ein Parlament erfolgt, das auf freie Wahlen zurückgeht und dem verschiedene Parteien oder Gruppen angehören können;

2. daß auch die Regierung wenigstens mittelbar auf eine Betätigung des Volkswillens in freien Wahlen und Abstimmungen zurückgeht.

Wenn hier hingegen die Gewaltenteilung nicht erwähnt wind, so liegt darin keine Stellungnahme zu der Auffassung von Herrn $\mathbf{P e}^{\prime}$ t $\operatorname{rs}^{2}$ ); ich will nur das Vergleichsobjekt England nicht ausschließen.

Das allgemein formulierte Thema verleitet dazu, Völkerpsychologie zu treiben. 1954 hat André Siegfried s) sehr geistvoll bemerkt, das Verhältnis zwischen Parlament und Regierung sei in den lateinischen Ländern durch ein subtiles und intelligentes Mißtrauen, in den angelsächsischen hingegen durch einen vertrauensbereiten Loyalismus gekennzeichnet. Wenn diese im Charakter der Nationen und ihrer Geschichte begründeten Unterschiede auch nicht iübersehen werden können, so scheint es mir nun jedoch aufgegeben zu sein, von einer Problematik auszugehen, welche den verschiedenen positiven Ordnungen gemeinsam ist und die also nicht in ihnen selbst gefunden werden kann, sondern von außen an sie herangetragen wird, und zwar von den für alle maßgeblichen Zeittendenzen ${ }^{4}$ ), unter denen hier einige durchaus willkürlich herausgehoben werden sollen, die für die Gesetzgebungsarbeit von Bedeutung sind, mit der ich mich besonders zu beschäftigen habe.

Die erste ist die geradezu ungeheuerliche Vermehrung der Sta t saufgaben in der neuzeitlichen Industriegesellschaft, bedingt durch die sachlichen Notwendigkeiten

2) Hans Peters: Die Gewaltentrennung in moderner Sicht (Arbeitsgemeinschaft für Forschung des Landes Nordrhein-Westfalen - Geisteswissenschaften Heft 20 1954).

3) Schlußwort nach dem Rundgespräch der Association Française de science politique am 3./4. 7. 1954, veröffentlicht in "Le travail parlementaire en Françe et à l'étranger", hrsg. von Fra n ç o i s Gog u e l, Paris 1955 (zitiert als "Travail Parlementaire") S. 200.

4) Zur allgemeinen Problematik"H. Fay at, W. J. Gans h of van der Meersch und P. Wig $n$ y in Aspects du regime parlementaire belge, Bibliothèque de L'institut belge de sience politique, 1956 (zitiert als "Aspects") sowie F. Gog u e l und G. Ga li ch on in "Travail Parlementaire"; ferner H. R otts ch a effer: The constitution and socio-oeconomic change, University of Michigan Law-School, the Thomas M. Coobey Lectures, ser. 1 (1948); A l ex a n der B r a dy in Parliamentary Government in the Commonwealth, hrsg. v. S y d n e y D. B a i l e y, 1951; C a r lo Schmid: Regierung und Parlament, Recht, Staat und Wirtschaft Bd. 3 (1951) S. 86 ff. 
der Technisierung. Auch wer sich innerlich dagegen sträubt, daB der Staat für sein Dasein zu sorgen bestellt sei, kann nicht in Abrede stellen, daß ein mit 120 Std.-km dahin brausendes Auto oder ein noch schnelleres Flugzeug höhere Anforderungen an den Gesetzgeber stelle, als ein gemächlich dahin trabender Landauer. Wo die natürliche Bintung des Meisters gegenüber dem Gesellen - allein schon wegen der Zahl der Arbeitnehmer - wegfällt, muß der Staat ergänzend und ersetzend eingreifen. Wo die Menschen so eng zusammenrücken wie in einer modernen Großstadt, ergeben sich neuartige Reibungsprobleme, die von dem Gesetzgeber gelöst werden müssen. Wer hätte noch vor $50 \mathrm{Jahren}$ an den Lärm als Rechtsproblem gedacht!

Nicht nur die Aufgabenvermehrung und der Zerfall der natürlichen Lebenseinheit, sondern auch der Rhythmus der Zeit setzen den Gesetzgeber unter Druck. Das Verhältnis des modernen Menschen zum Problem der Zeit - dem zweiten modernen Problem - hat zwei Seiten. Auf der einen Seite zwingt die Größe der zu bewältigenden Aufgaben wie die industrielle Raumplanung, der Aufbau einer neuzeitlichen Wasser- und Elektrowirtschaft und gar der einer Atomwirtschaft zu langfristigen Planungen, welche nur bewältigt werden können, wenn eine entsprechende Stabilität der Organe gewährleistet ist. Daraus ergeben sich Konsequenzen für die Dauer der Legislaturperiode und die Form der Regierungsbildung; auf der anderen Seite hat die Beschleunigung des Lebens-Rhythmus auch einen Einfluß auf den Arbeits-Rhythmus von Parlament und Regierung. Eine schnell laufende Maschine muß anders verzahnt sein wie eine langsam laufende. Die Hast der madernen Zeit verlangt schnelle Entscheidungen und eine weitgehende Arbeitsteilung.

Das dritte Phänomen schließlich ist das der In tern a ti on a lis i e rung zahlreicher Lebensbereiche. Während früher internationale Abkommen über wenige Materien des politischen Bereiches - Krieg, Frieden, Bündnis und internationalen Handelsaustausch - abgeschlossen wurden, wächst nun die internationale Ordnung immer stärker auch in die Funktion einer Koordinierung der Wirtschafts-, Sozial- und Kulturpolitik hinein. Das kann für das Verhältnis zwischen Regierung und Parlament nicht ohne Folgen bleiben.

Die Vermehrung der Staatsaufgaben

a) Für neue Aufgaben ist in einer Regierung immer Platz. Entweder werden neue Ministerien gegründet oder in die 
bestehenden werden Referate für Gebiete, die bisher nicht behandelt wurden, eingebaut. Neben die sogenannten klassischen Ministerämter traten neue: neben den Innenminister der Arbeits-, Sozial- und Pensionsminister, neben den Finanzminister der Wirtschafts-, Außenhandels-, Atom-Minister oder gar ein Minister für wirtschaftliche Zusammenarbeit, um nur einige Beispiele zu nennen. Damit sei keineswegs behauptet, die Zahl der Kabinettsmitglieder könne ohne Schaden schrankenlos erhöht werden. Die kollegiale Arbeitsweise des Kabinetts zieht dem entschieden eine Grenze. $V$ iscount Dudley fand 1827 schon 12 Minister entschieden zu viel und auch das Haldane Comittee sprach sich 1918 für 10, höchstens 12 Kabinettsmitglieder aus ${ }^{5}$ ). Inzwischen ist aber 18 die Durchschnittszahl geworden. Bei dieser Größe ist eine wirksame Koordination nur mit Hilfe ständiger oder ad hoc gegründeter Kabinettsausschüsse möglich, deren Stellung zum Gesamtkabinett bei ihrer Bildung jeweils festgelegt wind. Die Organisationsgewalt setzt die Regierung in die Lage, die Aufgabenstellung und die Rechte und Pflichten der Kabinettsausschüsse nach Belieben zu bestimmen.

Im Rahmen der einzelnen Ministerien ist jedoch für die augefallenste Spezialisierung Platz. Durch die Organisation des Ministeriums in Referate und Abteilungen ist dem vorgebeugt, daß der in den Apparat eingegliederte Spezialist seinen Sondergesichtspunkt zum Schaden des Ganzen übermäßig betont. Innerhalb des Ministeriums hat der höchste Fachbeamte (Generaldirektor oder ständiger Staatssekretär) die Gesamtheit der Gesichtspunkte des Arbeitsbereiches aufeinander abzustimmen.

b) Die innere Struktur des Parlamentes ist durch die Vermehrung der Staatsaufgaben und die in engem Zusammenhang damit stehende Spezialisierung sehr viel stärker berührt worden als die Regierung. In diesem Zusammenhang sind das Ausschußproblem, die Hilfseinrichtungen des Parlaments und die Verlagerung von Parlamentsaufgaben zu nennen.

aa) Alle Parlamente, die sich unter der Arbeitslast zur Arbeitsteilung gezwungen sahen ${ }^{6}$, haben Fachausschüsse

5) D. N. Chester : The Development of the Cabinet, Parliamentary Affairs Bd. IX (1955-56) S. $43 \mathrm{ff}$.; F a y at in "Aspects S. 38.

0) Anders z. B. in Neuseeland, wo wegen des geringen Arbeitsanfalls kein Bedürfnis nach Fachausschüssen auftrat. Vergl. W a l ter Nash: Parliamentary Government in New Zealand in Stephen K in g-Ha 11: Parliamentary Government in the Commonwealth. A Symposion, 1951 S. 59. 
eingerichtet und einen erheblichen Teil der Parlamentsarbeit in sie verlagert. Gemeint sind hier nicht die besonderen Ausschüsse für Petitionen, die Geschäftsordnung, die Wahrung der Rechte der Volksvertretung u. ä., deren das Parlament bedarf, um überhaupt funktionieren zu können, sondern die Fachausschüsse, welche Gesetzesbeschlüsse vorbereiten. Der Spezialisierung im Parlament sind jedoch Grenzen gesetzt. Diese ergeben sich zunächst aus der Zahl der Parlamentsmitglieder, die durch die Funiktion des Parlaments begrenzt ist: unter mehr als 500-600 Parlamentariern kann kein Interessenausgleich vorgenommen werden; daher kann auch die Aufteilung in einzelne Fachausschüsse nur unter diesen 500 bis 600 Menschen stattfinden. Allerdings kann dies in recht verschiedener Form geschehen. Wie im amerikanischen Kongreß können die Ausschüsse zahlenmäßig sehr klein gehalten werden und dann kann eine große Zahl von Ausschüssen besetzt werden. Das bringt die Gefahr einer einseitigen Interessenorientierung mit sich und ist nur durchführbar, wenn die parteienmäßige Zusammensetzung des Parlaments es erlaubt. Wo Parteien verschiedener Größenordnungen bestehen, stellt sich die Forderung nach größeren Ausschüssen ein, um auch kleineren Fraktionen oder Gruppen eine adäquate Vertretung zu sichern. Dann kann es unvermeidlich werden, daß jeder Abgeordnete mehreren Ausschüssen angehört ${ }^{7}$ ). Darunter leidet nicht nur die Arbeitsfähigkeit der Ausschüsse, sondern auch die Arbeitsteilung im Gesamtparlament. Das Plenum muß dann nicht nur den Ausschüssen die notwendige Arbeitszeit einräumen, sondern diese müssen sich auch untereinander abstimmen. Bei den Parlamentsreformen der letzten Jahrzehnte wurde immer wieder gefordert, die Ausschüsse zu verkleinern ${ }^{8}$ ) und auch bei uns ist erst jüngst wieder der Ruf danach laut geworden. Der Ausgang der letzten Wahl mit dem scharfen Zug zum Zweiparteiensystem erleichtert es,

7) $\mathrm{Zu}$ Beginn der 2. Legislaturperiode des Deutschen Bundestages gehörte jeder Abgeordnete durchschnittlich 11/2 Fachausschüssen als Hauptmitglied an; nimmt man die organisatorischen Ausschüsse und die Stellvertreterposten ohne die Untersuchungsausschüsse hinzu, so kommt man durchschnittlich auf 3-4 Ausschüsse. Vgl. die Ubersicht bei H. T ros s m a n n : Der 2. Deutsche Bundestag, 1954 S. $100 \mathrm{ff}$. In der französischen Assemblée Nationale sind die Verhältnisse ähnlich trotz der Bestimmung des Artikels (1) des Règlement „aucun Député ne peut faire partie de plus de deux Commissions générales".

8) In den Vereinigten Staaten bei der Kongreßreform von 1946; für Frankreich vgl. G. G a li c h on in Travail Parlementaire S. 147. 
dieser Forderung nachzukommen ${ }^{9}$ ); sie bricht sich nur an dem irrationalen politischen Postulat nach möglichst zahlreichen Vorsitzendenstellen und Ausschußsitzen.

Eine wichtige Grenze für die Aufspaltung des Parlaments in Fachausschüsse liegt aber darin, da $B$ das Parlament eine Einheit darstellt, die nicht zerstört werden darf. Parlamentsfunktion und Ausschußfunktion sind nicht identisch, sondern widersprechen sich sogar weitgehend. Die Funktion des Gesamtparlaments ist in der Unterhausdebatte vom 15. November 1945 von dem Labour-Abgeordneten $\mathrm{M}$ a u r i c e W e b b ${ }^{10}$ ) treffend umschrieben worden:

„Ich glaube, wir wären schlecht beraten, wenn wir die zentrale Funktion dieses Hauses als das große Forum für die Debatten über die hohe Politik und als der Platz, auf dem die mannigfaltigen Wünsche und Ziele des Volkes einander angeglichen und auf einen Nenner gebracht werden, beseitigten. Wir müssen das, koste es, was es wolle, bewahren und bei der Ausdehnung der Aufgaben der Ausschüsse darauf Rücksicht nehmen, damit wir keinesfalls dieser zentralen Funiktion Eintrag tun."

Es kommt nicht darauf an, ob alle Parlamente jeden Tag und jede Stunde der so gekennzeichneten Aufgabe leben, wesentlich ist, daß die Ausschüsse andere Funktionen haben, denn ein Forum und eine Stätte des Ausgleichs zu sein. Mühsame Facharbeit wind dort in der Stille und unter dem Schutze einer Beschränkung oder des Ausschlusses der Öffentlichkeit geleistet. Keine glänzenden Reden werden dort gehalten, sondern nüchterne Referate und die Fronten der Diskussion sind vorher nicht abgesteckt. Politische und ideologische Gesichtspunkte treten hinter den nüchtern sachlichen zurück, es gilt sich zu informieren und auch von der Sache her überzeugen zu lassen. Aber diese Arbeit ist doch nur Vorarbeit für die notwendigerweise unter andenen Gesichtspunkten im Plenum zu fällende endgültige Entscheidung, und daher ist es so wichtig, die Unterordnung der Arbeit im Ausschuß unter die Auseinandersetzung im Plenum zu sichern und zu verhindern, daB die zu Fachleuten gewordenen Aus-

9) Bei der Bildung der Ausschüsse des 3. Deutschen Bundestages wurde die Zahl der Ausschüsse zwar vermindert, die Abgeordneten gehören aber durchschnittlich immer noch rund 11/s Ausschüssen an, wenn man lediglich die Hauptmitgliedschaften in organisatorischen und Fachausschüssen rechnet; vgl. BT-Drucks. 18/57.

10) 415 H. C. Deb. 2370 - 1 (15. 11. 1945); dazu H e r ber t M or r i s o n : Regierung und Parlament in England 1954, deutsche Ausgabe 1956 S. 283. Zur Funktion des Parlaments auch H. F a y a t aaO. S. 29 und 35 ff.; Alexander Brady aaO. S. 8. 
schußmitglieder allein die Entscheidung des Plenums bestimmen.

Die kontinental-europäischen Ordnungen glauben das durch Normativbestimmungen erreichen zu können, die sagen, daß die Ausschüsse Organe des Parlaments sind und sich nur mit den ihnen vom Plenum überwiesenen Gegenständen befassen dürfen ${ }^{11}$ ).

Während das Plenum in Großbritannien jedoch bereits vor der Uberweisung an einen Ausschuß zu den grundlegenden Fragen eines Gesetzgebungsvorhabens Stellung nimmt und damit eine Grundlage für die Ausschußarbeit schafft und dieser die Richtung weist ${ }^{12}$ ), hat die erste Lesung im Deutschen Bundestage häufig nur sehr formalen Charakter; dennoch scheint es mir von großer Bedeutung zu sein, daß das Plenum überhaupt Gelegenheit erhält, darüber zu befinden, womit sich seine Organe beschäftigen dürfen; daher ist die erste Lesung unentbehrlich. In Frankreich wird allerdings die Vorlage ohne Erörterung unmittelbar durch das Bureau dem Ausschuß überwiesen ${ }^{13}$ ); wie im amerikanischen Kongreß, wo das Initiativrecht der Abgeordneten auch im Ausschuß und auch von diesem selbst ausgeübt werden kann, fehlt eine Kontrolle des Gesamtparlaments über das, was die Ausschüsse tun.

In der Schweiz glaubt man die Abhängigkeit der Ausschüsse dadurch sichern zu können, daß man den Abgeordneten gestattet, ihnen nur eine bestimmte Zahl von Jahren anzugehören $\left.{ }^{14}\right)$. Aber diese Vorkehrungen sind doch nur von sehr relativer Wirkung. Wo wie in unserer Zeit eine allgemeine Tendenz zur Spezialisierung besteht, kann dadurch kaum verhindert werden, daß die Ausschüsse ein starkes Eigenleben gewinnen. Sehr viel wirksamer sind die im Parlament Großbritanniens getroffenen organisatorischen Vorkehrungen; dort bestehen keine auf bestimmte Materien spezialisierten Fachausschüsse, sondern je nach Bedarf 4-5 Standing-Committees $\left.{ }^{15}\right)$, die nur mit einem Buchstaben bezeichnet sind und

11) $\$ 60$ (1), (3) Geschäftsordnung des Deutschen Bundestages vom 6. 12. 1951 (Bek. v. 28. 1. 52 BGBl. II S. 389 und And. Bek. v. 6. 12.55 BGBl. II S. 1048) - zitiert als „BT-GO'; dazu Bundestagspräsident Eh le r s in der 151. Sitzung vom 13. 6. 51 (S. 5946 D).

12) H. M o r r i s on aaO. S. $274 \mathrm{ff}$.

13) Art. 20 (1) des Règlement de l'Assemblée Nationale für die Vorlagen der Regierung und aus der Mitte des Haúses.

14) C. B u r khard: Parlamentarische Kommissionen der Schweizer Bundesversammlung, 1952, S. $162 \mathrm{ff}$.

16) $\mathrm{K}$. C. Wh e a r e : Government by Committee - an Essay on the british constitution, 1955, S. 121 ff.; J. G. S. S h e a re r : Standing Committies in the House of Commons 1945-50, Parliamentary 
turnusgemä $ß$ zur Verfügung stehen, wenn das Plenum eine Aufgabe zu vergeben hat. 20 ständige Mitglieder, die nach dem Grundsatz der Parteien-Proportionalität ausgesucht sind, bilden den Kern des Ausschusses. Für die Behandlung jedes einzelnen Gesetzentwurfs, der vom Plenum zugewiesen wird, wählt ein Auswahlausschuß unter dem Gesichtspunkt der Fachkenntnisse 30 weitere Mitglieder hinzu. Da der Wahlkörper proportional besetzt ist, wird auch bei der Auswahl dieser 30 Spezialisten der Gesichtspunkt des Parteienverhältnisses beachtet. Die 20 Stamm-Mitglieder werden die Sonderaufgabe unter dem Gesichtspunkt des Gemeinwohles oder - wenn man so will - der Interessen des Gesamtparlamentes (was ein und dasselbe sein sollte) betrachten, während die 30 ad hoc hinzutretenden Mitglieder bei den $\mathrm{Be}-$ ratungen ihre partiellen Fachgesichtspunkte entwickeln können und sollen. Dadurch, daß die Fachleute nach Erledigung ihrer Sonderaufgaben wieder auseinandertreten, ist wirksam verhindert, $\mathrm{da} \beta$ der Ausschu $\beta$ beginnt, sich als Teilparlament aufzuspielen, das nach spezifischen Fachgesichtspunkten entscheidet.

Ich bin darauf gefaßt, daß mir in der Aussprache entgegengehalten wird, die englische Regelung sei aus der alten parlamentarischen Tradition des Inselreiches zu erklären und habe soziologische Voraussetzungen, die auf dem Kontinent nicht vorlägen, obwohl sie noch gar nicht so alt ist, sondern erst 1945 eingeführt wurde, um ganz modernen Erfordernissen gerecht zu werden, nämlich das Nachkriegsgesetzgebungsprogramm der Labour-Regierung zu bewältigen $\left.{ }^{16}\right)$. Gewiß ist das englische Parlament stärker auf Regierungsbildung und -Kontrolle und weniger auf Gesetzgebungsarbeit zugeschnitten als die kontinentalen Parlamente; es scheint mir aber auch eine Rolle za spielen, daß in Großbritannien - dem einzigen Lande, in dem das Parlament in der politischen Wirklichkeit die Rolle behalten hat, die ihm von der Verfassungsordnung zugedacht ist - die staatsmännische Weisheit auch bei der Ausgestaltung scheinbar zweitrangiger Institutionen mit großem praktischem Sinn bemüht wird, während auf dem Kontinent die entwickelten und formulierten Verfassungsprinzipien bei der praktischen Ausgestaltung von Organen nicht in derselben Weise durchgehalten werden.

In der Bundesrepublik ist die Abhängigkeit der zwei wichtigsten Ausschüsse für Auswärtiges und für Verteidigung vom

Affairs Bd. 3 (1945/50) S. 558; zur Geschichte des Fachausschußwesens H. Mor r is o n aaO. S. 203.

16) I. G. S. Shearer : aaO. S. 558. 
Plenum neuerdings gelockert worden ${ }^{17}$ ). Aus der Tatsache, daß sie auch zwischen zwei Wahlperioden tätig werden können, darf $\mathrm{m}$. E. aber nicht hergeleitet werden, daB der Grundsatz der Organabhängigkeit völlig aufgehoben sei und sie auch während der Sitzungsperiode des Bundestages Fragen behandeln könnten, die ihnen nicht vom Plenum zugewiesen sind.

Eine weitere Lockerung der Organ-Abhängigkeit ist dadurch eingetreten, da $\beta$ die Ausschüsse des Deutschen Bundestages die Befugnis für sich in Anspruch nehmen, Unterausschüsse zu bilden, ohne das Plenum zu befassen. Schon die Mitgliederlisten dieser Unterausschüsse lassen die Gefahr erkennen, daß sie einseitig aus interessenorientierten Albgeordneten zusammengesetzt werden. Das muß sich ungünstig auswirken, wenn der Gesamtausschuß - um Arbeit zu sparen, wozu er ja die Unterausschüsse eingesetzt hat - ihre Ergebnisse ohne eingehendere Prüfung übernimmt und dem Plenum weiterleitet.

Von den europäischen Staaten ist Italien am weitesten gegangen, Ausschüssen die Funktionen des Plenums zu übertragen ${ }^{18}$ ). Der Gesetzesbeschluß kann vom Plenum in nicht öffentlich tagende Ausschüsse verlagert werden; die Regierung, ein Zehntel der Abgeondneten oder ein Fünftel der Ausschußmitglieder, kann bis zur Verabschiedung die Vorlage wieder in das Plenum bringen. Diese Verlagerung wurde häufig vollzogen und nur selten wurden Vorlagen aus dem Ausschuß wieder in das Plenum zurückgebracht. Mit einem geringen Zeitaufwand war das italienische Parlament in der Lage, eine große Zahl von Gesetzen zu verabschieden. Allerdings stellen die Zahl der Gesetze und der dafür benötigte Zeitaufwand kein zuverlässiges Kriterium für die Qualität des Verfahrens dar. Die Gefahr der Interessenbeeinflussung ist bei diesem Verfahren ungebührlich groß; die starke Vereinfachung schafft die Versuchung, hurtig viele Gesetze zu verabschieden, anstatt mit voller Utberlegung wenige gute zu machen. Die Kritik nennt das italienische Verfahren eine $\mathrm{Ka}-$ pitulation der politischen Funktionen des Parlaments vor dem fachlichen Spezialistentum.

Am Ende des Legislaturperiode des zweiten Bundestages sind Stimmen laut geworden, die zweite Lesung vom Plenum in einen Hauptausschuß zu verlegen. Wenn das nichts anderes

17) Art. 45 a des GG, eingefügt durch Ges. vom 19. 3.1956 (BGBl. I S. 111).

18) F. G o g u e I : La procédure italienne de vote des lois par les commissions, Travail Parlementaire S. 168 ff.; G. B et t on i : Die thertragung rechtsetzender Gewalt in Italien, am Anm. 38 angef. O. S. $422 \mathrm{ff}$. 
bedeutet, als daß statt 400 Abgeordneten vielleicht 100 über den Bericht des Fachausschusses beschließen, und zwar in der Offentlichkeit, wobei allerdings die für das Plenum geltenden Formalbestimmungen gelockert werden, ist dagegen nichts einzuwenden. Aber wenn das heißen soll, daß die Debatte den Augen der Offentlichkeit entzogen wenden soll, dann sind doch starke Bedenken anzumelden.

Ich möchte aber nicht in den Verdacht geraten, hier für die Offentlichkeit der Ausschußsitzungen zu sprechen ${ }^{19}$ ). Die Beschränkung oder der Ausschluß der Offentlichikeit im Ausschuß hat den Sinn, dort eine wirklich freie Diskussion entstehen zu lassen und den unter dem Druck der Parteidisziplin stehenden Abgeordneten die Freiheit zu wahren, sich den aus der Natur der Sache ergebenden Argumenten zu fügen, was im übrigen in größerem Maße geschieht, als gemeinhin angenommen wird. Die Vertraulichkeit der Ausschußberatungen verlangt, wenn ihr Charakter gewahrt werden soll, sogar einen verstärkten Schutz, und ich möchte Zweifel anmelden, ob es damit vereinbar ist, daß verschiedene Ausschüsse des Bundestages stenografische Protokolle anfertigen und diese einem ziemlich weiten Kreis zugänglich machen. Nicht nur die Ministerien erhalten sie in vielen Kopien, sondern auch das Bundesverfassungsgericht und offenbar auch eine gewisse Offentlichkeit. Jedenfalls findet man sie in juristischen Abhandlungen zitiert ${ }^{20}$ ).

In den anderen Ländern wird es mit der Vertraulichkeit der Ausschüsse sehr unterschiedlich gehandhabt. In England tagen sie überhaupt öffentlich, in den Vereinigten Staaten wird ein scharfer Unterschied gemacht zwischen dem Teil der Ausschußtätigkeit, welcher der Information gewidmet und öffentlich ist und der eigentlichen Beratungsphase, welche unter dem Schutz einer sehr ängstlich gehüteten Vertraulichkeit stattfindet. In Frankreich ziehen sich bei der Beratung sogar die Regierungsvertreter zurück, um nicht zu stören ${ }^{21}$ ).

19) So B. Dech a mp s : Macht und Arbeit der Ausschüsse, 1954 S. 74 .

20) Daß die stenografischen Protokolle nicht für die Offentlichkeit bestimmt sind, ergibt sich aus $\$ 73$ (1) der BT-GO: „Die Beratungen der Ausschüsse sind nicht öffentlich". Die Ausschuß-B e r i c h te gem. \& 74 (1) GO sind davon streng zu scheiden. Sie sind Material der öffentlichen Beratung des Plenums. Wenn auch § $27 \mathrm{GO} \mathrm{Ab-}$ weichungen zuläßt, so liegt hinsichtlich der stenografischen Protokolle doch $\mathrm{m}$. W. kein erforderlicher Beschluß des Bundestages mit $2 / 3$ Mehrheit vor, sondern es handelt sich um eine von den Ausschüssen eingeführte Ubung, die im Widerspruch zur Geschäftsordnung steht.

21) G. Gali c h o n in Travail Parlementaire S. 145. 
Ganz so sensibel ist man nicht überall. Unter den Fraktionen des Bundestages hat es sich eingebürgert, die in Ausschüssen anstehenden Fragen vorher in Arbeitsgemeinschaften zu behandeln, um den Fraktionsmitgliedern schon eine bestimmte Marschroute mitgeben zu können. Dagegen ist an sich nichts einzuwenden. In England bestanden vor der Bildung der Fachausschüsse überhaupt nur derartige Arbeitsgemeinschaften der Fraktionen. Aber wenn $\mathrm{zu}$ diesen Sitzungen Beamte hinzugezogen werden und den Abgeordneten schon vor der Ausschußsitzung ihre Gesichtspunkte darlegen, wird die Diskussion dort leicht ihrer Unmittelbarkeit beraubt.

Es war hier nötig, auf die Ausschußfragen näher einzugehen, da der Ausschuß im modernen Parlament der Ort ist, an dem die engste Berührung mit der Regierung stattfindet. Die Ausgestaltung der Ausschüsse ist m. E. - und dabei befinde ich mich nicht in Utbereinstimmung mit Herrn F r i e s e n h a h $\mathbf{~}^{22}$ ) - keine bloße Frage der Arbeitstechnik, sondern hat darüber hinausgehende verfassungspolitische Bedeutung.

Das Studium der parlamentarischen Kommissionen wird nicht zu Unrecht mit der Prüfung der Beziehungen der Legislative zur Exekutive und gar der Wirksamkeit der Demokratie identifiziert ${ }^{28}$ ). Es kann nicht gleichgültig sein, welche Vertreter der beiden Verfassungsorgane sich diort begegnen. Unter den Parlamentariern gibt es sicher mehr oder weniger Prominente, aber schon die parlamentarischen Handbücher lehren, daß die Prominenten unter ihnen den Ausschuß als das lohnendste Betätigungsfeld ansehen und manch einer von ihnen hat sich durch seine Arbeit in ihnen Ansehen und Einfluß erworben. Die Ausschüsse können die Anwesenheit jedes Mitgliedes der Regierung verlangen. Es gehört zu den typischen Situationen, daß Ausschußsitzungen mit der Beanstandung beginnen, warum der Minister oder sein Stellvertreter nicht persönlich anwesend seien, sondern an ihrer Stelle nur ein untergeordneter Beamter. Ich möchte auf das Problem der Vertretung der Regierung im Parlament am Schluß noch einmal zurückkommen und diesen Problem-Kreis jetzt mit einer Frage abschließen, die ich im Juni einen prominenten Ausschußvorsitzenden in Bonn an einen Ministerialbeamten richten hörte:

„Was werden Ihre Oberregierungsräte tun, wenn wir in die Ferien gegangen sind und Sie sie nicht mehr zu uns in die Ausschüsse schicken können?"

22) S. O.S. 32, 67 .

29) M. J. Ga s c on y M a r in: Le rôle des commissions parlementaires, Paris 1932 S. 1. 
bb) Die Notwendigkeit, das Parlament mit eigenem Sachverstand auszurüsten, ist vor allem in den Vereinigten Staaten empfunden worden, wo das Initiativrecht verfassungsmäßig ausschließlich beim Parlament liegt, sich aber der Mißstand eingeschlichen hatte, daß ein großer Teil der Vorlagen parakonstitutionell in den Amtern der Exekutive vorbereitet wurde. Um diesem Mißstande zu steuern, sind die Hilfseinrichtungen des Kongresses durch den Legislative Reorganization Act von 1946'4) wesentlich verstärkt worden. Vier Maßnahmen wurden getroffen, die in engem Zusammenhang standen: der einzelne Abgeondnete erhielt ein eigenes Büro, damit seine Arbeitskraft erhöht werde ${ }^{25}$ ), die Ausschußstäbe wurden erheblich verstärkt ${ }^{26}$ ), ein Stab von Gesetzgebungstechnikern wurde geschaffen und schließlich als ergänzende Maßnahme der Gesetzgebungshilfsdienst, eine parlamentarische Gegenbürokratie zur Erschließung des gedruckt vorliegenden Materials. Die eigenen Büros und der Stab der Gesetzgebungstechniker werfen keine besonderen Probleme auf. Das Büro arbeitet ganz nach den Weisungen der Abgeordneten, die Legislative Counsellors vollbringen eine objektiven Gesichtspunkten zugängliche Arbeit. Das soll freilich nicht heißen, diese Maßnahmen seien nicht wichtig gewesen. Für die praktische Arbeit stehen sie sogar im Vondergrund. Die Erfahrungen mit den Ausschußstäben waren nicht ermutigend ${ }^{27}$ ). Sie wurden einer parlamentarischen Einrichtung zugeteilt, in der politische Auseinandersetzungen stattfinden, d. h. wo gekämpft

24) v. 2. 8. 1946 , ch 753 , title II, $\S 203$ (a, b), 60 Stat. 836 ; die wesentlichen Bestimmungen sind wiedergegeben in U.S.Code (1946 ed.) Bd. I tit. 2.

Dazu G. B. Gollow a : The Operation of the Legislative Reorganization Act of 1946, American Political Science Review Bd. 45 (1945); S. 49 ff.; $M$ a x M. K a m p e l m a n : The legislative bureaucracy: its response to political change, The Journal of Politics Bd. 16 (1954) S. $539-550$.

25) Jeder Senator erhielt die Mittel zur Bezahlung eines hochqualifizierten wissenschaftlichen Assistenten, jedes Mitglied des Hauses 9500 Dollar für Bürokräfte. Es kann nicht völlig verhindert werden, daß diese Mittel bestimmungswidrig zur Unterstützung von Familienangehörigen oder persönlichen Freunden benützt werden; bei der starken Kontrolle der Offentlichkeit über die Verwendung von Staatsmitteln in den Vereinigten Staaten bedeutet ein Mißbrauch jedoch eine nicht unerhebliche Gefährdung der Wiederwahl.

20) Jeder Ständige Ausschuß erhielt bis zu 4 wissenschaftlich vorgebildeten Assistenten und 6 Bürokräften.

27) M. M. K a m pel ma $\mathrm{n}$ am a. O. S. $547 \mathrm{ff}$. insbes. 550: „It is expecting far too much to expect a professional staff member to work on behalf of contradicting policies and thus suit his facts to the change of political climate." 
wird. Daher wurde sie von vornherein politisch besetzt: Drei Sekretäre der Mehrheit und einer der Minderheit und beim Wechsel der Mehnheit und daher des Ausschußvorsitzes müssen sie ausgewechselt werden. Die für die fachliche Arbeit geschaffene Institution wunde in den politischen Kampf hineingezogen und damit wurde ihre Fähigkeit, fachlich $2 u$ beraten, beeinträchtigt.

Die Bedeutung des Gesetzgebungshilfsdienstes, über den es eine umfangreiche von seinen Mitgliedern verfaßte Literatur ${ }^{28}$ ) gibt, und der zu einem major sight seeing topic für AmerikaReisende geworden ist, wind $\mathrm{m}$. E. erheblich überschätzt. Er ist politisch unschädlich, da er selbst keine Gesetzentwürfe abfassen $\operatorname{darf}^{29}$ ), sondern Material zusammenträgt und weil sein Benutzerkreis sich vorwiegend aus den rund $1000 \mathrm{Ab}-$ geordnetensekretären, Gesetzgebrungstechnikern und Ausschußschußassistenten - also Fachleuten - rekrutiert, denen auch andere Informationsquellen in Regierungsämtern, Verbandsbüros, Pressearchiven und wissenschaftlichen Spezialinstituten zugänglich sind. Der Dienst verfügt daher über kein Informationsmonopol und dadurch ist der Gefahr vorgebeugt, daß er selbst Politik zu machen beginnt. Eine Untersuchung darüber, ob diese vier amerikanischen Maßnahmen ihr Ziel erreicht haben, die Abgeordneten in den Stand zu setzen, ihre Gesetzgebungsanträge selbst auszuarbeiten und die illegale Konkurrenz der Regierungsämter auszuschalten, ist mir bisher nicht bekannt geworden.

In Europa hat der Deutsche Bundestag die Hilfseinrichtungen des Parlaments am stärksten entwickelt. Zwar sind nur einzelne begüterte Abgeordnete in der Lage, sich einen eigenen Sekretär zu leisten ${ }^{30}$ ), doch haben nun wenigstens die Fraktionen einige Assistenten, die aus Mitteln des Bundes-

28) W. Brook Graves: The Legislative Reference Service, American Political Science Review Bd. 41 (1947) S. 289-93; G. B. Galloway: The legislative reference service of Congress, Parliamentary Affairs Bd. 8 (1955) S. 261-65; derselbe: The legislative process in Congress New-York 1953 S. 407-425. W. C. Gilbert: The Legislative Reference Service - a brief sketch, The Libary of Congress, Washington 1952 (vervielfältigt).

29) Vgl. den Auftrag in Section 203 des Legislative Reorganisation Act 1946 aaO.; a. A. W. C. Gilbert: aaO. S. 12, der eine subsidiäre Kompetenz zur Abfassung von Gesetzesentwürfen behauptet, soweit der Stab der Gesetzgebungstechniker nicht zur Verfügung stehe, so z. B. für Einzelmitglieder des Parlaments.

30) In einigen Fällen sollen auch Industriewerke einzelnen $A b-$ geordneten Nachwuchskräfte zur Verfügung gestellt haben, damit die künftigen Auftraggeber der Lobby das Haus kennenlernen, an das sich ihre Wünsche später richten werden. 
tages besoldet werden $\left.{ }^{31}\right)$. Bei den großen Fraktionen sind es 6 oder 7, was kaum ausreicht, zumal sie teilweise auch die Aufgabe der Gesetzgebungstechnilker verrichten. Zwei bis drei Ausschüssen ist je ein Sekretär zugeteilt. Das ist wenig, hat aber den Vorteil, daß der Sekretär so viel zu tun hat, daß er nicht dazu kommt, selbst Politik zu machen, sondern daran denken muß, objektiv zu arbeiten, um seinen Posten auch bei einem Wechsel des Ausschußvorsitzenden zu behalten. Sogar in hochpolitischen Ausschüssen ist das gelungen. Die Bibliothek des Bundestages ist nicht nur sehr reichhaltig, sondern auch durch vorzügliche Sachkataloge erschlossen ${ }^{32}$ ). Utber eine Gegenbürokratie gegen die der Bundesregierung verfügt zwar nicht der Bundestag, aber doch dank seiner Konstruktion immerhin der Bundesrat: nach Schätzungen arbeitet ein Drittel der Ministerialbürokratie der Länder für den Bundesrat und leistet dabei fachlich sehr nützliche Arbeit. Es scheinen mir hingegen gewichtige Gründe gegen eíne Nachahmung des amerikanischen Modells des Hilfsdienstes zu sprechen $^{93}$ ).

31) Sie werden aus den Zuschüssen des Bundestages an die Fraktionen besoldet. Für diesen $Z$ weck waren im Haushalt des Bundestages für 1956 DM 1008000 , - ausgeworfen (Bundeshaushaltsplan 1956 Einzelplan 0201 Titel 301).

32) K. G. We rn i cke : Wie die wissenschaftliche Abteilung (des Bundestages) entstanden ist und heute aussieht. Das Parlament Nr. 51 vom 15. 12. 1954: „Neuerdings taucht sogar schon die Forderung nach Ausarbeitung von Gesetzentwürfen auf“.

ss) Befürwortet wird sie von dem Abgeordneten Mom mer in einem Referat über die Einrichtungen der amerikanischen Legislative vom 9. 1. 1950 (Anlage zum Protokoll Nr.9 des Organisationsausschusses des Deutschen Bundestages - in der Bibliothek des Bundestages zugänglich); ferner W. A pe $1 \mathrm{t}$ : Die Gesetzgebungtechnik, 1950 (dazu meine Besprechung JZ 1951 S. 574); Th. Eschenburg: Verfassung und Verwaltungsaufbau des Südweststaates, $1956 \mathrm{~S}$. 56; K. K l e i $\mathrm{n}$ a h m : Gesetzgebungshilfsdienst für deutsche Parlamente? AöR Bd. 79 (1953/54) S. 137-157; dagegen W. H e n le : Das parlamentarische Gesetzgebungsbüro, DOV 1950 S. 14; U. S c h e u n e r auf der Kölner Tagung der Gesellschaft für Rechtsvergleichung (JZ 1951 S. 701) aus grundsätzlichen Erwägungen, da die Einrichtung nicht in ein parlamentarisches Regierungssystem passe. M. E. ist die Ausrüstung des Parlaments mit dem nötigen Sachverstand - und zwar außerhalb des Regierungsapparates - ein Problem, das auch bei den deutschen und anderen parlamentarischen Regierungssystemen Beachtung verdient. Vgl. auch den Vorschlag von B. Mosheim: Der Parlamentsanwalt JZ 1954 S. 685, nach englischem Muster den freien Parlamentsanwalt einzuführen. Dieser Vorschlag paßt in das deutsche Verfassungssystem zweifellos besser als eine parlamentarische Gegenbürokratie. Es scheint wir jedoch eine Illusion zu sein, daB sich die Interessenverbände des Parlamentsanwalts bedienen würden, anstatt die Referenten in den Ministerien zu beeinflussen. Die wesentliche Voraussetzung, daB ein Bürger - und damit auch eine Inter- 
Wollte man auch nur jedem Referat der Ministerialbürokratie einen einzigen Fachmann gegenüber stellen, so brauchte man deren 1000. Ein Benutzerkreis von Fachleuten wie in den Vereinigten Staaten besteht nicht, entscheidend scheint mir aber zu sein, daß die Exekutive in Deutschland eine so starke Anziehungskraft auf alle noch nicht bei ihr beschäftigten Fachleute ausiubt, daß kaum zu erwarten ist, eine parlamentarische Gegenbürokratie werde ihr gegenüber die notwendige Unabhängigkeit gewinnen, um eine Gegengewichtsfunktion erfüllen zu können.

Was bei uns fehlt, ist ein Organ für die verfassungsrechtliche Prüfung derGesetzesentwürfe nach objektiven Maßstäben, wie es die romanischen Länder in ihrem Staatsrat, die Vereinigten Staaten in den Gesetzgebungstechnikern besitzen. Diese Arbeit wird stattdessen von den Parlamentariern selbst in Rechtsausschüssen geleistet. Es ist nicht zu vermeiden, daß dabei politische Meinungsverschiedenheiten in der Form verfassungsrechtlicher Auseinandersetzungen ausgetragen wenden. Damit soll keine Kritik an diesen Ausschüssen und ihren Mitgliedern geübt werden, die häufig ein erstaunliches $\mathrm{Maß}$ an Objektivität gezeigt haben, sondern an der Aufgabenstellung: ein zum parlamentarischen Kampf ibestimmtes Organ ist nicht für eine Arbeit geeignet, die sich ausschließlich nach objektiven Gesichtspunikten vollziehen muß.

Es dürfte bei uns bisher auch noch keine rechte Form dafür gefunden worden sein, den außerhalb von Parlament und Bürokratie vorhandenen unabhängigen und interessengebundenen Sachverstand für die Gesetzgebungsarbeit zu nutzen. Gewi $\beta$ haben das Parlament und die Regierung eine Reihe von Sachverständigenausschüssen für verschiedene Aufgaben eingesetzt $\left.{ }^{34}\right)$. Der Bundestag gab im Jahre 1956 jedoch ganze $10000,-$ DM für die Arbeiten unablhängiger Sachverständiger aus ${ }^{33}$ ); selbst wenn man berücksichtigt, daß ihm alle beamteten Sachverständigen auf Kosten ihrer Dienstherren zur Verfüigung stehen, ist diese Summe erschreckend niedrig. Von der Möglichkeit, Sachverständige und Interessenvertreter in

essentengruppe - das Wort vor einem Parlamentsorgan von sich aus verlangen kann, ist im deutschen Parlament bisher nicht gegeben.

34) Folgende Arbeitsergebnisse liegen gedruckt vor: Die Neugliederung des Bundesgebietes. Gutachten des von der Bundesregierung eingesetzten Sachverständigenausschusses hrsg. vom Bundesminister des Inneren, 1955 sowie Rechtliche Ordnung des Parteiwesens. Probleme eines Parteiengesetzes, 1957.

s5) Bundeshaushaltsplan 1956 - Einzelplan 0201 Titel 218. 
öffentlichen Informationssitzungen ${ }^{36}$ ) anzulhören, wurde kaum Gebrauch gemacht. Anstattdessen wenden die Interessenvertreter seitens der Exekutive in einer Form angehört, welche eine Willkür des sachbearbeitenden Beamten keineswegs ausschließt. Die einzige Garantie für eine gleichmäßige und gerechte Anhörung liegt in der Erwartung, daß sich unerfüllte Interessentenwünsche bei der nachfolgenden Behandlung im Bundestage zu Worte melden werden.

Richtig ist, daß dort kanalisiert werden muß, wo ungeregelte Ströme fließen. Wo die Labby sich stärker an die Exekutive als an das Parlament wendet, hat es keinen Sinn, die Lobby erst im Parlament zu kanalisieren. Darin mag eine Antwort darauf gefunden wenden, warum die thernahme des amerikanischen Vorbildes der Hearings mißlang. Aber dann muß in einem früheren Stadium des Verfahrens eine Form für die Anhörung der Interessenten gefunden werden, welche die damit verbundenen Gefahren ausschließt.

In der Schweiz ${ }^{37}$ ) wird dasselbe, was in den Vereinigten Staaten bei den Hearings geschieht, auf der Regierungsebene durchgeführt; der Bundesrat hat ohne eine besondere gesetzliche Grundlage die Praxis eingeführt, bei wirtschaftlich und sozial bedeutungsvollen Vorlagen eine Kommission aus Angehörigen der beiden Räte, Vertretern der beteiligten Interessengruppen, unabhängigen Sachverständigen und Beamten zur Vorberatung des Departementsentwurfs einzusetzen. Das Departement kann aber vor der Einbringung beim Parlament zu den Ergebnissen der Arbeiten der Kommission Stellung nehmen. Durch dieses Verfahren wind die Interessentenkonsultation institutionalisiert und in geregelte Bahnen geleitet.

cc) Während sowohl die Arbeitsteilung in den Ausschüssen wie auch die Heranführung fremden Sachverstandes die Arbeitsfähigkeit des Parlaments steigern sollen, um den höheren Anforderungen gerecht zu werden, ist in vielen Staaten versucht worden, das Parlament dadurch zu entlasten, daß ihm zufallende Aufgaben auf andere Verfassungsorgane abge-

36) Gem. \$ 73 Abs. 2 BT-GO. Dort ist offen gelassen, unter welchen Voraussetzungen die zugelassenen Personen in der Sitzung das Wort ergreifen können und wer darüber entscheidet. Im Kongreß der Vereinigten Staaten ist mit dem Antrag auf Anhörung ein kurzes Exposé vorzulegen, auf Grund dessen über die Zulassung entschieden wird.

37) Kurt Eichenberger: Die oberste Gewalt im Bunde. Berner Dissertation 1949 S. 141 f.; d e r s. : Rechtssetzungsverfahren und -formen in der Schweiz (Verhandlungen des schweizerischen Juristenvereins 1954), Ztschr. f. Schweiz. Recht Bd. 73 (1954) S. 54 a bis $61 \mathrm{a}$. 
schoben wurden, oder daß das Parlament es duldete, daß andere Verfassungsorgane sich ihrer bemächtigten.

Das geschieht in verschiedenen Formen. Je nach der Ausprägung des Grundsatzes der Gewaltenteilung, je nach dem Maße von Gesetzes-positivismus, aber auch je nach den Mehrheitsverhältnissen im Parlament und der davon abhängigen Bewegungsfreiheit der Regierung. Der häufigste Fall ist die Ermächtigung des Parlaments an die Regierung, an seiner Stelle Recht zu setzen ${ }^{38}$ ). Die Regierung kann aber auch ohne Ermächtigung einen eigenen Bereich der Regelungsbefugnis in Anspruch nehmen und diesen mit Duldung des Parlamentes auch in Bereiche ausdehnen, die dem Parlament vorbehalten sind. Im Ergebnis kann dasselbe erreicht werden, wenn der Gesetzgeber sich auf die Festlegung allgemeiner Grundsätze beschränkt, in deren Rahmen sich die Exekutive frei bewegen kann.

In einem Staat ohne Gewaltenteilung ist die Lage einfach. Da kann das Parlament alles und daher auch seine Gesetzgebungsgewalt übertragen Das "Government by decree" ist in der Tat in Großibritannien sehr entwickel ${ }^{30}$ ).

Wo aber die Gesetzgebung verfassungsmäßig dem Parlament vorbehalten und deswegen auch als unübertragbar angesehen wird, da bleibt nichts übrig - wenn man das Prinzip als solches nicht preiszugeben bereit ist - als den Begriff des Gesetzes zu "durchlöchern" und aus ihm herauszuschneiden, was man eben auf anderem Wege geregelt zu sehen wünscht.

Die französische Entwicklung in den letzten 75 Jahren bietet ein warnendes Beispiel dafür, was juristische Kunst auf diesem Gebiete vermag. Trotz des Delegationsverbotes in der Verfassung gelang es der französischen Praxis und Doktrin auf dem Umwege über die Aufweichung des Gesetzesbegriffes so wichtige Zuständigkkeiten wie die Arbeitsweise, Finanzierung und Kontrolle der Sozialversicherung, die Preiskontrolle und Wirtschaftslenkung, die Ausnutzung der Energie, die Aufteilung der Rohstoffe und Fertigfabrikate und vieles andere aus

38) Vergl. Institut zur Förderung öffentlicher Angelegenheiten: Die Ubertragung rechtsetzender Gewalt im Rechtsstaat, 1952, mit den Berichten und Referaten von F. Klein und U. Sche uner, sowie den Vorberichten über die Verhältnisse in den Vereinigten Staaten, Großbritannien, Frankreich, Belgien, Luxemburg, der Schweiz und Italien mit eingehenden Literaturangaben (zitiert als „Ubertragung“).

39) H. K. J. R i d d e r : tbertragung S. 295-324 und die dort angegebene Literatur, insbes. Marguerite A. Sieghart: Government by Decree 1950; H. M orris on aaO. S. $196 \mathrm{ff}$.; Report from the select committee on delegated legislation ... printed 27. 10. 1953 London HMSO 1954. 
der Zuständigkeit des Gesetzgebers herauszubrechen und der Regelungsbefugnis der Regierung zuzuweisen ${ }^{40}$ ).

In Deutschland als einem der ganz wenigen Länder ist die Lage anders. Das Grundgesetz hat die Bundesregierung nur sehr engherzig mit Verordnungsrechten ausgestattet ${ }^{41}$ ); der Bundestag ist geizig mit Ermächtigungen und die Regierung zurückhaltend dabei sie zu verlangen. Während in England und Frankreich die nicht vorm Parlament gesetzten Normen ein Vielfaches der Gesetze ausmachen, übersteigen sie in der Bundesrepublik sowohl der Zahl wie dem Umfange nach die Gesetze nur um ein Geringes ${ }^{42}$ ). Parlamentarier und Regierungsmitglieder weisen gerne auf dieses Verhältnis hin ${ }^{43}$ ), ein Ergebnis des noch nachwirkenden Schocks auf das Ermächtigungsgesetz von 1933, das aber wohl kaum zu erreichen gewesen wäre, wenn in den beiden ersten Bundestagen nicht klare und eindeutige Mehrheitsverhältnisse es der Regierung erlaubt hätten, die ihr wesentlichen Gesetzesvorhaben durchzubringen. Freilich mußten dafür auch einige Nachteile in Kauf genommen werden: eine unsinnige Arbeitsüberlastung der Parlamentarier und eine unwürdige tiberlastung der Gesetzgebung mit Details.

Auch in Deutschland sind Stimmen laut geworden, welche eine Revision des überholten Gesetzesbegriffes des gewaltenteilenden Rechtsstaates anregen und vorschlagen, dem Parlament nur die Normensetzung vorzubehalten, die auf die Dauer bestimmt und geeignet ist, in das Rechtsbewußtsein der Bevölkerung einzugehen ${ }^{44}$ ). Es wird dabei daran gedacht, einen großen Teil der weitgehend technischen Steuer-, Zoll-, Wirtschaft- und Sozialgesetzgebung aus der Zuständigkeit des Parlaments auszuscheiden und der Regierung zu überlassen. Auf diesem Wege hätten z. B. etwa dreiviertel der im Jahre 1956 verabschiedeten Gesetze in einem sehr vereinfachten Verfahren verabschiedet werden können. Die Anregungen lassen

40) H. B a ll r e i c $h$ : Ubertragung S. 329 ff. und 338 ff.; G. G a $1 \mathrm{ich}$ on in Travail Parlementaire S. 134 ff.; zur Problematik auch W. J. Gansh of van der Meers $\mathrm{ch}$ in Aspects S. 133.

11) F. K 1 e i n : Ubertragung S. $28 \mathrm{ff}$., insbes. S. $48 \mathrm{ff}$.

42) Man vergleiche die Bundesgesetzblätter der letzten Jahre. Auch wenn man die im Bundesanzeiger veröffentlichten Rechtsverordnungen hinzunimmt, ändert sich das Bild nicht wesentlich.

43) u. a. W a lter Stra us : Ubertragung S. 2.

14) H. J a hrreis : Herrschaft nach dem Maß des Menschen, 1951, S. 224 f.; U. S c h e u n e r : Ubertragung S. 142 f.; H. S c h n e i der: Kabinettsfrage und Gesetzgebungsnotstand nach dem Bonner Grundgesetz VVDStRL Bd. 8 (1950) S. 52; H. Pete r s : Der Kampf um den Verwaltungsstaat, Festschrift für Laforet 1952 S. 19 insbes. S. $23 \mathrm{ff}$. 
aber unberücksichtigt, daß in der modernen Gesellschaft die Wirtschafts- und Sozialgesetzgebung den stärksten Widerhall bei der breiten Bevölkerung findet und deshalb auch am intensivsten von ihrem Rechtsbewußtsein umfaßt wird. Neben den Zehn Geboten ist die Lohnsteuertabelle das populärste Dokument und es darf auch nicht vergessen werden, daß historisch das Steuerbewilligungsrecht an der Wiege des modernen Parlamentarismus gestanden hat. Die soziologischen Faktoren sprechen genadezu dagegen, den Gesetzesbegriff historisierend zurückzubilden. Praktisch ist der Reformvorschlag nur durchführbar, wenn es gelingt, zwischen Parlament und Regierung ein sehr viel engeres Vertrauensverhältnis herzustellen als es bisher besteht.

Das schließt freilich nicht aus, für die weitgehend technischen Materien de lege ferenda ein Verfahren zu befürworten, welches ihren Besonderheiten Rechnung trägt und dennoch die letzte Entscheidung bei dem Parlament beläßt. Es ist im Rahmen dieses Referates nicht möglich, die verschiedenen Formen der parlamentarischen Kontrolle über die von Regierungen erlassenen Verordnungen ${ }^{45}$ ) zu würdigen. Ich kann mich jedoch des Eindrucks nicht erwehren, daß die deutschen Urteile über die Wirksamkeit dieser Kontrollen in GroBbritannien übermäßig kritisch sind. Während W a lte r Stra uss ${ }^{46}$ ) die parlamentarische Kontrolle in England als völlig leerlaufend bezeichnet, lautet das Urteil von $\mathrm{H}$ e ribert $\mathrm{M}$ or r is on ${ }^{47}$ ) über die Praxis der dafür im Unterhaus eingesetzten Ausschüsse wesentlich günstiger.

Aus der englischen Erfahrung läßt sich aber wohl die Lehre ziehen, daß das Parlament die Regierung nur dann dazu er-

45) Für die Bundesrepublik Deutschland F. Kle in: Ubertragung S. 91; zum ausländischen Recht U. S c h e u n e r : aaO. S. 152 und die Vorberichte von W. K. Geck (USA) aaO. S. 287; H. J. $\mathrm{R}$ id der (Großbritannien) aaO. S. 311; H. B a $11 \mathrm{re} \mathrm{i} \mathrm{c} \mathrm{h} \mathrm{(Frank-}$ reich) aaO. S. 345; P. S chneider (Schweiz) aaO. S. 395; G. B e t t o n i (Italien) aaO. S. 416; der von D ö r r aaO. S. 294 ff. erstattete Bericht über die Beratungen der insbs. mit der Prüfung des Problems der parlamentarischen Kontrolle der delegierten Gesetzgebung beauftragten zweiten Arbeitsgruppe zeigt, daß über diese Frage nicht nur die stärksten Meinungsverschiedenheiten vorliegen, sondern daß auch die Problematik noch der Klärung bedarf.

46) Ubertragung S. 3; vergl. auch $H$. J. Ridder: aaO. S. 324 unter 6.

47) AaO. S. 197: „Grundsätzlich halte ich deshalb das Verfahren der delegierten Gesetzgebung für richtig, doch möchte ich gleichzeitig betonen, daß das Parlament den Gebrauch, der davon gemacht wird, in all seinen Phasen aufmerksam, ja sogar eifersüchtig überwachen muß." S. 201: „Der AusschuB (für delegierte Gesetzgebung) hat ausgezeichnet gearbeitet. “ 
mächtigen kann, an seiner Stelle Recht zu setzen, ahne wesentlich an Macht einzubüßen, wenn zur Kontrolle Parlamentsorgane eingesetzt werden, die gezwungen sind, sich positiv oder negativ zu den Regierungsverordnungen zu äußern und durch intensive Beschäftigung mit den Materien in die Lage versetzt werden, ihre Kontrolle effektiv zu gestalten. Eine Arbeitsersparnis gegenüber der eigenen Gesetzgebung durch das Parlament tritt nur insofern ein, als diese Kontrolle einem Ausschuß anvertraut werden kann und die eigene Gestaltungsund Formulierungsarbeit des Kontrollorgans, das nur ja oder nein sagen kann, fortfällt' ${ }^{48}$ ).

\section{Das Problem der Zeit}

In welchem Sinne das Zeitproblem hier verstanden wird, ist schon oben angedeutet wonden: alles soll schneller gehen als in der guten alten Zeit.

a) In der Maschinerie der Regierung einschließlich der Ministerialbürokratie hat der Zeitdruck zu zahlreichen organisatorischen und technischen Verbesserungen Anla $B$ gegeben, um Entscheidungen schneller herbeizuführen, Informationen schneller durchzugeben und das Material rascher von einem Schreibtisch zum anderen zirkulieren zu lassen. Dazu gehört die Technik der Besprechungen auf den verschiedenen Ebenen, sei es des Kabinetts oder der Staatssekretäre der verschiedenen Ministerien, sei es der Abteilungsleiter oder auch der Referenten innerhalb eines Hauses, die Regeln übber die Unterschriftsleistung und die bürotechnische Organisation. Unter dem Druck der Zeitnot hat sich eine Wandlung des Arbeitsrhythmus vollzogen. Während früher von der Ełbene des Referenten, von dem die wesentliche Gedanikenarbeit zu leisten ist, nach oben gearbeitet wurde und auf den über ihm liegenden Ebenen nur eine Koordination seiner Arbeit mit der anderer Referenten oder Abteilungen stattfand, macht sich nun ein Zug geltend, Entscheidungen weiter nach oben zu verlagern. Häufig wird nicht mehr von unten nach uben, sondern von oben nach unten gearbeitet, was in mancher Hinsicht nachteilig ist. Der Mann, der eigentlich Zeit haben sollte zum Uberlegen, $d . h$. der Referent, muß gehetzt nach engen Anweisungen arbeiten

48) U. S c h e u n er: aaO. S. 155; seine Bemerkung, die geringe Wirksamkeit der nachträglichen Kontrolle in Groß-Britannien dürfe in erster Linie darauf zurückzuführen sein, daß das britische Unterhaus als einziges Parlament noch nicht den Weg einer Auflösung in Ausschüsse angetreten habe, dürfte wohl nur für die Zeit bis 1945 gelten. Er selbst hat die Arbeit des 1944 eingesetzten Select committee lobend erwähnt. Vergl. auch die in Anm. 47 wiedergegebenen Urteile von $H$. Morrison. 
und das Ergebnis seiner Arbeit staut sich dann mit denen vieler anderer an gewissen Engpässen, die man in der Bürokratensprache Flaschenhälse nennt. Wird der Druck an dem Flaschenhals zu stark, dann holt man sich von außen einen Kommissar, d. $h$. einen nicht in den tberlieferungen des Beamtentums stehenden energischen Mann mit Sondervollmachten, um den Weg durch den Flaschenhals zu öffnen. Wenn die Regierung ein zeitlich festgelegtes Gesetzgebungsprogramm hat, ist dieser Ubelstand zu vermeiden. In einigen Staaten wird ein derartiges Programm beim Antritt einer neuen Regierung verkündet. Die französischen Ministerpräsidenten pflegen es in ihrer Investiturrede zu unterbreiten und die englischen politischen Parteien warten damit sogar schon bei den Wahlen, in denen sie sich um die Regierungsgewalt bewerben, auf. Auch in der Bundesrepublik finden sich in den allgemeinen Regierungserklärungen, welche von Zeit zu Zeit abgegeben werden, gewisse Ansätze zur Entwicklung eines Gesetzgebungsprogrammes, es fehlt allerdings eine zeitliche Festlegung; die Gesetzesvorlagen werden in der Regel dem Parlament zugeleitet, wenn die Ministerien damit fentig geworden sind und das Kabinett zu diesem Zeitpunkt keine Bedenken hat, sie dem Parlament weiterzuleiten. Durch eine sorgfältige Vorausplanung ließe sich zweifellos die Zeit besser ausnützen. Es handelt sich hier aber um eine reine Frage der Arbeitsökonomie, die im wesentlichen innerhalb des Bereiches der Regierung entschieden wird.

b) Im Parlament ist die Frage der Herrschaft über die Zeit sehr viel komplizierter gelagert. Einerseits bestehen Ordnungsnormen übber den Arbeitsrhythmus. Sie betreffen in erster Linie die Zahl der Lesungen. Unsere Geschäftsordnung ${ }^{49}$ ) hält an der Regel von drei Lesungen fest, von denen die erste der Entscheidung gewidmet ist, ab das Parlament sich überhaupt mit der Aufgabe befassen soll. Davon war schon vorher die Rede. In der 2. Lesung wird die Ausschußarbeit sanktioniert, während die dritte dem Plenum nur eine Uberlegungsfrist gewähren soll, ehe es eine Ausschußvorlage ändert. Die drei Lesungen dürfen von der Verteilung der Drucksache ab im Laufe einer Woche absolviert wenden. Diese Frist kann schon von der einfachen Mehrheit ${ }^{\text {s0 }}$ ) auf drei bis fünf Tage, von der Zweidrittel-Mehrheit ${ }^{31}$ ) sogar auf $2-4$ Tage verkürzt werden. Wenn keine 5 Abgeordneten widersprechen, können sogar alle drei Lesungen an einem Tage stattfinden ${ }^{52}$ ). Die Mindestzeit,

49) $\$ 77$ (1).

50) 1. Beratung $\$ 77$ (2), 2. Beratung $\$ 80$ (1), 3. Beratung $\S 85$ (1); Verkürzung mit einfacher Mehrheit \$93.

51) $\$ 77$ (2) Satz 2.

52) 893 (2). 
welche sich das Parlament zur Ubberlegung vorbehält, ist also sehr kurz und man kann ohne Utbertreibung sagen, daß die dritte Lesung eigentlich schon falkultativ geworden ist. Im zeitlichen Abstand von der zweiten Lesung findet sie nur dann statt, wenn in dieser etwas an der Vorlage geändert wurde und auch wenn das geschah, kann sie unmittelbar an die zweite Lesung angeschlossen wenden, so lange nicht 10 Abgeordnete widersprechen ${ }^{5 s}$ ). Die letzten Sitzungen des zweiten Bundestages lehrten, welch gewaltigen Stoff das Parlament durchpeitschen kann, wenn die Zeit drängt.

Im deutschen Bundestag ist zwar eine Grundlage für schnelles Handeln geschaffen, sind aber keine genügenden Vorkehrungen getroffen, um zu verhindern, daß Vorlagen und Anträge im Parlament - vor allem in den Ausschüssen - versacken. Es gibt keine Bestimmung, wie in dem Règlement der französischen Assemblée ${ }^{54}$ ), daß sich Ausschüsse nicht länger als drei Monate mit einer Sache befassen dürfen und danach ihre Beratung im Plenum verlangt werden kann. Das dürfte keine zufällige Unterlassung, sondern absichtlich geschehen sein, um nicht jedem Inhaber des Initiativrechtes - also auch der Regierung - ein Interventionsrecht gewähren und damit an der Herrschaft über die Zeit beteiligen zu müssen.

Individuell wind diese Hernschaft ausgeübt durch Aufstellung der Tagesordnung und Interventionen im Fall der Verzögenung der Arbeit. Dafür gibt es ganz verschiedene Systeme. In Großbritannien, wo die Regierung die Parlamentsarbeiten leitet, setzt sie auch die Tagesordnung fest und hat durch das sogenannte Guillotine-Verfahren ein ganz massives Mittel in der Hand, um das Parlament zur Erledigung der ihm gestellten Aufgaben anzuhalten ${ }^{55}$ ). Ähnliches gilt auch für die Schweiz trotz ihres strengen Systems der Gewaltenteilung. Hingegen ist die Festsetzung der Tagesordnung nicht nur in den Vereinigten Staaten eine Aufgabe des Parlaments, die dort durch das Rules-Committee ausgeübt wind, sondern auch in den kontinental-europäischen Parlamenten; bei uns in einer sehr behutsamen Form, indem der Ältestenrat eine Verständigung herbeiführt, welche zwar meist befolgt, formell aber erst durch Plenarbeschluß verbindlich wird. Auf den Ältestenrat hat die Regierung nach dem geschriebenen Recht keinen unmittelbaren Einfluß, was natürlich nicht ausschließt, daß der Bundeskanzler den Bundestagspräsidenten oder auch die Ver-

53) $\$ 93$ in Verbindung mit $\$ 85$.

34) Art 35 (2) in Verbindung mit Art. 29 (3).

s5) H. Morris on : aaO. S. 325 und die S. 447 im Anhang B gegebenen praktischen Beispiele für das Guillotine-Verfahren. 
treter der Koalitionsparteien im Ältestenrat zu einem väterlichen Gespräch einlädt. In Frankreich ist hingegen der Regierung in dem die Tagesondnung festsetzenden Rat der Präsidenten zunächst Sitz und dann auch Stimme eingeräumt worden $^{58}$ ). Das Gremium hat eine eigenartige Struktur. Neben dem Kammerpräsidenten und den 6 Vizepräsidenten stimmen die 19 Ausschußvorsitzenden und alle Fraktionsvorsitzenden mit einem Regierungsvertreter über die Tagesordnung ab. Die Fraktionsvorsitzenden haben dabei so viel Stimmen, wie ihre Fraktionen Mitglieder haben und der Regierungsvertreter so viele Stimmen, wie Parlamentsmitglieder der Regierung angehören.

Die Regiemung wird also innerhalb eines Parlamentsorgans auf dieselbe Stufe wie ein Fraktion gestellt und in ähnlicher Weise steht sie den Parlamentsausschüssen gegenüber, wenn es sich darum handelt, eine dringende Abstimmung herbeizuführen ${ }^{57}$ ). Sie ist dem Plenum als Schiedsrichter unterworfen, wenn sie sich mit dem zuständigen Ausschuß nicht einigen kann. Ich kann auf diese eigenartige Stellung der Regierung im französischen Parlament hier nicht näher eingehen, wesentlich scheint mir aber doch zu sein, daß die Regierung überhaupt an der Ausübung der Herrschaft über die Zeit beteiligt wind, während das bei uns erst geschieht, wenn das Parlament aktionsunfähig gewonden ist, nämlich imFalle der Ersatzvornahme im Notstandsfalle gem. Art. 81 Grundgesetz, worüber 1949 in Heidelberg schon gesprochen wurde ${ }^{58}$ ). Wo der Regierung ein Initiativrecht zusteht, ist ihre Beteiligung an der Herrschaft über die Zeit $\mathrm{m}$. E. folgerichtig. Bei der lockeren Konstruktion unseres Ältestenrates, der nur eine Verständigung herbeiführt und niemals abstimmt, wäre dafür auch durchaus Raum. Unser bisheriges System müßte hingegen verändert werden, wenn man den Ausschüissen Fristen setzen und auch der Regierung das Recht einräumen wollte, nach deren Ablauf zu intervenieren, oder wenn der Regierung auch bei sonstigen Beschleunigungen des Beratungsverfahrens ähnlich wie in Frankreich ein Antragsrecht gewährt wenden sollte. Praktische Rücksichten der Arbeitsökonomie sprechen gewiß dafür, dem französischen Vorbild zu folgen, auch wenn man nicht so weit gehen will wie in England.

60) Art. 34 Abs. 3 des Règlement de l'Assemblée Nationale; dazu G. G a l i c h on in Travail Parlementaire S. $151 \mathrm{f}$.

57) "Vote sans débat" gem. Art. 39 (2) des o. a. Règlement.

68) Bericht W. J e 11 i n ek VDStRL Bd. 8 S. 15 ff.; Mitbericht H. $S c h n e i d e r$ aaO. S. 35 ff. 
(3)

\section{Die Internationalisierung}

Wie sich das Verhältnis zwischen Regierung und Parlament angesichts des Phänomens der Internationalisierung zahlreicher Gebiete der Rechtsondnung ${ }^{50}$ ) gestaltet, ist - soweit es die Bundesrepublik Deutschland betrifft - Gegenstand der Bonner Tagung gewesen und ich darf mich daher darauf beschränken, einige Arbeitsergebnisse in den Zusammenhang der hier verfolgten Thematik zu stellen und nur weniges dazu zu bemerken.

In dem Umfange, wie die internationale Ordnung auf neue Bereiche übergreift, die früher zum Gebiete der inneren Angelegenheiten der Staaten gehörten, erfolgt zunächst ein Machtzuwachs der Regierungen, sei es nun daß über die neuen Materien internationale Abkommen geschlossen werden, welche die Regierung verhandelt und mitgestaltet, um sie später dem Parlament zur Zustimmung zu unterbreiten ${ }^{80}$ ), sei

30) Dazu neuerdings meisterhaft Hen ri Rolin: Le rôle du Parlement et des parlementaires dans les relations internationales, Aspects S. $103 \mathrm{ff}$; im übrigen der Bericht über die Bonner Tagung der Vereinigung mit den Referaten von W. Gr e we und E. M e nzel zum Thema: Die auswärtige Gewalt der Bundesrepublik. W. Grew e hat die Technik des Abschlusses von Handelsverträgen aaO. S. $153 \mathrm{ff}$. stark betont. Quantitativ scheint mir eine größere Rolle zu spielen, daB heute zahlreiche internationale $\mathrm{Ab}$ kommen über Materien abgeschlossen werden, die früher fast ausschließlich innerstaatlich durch Gesetze geregelt wurden.

60) Die Zustimmung zum Abschluß oder zur Kündigung eines internationalen Abkommens unterscheidet sich nicht nur der juristischen Konstruktion nach von der Annahme oder Aufhebung eines Gesetzes. Das Parlament kann dabei nur in geringem Umfange gestaltend tätig werden, in der Regel besiegelt es nur das Ergebnis eines auBerhalb seines Bereiches vorgenommenen Gestaltungsaktes. Das wirkt sich auch auf das Verfahren im Parlament aus: über den Vertragstext gibt es keine Einzelabstimmungen (§ 83 Satz 2 BT-GO; Art. 69 (1) Règlement de l'Assemblée Nationale), es können daher keine Abänderungsanträge zum Vertragstext gestellt und keine Textänderungen vorgenommen werden. $\$ 88$ Satz 4 BT-GO läßt sogar die Schlußabstimmung „über Verträge mit auswärtigen Staaten und ähnliche Verträge" "wegfallen, da über sie gemäß $\$ 83$ Satz 2 schon in der 2. Beratung im ganzen abgestimmt sei. Dadurch wird allerdings nicht das Recht des Bundestages berührt, das Zustimmungsgesetz in der 3. Beratung zu ändern oder auch in der 2. Beratung an die Ausschüsse zurückzuverweisen, um z. B. die Frage zu prüfen, $o b$ es notwendig ist, eine bis dahin geltende und dem Abkommen widersprechende Gesetzesbestimmung des deutschen Rechtes aufzuheben, oder aber ob die Bundesregierung zur Vollziehung der Ratiflkation nur unter der Bedingung ermächtigt werden soll, daß sie einen nach den $\mathrm{Be}-$ stimmungen des Abkommens zulässigen Vorbehalt gegen eine einzelne Klausel erklärt. Darin liegt eine der wenigen Gestaltungsmöglichkeiten des Parlaments bei internationalen Abkommen.

7 Veröffentlichungen der Staatsrechtslehrer, Heft 16 
es daß der Kreis der Angelegenheiten der auswärtigen Politik, welche die Regierung allein zu behandeln zuständig ist, sich erweitert.

Das Vordringen der Parlamente bei der Kontrolle der Regierungen scheint mir eine Reaktion auf diese Entwicklung zu sein. Es vollzog sich in verschiedenen Formen: der Kreis der internationalen Abkommen, die nur mit Zustimmung der Parlamente endgültig abgeschlossen werden können, wurde erweitert. In Frankreich, den Niederlanden, Belgien und Skandinavien geschah das stänker als in der konservativen Bundesrepublik Deutschland ${ }^{61}$ ). In mehreren Ländern wurde den Parlamenten auch eingeräumt, vor der Kündigung eines Vertrages eingeschaltet $\mathrm{zu}$ werden $^{62}$ ), was jedenfalls bei Abkommen normativen Charakters, welche das Rechtsleben in ähnlicher Weise gestalten wie Gesetze, durchaus folgerichtig ist. Allerdings bin ich nicht der Meinung des Vorredners ${ }^{63}$ ), da $ß$ nach geltendem deutschen Recht das Plarlament vor der Kündigung eines Abkommens beteilígt werden müßte. Dafür ist schon die Form nicht vorgesehen. Die Ausdehnung des $\mathrm{Zu}$ stimmungsverfahrens ist aber nicht die einzige Form, in der das Parlament den Anspruch auf Teilnahme an der Gestaltung der internationalen Ordnung geltend macht. In vielfachen Formen dringen parlamentarische Elemente - durchaus nicht gegen Wunsch und Willen der Regierungen, sondern vielfach auf ihre Einladung - in die Verhandlungsphase ein, sei es indem einzelne Parlamentarier - auch aus der Opposition an internationalen Konferenzen als Beabachter teilnehmen ${ }^{84}$ ),

61) Art. 26 und 28 der französischen Verfassung vom 27. 10. 46; dazu $C h$ arles $R$ ous s e u : Le Régime actuel de conclusion des traités en Françe, Etudes Scelle Bd. 2 (1950) S. 665-84; J. L. de Gorail: Le rôle des chambres en matière de politique extérieur, Rev. du droit publique et de la science politique Bd. 72 (1956) S. $770 \mathrm{ff}$. Zur niederländischen und belgischen Verfassungsreform W. Grewe aaO. S. $144 \mathrm{ff}$; J. W. G a n s h of van der Meers ch, Aspects S. $137 \mathrm{f}$; $E$. Z i mmermann: Die Neuregelung der auswärtigen Gewalt in der Verfassung der Niederlande, ZaöRV Bd. 15 S. $164 \mathrm{ff}$.; zur deutschen Entwicklung W. Grewe aaO. S. $153 \mathrm{ff}$., 162; E. Menzel aaO. 191-193; H. M os le $\mathbf{r}$ : Die auswärtige Gewalt im Verfassungssystem der Bundesrepublik Deutschland, Bilfinger-Festschrift. (Betr. zum ausl. öff. Recht und Völkerrecht Heft 29) S. 292 ff.; vergl. auch die aufschlußreiche Schilderung über den Widerstand des Schweizer Bundesrates gegen die Bildung einer auswärtigen Kommission bei $C$. $\mathrm{B} \mathrm{u} \mathrm{r} \mathrm{k} \mathrm{h} \mathrm{a} \mathrm{r} \mathrm{d} \mathrm{aaO.} \mathrm{S.} 32 \mathrm{ff}$.

62) Art. 28 Satz 2 der französischen Verfassung vom 27. 10. 1946; Art. 60 (d) 2 der abgeänderten niederländischen Verfassung.

63) S. O. S. 70.

64) Spektakuläre Beispiele sind Clement Attle e als Oppositionsführer auf der 1. Potsdamer Konferenz (zu den dadurch in- 
sei es, daB Ausschüsse und Parlamentsfraktionen während des Laufes von Verhandlungen konsultiert werden ${ }^{85}$ ), besondere parlamentarische Beiräte für Verhandlungen bestellt werden $\left.^{68}\right)$, Grundsatzdebatten im Plenum vor der Unterzeichnung von Abkommen stattfinden ${ }^{67}$ ) oder gar Abgeordnete als Mitglieder oder Leiter von Verhandlungsdelegationen auftreten $^{88}$ ). Ihr Abhängigkeitsverhältnis zur Regierung ist je nach dem Auftragsverhältnis zu bestimmen. Auch wo ein solches begründet ist, wird die Regierung dem Abgeordneten gegenüber das Weisungsrecht nicht in der gleichen Form und dem gleichen Umfange ausüben können wie gegenüber einem in dauerndem Abhängigkeitsverhältnis stehenden Beamten. Im Rahmen der erteilten Verhandlungsrichtlinien wird sich der Parlamentarier freier bewegen können ${ }^{60}$ ).

Der auch in Bonn behandelte parlamentarische Beirat für handelspolitische Vereinbarungen ${ }^{70}$ ) scheint mir ein Musterbei-

nerhalb seiner Partei aufgetretenen Divergenzen vergl. $\mathrm{H}$. M o r ris on aaO. S. 183) und Carlo Schmid auf der Moskauer Konferenz von 1956.

65) Das geschah bei allen großen Vertragswerken, an denen die Bundesrepublik in den letzten Jahren teilnahm.

o6) $z$. B. bei den Verhandlungen über den Bonner Vertrag und über die Saar.

B7) So in der französischen Assemblée Nationale vor der Unterzeichnung des Abkommens über den Gemeinsamen Markt.

68) So der Abgeordnete Th. B la $n k$ bei den Verhandlungen über die europäische Verteidigungsgemeinschaft. Zahlreiche Beispiele vor allem aus der französischen und amerikanischen Praxis liefern die Delegationen bei den Friedensvertragsverhandlungen nach dem 1. und 2. Weltkriege und die Delegationen beim Völkerbund, den Vereinigten Nationen und ihren Spezialorganisationen. Deutschland ist in dieser Hinsicht lange zurückhaltend gewesen, hat sich aber in den letzten Jahren dem allgemeinen Brauch angeschlossen.

69) Anderer Ansicht H. Mosler aaO. S. 296. Die hier vertretene Auffassung stützt sich darauf, daß die Regierung dem Abgeordneten größere Freiheit zugestehen muß, wenn sie sich des Ansehens und der besonderen Beziehungen eines Abgeordneten zur öffentlichen Meinung bedienen will, um einer Verhandlungsdelegation auf der internationalen Ebene und sich selbst im parlamentarischen Zustimmungsverfahren die Arbeit zu erleichtern. Der Einzelauftrag bindet den Abgeordneten weniger stark als das auf Dauer berechnete Dienstverhältnis. Das dürfte auch Konsequenzen für die Verpflichtungen des Abgeordneten gegenüber der Regierung bei der literarischen Verwertung seiner Verhandlungserfahrungen haben. Trotz der Verpflichtung zur Wahrung des Verhandlungsgeheimnisses dürfte eine Pflicht zur Vorlage von Veröffentlichungen bei der auftraggebenden Regierung nicht ohne weiteres zu bejahen sein.

70) Referat W. Grewe aaO. S. 156; vergl. auch $\mathrm{H}$. Mo S Ier aaO. S. 297. 
spiel für die neuartige Zusammenarbeit von Regierung und Parlament auf diesem Gebiete zu sein, nicht nur wegen der durchaus neuartigen Grundlage seiner Existenz, sondern wegen seiner Arbeitsweise: ohne Beschlußfunktionen bietet dieses locker organisierte Gremium ${ }^{71}$ ) den beteiligten Verfassungsorganen - Bundestag, Bundesrat und Regierung - die Gelegenheit, die gegenseitige Haltung abzutasten, damit eine gemeinsame Grundlage des Verständnisses und des Vertrauens zu schaffen und gleichzeitig einen akuten Streit über $\mathrm{Zu}$ ständigkeiten auf homöopathischem Wege zu eliminieren.

Nach der Unterzeichnung der Ablkammen durch die Regierung sucht das Parlament noch Einfluß auf ihre Gestaltung zu nehmen durch Entschließungen, in denen es verlangt, die Regierung solle bei der Ratifikation Vorbehalte erklären ${ }^{72}$ ) oder sich später bei der Durchführung in bestimmter Weise verhalten. Wenn im allgemeinen die Regierung durch diese Entschließungen auch nur politisch als gebunden anzusehen sein wird ${ }^{73}$ ), so kann in ihnen doch auch die Ausübung eines dem Parlamente rechtlich zustehenden Kontrollrechtes liegen. Ich darf als Beispiel die Entschließung anläßlich der Zustim-

71) Die neun parlamentarischen Mitglieder werden zwar dem Ausschuß Nr. 23 (Numerierung der 2. Sitzungsperiode) für Außenhandelsfragen entnommen, handeln aber nicht für diesen; er ist auch kein offizieller Unterausschuß und erscheint auch daher nicht in den Ausschußverzeichnissen. Grundlage seiner Tätigkeit sind die „Vereinbarungen über das Zusammenwirken von Bundestag und Bundesregierung in Außenhandelsfragen“ BT-Drucksache Nr. 1207/ 49 Ziff 2, denen der Bundestag in seiner 81. Sitzung vom 21. 7. 50 (Stenoprot. S. 3047 C), der Bundesrat in der 35. Sitzung vom 22. 9. 50 (BR-Drucksache $\mathrm{Nr}$. 756/50) zugestimmt haben. Er soll danach als Bindeglied „dafür sorgen, daß die grundsätzliche Verantwortung des Parlamentes für die Gestaltung der allgemeinen politischen und wirtschaftlichen Geschehnisse auch auf dem Gebiet der Außenhandelspolitik zur Auswirkung kommt". Der seit über 7 Jahren bestehende Ausschuß arbeitet auf der Grundlage, da $\beta$ seine Mitglieder nicht $\mathrm{zu}$ dirigieren versuchen, sondern sich darauf beschränken, den Regierungsunterhändlern Anhaltspunkte zu geben, welche Haltung die Ausschüsse, vor welche das Abkommen einmal kommen kann, bei einer formellen Behandlung wohl einnehmen werden; die vor und während des Laufes der Verhandlungen gegebenen Informationen werden dazu benützt, den Parlamentsausschüssen den Sinn und Lauf der Verhandlungen klar zu machen. Die Protokolle des Ausschusses sind vertraulich.

72) Vergl. den Bericht des Verfassers: Die europäische Menschenrechtskonvention vor den nationalen Parlamenten, ZaöRV Bd. 17 (1956) S. 102.

73) Ubereinstimmend $\mathrm{H}$. M os le r aaO. S. 294; in der Tendenz auch W. Grewe aaO. S. 138; abweichend E. Menzel aaO. S. $195 \mathrm{ff}$. 
mung zu den Abkommen über den Gemeinsamen Markt und die Europäische Atomgemeinschaft nennen ${ }^{74}$ ).

Die stärkste Form der Teilnahme parlamentarischer Elemente an der Gestaltung der internationalen Ondnung dürfte in der Mitwirkung an den ständigen Beratenden Versammlungen der europäischen Organisationen, insbesondere des Europarates, liegen. Ein großer Teil der im Rahmen des Europarates zustande gekommenen Konventionen entstammt nicht nur der Initiative von Abgeordneten der Beratenden Versammlung, sondern ist von ihnen auch weitgehend mitgestaltet worden $\left.{ }^{75}\right)$. Es scheint mir weder politisch noch verfassungsrechtlich zulässig, diesen Abgeordneten das Recht zu versagen, das Ergebnis ihrer Arbeit auf die nationale Ebene zu projizieren und - abweichend von dem sonst geltenden Recht - selbst Zustimmungsgesetze zu diesen Abkommen einzubringen, ohne daß darin ein Eingriff in den Bereich der Regierung gesehen werden könnte $\left.{ }^{76}\right)$. Indem die Regierung der internationalen Organisation beitrat und die Grundlage für die Tätigkeit parlamentarischer Vertreter in ihren Gremien schuf, gab sie ihre ausschließliche Dispositionsfreiheit über auswärtige Angelegenheiten insoweit preis.

Sobald in der Zukunft die parlamentarischen Gremien auf europäischer Ebene Beschlußfunktionen erhalten, werden für das Verhältnis zwischen Parlament und Regierung auf der nationalen Ebene neue Probleme auftreten. Eine unmittelbare Verzahnung zwischen der Arbeit der europäischen parlamentarischen Institutionen und den nationalen Parlamenten wird vorgenommen werden müssen und es wird dabei kaum zu vermeiden sein, daß die Zuständigkeiten der nationalen Regie-

74) Art. 2 des Ges. zu den Verträgen vom 25. 3. 1957 zur Gründung der Europäischen Wirtschaftsgemeinschaft und der Europäischen Atomgemeinschaft vom 27. Juli 1957 (BGBl. II S. 753).

73) Vergl. den Bericht des Verfassers: Die Entstehung der europäischen Menschenrechtskonvention, ZaöRV Bd. 15 (1954) S. $631-660$.

70) A. A. H. M o s le r aaO. S. 289 f., 293 unter Berufung auf „die Konzentration der politischen auswärtigen Gewalt bei der Bundesregierung" und das Dispositionsrecht der Regierung über auswärtige Angelegenheiten. Da sie dieses Dispositionsrecht bei dem Abschluß multilateraler Abkommen in internationalen Organisationen mit parlamentarischen Versammlungen auf der internationalen Ebene nicht einschränkungslos besitzt, kann es ihr $\mathrm{m}$. $\mathbf{E}$. auch bei der parlamentarischen Behandlung auf der nationalen Ebene nicht ausschließlich zustehen. Ich möchte allerdings annehmen, daB die Regierung auch in diesen Fällen frei zu entscheiden hat, ob und wann sie die zwischenstaatliche Ratifikation vollzieht. 
rungen abgebaut werden ${ }^{77}$ ). Damit haben wir jedoch schon einen Blick in eine Zukunft getan, die jetzt noch nicht klar überschaubar ist.

Gewichtsverteilung zwischen Regierung und Parlament

Aber kehren wir zurück zu dem Verhältnis von Parlament und Regierung im souveränen Staat, wie er jetzt noch besteht.

Wa lter Lippmann ${ }^{78}$ ) hat unlängst die Funktionsaufteilung der beiden Verfassungsorgane im modernen staat mit einem Anspruch auf Allgemeingültigkeit zu zeichnen versucht und dabei der Exekutive allein und ausschließlich die Rolle zuerkannt, aktiv handelnd vorzuschlagen und zu fordern, während es dem Parlamente nur zukomme, das Vorgeschlagene zu bewilligen oder abzulehnen, die Regierungshandlungen zu billigen oder zu kritisieren und allenfalls in Entschließungen gewisse Handlungen von ihr zu fordern. Von einer eigenen gestaltenden Funktion des Parlaments ist bei ihm nicht die Rede, er will sie vielmehr ausschließen und spricht mit Bitterkeit von seinen unzulässigen Utbergriffen in den Bereich der anderen Gewalt. Aus Verteidigern der Freiheitsrechte seien die Parlamente zu Oligarchien gewonden, die von einem Herrschaftswahn besessen seien und die Sicherheit, Zahlungsfähigkeit und Freiheit des Staates bedrohten.

Dieses Bild ist zweifellos an der englischen Verfassungswirklichkeit des Vorkrieges als Ideal orientiert und hat seine polemische Zuspitzung aus der Kritik an gewissen amerikanischen Zuständen erhalten. Hingegen hat der Blick auf das Zusammenspiel von Regierung und Parlament unter dem Einfluß der modernen Zeittendenzen gezeigt, $\mathrm{da} \beta$ es die Regierung zwar leichter hat, ihre aktive Rolle in diesem Verhältnis zu spielen und zu entwickeln, daß aber doch Mittel und Wege gefunden wurden, um es auch den Parlamenten zu ermöglichen, auf dem Gebiete der Gesetzgebung die ihnen nach den kontinentaleuropäischen Verfassungsordnungen zukommende aktive Funktion bei der Gestaltung der Lebensordnung zu erfüllen.

Die Bereitschaft, diese Funktion wahrzunehmen, läßt sich auch daran ablesen, in welcher Weise im Parlamente von dem

77) Vergl. den Plan des engl. Labour-Abgeordneten M a ck a y : Motion recommending the investment of the Council of Europe with legislative and executive powers, proposed by Mssrs. Mackay, Schumann, Mollet and others. Document AS (2) 19 der 2. Sitzungsperiode des Europarates.

78) Essays in the public philosophy, Boston 1955 S. 30, 54. 
Rechte Gebrauch gemacht wind, Gesetzesanträge einzubringen und an der Formulierung der von den Regierungen eingebrachten Vorlagen mitzuwirken.

Während beides im englischen Unterhaus wegen der starken Führungsrolle der Regierung kaum geschieht ${ }^{70}$ ), und auch in der Schweiz wegen der kurzen Sitzungsperioden nur in ganz beschränktem Umfange ${ }^{80}$ ), weisen die im steigenden $\mathrm{MaBe}$ aus Berufsparlamentariern bestehenden Parlamente des europäischen Kontinents eine stärkere Aktivität auf. Im zweiten Bundestage sind fast ebenso viel Gesetzentwürfe aus der Mitte des Parlamentes eingebracht worden, wie ihm von der Regierung vorgelegt wurden ${ }^{81}$ ). Dabei ist freilich die Art dieser Anträge zu berücksichtigen. Es gibt Initiativanträge der Regierungsparteien, die eigentlich von der Regierung stammen, aber nur deswegen im Bundestage eingebracht werden, um den Umweg über den Bundesrat zu sparen; es finden sich gemeinsam mit der Opposition eingebrachte Anträge, um einem Gesetzesvorhaben eine breite Mehrheit zu sichern; dann Initiativentwürfe von eigenwilligen Mitgliedern der Regierungsfraktionen, die durch sie eine persönliche Auffassung durchsetzen wollen (ich erinnere an das Kartellgesetz); dann Initiativentwürfe von Mitgliedern der kleineren Koalitionsparteien, um Wahlversprechen einzuhalten, deren Erfüllung sie im Kabinett nicht' durchzusetzen vermochten. Schließlich die Initiativentwürfe der Opposition, manchmal sorgsam ausgearbeitet, manchmal aber auch nur hingeworfen, um die Regierung zu einem Gegenentwurf zu zwingen. Die Opposition kann dadurch positiv an der Gesetzgebungsarbeit teilnehmen und sich davor retten, immer nur Nein sagen zu müssen. Eine geschickte Opposition, welche die Zeichen der Zeit erkannt hat, vermag der Regierung das Gesetzgebungsprognamm aus der Hand zu nehmen und ihr die Führungsrolle im Parlament zu entwinden, obwohl die Regierung keine einzige Aibstimmung verliert. Nach deutschem Recht sind alle Formen der geschilderten Initiativanträge zulässig, verfassungspolitisch sind

79) H. M orris o n : aaO. Abschnitt XI: Das Gesetzgebungsprogramm, S. 292 bis 320 , insbes. 304 f.; Ernes t Davies: The role of private members bills, The Political Quarterly Bd. 28 (1957) S. 32.

80) K. E i c h e n berger aaO. S. 155; für Belgien vergl. G a n s h of van der Meersch, Aspect S. 130: "Il souffre, désemparé du manque d'experts et de sécrétariat et, d' autre part, d'une certaine insuffisance d'information."

81) Vergl. die alle 14 Tage im Bundesanzeiger erscheinenden Ubersichten über die Bundesgesetzgebung. 
allenfalls Bedenken gegen die den Abgeordneten in die Tasche gesteckten Regierungsentwürfe anzumelden.

Auch bei der Formulierungsarbeit ist jedenfalls im Bundestag eine starke Alktivität des Parlaments festzustellen. Sie findet ihre Grundlage darin, daß der Inhaber des Initiativrechtes keinen Einfluß darauf hat, was aus seinen Formulierungen wird und noch nicht einmal verlangen $k a n n, d a B$ in der zweiten ader dritten Lesung darüber abgestimmt wird, $a b$ seine oder die vom Ausschuß gewählte Formulierung der $\mathrm{Ab}$ stimmung zugrunde gelegt wird ${ }^{82}$ ). Viele Regierungsvorlagen kommen aus dem Bundestag, die völlig umgebaut wurden. Aufbau, Systematik, Begriffsbildung, Sprache - alles macht das Parlament neu. Nicht immer, weil das Parlament sachlich etwas gegen den Regierungsentwurf hätte, sondern häufig aus dem Grunde, weil es der Bürokratie, von der der Entwurf stammt, keine ihm gegenüber loyale Formulierung zutraut, weil es sich vor Fußangeln fürchtet, in denen es sich fangen könnte. Daraus, in welchem Umfange das Parlament neu formuliert, läßt sich ablesen, in welchem Maße zwischen Parlament und Regierung ein Vertrauensverhältnis herrscht, jedoch nicht, wie die Macht zwischen ihnen verteilt ist; dasselbe gilt mutatis mutandis auch für die Ausübung des Initiativrechtes. Sonst gelangte man zu dem Ergebnis, daß unser Parlament mächtiger wäre, als die aller anderen Staaten mit parlamentarischem Regierungssystem, dann würden die Parlamente der romanischen Länder des Kontinents folgen, während Großbritannien im Dämmer parlamentarischer Ohnmacht läge. In Wahrheit dürfte das Verhältnis eher umgekehrt sein.

Bei der Ausübung der Gesetzgebungshoheit ist im modernen Verwaltungsstaat neben die Regierung und das Parlament ein drittes Element - ich vermeide es absichtlich, von einer dritten Gewalt zu sprechen - getreten, das zwar der Regierung zur Verfügung steht, aber doch kaum als ihr Bestandteil oder Anhängsel zutreffend charakterisiert wäre; die Bürokratie, eine permanente Hierarchie, deren Existenz von der jeweils am Ruder befindlichen Regierung unabhängig ist, sie überdauert und eine eigene auf der Sach- und Fachkenntnis beruhende Mentalität entwickelt hat. Ihre Bedeutung ergibt sich schon daraus, daß es der Regierung nur mit ihrer Hilfe gelang, der spezifischen Tendenzen der modernen Zeit zur Speziali-

82) So Art. 73 des Règlement de l'Assemblée Nationale. In den Ausschußberichten des Deutschen Bundestages an das Plenum werden allerdings häufig die ursprünglich von der Bundesregierung vorgelegten Fassungen den in den Ausschußsitzungen erarbeiteten Fassungen gegenübergestellt. 
sierung und zur Beschleunigung des Arbeitsprozesses Herr zu werden.

Das Parlament, das eine derartige Stütze nicht besitzt, und nicht besitzen kann, wenn es nicht nur seine Struktur, sondern auch seine Funktion bewahren will, lebt in einem dauernden Zustande des Mißtrauens gegen diese Hierarchie, für die wir zahlreiche Beispiele in den nicht immer legitimen Versuchen haben, sie unter Kontrolle zu bringen ${ }^{83}$ ). Angesichts dieser Situation, die sich nicht nur in Deutschland findet, die sich hier aber angesichts eines ausgesprochen rückgewandten Beamtenrechts besonders stark ausprägte, ist es von entscheidender Bedeutung, in welcher Weise die Regierung im engeren Sinne, d. h. das Kabinett zum Parlament hin orientiert und mit ihm verzahnt ist. Das ist nur teilweise eine Frage des Verfassungsrechts.

Zunächst spielt ein Rolle, ob die Regierungsmitglieder derm Parlament entnommen werden müssen oder doch üblicherweise entnommen werden und wohin sie sich dann gehörig fühlen: zum Parlament oder zur Bürokratie. Dafür ist natürlich nicht nur die Form der Ministerbestellung maßgebend, sondern auch persönliche Falktoren ${ }^{84}$ ). Ferner ist wichtig, ob ein Minister in seiner Arbeit ganz auf Beamte angewiesen ist, die ihm wamöglich sogar den persönlichen Referenten unter dem Gesichtspunkt auswählen, ihn auf einen ressortgemäßen Stil festzulegen, oder ob er in seiner Eigenschaft als Politiker über eigene Hilfskräfte verfügt, die nicht in die Hierarchie des Ministeriums eingegliedert sind. Die französische Praxis hat daher die Einrichtung der Ministerkabinette entwickelt.

Für das Wirken im Parlament ist eine andere Einrichtung noch wichtiger, deren sich nicht nur Großbritannien und einige Länder des Kontinents, sondern seit einigen Jahren auch ein deutsches Land ${ }^{85}$ ) bedienen: die parlamentarischen Staatssekretäre, die parlamentarischen Vertreter der Minister oder wie die Bezeichnung immer lautet; sie mögen auch Staatsminister genannt werden, um die Vorstellung zu bannen, das Amt des berufsmäßigen Staatssekretärs solle politisiert werden. Unter einem parlamentarischen Staatssekretär wird hier wie in England ${ }^{86}$ ) ein dem Minister beigegebener und nicht in

83) Beisp. bei W. G r e w e : aaO. S. 139.

84) Ein Minister, der aus der Beamtenkarriere kommt, kann trotz jahrzehntelanger parlamentarischer Erfahrung in seiner Mentalität durch die Bürokratie geprägt bleiben.

85) In Schleswig-Holstein sind den Ministern, die nicht gleichzeitig Landtagsabgeordnete sind, parlamentarische Vertreter beigegeben.

86) H. M orris o n : aaO. S. 79, $85 \mathrm{f}$., $88 \mathrm{ff}$.; zur allgemeinen Problematik Wig n y in Aspects S. 24. 
die Hierarchie des Ministeriums engegliederter Parlamentarier verstanden, der neben dem beamteten Staatssekretär steht und ihm und den ihm unterstellten Beamten gegenüber keine Weisungsbefugnisse hat. Er hat den Minister bei der Vertretung im Parlament zu unterstützen und seine parlamentarischen Kollegen in der Sprache und Denkart des Parlamentariers, die sich im politischen Kampf und nicht in der Atmosphäre des Beamtentums gebildet hat, vor allem in den Ausschüssen klar zu machen, was die Regierung mit einer vorgeschlagenen Gesetzgebungsmaßnahme beabsichtigt und warum sie dabei die Form wählt, in der sie diese dem Parlament vorlegt. Er hat also die Kluft des Argwohns zwischen Parlament und Bürokratie zu überbrücken und natürlich auch im Ministerium selbst die Aufgabe, den Beamten gegenüber als Interpret des Parlaments zu wirken und ihnen klar zu machen, daß sie nicht alles in die Gesetze hinein schreiben können, was sie vielleicht aus systematischen Gründen für notwendig halten mögen, was aber im Parlament kein Verständnis findet, sondern sogar Argwohn erregen kann. Seine Vermittler-Rolle erfüllt er nicht zwischen zwei Interessengruppen, sondern zwischen zwei untereinander grundverschiedenen Denk- und Sehweisen, die seinerzeit von $\mathrm{Max} W$ e b e $\mathrm{r}^{87}$ ) sehr prägnant herausgearbeitet wurden und die hier nur durch ein Wort gekennzeichnet seien, das einmal ein Abgeordneter in einem Ausschuß einem Beamten gegenüber gebraucht haben soll: "Ich werde mich auch durch Ihren höheren Sachverstand nicht von der Richtigkeit meiner Ansicht abbringen lassen." Zweck-

87) aaO. S. 50 f.: „Es ist, wie gesagt, nicht Sache des Beamten, nach seinen eigenen Ubberzeugungen mitkämpfend in den politischen Streit einzutreten und, in diesem Sinn „Politik zu treiben“, die immer Kampf ist. Sein Stolz ist es im Gegenteil, die Unparteilichkeit zu hüten und also seine eigenen Neigungen und Meinungen überwinden zu können, um gewissenhaft und sinnvoll durchzuführen, was allgemeine Vorschrift oder besondere Anweisung von ihm verlangen, auch und gerade dann, wenn sie seinen eigenen politischen Auffassungen nicht entsprechen. Die Leitung der Beamtenschaft, welche ihr die Aufgabe zuweist, hat dagegen selbstverständlich fortwährend politische - machtpolitische und kulturpolitische - Probleme zu lösen. Sie darin zu kontrollieren, ist die erste grundlegende Aufgabe des Parlaments. Und nicht nur die den höchstgestellten Zentralinstanzen zugewiesenen Aufgaben, sondern jede einzelne noch so rein technische Frage in den Unterinstanzen kann politisch wichtig und die Art ihrer Lösung durch politische Gesichtspunkte bestimmt werden. Politiker müssen der Beamtenherrschaft das Gegengewicht geben. Dagegen aber wehrt sich das Machtinteresse der leitenden Instanzen einer reinen Beamtenherrschaft, welche stets der Neigung zu möglichst unkontrollierter Freiheit und vor allem zur Monopolisierung der Ministerstellen für das Beamtenavancement nachgehen werden..... 
mäßigerweise sucht der Minister sich seinen parlamentarischen Gehilfen unter den jüngeren Parlamentariern aus, die auf diese Weise eine wertvolle Vorschule zum Ministeramt durchmachen. Es wäre ideal, wenn er nicht in die Koalitions-, Religions-, Regional- und Sozialarithmetik einbezogen würde, um zwischen dem Minister und ihm keine Spannungen entstehen zu lassen, doch das ist kaum zu hoffen. Ich bin deswegen im Gegensatz zu Esch en $\left(b u r g^{88}\right.$ ) der Auffassung, daß es heute wenige Tage vor der Regierungsbildung - keineswegs zu spät ist, diese Einrichtung bei uns einzuführen. Je später sie kommt, desto weniger wird das Amt koalitionsmäßig ausgehandelt.

Die Einrichtung ist im Parlamentarischen Rat auf Anregung von Carlo Schmid diskutiert worden ${ }^{89}$ ) und man war sich darüber einig, daß nichts im Wege stehe, sie einzuführen. Man hat jedoch davon abgesehen, sie im Grundgesetz ausdrücklich zu erwähnen, da es der Praxis überlassen bleiben sollte, ob sich die Bundesregierung ihrer bedienen wolle ${ }^{80}$ ). Vor wenigen Tagen verlautete, das solle nun geschehen.

Mehrere Argumente pflegen gegen die Einrichtung vorgebracht zu werden:

1. unter den Parlamentariern von heute gebe es keine Menschen für dieses Amt; es verleiht jedoch dem Amt des Parlamentariers einen neuen Anreiz und es ist durchaus nicht ausgeschlossen, daß sich die Fähigen um einen Sitz im Parlament bewerben werden, um auf diese Weise in den Kreis der politischen Elite aufzusteigen und ministrabel zu werden.

2. Die Beamten würden dem parlamentarischen Staatssekretär nicht die notwendigen Informationen geben und damit die Voraussetzungen für eine sinnvolle Arbeit zerstören. Ob das eintritt, wird davon abhängen, welche Unterstützung der Minister dem jungen Parlamentarier gewährt.

88) „Wozu Zweitminister? - Antwort auf einen Vorschlag Adenauers." Die Zeit vom 3. 10. 1957.

89) In der 7. Sitzung des Organisationsausschusses des Parlamentarischen Rates vom 29.9. 1948 wurde ein Antrag des Abgeordneten de Chapeaurouge (CDU) angenommen, eine Bestimmung einzufügen: „Dem Bundeskanzler und den Bundesministern können beamtete und politische Staatssekretäre beigegeben werden. Sie sind nicht Mitglieder der Bundesregierung."

90) Der Hauptausschuß hat in seiner 3. Sitzung am 16. 11. 1948 die in Anm. 89 wiedergegebene Formulierung gestrichen, weil der Begriff des politischen Staatssekretärs nicht klar umrissen sei und eine Regelung der Bundesregierung oder einem Bundesgesetz überlassen werden solle. Vgl. die Ausführungen des Abgeordneten T h. Dehler. 
3. Er werde in dauerndem Streit mit dem ständigen Staatssekretär leben. Wenn dadurch die Auseinandersetzungen zwischen dem Parlament als solchem und der Bürokratie vermindert würden, wäre die Einrichtung schon gerechtfertigt.

4. Sobald der parlamentarische Staatssekretär sein Amt antrete, wechsle er in das Lager der Regierung über und finde daher bei den parlamentarischen Kollegen nicht mehr den nötigen Widerhall. Dieselbe Erfahrung sei bei den Bundesministern für besondere Aufgaben gemacht worden, welche die Verbindung zwischen den Fraktionen stänken sollten, aber keinen Erfolg gehabt hätten.

Dieser letzte Einwand - der stärkste von allen - fußt auf einem tiefen Pessimismus hinsichtlich der Möglichlkeit, das Verhältnis zwischen Regierung und Parlament in Deutschland zu ändern. Aber wäre diesem Pessimismus nicht doch entgegenzuhalten, der Versuch des Jahres 1953 sei isoliert unternommen worden und auch die Einrichtung des parlamentarischen Vertreters des Ministers oder Staatsministers werde sich nur durchsetzen, wenn sie von anderen Maßnahmen begleitet sei, um die Regierung zum Parlament hin zu orientieren und aus den Verstrickungen der Bürokratie zu lösen? $\mathrm{Zu}$ diesen Maßnahmen gehört z. B. die Wahl des Adressaten für wichtige politische Erklärungen. In Großbritannien besteht die Arbeit der Pressereferenten der Minister darin, diese daran zu hindern, anderswo als vor dem Parlament wichtige und grundsätzliche Enklärungen abzugeben Bei uns hat sich dieser Stil noch nicht ganz durchgesetzt, sondern es wird immer wieder beanstandet, daß Regierungsmitglieder das Forum für ihre Erklärungen gern außerhalb des Parlaments suchen.

Was hier unter Orientierung zum Parlament hin verstanden wird, kann vielleicht am sinnfälligsten erklärt werden durch ein Symbol für das Verhältnis zwischen den beiden Verfassungsorganen. Ich meine die Sitzondnung, in der die Regierungsmitglieder ihre Diskussionen mit den Parlamentariern führen. Schon 1917 bemerkte $M$ a $\times$ W e be ${ }^{01}$ ), man habe jahrzehntelang darüber gespottet, daß die deutschen Parlamente und ihre Parteien in den Regierungen immer eine Art von natürlichem Feind sähen; das ist aber nicht erstaunlich, wenn die Regierungsmitglieder mit den Beamten im Rücken aus luftiger Höhe auf die Abgeordneten herabschauen. Die Frage, wohin die Regierungsmitglieder im Sitzungssaal des Parlamentes gehören - oben auf ihre hohe Tribüne, auf eine

o1) aaO. S. 46 . 
Bank in gleicher Höhe wie die ersten Reihen der Abgeordneten, aber diesen gegenüber oder in die ersten Reihen der Koalitionsfraktionen selbst - ist in den letzten Tagen des zweiten Bundestages wieder aufgegriffen worden. Das Parlament selbst wind über sie zu entscheiden haben; aber es wird jedenfalls aufschlußreich dafür sein, welche Stellung sich die Regierung dem Parlament gegenüber wünscht, wie sie sich sellbst bei den kommenden Erörterungen über die Sitzordnung verhält. Und damit scheint mir der Kern des Verhältnisses von Regierung und Parlament überhaupt berührt: es ist eine Frage des politischen Stils und der eigenen Willensentscheidung der Regierung, wo sie sich selbst sieht: vor dem Beamtenapparat oder im Parlament. Davon hängt weitgehend die Führungsrolle der Regierung im Parlamente ab und damit auch die Macht, welche das Parlament im Leben eines Staates auszuüben in der Lage ist. 


\section{Leitsātze des Mitberichterstatters über: Parlament und Regierung im modernen Staat}

Jeder moderne Staat hat mit den tats ächli chen En twicklungen der Gegenwart fertig zu werden. Die Vermehrung der Staatsaufgaben, der Zerfall der natürlichen Lebenseinheit in geschiedene Spezialgebiete, die. Hast der Zeit und die Internationalisierung zahlreicher Lebensgebiete beeinflussen die Stellung von Regierung und Parlament in der freiheitlichen Demokratie und auch ihr Verhältnis zueinander, ganz gleich wie diese verfassungsmäßig oder durch ungeschriebene Normen geregelt sind. Das gilt auch für die Wahrnehmung von Gesetzgebungsaufgaben durch sie.

Die genannten Zeitströmungen stärken die Macht der Regierungen und der hinter ihr stehenden Apparate, die unbeschränkt ergänzbar, minutiöser Spezialisierung fähig und rasch zu handeln in der Lage sind. Das Parlament eine Körperschaft mit einer großen Zahl gleichgeordneter Mitglieder ohne hierarchische Gliederung - hat es hingegen schwerer, den Zeitströmungen gerecht zu werden und dennoch seine Rolle als zentraler politischer Gestaltungsinstanz und als Gegengewicht zu Regierung und Bürokratie zu behaupten.

1. Die Vermehrung der Staatsaufgaben stellt die Regierung vor organisatorische Probleme. Das Parlament hat durch sie und die dadurch bedingte Spezialisierung seine Struktur gewandelt. Es konnte seiner Aufgaben nur Herr werden, indem es sich aufspaltete. Der Arbeitsteilung im Parlament sind jedoch Grenzen gesetzt. Sie hat in vielen von ihnen schon einen bedenklichen Umfang erreicht (Herrschaft der Ausschüsse). Organisation und Befugnisse der Ausschüsse und ihrer Stäbe sind nicht nur im Hinblick auf ihre Arbeitsfähigkeit, sondern auch unter dem Gesichtspunkte, daß die Einheit des Gesamtparlaments unter allen Umständen gewahrt bleiben muß, zu betrachten. Denn der politische Interessenausgleich kann nur vom Gesamtparlament in der Offentlichkeit vollzogen werden, niemals aber von einem Ausschuß unter fachlich-sachlichen Gesichtspunkten. 
Die Organisation des Parlamentes, seiner Organe und Hilfsdienste werden weitgehend mit dem Ziel gestaltet, den Abgeordneten genau so sachverständig zu machen wie den Funktionär der Exekutive. Dieser Wettlauf ist nicht nur aussichtslos, sondern entspricht auch nicht den Aufgaben des Parlaments. Es ist wichtig, dem Abgeordneten eigene Informationsquellen $z u$ erschließen und ihn von der Materialsuche und von allen seiner Aufgabe fremden technischen Arbeiten zu entlasten, doch kann es ihm nicht abgenommen werden, da $\beta$ er selbst - und zwar als Politiker, nicht als Sachverständiger - entscheidet.

Um den Druck der Arbeitslast auf das Parlament zu mindern, haben viele Staaten den Ausweg beschritten, Gesetzgebungsaufgaben aus dem Parlament heraus zu verlagern. Soweit dies unter Aufweichung des Gesetzesbegriffes geschieht, sind dagegen schwere Bedenken anzumelden; aber auch sonst kann dieser Weg ohne Minderung der Macht und des Ansehens des Parlaments nur beschritten werden, wenn die substanzielle Entscheidungsbefugnis bei dem Parlament verbleibt und dieses mindestens eine wirksame Kontrolle darüber ausübt, wie sein Auftrag erfüllt wird.

2. Das $Z$ e it p roble $m$ ist auf der Regierungsseite eine Frage der rechtzeitigen Planung des Gesetzgebungsprogramms und einer guten Arbeitsökonomie. Im Parlament ist der Arbeitsrythmus durch die Bestimmungen über die Zahl der Lesungen, Fristen und Redezeiten festgelegt. In diesem Rahmen ist die Herrschaft über die Zeit bestimmten Organen zugewiesen (Aufstellung der Tagesordnung, Fristverkürzungen, dringliche Vorlagen). Es geht eine Tendenz dahin, jeden Inhaber des Initiativrechts an der Herrschaft über die Zeit zu beteiligen.

3. Die zunehmende Internationalisierung der Ordnung zahlreicher Lebensgebiete hat es notwendig gemacht, neue Formen der parlamentarischen Beteiligung am Abschlu $\beta$ internationaler Verträge zu entwickeln (Unterwerfung weiterer Vertragstypen unter den Zustimmungszwang, Ausdehnung des Zustimmungserfordernisses auch auf die Kündigung, Einräumung eines parlamentarischen Initiativrechts in gewissen Fällen, Beteiligung parlamentarischer Elemente an der Verhandlungsphase). Darin liegt kein Einbruch in den Bereich der Regierung, sondern eine folgerichtige Konsequenz aus dem Übergreifen der internationalen Ordnung auf Gebiete, die bisher innerstaatlich geregelt waren. 
4. Die Gewichtsverteilung zwischen Regierung und Parlament hängt nicht nur davon ab, ob und in welcher Weise die Regierung dem Parlament verantwortlich ist, wie die Zuständigkeiten zur Gesetzgebungsinitiative und im Gesetzgebungsverfahren geregelt sind und ausgeïbt werden können, sondern weitgehend davon, wie die Regierung im engeren Sinne (d. $h$. das Kabinett) im Raume zwischen Parlament und Funktionärskörper eingebettet ist. Es gibt Methoden, den Minister in seiner Funktion als leitender Politiker von dem ihm unterstehenden Beamtenapparat abzuheben (Ministerkabinette) und die Verbindung zwischen ihm und dem Parlament enger zu gestalten (parlamentarische Staatssekretäre); weitgehend ist es aber eine Frage des politischen Stils und der eigenen Willensentscheidung der Regierung, wohin sie sich selber stellt: vor den Beamtenapparat oder in das Parlament; symbolisch dafür ist, wo sie sich im Parlament hinsetzt. Von dieser Orientierung der Regierung hängt es $a b$, ob sie im Parlament eine Führungsrolle auszuüben vermag und schließlich auch, welche Macht das Parlament als solches innehat. 
3. Aussprache über:

\section{Parlament und Regierung im modernen Staat}

\section{I p s e n - Hamburg:}

Wenn ich als erster spreche, so folge ich damit einer Aufforderung unseres Präsidenten, mögliche Ansatzpunkte zur Aussprache zu bezeichnen.

Das Thema, das unseren beiden Referenten gestellt war, zeichnete sich einmal durch seine besondere Weite aus, ferner - abgesehen noch von dem Wörtchen ,und" und dem, was darin steckt - durch seine mangelnde Präzision, endlich durch eine eigenartige Aktualität, wenn ich nämlich daran denke, daß wir vor acht Jahren, vor zwei Wahlperioden des Bundestages am Beginn des Grundgesetzes, mit unserem Heidelberger Thema zum Regierungssystem den ersten Akt gespielt haben, dem heute mit unserem Thema der zweite Akt folgt. So gesehen, hätte die Behandlung des Themas von vornherein schon durch eine gewisse Blickrichtung bestimmt werden können.

Aber bevor ich auf die Möglichkeiten, das Thema anzugreifen, eingehe und zu kennzeichnen versuche, wie die beiden Referenten es erörterten, möchte ich etwas sagen zu der Methode, die mir in den beiden Referaten durchzuklingen schien. Sicherlich hat es, wenn ich zunächst von Herrn Friesenhahn spreche, ihm mancherlei Selbstverzicht und Bescheidung gekostet, auch Dinge vorzutragen, die in unserem Kreise wohl nicht problematisch sind, sondern Schilderung des gewordenen Befundes darstellen. Herr Friesenhahn hat, z. T. rechtsvergleichend ausholend, in seinem Referat, in seinen Thesen und auch in seinen Ergänzungsthesen für die Diskussion mancherlei zum Ausdruck gebracht, was in unserem Kreise kaum streitig werden wind und vielleicht auch in der Diskussion keiner weiteren Vertiefung bedarf. Diesen deskriptiven Teil seines Referates würde ich in der Art der Darstellung in die Nähe mancher literarischer Behandlungen des angelsächsischen Verfassungsrechts bringen, die in ihrer Methode gewisse Bezüge zur Nachbardisziplin der political science aufweist und die das darf ich offen bekennen - meinem innersten Anliegen zur Behandlung dieser Fragen nicht entspricht. So erklärt es sich vielleicht auch, daß manches in den Thesen beider Referenten 
erscheint, was wir als ein Idealbild eines parlamentarischen Regierungssystems sicherlich uneingeschränkt unterschreiben würden. Als Beispiel dafür nenne ich den Leitsatz 7 von Herrn Friesenhahn: "Die Macht im Staat steht weder bei den Parteien, noch bei den Verbänden, sondern bei Parlament und Regierung, die die widerstreitenden Interessen zum Ausgleich bringen und ihre Entscheidungen nach den Forderungen des Gesamtwohls treffen." Wer wollte das bestreiten? Darüber gibt es schwerlich etwas zu diskutieren, und in einem modern geschriebenen „Fürstenspiegel“ wünde diese Aussage zweifellos einen guten Platz finden. Ich fürchte nur, daß sie die Problematik unseres Themas nicht gerade vom Fleck bewegt. Vielleicht gilt das auch für die Leitsätze 10 und 12, wo sich die Wendung von der Notwendigkeit der "gesunden Spannung“ zwischen Regierung und Parlament findet, während die Wörter "gesund" und "Spannung" ja nun gerade die Problematik aufgeben, auf die es ankommt. Ich will einmal versuchen, medizinisch $\mathrm{zu}$ werden. Ich glaube an eine Pathologie unseres Problems. Wir sollten sezieren - wenn es nötig ist, am Leichnam. Gelegentlich werden ja aber auch Lebewesen seziert. Es kann für uns nicht darauf ankommen, hier nur die sympathischen Empfindungen einer Massage oder einer Diathermiebehandlung wiederzugeben.

Eine spezifische Problematik des Themas liegt - und damit will ich zu der Frage übergehen, wie es in der Diskussion hier erörtert werden könnte - $\mathrm{m}$. $\mathrm{E}$. in der Aufgabe, nach acht Jahren des Grundgesetzes zu überprüfen, ab unsere Staatspraxis jene Methode des Grundgesetzes als richtig bestätigt hat, im Rückblick auf die Erfahrungen vergangener Epochen, speziell der Weimarer Zeit, prohibitiv und prophylaktisch zu ordnen und zu normieren. Diese Fragestellung hat Herrn Friesenhahn speziell beschäftigt in seinem Leitsatz 26 und seinen Ausführungen zum konstruktiven Mißtrauensvotum mit seiner Feststellung, die ich für zutreffend halte, eine wegen der Modalitäten des konstruktiven Mißtrauensvotums nicht gestürzte Regierung, die eine Gefolgschaft im Parlament nicht mehr besitzt, verfüge gleichwohl über die volle Legalität einer Regierung, die der Drohung eines Mißtrauensvotums nicht ausgesetzt war.

Im übrigen haben die beiden Referate verdeutlicht, $\mathrm{da} \beta$ das Thema gegenständlich und methodisch mindestens zwei große Seiten hat. Einmal ein Thema A, das das Regie rungssystem als solches betrifft, also die Frage nach den großen Leitprinzipien unserer Verfassung in ihrem organisatorischen Teil mit dem Utbergriff in die Gruppenorganisation, die 
mit dem Stichwort „politische Parteien, Verbände usw.“ gegeben ist. $\mathrm{Zu}$ diesem Thema, also dem Bereich des Regierungssystems im materiellen Sinne, würden drei Punkte gehören, die der Erörterung bedürfen und die auch von den Referenten, wenn auch mit verschiedenen Gewichten, bedacht worden sind: 1. Regierungsbildung und -Bestand; zur Bestandsfrage gehört jenes Spannungsthema, das mehrfach angespnochen wurde, und die Eigenart des parlamentarischen Systems, zum Kompromiß zu führen mit der überaus beachtlichen Fragestellung, die Herr Friesenhahn am österreichischen Beispiel aufwarf, ob es nämlich Aufgabe einer Verfassungspraxis sein könne, jene Kompromißbildung schon bei der Regierungsbildung zu institutionalisieren. Der 2. Punkt würde alle Fragen zusammenfassen können, die die nichtparteiliche Intervention irgendwelcher Gruppen auf das Parlament umfaßt, einbezogen auch die Fragestellungen, die hier berührt wunden zu dem Thema: „Soziologie des Abgeordneten, Rechtsstellung des Abgeordneten, Problematik der Art. 21, 38 GG“. Das 3. Thema dieses Hauptabschnitts $A$ ist das Prablem der Delegation der Normsetzung irgendwelcher Formen, wozu die Frage der nachträglichen Kontrolle der Delegation, der Uberprüfung, der Innehaltung der Delegationsmaßstäbe usw. gehören würde, ebenso wie auch rechtstechnische Fragen der Handhabung der Delegationsquellen. Diese drei Punkte (Regierungsbildung und -Bestand, Kompromißproblem; die nichtparteiliche Gruppenintervention; die Delegation der Normsetzung) bilden den Kern der Themabehandlung unter dem Gesichtspunkt „Regierungssystem im materiell-verfassungsrechtlichen Sinne“. Hierzu finden sich in dem Referat von Herrn Friesenhahn mannigfaltige Ausführungen, Gesichtspunkte und Anregungen, während das Referat von Herrn Partsch in größerem AusmaB in eine Betrachtungsweise $B$ unseres Themas hineinpaBt, die bezeichnet werden könnte als eine $F u n k t$ ionslehre des $P$ a r la menta r is mus in der modernen Zeit.

Aber bevor ich auf diesen Abschnitt $B$ eingehe, zunächst noch einige Worte zu der Themabetrachtung unter dem Aspekt A: Herr Friesenhahn hat in der Frage der Regierungsbildung und des Regierungsbestandes mit guten Gründen wesentliche Unterschiede herausgehoben zwischen der Struktur des Bundesrechts und der Verfassungspraxis des Bundes einerseits und derjenigen in den Ländern auf der anderen Seite. Hierzu pflichte ich ihm einmal darin bei, da $B$ das Landesverfassungsrecht in höherem Maße als die Bundespraxis die Möglichkeit der Allparteien-Regierung anbietet. Zum anderen freue ich mich - zumal ich hierin bislang recht isoliert dage- 
standen habe - über seine Auffassung, eine vom Parlament kreierte Regierung habe bei der Beendigung der Legislaturperiode (jedenfalls nach eindeutiger Wahlniederlage) die verfassungsrechtliche Verpflichtung zur Beendigung ihres Amtes, zum Rücktritt, wenn nicht bereits automatisch kraft Gesetzes Amtsende eintritt, während die Verfassungspnaxis in einigen Ländern, so zuletzt i. J. 1953 auch in Hamburg, anders verfährt. Ich brauche das nicht näher auszuführen. In meinen wie mein Freund S töd te r sagt - „Hamburgischen Nebenstunden "*) habe ich mich des näheren zu diesem Punkte geäußert. Zu Abschnitt A im weiteren ist von Herrn Friesenhahn die Problematik der Intervention anderer Gebilde als der politischen Parteien in das Parlamentsgeschehen erörtert worden in den Leitsätzen 2, 3 und 4 und speziell 7 und 8; wobei der Gesichtspunkt der föderalen Einflußmöglichkeiten (Stichwort "Bundesrat" - „politische Parteien und Bundesrat") zu kurz gekommen sein mag. Dahin gehört auch, was Herr Partsch so plastisch als notwendige Kanalisierung der "lobby" bezeichnet hat. Dazu gehören ferner die Fragen der Delegation der Rechtsetzung mit ihren Gesichtspunkten der Respektierung der Gewaltenteilung und der Rechtsstaatlichkeit. Die Rolle der Finanzgewalt, die uns in dem Hamburger Referat von Herrn Hettlage verdeutlicht worden ist, klang in diesem Zusammenhang nur einmal an; vielleicht könnte sie vertieft wenden. Soviel zu der Behandlung des Themas unter dem Blickpunkt A.

Herr Partsch hat sein Anliegen im wesentlichen darin gesehen, eine Art Funktionslehre des Parlamentarismus vorzuführen. In unserer Diskussion sollten wir diese Funktionslehre des Parlamentarismus nicht so sehr ausbreiten, sondern das Schwergewicht der Aussprache auf die Blickrichtung A legen, wobei es auf die Neigung des einzelnen ankommt, mehr der dogmatisch-konstruktiven Betrachtung nachzugehen, als der anderen Methode zu folgen. Wenn ich selbst den dogmatischkonstruktiven Weg nach $A$ vorziehe, braucht darüber die aus Staatspraxis, Verfassungswirklichkeit, Politik und Soziologie geschöpfte Erfahrung und Einsicht gleichwohl nicht vernachlässigt $\mathrm{zu}$ werden. Nur meine ich, daß ihre Resultate in unserem Kreis als bekannt vorauszusetzen sind und nicht den Gegenstand unserer Uberlegungen, sonder ihren Hintergrund bilden. Zu Abschnitt B des Themas würden wir uns einmal mit der Würdigung der Verhältnisse zu befassen haben, die mit

*) H. P. I p s e n, Hamburgs Verfassung und Verwaltung (1956) S. $290 \mathrm{ff}$., von $T$ h i e m e AOR Bd. 82 (1957) S. 353/54 offenbar mißverstanden. 
dem Stichwort „moderner Staat" auftauchen, mit den Störungen und Beeinflussungen, denen das Parlament en fonction heutzutage unterliegt, so unter dem Gesichtspunikt der Zeitnot, in der Bemühung, über die Zeit zu disponieren, über sie zu herrschen, in der Auseinandersetzung zwischen dem Politiker und dem Experten (als Sachverständiger im Parlamentsausschuß oder im Gewande des Ministerialrats). Dahin gehört die Problematik der richtigen Organisation des "parlamentarischen Gesetzgebungshilfsdienstes", möglicherweise die Idee des parlamentarischen Staatssekretärs, die sogenannte "Soziologie" des Abgeordnetentyps usw.

Zum Schluß will ich einen eigenen Diskussionsbeitrag anfügen, der thematisch zu allen drei Punkten meines Schemas A das eine oder andere beitragen könnte. Nur mit dem Leitsatz 4 von Herrn Partsch und einer zusätzlichen Bemerkung, die er in seinem Referat dazu machte, ist bisher das Tor in das Land, das mir vorschwebt, ein wenig geöffnet, danach leider sogleich wieder verschlossen worden. Für unsere Disziplin dürfte der Zeitpunkt gekommen sein, unsere Betrachtungen für die $\mathrm{Zu}$ kunft von einem ganz anderen Standort aus anzustellen, als wir ihn bisher einzunehmen pflegten. Ich meine die Tatsache, daß wir vor der Eröffnung der Europäischen Wirtschaftsgemeinschaft und des EURATOM stehen und mit der Montanunion seit einigen Jahren bereits eine Vorstufe dieser Entwicklung hinter uns gebracht haben. Unser Thema „Regierung und Parlament" ist heute Vormittag bewußt und absichtlich vom "Binnenstandpunkt" her innerhalb unserer souveränen Staatlichkeit behandelt worden. Uns steht bevor, daß die wachsende „Präponderanz des Wirtschaftlichen“ und eine supranationale Organisation einen erheblichen Bereich unserer staatlichen Politik der nationalen Entscheidung entziehen wird. Mit Hilfe des Art. 24 GG wird dieser Kompetenzbereich in die Hände übernationaler Instanzen gelegt werden. Was das bedeutet, ist in Gutachten zu den EVG-Verträgen (z. B. von unseren völkerrechtlichen Kollegen $\mathrm{Kr}$ a us $\mathrm{s}$ und Kruse) als Frage der „Homogenität" jener Ordnungen mit unserer nationalen Verfassungsordnung schon angesprochen worden. Wir stehen vor der Tatsache, daß in einem weiten Bereich heutiger nationaler Regierungspolitilk und -Kompetenz des Ökonomischen und der Verwendung moderner Energiequellen, die besondere Sicherheitsprobleme auslösen, in $\mathrm{Zu}$ kunft nichtnationale Organe tätig sein werden unter Ausklammerung nationaler Entscheidungskompetenzen; und die Funktionen dieser Kompetenzträger wenden nicht unter jener Kontrolle stehen und nach jenen Maßstäben sich orientieren, 
die wir binnenstaatlich unter der Thematik „Parlament und Regierung" bisher im Griff hatten oder hoffen, heute noch im Griff zu haben. Wenn Sie sich die maßgebenden Verträge ansehen, können Sie feststellen, daß mindestens für die Übergangszeit das parlamentarische Gremium der Europäischen Wirtschaftsgemeinschaft nur mittelbar demokratisch legitimiert sein wird, und das Ziel, es unmittelbar demokratisch zu legitimieren, hängt in weiter Zukunft. Wir stehen ferner vor der Tatsache, daß jene Organe, die die laufenden Angelegenheiten dieser Gemeinschaft zu entscheiden und zu leiten haben, aus Funktionären bestehen, die unabhängig sind, die vergessen sollen, aus welchem Staate sie kommen, und die sich als fähig erweisen müssen, jede Intervention heimischer Herkunft zurückzuweisen mit dem Argument ,ich bin ein Europäer und kenne keine Farben, jedenfalls keine heimischen mehr". Diese Funktionäre in der Kommission und in der Hohen Behörde haben Entscheidungskompetenzen, die den heimischen Exekutivbereich bei weitem hinter sich lassen, die zum guten Teil normativen Charakter besitzen. Und oberhalb unserer binnenländischen Ordnung von Parlament und Regierung erwächst in der Zukunft im Gesamtbereich des OKonomischen, der hier internationalisiert ist, eine Ordnung, die den Prinzipien nicht gehorcht - jedenfalls vorläufig nicht - , die wir für das Verhältnis von Parlament und Regierung unser eigen nennen. Wenn wir das Problem, das uns heute gestellt ist, mit hinreichendem Weitblick für die Zukunftsentwicklung betrachten wollen, sollten wir diese Blickrichtung auf die Verhältnisse, die auf uns zukommen, nicht vernachlässigen.

\section{Pfe if e r - Wien:}

Wenn ich hier das Wort ergreife, und zwar an früher Stelle, so habe ich es mir deswegen erlaubt, weil ich einerseits nun 8 Jahre Mitglied des Nationalrates in Osterreich bin, und weil andererseits das derzeitige österreichische Regierungssystem, das ja auch schon kurz gestreift wurde, vielleicht klar erhellt, wie sich ein parlamentarisches Regierungssystem doch verschieden auswirken kann, je nachdem, welche Kombinationen und Konstellationen eintreten. Wenn von dem parlamentarischen Regierungssystem die Rede ist, so ist es klar, daß hier daran gedacht ist, daß eine Partei oder mehrere Parteien, die zusammen eine Kaalition bilden und im Parlament die Mehrheit haben, zugleich die Regierung bilden. Und das möchte ich doch gleich vorausschicken, da $B$ ich der Meinung bin, da $B$ dieses parlamentarische Regierungssystem allein schon bewirkt, daß die ursprüngliche Spannung, die noch im 
konstitutionellen Staate vorhanden war zwischen Parlament und Regierung, die in der Regel eine vom Monarchen eingesetzte Beamtenregierung war, vermindert ist, weil nun einmal die Parteifreunde derer, die da als Abgeordnete im Abgeordnetenhaus sitzen, zugleich auf der Regierungsbank sitzen. Aber doch ist im einzelnen in der Durchführung des parlamentarischen Regierungssystems ein wesentlicher Unterschied zwischen diesem und jenem Staat. So besteht derzeit sicherlich ein Unterschied zwischen der Bundesrepublik Deutschland und dem System, wie es jetzt in Osterreich ist, und besteht ferner ein bedeutender Unterschied zwischen Deutschland und Frankreich auf der anderen Seite, wie es etwa Herr von der $\mathrm{H}$ e y $\mathrm{d} t \mathrm{e}$ in der Festschrift für $\mathrm{N} \mathrm{a} \mathrm{w} \mathrm{i} \mathrm{a} \mathrm{s} \mathrm{k} \mathrm{y} \mathrm{so} \mathrm{klar} \mathrm{herausgestellt} \mathrm{hat.}$

Wenn ich daher diese kurze Betrachtung beginne, so erlauben Sie mir, daß ich da noch an ein Wort von A r is t o teles erinnnere. Es heißt dort in seinem Werk .,Politilk":

„Es kommt vielerorts vor, daß zwar die gesetzmäßige Verfassung nicht demokratisch ist, aber doch vermöge der Sitte und der Geschäftsführung demokratisch regiert wird, und ebenso wieder bei anderen, daß die gesetzmäßig bestehende Verfassung zwar stärker demokratisch ist, aber vermöge der Geschäftsführung und der Sitten mehr oligarchische Verhältnisse herrschen."

Gerade dieser zweite Fall besteht derzeit in Osterreich, daß also, obwohl die Verfassung, die Osterreich im Jahre 1920 beschlossen hat und zu der es im Jahre 1945 wieder zurückgekehrt ist, demokratisch ist, dennoch - aus den von Aristoteles angegebenen Gründen - oligarchische Verhältnisse herrschen. Das hängt eben z. T. mit dem Koalitionssystem zusammen, das wir derzeit haben, das seinen besonderen Ausdruck findet in dem Koalitionspakt, der erstmals nach der letzten Nationalratswahl veröffentlicht wunde. Und hier krommen wir gleich zu einem anderen Punikt, der ja auch schon in dem Referat des Herrn Kollegen Fries e $\mathrm{n}$ hahn heute berührt wurde, zur Rechtsstellung des Abgeordneten, insbesondere zur Frage des Prinzips des freien Mandates, auf das es hier ankommt im Zusammenhang mit den Parteien.

Wenn der Herr Kollege Fries enhahn gesagt hat, daß der Art. 38 der deutschen Verfassung und der Art. 21 in keinem unauflösbaren Widerspruch stehen, so stimme ich ihm darin völlig bei. Ich bin durchaus der Meinung, daß dieses Prinzip des freien Mandates gilt, auch wenn politische Parteien bestehen, - das ist ja das Wesen dieser parlamentarisch regierten Staaten, daß solche Parteien an der Herrschaft in Parlament und Regierung irgendwie beteiligt sind, - da $B$ auch, 
wenn solche Parteien bestehen, trotzdem die Freiheit des Abgeondneten keineswegs aufgehaben sein kann und darf, die Freiheit seiner Entschließung bei Abstimmungen und die Freiheit seiner Rede. Denn wenn diese Freiheit aufgehoben ist, dann schlägt die Sache ins Gegenteil um. Und gerade das ist dasjenige, was wir jetzt leider in Österreich bezüglich der Regierungsparteien festzustellen haben und was in dem Koalitionspakt tatsächlich niedergelegt ist.

In Punkt 5 des Koalitionspaktes ist folgendes gesagt: „Regierungsvorlagen, über die ein einstimmiger Beschluß der beiden in der Bundesregierung vertretenen Koalitionsparteien in materieller und formeller Hinsicht erzielt worden ist, sind für die im Nationalrat vertretenen beiden Koalitionsparteien verbindlich. Grundsätzliche Abänderungsvorschläge bedürfen der Zustimmung des Koalitionsausschusses. Ist anläßlich der Beschlußfassung über eine Regierungsvorlage ein Beschluß der Regierung gefaßt worden, die parlamentarische Behandlung der Regierungsvorlage im Nationalrat den Koalitionsparteien freizugeben, so haben die beiden Koalitionsparteien bei der Behandlung einer solchen Regierungsvorlage im Nationalrat freie Hand." Das heißt mit anderen Worten: Wird eine Regierungsvorlage für die freie Behandlung und Abstimmung im Nationalrat $\mathrm{n}$ i ch $\mathrm{t}$ freigegeben, - und dies ist die Regel, so sind nach diesem Koalitionspakt die Abgeordneten der Regierungsparteien gehalten und verbunden, für die Regierungsvorlage $\mathrm{zu}$ stimmen, und sie dürfen von der Vorlage im Grundsätzlichen nicht abweichen, außer es stimmt der Koalitionsausschuß einer solchen Abweichung zu.

Meine sehr verehrten Damen und Herren, das hebt praktisch die Verfassung auf, hebt sie aus den Angeln, denn dann hört natürlich das notwendige Spannungsverhältnis zwischen Parlament und Regierung auf, dann hört der ganze Sinn des Parlamentes auf, dann hört das auf, was die gesetzgebende Körperschaft ausmacht, da $B$ sie letzten Endes zu entscheiden hat, was Gesetz werden soll und was nicht oder wie es Gesetz werden soll.

Es hat ein österreichischer Bundespräsident, der Bundespräsident Dr. Kö r n e r, am 7. Mai 1952, als er die Abgeordneten bei sich in der Hofburg empfing, folgende Worte zu ihnen gesprochen: „Parlament und Parlamentarier sollen stets bereit sein, widerstreitende Meinungen Außenstehender anzuhören und sich von Sachverständigen beraten zu lassen. Die Entscheidung aber, die eigentliche und endgültige gesetzgeberische Arbeit darf sich das Parlament von niemandem aus der Hand winden lassen, von keiner politischen und keiner wirtschaft- 
lichen Körperschaft, von keinem Gremium einzelner Berufe, Stände oder Schichten. Denn nur das Parlament ist von allen entsandt, für alle da, das Parlament allein vertritt die Rechte des Volkes in seiner Gesarmtheit, es ist ihm für seine Zukunft verantwortlich, und es kann diese Verantwortung mit niemanden teilen."

So gut diese Worte gesprochen wurden und so sehr man ihnen beipflichten kann, so gegenteilig ist das Herrschaftssystem, das beide Regierungsparteien ausüben, vermöge dieses Koalitionspaktes, den ich Ihnen in einer Kernbestimmung jetzt schon vorgeführt habe. Es sind noch weitere solche Bestimmungen darin, die jedes freie Handeln eigentlich praktisch ausschließen. So etwa, wenn es in Punkt 6 heißt: „Bei allen sonstigen Vorlagen und Anträgen", - also wenn es nicht Regierungsvorlagen sind, - „wenden die beiden Parteien im Parlament die Abstimmung, nötigenfalls auch die Freigabe der Abstimmung absprechen."

Es kommt also hie und da vor, daß die Bundesregierung, weil sie so rein innerlich doch nicht ganz einig war über die Vorlage, die eine oder andere Regierungsvorlage zur parlamentarischen Behandlung freigibt. Es besteht ja in Österreich die Besonderheit, abweichend von der Bundesrepublik Deutschland, daß die Regierung, der Ministerrat kraft Gewohnheitsrechtes Beschlüsse nur „einstimmig" fassen kann, daher zu jeder Regierungsvorlage die Einstimmigkeit notwendig ist. Und es kann natürlich sein, daß eine solche Einstimmigkeit einstweilen erzielt wird mit dem Vorbehalt, die endgültige Gestaltung dieses Gesetzentwurfes wind noch dem Parlament anheimgegeben. Dann bietet sich noch die Möglichkeit, im Parlament etwas zu tun. Wenn aber eine Regierungsvorlage von Anfang an für die Regierungsparteien venbindlich ist, sie also nicht freigegeben wird, dann ist bei uns die Lage derart auf die Spitze getrieben, daß nicht nur, wie es wohl auch hier bei Ihnen im großen und ganzen sein mag, im Plenum nicht mehr die Entscheidungen fallen, sondern im Plenum nur mehr die Tribüne ist, von der aus die Regierungsparteien die Gründe für eine Vorlage, die Opposition allenfalls die Gründe dagegen anführen, sondern es ist dann so, daß auch schon im Ausschuß praktisch fast nichts mehr zu ändern ist.

Es ist sehr oft vorgekommen, daß die Opposition mit durchschlagenden Argumenten gekommen ist, - ich gehöre einer Oppositionspartei an, - daß man gesagt hat: bitte das ist falsch und das ist selbst verfassungswidrig, ja, dann wollte der eine oder andere von den Regierungsparteien auf die Sache 
eingehen, es bessern, dann aber erhab sich ein Dritter und sagte: „Halt, das ist eine Regierungsvorlage, die eben nicht freigegeben wurde. Daran wird kein Wort geändert; das ist so anzunehmen, wie es ist." Das war die Situation im Ausschuß schon. Sie sehen also, daß man mit einem solchen Pakt, wie wir ihn jetzt in Österreich haben, tatsächlich allein die Verfassung aus den Angeln heben kann.

Und hier erhebt sich noch die Frage nach den Kontrollmitteln, die auch von einem der Herren Vorredner angeschnitten wurde; er sagte, da $B$ diese Kontrollmittel ursprünglich dem Parlament zugedacht, nunmehr Mittel der Opposition geworden waren. Das wäre sehr schön, wenn es immer so wäre, aber bei uns zumindest, in der österreichischen Verfassung, ist es so, da 3 die Kontrollmittel, die da sind, der Opposition meist nicht zur Verfügung stehen, weil sie in der Regel der Mehrheit zustehen, also z. B. ein Mißtrauensbeschluß oder eine Anklage beim Verfassungsgerichtshof voraussetzt, daß eine Mehrheit diesen Beschluß faßt. Die Möglichkeit, die Sie hier haben, daß eine Minderheit das Verfassungsgericht anrufen und einen Antrag auf Ubberprüfung der Verfassungsmäßigkeit eines Gesetzes stellen kann, ist in Österreich leider nicht gegeben. Die Minderheit ist im wesentlichen auf das Anfragerecht beschränkt.

Also, ich muß, soviel ich weiß, schon zum Schluß eilen, habe aber noch vieles nicht erörtern können. Ich wollte nur zeigen, daß man mit einem solchen Koalitionspakt praktisch die Verfassung aus den Angeln heben, und das, was richtig ist, das natürliche Spannungsverhältnis zwischen Parlament und Regierung, mit einem Striche beseitigen kann. Es kommt eben letzten Endes darauf an, daB die Abgeordneten selbst sich der weittragenden Bedeutung des Prinzips des freien Mandates bewußt sind, daß, wenn man dieses fallen läßt oder untergräbt, das ganze parlamentarische System in sich zusammenfällt.

\section{Sche un er-Bonn:}

Ich darf zunächst zu der methodischen Frage Stellung nehmen, die Herr Ipsen aufgeworfen hat. Man kann den Parlamentarismus nicht behandeln, ohne die politische Wirklichkeit ins Auge zu fassen. Eine Beschreibung des Parlamentarismus bedeutet, Staatsrecht als Wissenschaft eines Lebenden zu betreiben und sich nicht auf die Auslegung einiger Verfassungsbestimmungen zu beschränken. In diesem Sinne möchte ich meine Bemerkungen hier auf drei Punkte begrenzen: Die 
ideelle Rechtfertigung des ganzen Systems, sodann das Problem Regierung und Parlament, von dem ich nur den Bezirk der Regierung berühren kann und endlich das, was Herr Partsch uns vor Augen geführt hat, das freilich mit der Benennung durch Herrn Ipsen als "Funktionslehre" mir nicht richtig gekennzeichnet erscheint, sondern das ich nennen möchte: Beobachtung der Entwicklung eines lebendigen Verfassungssystems an den feinen Erscheinungsformen der organisatorischen und geschäftsordnungsmäßigen Auseinandersetzungen.

Zur Rechtfertigung des Parlaments hat Herr Friesenhahn in seiner These I, 10 mit Recht darauf hingewiesen, da $B$ sich das heutige Parlament nicht mehr allein aus dem Gedanken der Diskussion rechtfertigen läßt. Darin liegt eine Absage an bestimmte Fehldeutungen des parlamentarischen Systems. Die eine von ihnen kommt von der monarchischen Tradition her. Sie meint, nur dann sei ein Staat funktionsfähig, wenn in ihm eine sichtbare exekutive Spitze gegeben sei. Die Herstellung einer solchen festen exekutiven Struktur ist gewiß eine Möglichkeit, den Staat aufzubauen, aber nur eine von vielen. Das parlamentarische System ist ein monokratisches Gebilde, aber es wendet sich nach einer ganz anderen Richtung. Es sucht das Problem der Staatsführung dadurch zu lösen, daß es die politische Entscheidung gründet auf den Kreis von Menschen, der sich im Parlament aus der Wahl des Volkes heraus versammelt. Wir sollten hier die ideellen und ideologischen Vorstellungen des 19. Jahrhunderts nicht überschätzen, sondern den Blick auf die Tatsache lenken, daß in jedem Staat notwendig ein kleiner Kreis von Personen die staatlichen Entscheidungen zu treffen hat. Das parlamentarische System beantwortet die Frage nach Zusammensetzung und Wirksamkeit dieses Kreises dahin, daß das Handeln der Regierung in der Öffentlichkeit vor sich geht und in ständiger Auseinandersetzung mit einer mehrhundertköpfigen Körperschaft gewählter Volksvertreter. Hierin besteht der eigentliche Kern dieser Regierungsform, während in den Vereinigten Staaten etwa in Gestalt des volksgewählten Präsidenten im Gegenüber mit einer gewählten Volksvertretung ein ganz anderes System der Staatsführung aufgerichtet ist. Ideell steckt hinter jeder demokratischen Staatseinrichtung das Vertrauen auf den Wettbewerb verschiedener politischer Richtungen und die Wirkung der Offentlichkeit. Dagegen kommt es nicht so entscheidend auf das Moment oder gar die Formen der Diskussion an, wie auch die ganzen Arbeitsmethoden des Parlaments im Lauf der Zeit sich wandeln können. Die entscheidende und zugleich vielleicht 
auch die pathologische Seite des heutigen Parlamentarismus liegt nicht so sehr in der Spannung von Regierung und Parlament, sondern in der Relation Parlament-Volk. Sie betrifft die Legitimationskette, die vom Volk über das Parlament zur Regierung reicht. Das berührt einen Fragenkreis, der noch über unser heutiges Thema hinausreicht, das Wahlrecht, die Stellung der Abgeordneten, ihre repräsentative Position. Ist die Uberzeugungskraft dieser Legitimation des Abgeordneten nicht in Ordnung, so wird die Legitimation des Parlaments erschüttert. Das System vertraut auf die Möglichkeit, auf diesem Wege durch das Parlament die Bildung einer politischen Elite, die Gewinnung eines Kreises hervorragender Männer zu erreichen, der das Vertrauen rechtfertigt, hier werde eine Regierung für das Volk geführt. Deshalb ist eine Gefährdung dieser Rechtfertigung der parlamentarischen Regierung dort gegeben, wo entscheidende Einflüsse nicht den Weg durch diese konstitutionellen Formen gehen, sondern andere Bahnen sich suchen. Das gilt nicht für die Parteien. Sie gehören zu diesem System als mitbestimmende Faktoren, auch wenn ich nicht, wie Herr Leibholz - den wir heute nicht unter uns haben - glaube, daß die Institutionalisierung der Parteien als Verfassungsbestandteile schon weitgehend vollzogen sei, vielleicht sogar staatsrechtlich bis $\mathrm{zu}$ einer Anerkennung als staatliche Einrichtungen fortgeführt werden müsse. Auch die Stellung der Verbände gehört in diesen Zusammenhang. Thre Position scheint mir dadurch gekennzeichnet, daß so wie der einzelne Abgeordnete sich heute in organisiertem Rahmen in Fraktion und Partei einfügt, so auch die Wählerschaft nicht mehr aus isolierten Individuen besteht, sondern auf einer gruppenförmigen Verfestigung des öffentlichen Lebens beruht.

In beiden Vorträgen, vor allem bei Herrn Friesenhahn (These I, 13), scheint mir die Stellung der Regierung ein wenig zu schwach gezeichnet. Auch im parlamentarischen System muß regiert werden, und zwar durch eine aktionsfähige Regierung. Denn nur der kann Verantwortung tragen, der wirklich zu handeln vermag. Deshalb würde ich Herrn Friesenhahns Meinung nicht teilen, es gebe kein Vonbehaltsgebiet der Regierung. Wenn das Parlament die personelle Zusammensetzung eines Ministeriums ins einzelne bestimmen würde, so könnte man den Minister nicht mehr für das verantwortlich machen, was in seinem Hause geschieht. Es gibt bestimmte Grenzen, jenseits deren das Parlament selbst regieren würde, nicht aber mehr den Ministern eine verantwortliche Regierung überträgt. Es gehört jedenfalls zu dieser Funktionsform der Regierung, daß sie insofern vom Parlament unabhängig ist, 
als sie in ihrer Vorbereitung politischer Initiativen nicht auf die parlamentarische Anregung zu warten braucht. Das Element des Programms, des Planes, der Vorausschau enthält ein exekutives Moment, es gehört dem eigentlichen Regierungshandeln, nicht aber der parlamentarischen Sphäre an. Wenn Herr Ipsen hier auf die Bedeutung der internationalen Sphäre hingewiesen that, so würde ich meinen, da $B$ auch hier die Probleme nicht in einer Machtverschiebung zwischen Regierung und Parlament liegen. Noch ist eine eigentlich supranationale Instanzenbildung hier nicht tatsächlich erfolgt und erst recht nicht eine Stufe föderativer Entwicklung erreicht, in der die nationalen Regierungen mediatisiert sein wünden. Denn noch trägt unzweifelhaft für jedes Land die eigene nationale Regierung die Verantwortung für die nationale Solidarität in sozialer und wirtschaftlicher Hinsicht. Solange nicht eine wirkliche Föderation erfolgt ${ }_{n}$ wenden auch die nationalen Parlamente darüber wachen, daß nicht eine Verlagerung dieser Verantwortung erfolgt, daß sie vielmehr bei den einzelnen Gliedern eines europäischen Zusammenschlusses bleibt.

Endlich ein kurzes Wort noch zur strukturellen und funktionellen Gestalt des Parlaments. Die Wandlungen der Arbeitsweise und Geschäftsordnung des Parlaments stellen gewissermaßen Signale dar für die tiefer liegenden strukturellen Veränderungen der Staatsleitung. Wenn sich die Entscheidungen der Parlamente in die Ausschüsse verlagern, so werden damit strukturelle Veränderungen der Mehrheitsbildung und möglicherweise auch der Meiungsibildung hervorgerufen. Das ist mehr als eine Verfahrensfrage. In einem neueren Gutachten des Internationalen Gerichtshofes hat Sir Hersch Lauterpacht in seinem Sondervotum gesagt: "The size of the majority required for the validity of the decisions of a corporate body is not a mere matter of technical convenience or mathematical computation. It is expressive of the basic political philosophy of the organization:" (I. C. J. Reports of Judgments 1955 S. 108). Es möge genügen, diese strukturellen Änderungen nur noch an einem Beispiel zu beleuchten. Die Auflösung des Parlaments ist heute überall zu einer Selbstauflösung des Parlaments geworden. Es gibt keine Auflösung als Kampfmaßnahme gegen ein Parlament mehr; auch die Zeitprämie, die in der Wahl des Zeitpunkts der üblichen Auflösung des britischen Parlaments liegt, ist durch die Mehrheit des Parlaments gedeckt, die hinter der dies Recht ausübenden Regierung steht. Die Auflösung dient also nicht mehr einer Auseinandersetzung zwischen Regierung und Parlament. Darum kann ich die Meinung von Herm Friesenhahn nicht teilen, der der 
Bundesregierung eine echte Auflösungsbefugnis zuteilen möchte (These I 27). Die Exekutive sollte im heutigen Stand der Entwicklung sich zurückhalten; es ist Sache des Parlaments selbst, sich selbst aufzulösen, wenn es seine Aufgaben nicht mehr erfüllen kann.

\section{Merk-Tübingen:}

Bei der Kürze der zur Verfügung stehenden Zeit ist es mir leider nur möglich, einige bedeutsamere Punkte zur Sprache zu bringen, zu denen mir die beiden Vorträge $A$ la $B$ geben.

1. Herr Friesenhahn hat mit Recht an der Spitze seiner Ausführungen auf das Musterbild der englischen Verfassung abgehoben, wo die parlamentarische Regierungsweise, geschichtlich geworden und gewachsen, man kann wohl sagen, am besten sich bewährt hat. Dort bestehen im allgemeinen zwei Parteien, die in ihren gesellschaftlichen und politischen Auffassungen keine wesentlichen Unterschiede aufweisen, so daß ein englischer Staatsrechtslehrer, wie Jennings, sagen konnte, da $\beta$ die Konservativen und die Arbeiterpartei sich in ihren politischen Auffassungen nur dem Grade nach unterscheiden. Wenn sodann gesagt worden ist, die Bedeutung der Gegenseite oder Gegenpartei (der sogenannten Opposition) liege darin, daß sie eine sogenannte „Alternativpolitik“ zu betreiben und die Regierung zu bekämpfen habe, so möchte ich statt dessen lieber sagen: sie hat die Aufgabe einer förderlichen Kritik der Regierung. Das braucht freilich nicht immer der Fall zu sein; es kann ja die Regierung auch sich auf dem "richtigen Wege“ befinden. Vor allen Dingen wünschenswert wäre es $\mathrm{m}$. $\mathbf{E}$. für unser Volk, daß es wenigstens auf außenpolitischem Gebiete in wichtigen Fragen zu einheitlichen Auffassungen zwischen Regierung und Gegenseite käme, nötigenfalls auf Grund eines Gesprächs am runden Tisch, wie die Engländer sich ausdrücken, unter Ausschaltung von rechthaberischem Festhalten an der eigenen Meinung, statt den Blick hier wie auch sonst vor allem darauf $\mathrm{zu}$ richten, wie die zur Behandlung stehenden augenblicklichen politischen Fragen zum Wohle der Allgemeinheit zweckmäßigerweise am besten zu lösen sind. Es muß eben gegebenenfalls ein Ausgleich der verschiedenartigen Belange gesucht und gefunden werden und der Wille und die Bereitschaft dazu sowohl auf Seiten der Regierung und der Regierungsparteien wie auch auf Seiten der Gegenparteien vorhanden sein. Je mehr bei uns das Weltanschauliche in der Behandlung politischer Fragen bei den Parteien zurücktritt, um so mehr darf man hoffen, daß dies in der Zukunft auch bei uns 
einmal möglich sein wird, zumal da jetzt alle im Bundestag vertretenen Parteien auf dem volksherrschaftlichen und rechtsstaatlichen Boden stehen.

2. Ich bin dann weiter mit Herrn Friesenhahn in Ubereinstimmung darin, daß es im Grunde genommen keinen unauflöslichen Widerspruch zwischen Art. 21 und Art. 38 GG gibt, d. h. zwischen der Anerkennung der politischen Parteien als Mitträgern der politischen Willensbildung, kurz gesagt, zwischen dem sogenannten Fraktionsewang einerseits und der Eigenschaft der Abgeondneten als Vertretern des ganzen Volkes, die an Aufträge und Weisungen nicht gebunden und nur ihrem Gewissen unterworfen sind, andererseits. Im Hinblick auf die verfassungsrechtliche Stellung der Parteien läBt es sich nicht ausschließen, daß gegebenenfalls durch Mehrheitsbeschluß der Fraktion zu bestimmten Fragen Stellung genommen wird, mit der inneren Bindung für die Fraktionsmitglieder, daß sie ihre Stimme entsprechend abgeben. Wünschenswert mag jedoch wohl erscheinen, $\mathrm{da} B$ kein übermäßiger Gebrauch von solchem Fraktionszwang gemacht wird, sondern auf Grund des Vertrauens zur Parteiführung und eigener freier Uberzeugung abgestimmt wird. Wichtig ist jedenfalls, daß der Abgeordnete die Eigenschaft als solcher nach außen nicht verliert, wenn er entgegen einem inneren Fraktionsbeschluß seine Stimme auf Grund freier Utberzeugung abgibt; welche Folgen dies im Verhältnis zur Fraktion bzw. Partei hat, ob er etwa deswegen aus diesen ausgeschlossen wird, das ist eine andere Frage. Aber so wird doch die Freiheit des Einzelnen nach außen hin gewahrt.

3. Auch dem Satze, daß Parlament und Regierung in ihrem Wirken nicht auf die Fragen beschränkt sind, die eine Rolle im Wahlkampf gespielt haben, stimme ich voll zu. Die Abgeordneten werden auf vier Jahre gewählt und es läßt sich gar nicht voraussehen, was im Laufe dieser Zeit etwa an neuen Fragen auftaucht. Aber es wäre bei einer Neuordnung der Verfassung doch zu erwägen, ob nicht bei wichtigen Fragen gegebenenfalls mehr Rücksicht auf einen offensichtlich eingetretenen Wandel in der Volksmeinung gegenüber der Zeit der Wahl genommen werden kann. Es sei auch hier auf die beispielhafte englische Utbung hingewiesen, wo man in solchen Fälen zur Auflösung des Unterhauses und zu Neuwahlen schreitet. Bei uns ist leider, möchte ich hier sagen, das Auflösungsrecht des Bundespräsidenten nach dem GG zu sehr eingeschränkt, so daß es nur $u$. U. bei der Bundeskanzlerwahl und bei der Ablehnung der Vertrauensfrage eine Rolle spielt. 
4. Bei Ziff. 7) der Leitsätze, wonach die politische Macht im Staat weder bei den Parteien noch bei den Verbänden, sondern bei Parlament und Regierung stehe, welche die widerstrebenden Belange zum Ausgleich nach den Forderungen des Gemeinwohls zu bringen haben, wird $\mathrm{m}$. E. nicht genügend zwischen der rechtlichen und der politischen Betrachtungsweise unterschieden. Es läßt sich doch nicht bestreiten, daß nach dem Wegfall der Einherrschaft, politisch betrachtet, die Parteien und deren Führer die Träger der politischen Macht geworden sind, insbesondere die Mehrheitsparteien, die die Regierung bilden als die sogenannten Regierungsparteien.

5. Es ist dann verschiedentlich von dem Spannungsverhältnis zwischen Regierung und Parlament gesprochen worden (vgl. Ziff. 12 d. Leits.). Aber bei der parlamentarischen Regierungsweise ergibt sich ein engerer Zusammenhang zwischen der gesetzgebenden Gewalt und der vollziehenden Gewalt, insofern die Regierung aus den Mehrheitsparteien hervorgeht, und so besteht das Spannungsverhältnis, wie es in der verfassungsmäßig beschränkten Einherrschaft zwischen Regierung und Volksvertretung bestand, in dem Maße nicht mehr, sondern es besteht vor allem zwischen der Regierung bzw. den Regierungsparteien und den Parteien der Gegenseite. Und es darf hier auch nicht übersehen wenden - um grade auf unsere Verhältnisse abzuheben -, daß der Bundeskanzler nicht nur Vorsitzender der Bundesregierung ist und die Richtlinien der Politilk bestimmt, sondern daß er auch Führer der Regierungspartei ist; diese andere Seite seiner Machtstellung darf nicht außer acht gelassen werden. Die Bildung einer „Allparteienregierung" mag gewiß in Krisenzeiten, wie insbesondere im Falle eines Krieges, ihre große Bedeutung haben, wie dies, auch hier in vorbildlicher Weise, in England immer wieder hervorgetreten ist. Im übrigen aber würde es an der erforderlichen öffentlichen Kritik der Tätigkeit der Regierung fehlen. Deshalb ist $\mathrm{m}$. E. die Allparteienregierung in regelmäßigen Zeiten im großen Staatswesen im allgemeinen als nicht wünschenswert zu bezeichnen. Bei den Ländern mögen die Verhältnisse anders liegen, da sie, im ganzen gesehen, mehr die Aufgabe haben, zu verwalten und keine große Politik zu treiben haben.

6.1) Schwere Bedenken habe ich sodann gegen Ziff. $13 \mathrm{~d}$. Leits., wonach es keine verfassungsmäßigen Vorbehaltsgebiete

1) Dieser von mir für die Aussprache aufgezeichnete Punkt ist infolge eines bedauerlichen Versehens nicht zur Sprache gekommen, obwohl mir an ihm sehr gelegen war; er wird deshalb nur mit diesem Vorbehalt andeutungsweise mitaufgeführt. 
der Regìerung gebe und die Staatsleitung dem Parlament und der Regierung gemeinsam zustehen, so da $B$ das Parlament auch auf die Regierungshandlungen Einfluß nehmen und der Regierung Weisungen erteilen könne. Hier ist doch die in Art. 20 GG festgelegte Gewaltentrennung, wonach die vom Volk ausgehende Staatsgewalt vom Volke in Wahlen und Abstimmungen und durch besondere Willensträger der Gesetzgebung, der vollziehenden Gewalt und der Rechtssprechung ausgeübt wird, nicht genügend beachtet.

7. Auch den Ausführungen über die Schweizerischen und Bayerischen Verfassungsverhältnisse vermag icht nicht zuzustimmen. Der Bundesrat wird in der Schweiz auf Zeit, nämlich auf drei Jahre, von der Bundesversammlung gewählt, aber doch, soviel mir bekannt, unter Zugrundelegung der dort bestehenden parteipolitischen Verhältnisse. Eine Sicherung der Regierung gegen ihre Abberufung ist $\mathrm{m}$. E. nicht, wie gesagt worden ist, in den Bestimmungen über die Volksabstimmung zu erblicken (Ziff. 23 d. Leits.); diese bedeuten vielmehr ein Gegengewicht gegen die Macht der Volksvertretung und der politischen Parteien. In Bayern wird der Ministerpräsident nach Schweizer Vorbild ebenfalls auf Zeit, auf 4 Jahre, vom Landtag gewählt, allerdings mit der Verpflichtung zurückzutreten, wenn die politischen Verhältnisse eine vertrauensvolle Zusammenarbeit zwischen ihm und dem Landtag unmöglich machen.

8. Entgegen Herrn Friesenhahn möchte ich doch in dem Erfordernis des einsetzenden oder aufbauenden Mißtrauensbeschlusses einen Fortschritt erblicken gegenüber der Einrichtung des bloß absetzenden Mißtrauensbeschlusses, wie es nach der Weim. RV galt. Es konnte da vorkommen, daß die verschiedenartigsten Parteien sich zusammentaten, nur in der Absicht, die Regierung zu stürzen, ohne daß nachher klar war, wer nun für die Zukunft die Regierung zu übernehmen hat, wie sich dies bei der Zweiparteiengestaltung ohne weiteres ergibt. Etwas ganz anderes haben wir heute, wenn gleichzeitig mit dem Mißtrauensbeschluß ein neuer Bundeskanzler mit der Mehrheit der Mitglieder des Bundestags gewählt werden muß; wenn dies nicht zustande kommt, dann ist eben die Regierung nicht gestürzt. Sie hat danach eine ganz andere Stellung als eine durch absetzenden Mißtrauensbeschluß gestürzte Regierung, die lediglich allenfalls bis zum Zustandekommen einer neuen Regierung die Geschäfte weiterzuführen hat.

9. Zu den Ausführungen des Herrn Partsch kann ich infolge Zeitmangels leider nicht mehr viel bemerken.

9 Veröffentlichungen der Staatsrechtslehrer, Heft 16 
Ich möchte aber ihm gegenüber (Ziff. 2 seiner Leits.) doch einmal betonen, da $B$ die Bedeutung der Arbeit der Parlamentsausschüsse - von besonderen Ausschüssen, wie dem sogenannten Zwischenausschuß usf., abgesehen - in der Vorbereitung der Beschlüsse der Vollversammlung liegt. Hier kommt im Zusammenwirken mit den Vertretern der Regierung das Fachlich-Sachliche, aber doch auch das Politische, zu Wort, indem die Parteien nach ihrer Stärke in ihnen vertreten sind. Äußerlich werden zwar die maßgeblichen Entscheidungen von der Vollversammlung getroffen; aber die Parteien haben regelmäßig ihre Stellungnahme schon vorher, sei es vor der zweiten oder dritten Lesung, festgelegt.

10. Was sodann den Sitz der Regierung in der Volksvertretung anbelangt, so glaube ich, wir sollten auch nach 1945 nicht einfach auswärtige Einrichtungen ohne ausreichende Gründe nachahmen. In England ist es alte geschichtliche Uberlieferung und hat dort einen guten Sinn, daß die Regierungspartei einschließlich der Regierung und die Gegenseite einander gegenübersitzen. Dort sind die Parteien - ursprünglich die Konservativen (Tories) und die Liberalen (Whigs), die jetzt in der Hauptsache durch die Arbeiterpartei abgelöst worden sind - aus früheren den Staat tragenden Adelsparteien hervorgegangen. Dort handelt es sich um ein Spiel um die politische Macht; auch gehören dort sämtliche Mitglieder des sogenannten Kabinetts als Abgeordnete dem Parlament an. Bei uns wirken noch bis zu einem gewissen Grade die alten Verhältnisse der früheren - vor allem auf ein Berufsbeamtentum sich stützenden - Einherrschaft nach, vielleicht aber doch auch noch der Gedanke, daß die Regierung nicht nur eine Parteiregierung, ein "party government", wie die Engländer sagen, darstellt, sondern daB sie treuhänderisch die Gesamtbelange wahrzunehmen hat und insoweit doch in gewisser Weise über den Parteien stehen soll; weiter haben wir nicht oder noch nicht ein ausgeprägtes Zweiparteiengefüge nach englischer Art. Im übrigen meine ich, wir sollten die parteipolitischen Dinge nicht überspitzen und insbesondere die sachliche Bedeutung des fachlich vorgebildeten und verwaltungserfahrenen Berufsbeamtentums - zwar im Dienste der Regierung, aber als Diener nicht einer Partei, sondern der Gesamtheit - nicht gering anschlagen.

\section{Carstens - Bad Godesberg:}

Aus der großen Fülle der Themen, die von den beiden Herren Referenten behandelt worden sind, möchte ich nur zu einem Fragenkomplex, und zwar zu dem Verhältnis von Regierung 
und Parlament im Bereich der internationalen Politik Stellung nehmen, in Anknüpfung an das, was Herr Partsch ausführte. Herr Partsch hat ganz mit Recht darauf hingewiesen, daß sich der Einfluß des Parlaments auf den Bereich der auswärtigen Politik in verschiedenen Formen und auf verschiedene Weise vollzieht, sei es, daB das Parlament bei den Vertragsverhandlungen beteiligt wird, oder in der Form, daB. es seine Zustimmung geben muß, bevor ein Vertrag in Kraft tritt, und schließlich in der Weise, daß Mitglieder des Parlaments zugleich Mitglieder internationaler parlamentarischer Instanzen sind und daher im internationalen Bereich, in den internationalen Organisationen, ein gewisses Kontrollrecht ausüben können. Nicht behandelt worden ist in den Referaten, und ich glaube auch in den bisherigen Diskussionsbeiträgen nicht, ein weiteres Problem, da $\beta$ mir besonders aktuell zu sein scheint, nämlich die Frage: wer kontrolliert die Ministerräte, d. $h$. die Organe, die aus Regierungsvertretern bestehen, und die ja bei mehreren internationalen Organisationen eine außerondentliche Machtfülle auf sich vereinen? Man braucht gar nicht nur an die drei europäischen Gemeinschaften zu denken, die Montangemeinschaft und die Gemeinschaften, die im Begriff sind, zu entstehen, sondern man kann auch Bezug nehmen z. B. auf die OEEC, wo ein Ministerrat in der Lage ist, Beschlüsse zu fassen, die für die Mitgliedstaaten venbindlich sind, und in denen Fragen von weittragender wirtschaftlicher Bedeutung geregelt werden. Hier ist ein Raum, in dem eine parlamentarische Kontrolle zu fehlen scheint. Bei den Gemeinschaften der „6“, bei der Montangemeinschaft, bei dem Gemeinsamen Mankt und bei der Atomgemeinschaft ist zwar eine parlamentarische Instanz gebildet. Herr Ipsen hat davon gesprochen. Man kann vielleicht darüber streiten, wie stark ihre demokratische Legitimation ist, aber immerhin ist doch ein sehr ernsthafter Versuch unternommen worden, eine parlamentarische Kontrolle in diesem Bereich einzuführen. Aber diese Kontrolle bezieht sich auf die Tätigkeit der unabhängigen Exekutivorgane dieser Gemeinschaften, also der Hohen Behörde und der beiden Europäischen Kommissionen. Die Tätigkeit der Ministerräte unterliegt der Kontrolle dieses parlamentarischen Organs nicht; und sie unterliegt auch nur in einem sehr geringen Ausmaße der Kontrolle der nationalen Parlamente. Es ist zwar richtig, daß der Minister, der in diesen Ministerräten der internationalen Organisationen an einer Entscheidung mitwirkt, seinem eigenen nationalen Parlament verantwortlich ist; aber da die Abstimmungen und Beratungen geheim sind und da in vielen Fällen Mehrheitsent- 
scheidungen möglich sind, ist die Ausübung der nationalen parlamentarischen Kontrolle gegenüber der Tätigkeit der nationalen Vertreter in den Ministerräten praktisch außerondentlich schwierig. Diese Frage hat bei den Beratungen der beiden neuen europäischen Verträge im Bundestag und Bundesrat eine große Rolle gespielt. Und sie hat schließlich zu einer Lösung geführt, die ihren Niederschlag gefunden hat in dem Art. 2 des Zustimmungsgesetzes zu diesen Verträgen, in dem es dem Sinne nach heißt, daß die Bundesregierung verpflichtet ist, Bundestag und Bundesrat über die Führung der Geschäfte in den Ministerräten der beiden europäischen Ge-meinschaften auf dem laufenden zu halten und daB die Unterrichtung im Voraus erfolgen muß, bevor es in einem dieser Ministerräte zu einer Beschlußfassung kommt, durch die entweder eine Änderung der deutschen Gesetzgebung erforderlich wird oder unmittelbar verbindliches Recht in der Bundesrepublik gesetzt wird. Hier ist also der Versuch gemacht worden, das deutsche Parlament bei der Instrulktionserteilung an den deutschen Vertreter im Ministerrat der Europäischen Wirtschaftsgemeinschaft und der Europäischen Atomgemeinschaft einzuschalten. Die Bundesregierung wird verpflichtet, dem Parlament die Problematik zu unterbreiten, bevor ein Beschluß im Rate gefaßt wird. Daraus ergibt sich die Möglichkeit einer Diskussion der beabsichtigten Maßnahmen im nationalen Parlament und eine Einwirkungsmöglichkeit des Parlaments auf diese Maßnahmen. Eine weitere Frage, die sich stellte, ist nicht entschieden worden, nämlich, ob es möglich und zulässig wäre, die Mitwirkung des deutschen Vertreters bei der Beschlußfassung der Ministerräte an die vorherige $\mathrm{Zu}-$ stimmung der deutschen gesetzgebenden Körperschaften zu binden. Diese Forderung ist zeitweilig erhoben worden, sie ist später aber fallen gelassen und zugunsten der erwähnten Informationspflicht der Regierung aufgegeben wonden. Die Bedenken gegen die Bindung des Regierungsvertreters an die parlamentarische Zustimmung liegen auf der Hand. Durch eine solche Maßnahme würde die Entscheidungsmöglichkeit der europäischen Organe ganz außerordentlich eingeschränkt und erschwert. Nehmen wir an, daß die übrigen Mitgliedstaaten ähnliche Regelungen getroffen hätten, so hätte das bedeutet, daB, bevor der Ministerrat normsetzende Beschlüsse hätte fassen können, entsprechende zustimmende Beschlüsse in allen sechs Parlamenten hätten herbeigeführt werden müssen. Damit wäre der Zweck des Vertrages, den europäischen Organen gewisse Entscheidungen zu übertragen, vereitelt worden. Ich habe hier nur auf die Problematik hinweisen wollen. 
Ich glaube, daß eine saubere Lösung dieser Fragen erst dann möglich sein wird, wenn der Schritt getan worden ist, von dem Herr Scheuner sprach, der Schritt zu einer Föderation, in der einer europäischen Staatengemeinschaft echte gesetzgeberische Funktionen, die bei einer parlamentarischen Instanz liegen müßten, übertragen werden. In der Zwischenzeit wird man sich mit Hilfskonstruktionen behelfen müssen, und ich glaube sagen zu dürfen, auch behelfen können; die Erfahrungen der OEEC scheinen mir zu zeigen, daß in den 8 Jahren ihrer bisherigen Tätigkeit das Fehlen einer unmittelbaren parlamentarischen Kontrolle gegenüber dem Ministerrat trotz der sehr weitgehenden Beschlüsse, die dort gefaßt worden sind, keine bedenklichen Folgen gehabt hat.

\section{Mü n c h - Berlin:}

Ich glaube, daß der Grundtenor des Referats von Herm Friesenhahn ein zustimmendes Echo verdient, daß man nämlich unsere Verfassung würdigen muß, und da $B$ man sie nicht diskriminieren darf, indem man Vorstellungen politischer Wissenschaft von vor etwa 30 Jahren hereinbringt. Er hat mit großem Recht betont, daß der politischen Persönlichlkeit doch heute noch ein sehr großer Wirkungsbereich und ein sehr großes Gewicht beizumessen ist, und daß man - glaube ich sich in veralteten Vorstellungen bewegt, wenn man so viel vom Parteienstaat oder Verbandsstaat spricht. Es genügt $\mathrm{m}$. E. ein Willensentschluß einmal der Beteiligten, dann aber auch aller derjenigen, die das Ohr der Offentlichkeit haben - auch wir haben es ja in gewisser Weise in unseren Hörsälen - um hier einen großen Wandel zu schaffen.

Was heißt „moderner Staat", wenn wir nach Kopfzahl gehen und etwa alle Staaten aufzählen und mit gleichem Gewichte wägen, die auf der Welt existieren oder in den Vereinten Nationen vertreten sind? Wir müßten sagen: der moderne Staat ist die Pseudodemokratie. Nun haben sich die Herren Referenten auf unsere westlichen Vorstellungen beschränkt. Aber auch da haben wir zweierlei: nicht nur das parlamentarische Regierungssystem, sondern auch mit ebenso großem Gewicht und ebenso großer Bedeutung das Präsidialsystem. Und wenn wir uns auf den Kreis der parlamentarischen Demakratien beschränken, haben wir wiederum verschiedene Modelle: das französische auf der einen, das englische auf der anderen Seite, und können eigentlich nur das tun, was Redslob seinerzeit getan hat, als er sich ein Idealbild von parlamentarischem Regierungssystem schuf und damit die Verfassung, die zu entwerfen war, wertete. Wenn wir das heute tun, dann 
bewerten und interpretieren wir das Grundgesetz nach einem abstrakten Ideal, das wir uns gebildet haben. Und da möchte ich der Kritik von Herrn Ipsen folgen, der sagte, daß das eigentlich keine Rechtswissenschaft sei. Jedenfalls geraten wir in Gefahr, die Verfassungsartikel nicht mehr zu interpretieren, sondern weiterzuentwickeln und vielleicht mißzuverstehen.

Zu einzelnen Thesen: Nr. 5, 7 und 10 des Referates von Herrn Friesenhahn sprechen von der Rechtfertigung des parlamentarischen Regierungssystems. Die Bereitschaft und die Fähigkeit zum Kompromiß wird hier hervorgehoben, z. B. in der These 7: "widerstrebende Interessen zum Ausgleich bringen“. Das ist aber etwas anderes als das, was nun mit einem "und" angehängt wird: „Entscheidungen nach den Fonderungen des Gesamtwohls treffen." Die Forderungen des Gesamtwohls sind nicht in einem Kompromiß zu finden, sondern sind etwas ganz anderes. Aus Rausseau, obwohl er heute wenig zitiert wird, wissen wir, daß die "volonté de tous" etwas anderes ist als die "volonté générale“. Und nur um die "volonté générale" handelt es sich. Es ist ja auch in den Referaten und in unseren Erörterungen schon gezeigt worden, daß die Diskussion und damit der Ausgleich der Interessen gar nicht mehr das Entscheidende heute ist, sondern die Führung der Politik in aller Offentlichkeit, so wie es gerade in der These 10 hervorgehoben ist, also die Suche nach dem Gesamtwohl vor aller Offentlichkeit und die Darlegung der Gründe in aller Offentlichkeit.

Utbrigens noch zum modernen Staat: Wenn wir angesichts der Verfassungen der supranationalen Gemeinschaften, insbesondere der Montan-Union unterstellen wollen, hier seien die Erkenntnisse der Staatslehre verwertet und die Folgerungen aus der bisherigen Geschichte des parlamentarischen Systems und der modernen Demokratie überhaupt gezogen, dann müssen wir im modernen Staat keine parlamentarische Demokratie mehr sehen, sondern den Absolutismus einer Exekutivelite, die nur sehr stark rechtsstaatlich gebunden ist. Das Parlament der Montanunion kann nur einmal im Jahr die Exekutive stürzen und sich in kein einzelnes Geschäft einmischen. Diese Exekutivelite hat auch das Gesetzgeb.ungsrecht, soweit noch vorhanden, soweit nicht das Statut der Montanunion, also die Verfassung, alles schon festgelegt hat. Da wäre also doch die Frage, ob wir im modernen Staat nicht schon eine Tendenz zu einer Exekutivelite haben, die nur noch rechtsstaatlich gebunden ist - jedenfalls eine Formel für einen Staat, die hinter den aktuellen Formeln steht und an deren Stelle treten könnte, wenn wir mit der parlamentarischen Demokratie wieder einmal scheitern sollten. So glaube ich, 
daß man auch die Stellung der Regierung bei uns noch etwas unabhängiger sehen muß; sie nimmt bei uns sicher eine Zwischenstellung ein zwischen der französischen und der englischen. In der englischen führt sie - das haben ja mehrere Redner betont - das Parlament in einer Weise, die uns unbekannt ist und gegen die man sich bei uns sträubt. Jedenfalls hat sie nach unserer Tradition und so, wie die Verfassung jetzt gehandhabt wird, das Ansehen eines ganz besonderen Organs; sie geht zwar aus dem Parlament hervor, tritt ihm aber dann in dem ganzen politischen Spiel mit eigenen Rechten entgegen.

Und hier, scheint mir, ist auch der Bundespräsident etwas vergessen worden in den Thesen von Herrn Friesenhahn I, 18, I, 27 und II, 11. Seine Rolle ist $\mathrm{m}$. E. verkümmert. Zur These II, 11 insbesondere glaube ich, daß der Bundespräsident das materielle Prüfungsrecht der Gesetze hat und daB die Bundesregierung infolgedessen in einer merkwürdigen Konsequenz, die aus der Gegenzeichnungspflicht und aus dem Gegenzeichnungsrecht hervorgeht, die präsidialen Befugnisse zunächst ausübt. Ich erinnere an das Platow-Amnestiegesetz, das kleine Spezialgesetz, welches von der Bundesregierung unterschlagen worden ist, die die Gegenzeichnung zur Ausfertigung nicht leistete, weil sie verfassungsrechtliche Bedenken hatte.

Auch glaube ich nicht, daß das Weisungsrecht des Parlaments gegenü:ber der Regierung, wie es in den Thesen I, 19, II, 2, II, 13 und in gewisser Weise I, 25 geschildert ist, in dieser Weise besteht. Es ist natürlich richtig, daß das Regierungsprogramm die Mehrheit des Parlamentes hinter sich haben muB. Das halte ich aber nur für eine politische Forderung, einfach eine Nützlichkeitserwägung. Die andere Alternative wäre das, was die ostzonale Verfassung ausdrücklich sagt - ich sehe jetzt von dem Zwiespalt zwischen Verfassungsrecht und Verfassungswirklichkeit ab -, daß die Richtlinien der Regierungspolitik durch Beschlüsse des Parlamentes festgelegt werden. Ich glaube, aus wohlerwogenen Gründen hat man das nicht bei uns.

Uber die Rolle, die die Regierung durch ihre Beteiligung in internationalen Organisationen gewonnen hat, will ich nur noch wenige Worte sagen; denn verschiedene meiner Herren Vorredner sind schon darauf eingegangen. Es ist in der Tat so, daß die Regierungen diejenigen Gremien in den internationalen Organisationen bilden, die dort die Beschlüsse fassen. Je mehr Gegenstände internationalen Organisationen zugewiesen werden, um so mehr verstärkt sich auf diese Weise das Gewicht der Exekutive bei uns. Selbst dort, wo in die in- 
ternationalen Organisationen demokratische oder parlamentarische Gremien eingefügt werden, wie bei der Montanunion, müssen wir beabachten, daß sie die Funktion des Parlamentes nicht haben, daß sie dort keine Gesetzgebung ausüben, sondern nur eine verhästnismäßig schwache Kontrolle haben. Es taucht also tatsächlich das Problem auf, das Herr Carstens behandelt hat: gibt es eine Möglichkeit, auf einem Umwege die Beschlüsse nicht nur der Ministerräte, sondern auch aller anderen internationalen Organe, die von Regierungsdelegierten beschickt werden, zu kontrollieren? Ich glaube auch hier nicht, $\mathrm{da} B$ das Parlament der Regierung Weisungen für ihre Verhandlungen geben kann; Auffondemungen zu Vorbehalten bei der Ratifikation sind $m$. E. politische Demonstrationen, die nur die politische Sanktion haben können, daß eventuell ein Regierungssturz folgt. In diesen Zusammenhang gehört, daß auch die Beteiligung der Parlamente bei der Beratung von internationalen Verträgen gering ist; die Verträge können nicht durch die Beschlüsse des Parlaments geändert wenden In der niederländischen Verfassung ist es seit der Novelle so, daß die Verträge nur deponiert werden und daß lediglich auf den Antrag des Parlaments in eine Beratung eingetreten wird. Also gibt es hier rein geschäftsordnungsmäßig die Möglichkeit, daß sich das Parlament zu internationalen Abkommen verschweigt.

\section{K or d t - Köln:}

Darf ich auf den Diskussionsbeitrag von Herrn Carstens zurückkommen, um Mißverständnisse, die möglicherweise entstanden sein könnten, zu klären. Seitens des Bundesrates bestand nicht die Absicht, durch Einfügung der erwähnten Bestimmungen in die Genehmigungsgesetze zu den Römischen Verträgen in den exekutiven Bereich einzugreifen. Die Absicht war vielmehr, sicherzustellen, da $B$ der Bundesrat zur Beratung zugezogen werde. Es erscheint mir bei uns die Tendenz zu bestehen, Regierung und Parlament ausschließlich in der Rolle der Exekutive und der Legislative zu sehen. Das positive Recht zeigt, daß dem Parlament entgegen der These XIII des ensten Referenten die richterliche Gewalt nicht unbedingt fremd zu sein braucht. Man denke an die Funktion des britischen Oberhauses oder an die quasi richterliche Funktion des Bundesrates nach Art. 84 Abs. 4 GG. Es gibt zahlreiche Beeinflussungsvorgänge, die neben den drei Montesquieu'schen Gewalten stehen und die nicht weniger wichtig sind als diese drei. In der Staatslehre der asiatischen Reiche spielen Beratung, Kontrolle und Examen eine große Rolle. Die 
Beratungsfuniktion des Bundesrates scheint mir sehr wichtig zu sein. Der Bundesrat hat bei dem ersten Referenten wenig Gnade gefunden. Er schien ihm ein merkwürdiges atavistisches Uberbleibsel Bismarck'scher Staatskonstruktion zu sein. Ich meine, in unserer Verfassung ist im Bundesrat allein das Beratungselement institutionell verankert worden. Die Tatsache, daß der Bundesrat bei Initiativgesetzen aus der Mitte des Bundestages seiner eigentlichen Beratungsfunktion anläBlich des ersten Durchganges von Gesetzen enthoben ist, hat sich meist nicht glücklich ausgewirkt. Ich erinnere an den Gesetzentwurf über die Geschwindigkeitsbegrenzung. Der Bundesrat, der hier nicht beim ersten Durchgang beratend tätig werden konnte, sah sich in die peinliche Zwangslage versetzt, in aller Offentlichkeit Einwendungen dagegen zu erheben, daß auch die Polizei und die Feuerwehr an die Einhaltung der Höchstgeschwindigkeit von $50 \mathrm{~km}$ pro Stunde gebunden sein sollten.

Heute vormittag wurde betont, daß Menschen und nicht Institutionen das wichtigste im Verfassungsleben seien. Ich meine, daß hinsichtlich der Beratungsfunktion bei uns nicht genügend Institutionelles geschaffen worden ist. Es wäre meiner Ansicht nach von Vorteil, wenn institutionelle Beratungsgremien sowohl Regierung als auch Parlament in stärkerer Weise unterstützten. Die unterirdischen Einflüsse, von denen der zweite Referent gesprochen hat, würden alsdann stärker im Lichte der Offentlichkeit stehen. Auch hinsichtlich einer nachträglichen Kontrolle scheint es mir an Institutionen zu mangeln. Die Kontrolle sollte sich nicht auf Rechnungskontrolle durch den Rechnungshof und parlamentarische Entlastungsbeschlüsse beschränken; wichtig wäre auch eine unpolemische, sachgemäße politische Beurteilung von Regierungsmaßnahmen.

Im ersten Referat sind meiner Ansicht nach die Sicherungen unterbewertet worden, die in das Grundgesetz eingebaut wurden. Ich meine die 5\%-Klausel und das konstruktive Mißtrauensvotum. Nur ein kurzer Hinweis:

Hätte wohl Hindenburg Papen die Genehmigung für den Staatsstreich gegen Preußen am 20. Juli 1932 gegeben, wenn es sich nicht um eine gestürzte, nur noch geschäftsführende Regierung gehandelt hätte, sondern um eine Regierung, die infolge des Erfondernisses des konstruktiven Mißtrauensvotums noch voll geschäftsfähig gewesen wäre?

In der These XVIII wird die Ansicht vertreten, der Bundespräsident sei verpflichtet, Vorschlägen des Bundeskanzlers hinsichtlich der Ernennung von Ministern eu folgen. Es herrscht eine große Verwirrung hinsichtlich der Bedeutung der 
Worte „Vorschlag“ und „Empfehlung“. Dies gilt besonders für internationale Verträge, in denen das Wort „Empfehlung“ fast jedesmal eine andere Bedeutung erhält. Empfehlung und Vorschlag bedeuten jedenfalls nicht, daß der Adressat einen Befehl erhält, dem er zu folgen hat.

In These XIX wird die Ansicht vertreten, die Bildung einer Allparteienregierung bedeute Verzicht auf eigene Politik. Ich glaube, in Krisenzeiten trifft dies jedenfalls nicht $z u$. Die Regierung Churchill's während des Zweiten Weltkrieges war Allparteienregierung. Sie war aber sicher nicht nur Vollzugsausschuß des Parlaments; sie betrieb im Gegenteil eine sehr eigenwillige Politik. Dasselbe gilt auch für die Regierung unter Lloyd George im Ersten Weltkriege.

Etwas traurig stimmte mich die These XX, wonach die Länder nur noch Verwaltungskörperschaften sein sollen. Vielleicht gestatten Sie mir, die These unter Berufung auf die ,atavistischen Möglichkeiten" des "fehlikonstruierten Bundesrates" in Zweifel zu ziehen, der doch einen gewissen Einfluß auf die Bundespolitik auszuüben vermag.

These II der zusätzlichen Leitsätze besagt, daß akzentuierte Haushaltsansätze bindende Weisungen des Parlaments darstellen könnten; dies scheint mir gefährlich zu sein. Ebenso finde ich die These nicht akzeptabel, eine Landesregierung habe hinsichtlich ihrer Abstimmung im Bundesrat der Weisung ihres Landtags zu folgen. Dadurch würde dem Bundesrat die Möglichkeit zu bemerkenswerten Entscheidungen genommen, wie in der Frage der Montanunion und in anderen Fragen, in denen er sich von parteipolitischen Normen freimachte.

Besonders begrüßt habe ich den Hinweis des ersten Referenten, wie wichtig es ist, daß die Staatslehre nicht hinsichtlich dessen was erreicht worden ist, Defaitismus verbreitet, indem sie unzweifelhaft vorhandene Mängel allzustark in den Vordergrund stellt. Bei der Jugend wird dadurch ein Eindruck erweckt, der nicht beabsichtigt sein mag. Auch hinsichtlich des Gebrauchs des Wortes "Provisorium" sollte man vorsichtig sein. Es wunde ursprünglich aus der Empfindung heraus benutzt, daß der Bau des deutschen Staates so lange unvollendet bleibt, bis unsere Brüder und Schwestern unter sowjetischer Herrschaft freigegeben worden sind. Manchmal wird durch das Wort „Provisorium“ aber der fatale Eindruck erweckt, als lohne es sich nicht, Schwächen im bestehenden deutschen Staat zu beseitigen, ja, als sei deren Erhaltung geradezu wünschenswert, da alsdann das große Ziel das „Provisorium“ zu überwinden, besser erreicht werden könne. 


\section{Hans Schneider-Heidelberg:}

In den Mittelpunkt seines Referates hatte Herr Friesenhahn gestellt das Spannungsverhältnis zwischen Regierung und Parlament. Aber zu diesem Spannungsverhältnis gehört auch eine dritte Kraft, die es überwacht. Und da bedaure ich, ebenso wie Herr Münch und z. T. auch Herr Kondt, daß der Referent die Befugnisse, die das Grundgesetz dem Bundespräsidenten bietet, nicht nur verkürzt, sondern ihm gänzlich abgesprochen hat. Herr Friesenhahn hat z. B. in der These 27 erklärt, $\mathrm{da} \beta$ dem Bundespräsidenten nach dem Vorschlag des Kanzlers die Auflösung des Parlaments als eine verfassungsrechtliche Pflicht obliege. Das steht doch in klarem Widerspruch zum Wortlaut des Artikels 68 GG, wo ausdrücklich die Rede davon ist, daß der Bundespräsident dem Vorschlag entsprechen "k a n n". Ich halte also jene These für eine Auslegung, die über das hinausgeht, was man vertreten darf. Sodann die These: der Bundespräsident müsse die Gesetze ausfertigen und sogar unverzüglich; die Verfassungsmäßigkeit dürfe er nicht prüfen. Ich halte auch das für nicht tragbar. Gewiß, maßgeblich und verbindlich entscheiden kann der Präsident über die Verfassungsmäßigkeit nicht. Das obliegt dem Bundesverfassungsgericht. Aber es ist ja seine Eidespflicht, daß der Bundespräsident in eine Prüfung eintritt, er kann dazu auch ein Gutachten einholen.

Ähnliches gilt von der These 18, daß der Bundespräsident die Entlassung und Ernennung der Minister vornehmen m üs s e. Der Wortlaut ergibt dergleichen nicht. Gerade der Vergleich mit anderen Verfassungsartikeln, die den Artikel 64 einrahmen und in denen das Grundgesetz ausdrücklich von einer Pflicht spricht (durch die Wahl der Worte „ist", "hat", „muß", usw.), zeigt, daß hier eine verfassungsrechtliche Verpflichtung, den Vorschlägen des Bundeskanzlers zu folgen, $\mathrm{nich} t$ besteht. Vor allem der Sinn der ganzen Regelung spricht gegen die Annahme des Referenten. Wenn man mit Herm Friesenhahn davon ausgeht, daB die Stärke des parlamentarischen Systems in der Bereitschaft zum Kompromiß liegt, dann ist es doch eine legitime Möglichkeit des Bundespräsidenten, auf einen solchen Kompromiß hinzuwinken. Dazu müssen dem Bundespräsidenten die Befugnisse, die ihm die Verfassung in die Hand gibt, belassen werden. Wenn das Staatsoberhaupt als pouvoir neutre, als Vermittler, als Modérateur tätig sein soll, so kann er nicht verpflichtet sein, jedem Vorschlag des Bundeskanzlers zu entsprechen. Es ist nicht so, daß die Vorschläge des Kanzlers eine parlamentarische Legitimation besitzen, wie in den Fällen, in denen dem Bundespräsidenten vom Grund- 
gesetz die Verpflichtung auferlegt ist, einem Vorschlage zu entsprechen, weil eine parlamentarische Abstimmung schon vorliegt. Dem Kanzler mag es auch willkommen sein, wenn er bei seinen Koalitionsgesprächen und den anderen Wahllkapitulationen darauf hinweisen kann, daß er verbindliche Zusagen nicht abgeben könne, weil er nicht wisse, in welchem Umfang der Bundespräsident bereit sei, mitzumachen. Wenn ein Kanzler darauf besteht, daß ein Minister seiner Wahl ernannt werde, so kann er schließlich durch Drahung mit dem Rücktritt den Bundespräsidenten vor die Wahl stellen, ob er entweder den Minister ernennen oder riskieren will, daß der Kanzler geht. Ich halte diese ausgleichende Funktion des Bundespräsidenten für um so wichtiger, als das Bundesverfassungsgericht seiner Natur nach als Gericht dieser Aufgabe nicht gerecht wenden kann.

\section{$\mathrm{K}$ a i s e $\mathbf{r}$ - Freiburg:}

Die rechtswissenschaftliche $\mathrm{Dog}$ m a $\mathrm{t} i \mathrm{k}$, die ich sicher nicht weniger hoch schätze als Herr Ipsen, wird, wenn sie nicht retrospektiv sein will, sich unter Umständen angesichts gegebener Tatsachen korrigieren müssen, zu deren Erkenntnis und Bestandsaufnahme die Mittel der political science wie der Soziologie sich als geeignet erweisen mögen.

Darf ich in der gebotenen Kürze den Versuch machen, aus einigen hier namhaft gemachten Tatsachen mir sich aufdrängende Konsequenzen für die Dogmatik des Themas „Verhältnis von Regierung und Parlament" zu ziehen? Dabei scheint mir im Vordergrund zu stehen, daß diesem Bezugssystem von Regierung und Parlament, das in Punkt 8 des ersten Referats hervorgehoben und in Punkt 10 näher dargestellt ist, nicht mehr jene außerondentliche, nahezu ausschließliche Bedeutung für die Formulierung der Politik zukommt, wie es im vorigen Jahrhundert noch der Fall war, und von dem die hergebrachte Dogmatik noch mehr oder weniger als selbstverständlich ausgeht. Es ist heute mehrfach zum Ausdruck gekormmen, daß die Regierung die Auseinandensetzung über ihre politischen Ziele, die Darstellung und das Publikmachen ihrer politischen Vorhaben nicht selten unter Umgehung des Parlaments herbeiführt. Wichtiger für die Dogmatik unseres Themas scheint es mir zu sein, daß das Volk seinerseits noch häufiger den Kontakt und die Auseinandersetzung mit der Staatsfüthrung unter Umgehung des Parlaments sucht. Dafür lassen sich zahlreiche Beispiele anführen. Der Kampf um das Gesetz über die Mitbestimmung der Arbeitnehmer bei Kohle, Eisen und Stahl ist ein extremes, aber aussagekräftiges Beispiel. Ein außergewöhn- 
liches, aber in diesem Zusammenhang erwähnenswertes Beispiel ist auch der Fall, daß Verbände die Auseinandersetzung über die Regierungspolitik auf dem Umweg über internationale Instanzen führen können, indem etwa nach Art. 35 des Vertrages über den Gemeinsamen Markt für Kohle und Stahl die Hohe Behörde von einem Verband oder Unternehmen der Montanindustrie mit dem Gegenstand einer Regierungsmaßnahme, eines Gesetzes oder eines internationalen Vertrages befaßt wird, und indem in derselben Sache etwa auch der Montangerichtshof angerufen wird.

Diese und andere Symptome stellen die im alten Sinne repräsentative Funktion des Parlaments in Frage. Die Medien der öffentlichen Meinung, die Presse, die Einrichtungen zur Meinungserfragung und besonders die Verbände spielen hier ihre Rolle als Konkurrenten des Parlaments. Angesichts dieser Verhältnisse, die man teilweise vielleicht schon als Verfassungsbräuche charakterisieren darf, drängt sich einer rechtswissenschaftlich - dogmatischen Behandlung unseres Themas die Frage auf, ab das Parlament wirklich noch ausschließlich, noch absorbtiv repräsentiert, oder ob nicht auch andere Einrichtungen, insbesondere die Konkurrenz und die Balance der Interessengruppen, bereits heute eine faktische Repräsentation darstellen. Daraus mögen sich auch Konsequenzen für die Praxis ergeben, insbesondere im Sinne einer Bescheidung des Parlaments; Herr Partsch sprach sich mit Recht für den Verzicht auf eine parlamentarische Gegenbürokratie aus; in den Münchener Arbeiten über die Staatsvereinfachung ist auch die Verminderung der Abgeordnetensitze angeregt worden ${ }^{1}$ ).

B öh m er t - Kiel:

Es ist davor gewarnt wonden, das Grundgesetz zur Sprache zu bringen, aber mit Recht hat der Erstreferent den Nachdruck darauf gelegt, daß die Rechtsgrundlage des Verhältnisses zwischen Parlament und Regierung die jeweilige Verfassung, d. h. für uns das Grundgesetz ist. Das Grundgesetz ist nun keineswegs ein vom grünen Tisch nach abstrakten Erwägungen der allgemeinen Staatslehre gewissermaßen voraussetzungslos geschaffenes Dokument, sondern es legt die Begriffe zu Grunde, die in unserer Verfassungsgeschichte der letzten $150 \mathrm{Jahre}$ entwickelt worden sind. Diese Begriffe sind für das heutige Thema 1. die Ministerverantwortlichkeit und 2. das

1) Staatsvereinfachung in Bayern, Gutachten der Arbeitsgemeinschaft für Staatsvereinfachung, München 1955, S. 18 f. 
parlamentarische Prinzip. Der erstere Begriff, der aus dem Konstitutionalismus stammt, bedeutet Verantwortlichkeit des Ministers gegenüber dem Parlament für die VerfassungsmäBigkeit und Gesetzmäßigkeit seines Handelns, eine Verantwortlichkeit, die sich im Wege der Staatsanklage und der parlamentarischen Debatte mit dem Minister vor dem Parlament und dessen Ausschüssen realisiert. Der zweite Begriff, das parlamentarische Prinzip ist erst nach dem Utbergang zur Republik endgültig zu der Ministerverantwortlichkeit hinzugekommen und bedeutet, daß die Minister zu ihrer Amtsführung des Vertrauens des Parlamentes bedürfen, eines Vertrauens, das ihnen auch dann entzogen werden kann, wenn ihnen keinerlei gesetz- und verfassungswidriges Handeln vorgeworfen wird. Die Weimarer Verfassung brachte die Zweiteilung dieser beiden Institute klar zum Ausdruck, und auch das Grundgesetz hat sie übernommen, wenn es auch in der Art ihrer Verwirklichung einige Beschränkungen brachte, die Ministeranklage als überflüssig strich und durch das konstrulktive Mißtrauensvotum die formelle, zum Rücktritt führende Vertrauensfrage einerseits auf den Kanzler beschränkte und zum andern mit der Kanzlerneuwahl verband. Diese Einschränkungen haben nun zu einer Auslegung der Verantwortlichkeit der Bundesminister im Gegensatz zu der Verantwortlichkeit des Bundesk anzle rs geführt, die meines Erachtens dem Sinne der Verfassung widerstreitet. Man hat gesagt, da $B$ in dem Art. 65 GG über die Ministerverantwortlichkeit das Wort „Verantwortlichkeit“ nur bezüglich des Bundeskanzlers den alten in unserer Verfassungspraxis und unserer Verfassungslehre seit 150 Jahren überkommenen Sinn einer Ministerverantwortlichkeit gegenüber dem Parlament habe, während Ministerverantwortlichkeit der Bundes $\mathrm{m}$ in is $\mathrm{t}$ e $\mathrm{r}$ seltsamerweise den völlig neuartigen, in unserem bisherigen Verfassungsleben unbekannten Sinn einer Verantwortlichkeit gegenüber dem Bundeskanzler haben soll. Diese These wird damit begründet, daß die im Art. 54 der Weimarer Verfassung hinter dem Wort "Verantwortlichkeit" stehenden Worte "gegenüber dem Reichstag" nicht in das Grundgesetz übernommen sind, ein Argument, das rechtlich zweifelhaft ist, weil diese Worte in beiden Fällen fehlen: sowohl bei der Verantwortlichkeit des Bundeskanzlers, wie auch bei der Verantwortlichkeit der Bundesminister, was gerade nicht für einen Willen des Gesetzgebers zur Sinnesänderung der übernommenen Weimarer Formel, sondern nur für dessen Wunsch nach Breviloquenz spricht. In gleiche Richtung weist, daß die Weimarer Formel des Art. 54 W.V. teils mit, teils ohne die Ver- 
kürzung des Grundgesetzes in die Landesverfassungen übernommen worden ist und es unmöglich erscheint, da $B$ sie dort teils den neuen, teils den alten Sinn haben soll. Das Referat des Erstreferenten scheint mir nun der hier bezweifelten neuartigen Auslegung der Verantwortlichkeit der Einzelminister ihren Boden entzogen zu haben. Denn, wenn schon nach seiner 25. These Mißbilligungsanträge des Parlaments, Anträge also, die die Frage des Vertrauensverhältnisses zwischen Parlament und Minister betreffen, und nicht deren Verantwortlichkeit gegenüiber dem Parlament für die Rechtmäßigkeit ihres Handelns, zulässig sein sollen, so mußß der Herr Erstreferent de majore ad minus der Meinung sein, daß die hier bekämpfte Auslegung des Art. 65, nach der „Verantwortlichkeit der Bundesminister" die Verantwortlichkeit gegenüber dem Bundeskanzler betreffen soll, nach seiner Meinung erst recht unhaltbar ist. Innerhalb der Bundesregierung, die dem Bundestag gegenübertritt, haben die Bundesminister im Rahmen der allgemeinen Richtlinien eine selbständige Stellung auch neben dem Bundeskanzler. U.a. tritt diese in ihrer selbständigen Verantwortlichikeit gegenüber dem Parlament hervor.

\section{E r l e r - Göttingen:}

Im Zusammenhang mit dem, was Herr Carstens, Herr Kordt und Herr Ipsen über die Machteinschränkung des Parlaments durch die Hingabe von Hoheitsrechten an internationale Gemeinschaften gesagt haben, ist auf ein Problem hinzuweisen, das sehr häufig übersehen wird, nämlich auf das der parlamentarischen Haushaltskontrolle. Traditionell wird es als eine wesentliche Komponente der Macht des Parlamentes angesehen, $\mathrm{da} B$ es auf die Gestaltung des Staatshaushaltes durch die Haushaltsbewilligung und die Haushaltskontrolle einen entscheidenden Einfluß hat. Aber in immer steigendem Maße ist es durch die Abgabe von Hoheitsbereichen an internationale Gemeinschaften, aber auch ohne diese schon durch die Bindung des Staats durch langfristige internationale Verträge dazu gekommen, daß der Haushalt mit gewissermaßen international festgeschriebenen Positionen belastet ist.

Ich darf Sie zunächst an die Beiträge erinnern, die an internationale Organisationen zu leisten sind. Natürlich bleibt die Summe dieser Beträge noch relativ harmlos, soweit es sich lediglich um Umlagen zur Verwaltungsgestaltung internationaler Organisationen handelt. Aber denken Sie darüberhinaus an die Festlegung von Anteils- und Garantiesummen in inter- 
nationalen Fonds, wie wir sie im Internationalen Währungsfonds, in der Weltbank, in der Europäischen Zahlungsunion und den verschiedenen Investitionsfonds heute schon haben. Denken Sie darüberhinaus an solche Dauerverpflichtungen wie das Schuldenabkommen, das noch über 40 Jahre hinaus das Parlament bindet. Denken Sie ferner an die internationale Besteuerung, wie wir sie schan bei der Montangemeinschaft in Form der ondentlichen Produktionsumlage haben. Sie ist zwar nur mittelbar für den Staatshaushalt belastend, auf der Rückseite gewissermaßen; aber dort, wo Besteuerungen der internationalen Gemeinschaften durch die staatlichen Grenzen hin durchgeführt werden, kann der nationale Besteuerer die Quelle nicht mehr so stark anzapfen, wie er es sonst vermöchte.

Denken Sie endlich auch an die anteiligen Quoten, an die Aufwendungen, die für große internationale Gemeinschaften und Aufgaben in steigendem Maße verlangt wenden. Wenn Hoheitskompetenzen, wie etwa die der gemeinsamen Verteidigung, der Wirtschafts- und Energieverwaltung, aus dem nationalen Bereich ausgeklammert und in eine internationale Kompetenz überführt werden, dann werden von den internationalen Verwaltungsträgern auf die einzelnen beteiligten Staaten notwendig sehr hohe Beiträge umgelegt. Das Beeinträchtigende für die Parlamente der Einzelstaaten liegt in der Tatsache, daß diese Beiträge nicht mehr in ihrer Höhe von dem Parlament selbst bestimmt werden, sondern daß ihre jährliche Festsetzung in die Hände von Gremien kommt, die ohne wesentliche parlamentarische Kontrolle und ohne eine bestimmende Einflußnahme des Parlamentes der Staaten, die finanziell belastet werden, beschließen, was jeder einzelne Mitgliedsstaat zu zahlen hat. Zwar sind diese Festsetzungen heute noch von vielen Klauseln umgeben; aber letztlich kann sich kaum ein Staat dem politischen, wirtschaftlichen und moralischen Druck einer solchen internationalen Germeinschaft, sich prozentual an den notwendig werdenden Ausgaben zu beteiligen, entziehen. So ergeben sich Jahr für Jahr für den Staat Haushaltspositionen, die durch langlebige internationale Verträge festgelegt sind oder in wechselnder Höhe durch internationale Stellen beschlossen wenden und die automatisch den Haushalt mit festgeschriebenen Posten belasten.

Ich glaube, es ist nicht ganz uninteressant, auf diese Entwicklung, die sich hier anbahnt, - die heute noch nich.t voll zur Wirkung kommt, die aber zweifellos in der Zukunft immer deutlicher wenden wind, - hinzuweisen. Sie zeigt, daB durch die Auswirkungen der internationalen Vereinbarungen und internationalen Körperschaften die Kompetenzfülle des Parla- 
mentes - gewissermaßen lautlos - dadurch eingeengt wird, daß sie sich nicht mehr uneingeschränkt bei einer der vornehmsten Funktionen des Parlamentes, bei der Festsetzung des Haushaltes, äußern kann.

Ein Wort sei noch gesagt zu den Problemen der begleitenden und der rückblickenden Kontrolle über den Haushalt. Bisher hat sich offenbar eine wirksame parlamentarische begleitende und rückblickende Kontrolle über die internationalen Gemeinschaftshaushalte nicht verwirklichen lassen. Es wird notwendig sein, völkerrechtliche oder staatengemeinschaftliche Formen zu entwickeln, durch die eine echte parlamentarische Kontrolle über die Ondnungsmäßigkeit der öffentlichen Ausgaben in internationalen Gemeinschaften sichergestellt wird.

\section{Parts ch-Kiel (Schlußwort):}

Ich kann mich sehr kurz fassen, da sich die meisten Diskussionsredner an den Vorschlag von Herrn Ipsen gehalten haben, sich auf die Fragen des positiven deutschen Rechts zu beschränken.

Herr Münch hat - wie mir scheint - sowohl Herrn Friesenhahn - wenn ich das hier sagen darf - wie auch mich mißverstanden. Wir haben den Begriff des modernen Staates beide in keiner Weise mit dem parlamentarischen Regienungssystem identifiziert, sondern waren uns beide - so glaube ich - darin einig, daß es nicht e in parlamentarisches Regierungssystem, sondern da $B$ es verschiedene Typen von parlamentarischen Regienungssystemen gibt. die sich untereinander stank unterscheiden und daß wir deswegen so vorsichtig sein mußten, wenn wir hier Rechtvergleichung betrieben, weil wir bei jedem Vergleich mit dem Einwand rechnen mußten, er sei unzulässig, da in der herangezogenen fremden Rechtsordnung diese oder jene Faktoren mitspielten, welche ihr ein eigenes Gepräge gäben.

Herr Carstens hat das interessante Problem der Kontrolle der Ministerräte in internationalen Organisationen angeschnitten, das zu dem Komplex der Regierungskontrolle gehört und nicht zu meinem Prablemkreis, da ich mich auf das Parlament als Normensetzer beschränkt habe. Ich glaube allerdings, daß man die Frage nicht so pessimistisch wie Herr Carstens anzusehen braucht; der Minister, der im Ministerrat abstimmt, ist natürlich dem nationalen Parlament für das, was er dort tut, verantwortlich. Wenn das Parlament sein Verhalten zum Gegenstand einer Diskussion zu machen wünscht, dann ist es daran nicht dadurch gehindert, daß die Abstim- 
mungen in diesem Gremium geheim waren, denn das Parlament hat die Möglichikeit, die Diskussion darüber auch seinerseits in einen geheim tagenden Ausschuß zu verlegen; der auswärtige Ausschuß ist das gegebene Forum dafür. Wir haben nicht nur im deutschen Parlament, wir haben auch im amerikanischen Senat viele Beispiele dafür, daß in den Ausschüssen allergeheimste Dinge beraten wurden und die Minister dabei sehr eingehenden Verhören über ihr Verhalten in den Ministerräten der internationalen Organisationen unterzogen wurden.

Wenn ich dann noch eine Kleinigkeit berichtigen darf: Herr Ipsen hat mich offenbar mißverstanden. Ich habe nicht davon gesprochen, da $\beta$ die Kanalisierung der lobby im Parlament stattfinden müßte, sondern habe gerade darauf hingewiesen, $\mathrm{da} B$ es notwendig ist, sie auf der Regierungsebene vorzunehmen.

Diese drei Punkte würden es nicht rechtfertigen, daß ich von dem Rechte Gebrauch mache, am Schluß der Diskussion das Wort zu ergreifen, sondern ich tue es in erster Linie, um meine Methode zu verteidigen, nachdem sie - vor allem von Herm Ipsen - angegriffen worden ist. Ich glaube, sie würden die Staatsrechtswissenschaft etwa auf den Stand der Zivilrechtswissenschaft aus der Zeit vor 1910 zurückwerfen, wenn wir uns darauf beschränken wollten, wie Herr Scheuner es so treffend darlegte, einzelne Grundrechtsartilkel zu interpretieren. Die moderne Zivilrechtswissenschaft hat ihren Impuls erst dadurch bekommen, da $B$ die Interessenjurisprudenz einbrach, die Begriffjurisprudenz hinwegschwemmte und statt dessen lehrte, die Rechtsnormen auf der Grundlage einer intensiven Tatsachenerforschung am Leben zu messen. Mir scheint, daß wir auf der staatsrechtlichen Ebene etwas ähnliches tun müssen, indem wir uns mit dem Leben der Institutionen, die durch die Verfassung geschaffen wurden, beschäftigen, und $\mathrm{da} B$ wir erst auf dieser Grundlage weiterschreiten können.

\section{Friesenhahn-Bonn (Schlußwort):}

Ich möchte Ihnen zunächst danken für die Anregungen, die mir die Diskussion gebracht hat, aber ich kann meine Enttäuschung nicht verhehlen. Ich hatte mir hier einen frischfröhlichen Streit erhofft und bedaure außerondentlich, daß unsere Diskussionen immer darunter leiden, da $\beta$ die Guillotine des Parlamentes auch hier eingeführt wird, und da $B$ dann, wenn Kollegen sehr wichtige Dinge zu sagen haben, die Klingel des Vorsitzenden ertönt. Unsere Verhandlungen leiden, wenn im- 
mer nur ganz kurze Ansätze in der Diskussion vorgebracht werden können.

Was meine Methode angeht, so möchte ich Herm Scheuner danken, daß er mich gegen Herrn Ipsen etwas verteidigt hat. Ich glaube, Herr Ipsen, an sich sind wir sehr verwandte Naturen. Man wirft mir oft vor, daß ich zu sehr dogmatischkonstruktiv arbeite, aber hier muß ich sagen: eine Behandlung dieses Themas in der Weise, wie Sie sie vorschlagen, ist überhaupt nicht möglich. Wenn ich es etwas scharf zuspitze, so wollten Sie mir vielleicht sagen, daß ich so ein bißchen staatsbürgerliche Bildung betrieben habe, so etwas versucht habe, unser Verfassungssystem für höhere Schüler schmackhaft zu machen. Ich darf dem entgegenhalten, daB alles das, was ich gesagt habe, in der Gegenposition auch im staatsrechtlichen Schrifttum zu finden ist, und daß es darum schon wichtig ist, auch solche Dinge hier anzurühren. Nur von diesen Faikten aus gesehen, lassen sich auch wesentliche Fragen unseres Verfassungsrechts lösen. Ich konnte also gar nicht anders vorgehen, als zunächst eine gewisse Typenlehre auszubreiten.

In der Diskussion wurde als Lücke empfunden, daß das Referat den Bereich der supranationalen Gemeinschaften nicht behandelt habe, und die Diskussion hat sich besonders eingehend darauf erstreckt. Nun habe ich natürlich auch diesen Problemkreis gesehen, aber ich habe ihn bewußt ausgeklammert, weil ich sonst noch länger hätte reden müssen. Die Erörterung der Fragen:

a) Wie sollen auf der supranationalen Ebene die Beziehungen zwischen Beratender Versammlung, Exekutivbehörde und Ministerrat geordnet werden?

b) Wie sind die Relationen zwischen den supranationalen und den nationalen Organen?

wäre ein Referat für sich gewesen. Das konnte ich einfach nicht bringen.

Ich weiß natürlich auch, daß wir nicht-parlamentarische Regierungen haben, Aber wenn ich versucht hätte, die Probleme, die mit der Themen-Stellung aufgeworfen sind, der Reihe nach durchzuarbeiten a) für Präsidialregierungen, b) für parlamentarische Regierungen aller Typen, wäre ich nie zu Ende gekommen. Ich konnte also nur den Versuch machen, eine Schneise zu legen, um dann auch einmal nach rechts und links Ausblicke zu geben, rechtsvergleichende Ausblicke auf andere Systeme. Wir hatten weiter schon hinter uns die Heidelberger, Bonner, Hamburger und Mainzer Tagung, alles Tagungen, auf denen genau die gleichen Fragen von irgendeinem 
Punkt her schon angerührt worden sind. Wir haben in Heidelberg bereits die Kabinettsfrage und den Gesetzgebungsnotstand behandelt. Wir haben uns in Bonn mit der auswärtigen Gewalt beschäftigt, und ich stehe heute Herrn Menzel näher als damals, wie Sie bemerkt haben werden. In Hamburg haben wir von der Finanzgewalt gesprochen, und in Mainz war das Maßnahmegesetz Verhandlungsgegenstand.

Es wäre reizvoll gewesen, die Finanzgewalt von dem hier gewählten Ausgangspunkt aus eingehender zu behandeln. Unter II 2 habe ich dazu noch beiläufig eine These mit eingeflickt. Und Herr Erler hat zum Schluß noch darauf hingewiesen, wie die Masse der fixen Posten so außerordentlich stark geworden ist, so daß das Parlament kaum noch Bewegungsfreiheit hat. Daraus gerade ist meine These erwachsen: weil die Budgetkontrolle heute nicht mehr die alte Bedeutung hat, müssen die ülbrigen Kontrollen um so stärker eingesetzt werden.

Wenn einer der Redner, es war Herr Kordt, gesagt hat, ich würfe den Blick zu stark auf die Legislative, so muß ich darauf hinweisen, daß ich nicht von "Legislative“ und „Exekutive", sondern ganz bewußt nur von Regierung und Parlament gesprochen habe, um zwei Organe zu bezeichnen und nicht die Funktionen. Gerade da $\beta$ das Parlament eben nicht nur Legislative ist, war eine meiner Hauptthesen, und ich habe auch keineswegs, wie andere Redner geglaubt haben, etwa die These verfochten, das Parlament solle Exekutive werden. Ich habe von einer "Mitwirkung“, von einer Staatsführung „zur gesamten Hand" gesprochen. Bei der Kürze, deren ich mich hier befleißigen mußte, ist wohl nicht alles so klar herausgekammen, wie es an sich nötig gewesen wäre.

Wenn Herr Scheuner mir entgegenhält: Um Gattes willen, wie kann noch ein Minister verantwortlich sein, wenn das Parlament ihm in die Ernennung der Beamten hineinredet?, so erwidere ich, daß insofern sehr genau unterschieden werden muß. Vielleicht wissen es viele Kollegen gar nicht, daß ein Staat wie Hamburg es fertig bringt, alle Ernennungen und Beförderungen der Beamten von der Zustimmung eines Ausschusses abhängig zu machen, der aus einigen höheren Beamten und einigen von der Bürgerschaft gewählten Mitgliedern besteht. Auch das gibt es also. Meine These war zunächst nur im Hinblick auf den bekannten Streit in Niedersachsen konzipiert worden: Das Haushaltsgesetz band die Ernennung der Mitglieder des Rechnungshofs an die Zustimmung des Parlamentes; die Regierung erklärte eines Tages, das sei als Verstoß gegen die Gewaltenteilung verfassungswidrig und nichtig; 
daraufhin wurde sofort auf Antrag aller Parteien die Verfassung geändert. Das halte ich nicht für notwendig, weil, Herr Ipsen wird mir zustimmen, - der Rechnungshof doch ein Kontrollorgan des Parlamentes ist, und es daher durchaus legitim ist, wenn das Parlament sich ein Mitwirkungsrecht vorbehält, auch wenn diese Beamten formell von der Regierung ernannt werden. Ich denike also nicht daran, es für zulässig zu halten, die gesamte Beamtenernennung durch einfaches Gesetz an parlamentarische Zustimmung zu binden.

Worauf es mir ankam, war darzulegen, daß es kein verfassungskräftiges Vorbehaltsgebiet für die Regierung in dem Umfang gibt, wie es vielfach in Anwendung eines überspitzten Gewaltenteilungsdogmas angenommen wird. Natürlich haben wir einen gewissen Bereich der Regierung, nur glaube ich, da $B$ viele Herren Kollegen - entschuldigen Sie, Herr Weber, wenn ich Sie hier apostrophiere - die Grenze der Gewaltenteilung zwischen Regienung und Parlament etwas all zu scharf ziehen. Wo parlamentarische Regierungsweise herrscht, kann man nicht so scharfe Grenzen ziehen; hier gibt es ein Hinüberund Herüberwirken. Dabei habe ich die durchaus führende Funktion der Regierung deutlich herausgestellt. Es kam mir darauf an, diese Wechselwirkung, die man - wie ich glaube gar nicht in ganz klare Formeln bringen kann, herauszuheben, durchaus die Initiative der Regierung $\mathrm{zu}$ betonen, aber auch dieses Getragensein vom Parlament, das unter Umständen seinen Willen der Regierung auferlegen kann. Wenn ich von "Weisungen" gesprochen habe, so weiß ich natiürlich auch, daß das nicht Weisungen sind, die eine Ministeranklage zur Folge haben könnten, wenn sie nicht befolgt werden. Aber es geht um die Frage, ob das Parlament überhaupt Beschlüsse über die Führung der Politilk fassen darf, oder ob solche Anträge gar nicht zur Abstimmung gestellt wenden dürfen, weil das Parlament damit den ihm durch die Verfassung zugemessenen Kompetenzbereich überschreitet. Es kommt mir darauf an, daß das Parlament legitimerweise allgemeine politische Debatten führen und mit solchen Willenskundgebungen abschließen darf. Ich erinnere an die Debatten im Bundestag über die Wiedervereinigung und über die Saarfrage, insbesondere an die Atomrüstungsdebatte mit ihrer abschließenden Weisung, die der Regierung solche Kopfschmerzen gemacht hat. Das ist also verfassungsrechtlich legitim und kann nicht von vornherein abgebogen wenden mit der Behauptung: das gehört gar nicht zu den Aufgaben des Parlaments.

Ähnlich liegt es, Herr Böhmert, mit der Frage der Verantwortung der Bundesminister. Was Sie ausgeführt haben, steht 
ungefähr wörtlich in meinem zweiten Teil. Es ist ganz klar für mich, daB die Bundesminister auch dem Parlament verantwortlich sind, und nicht nur dem Bundeskanzler. Man muß unterscheiden zwischen der Verantwortlichkeit und den Mitteln, die Verantwortlichkeit geltend zu machen. Meine These geht dahin: Verantwortlichkeit vor dem Parlament bedeutet, da $B$ das Parlament den Minister zitieren kann, daß der Minister Rede und Antwort stehen, auf Anfragen replizieren muß usw. Eine weitere Frage ist dann, ob das Parlament auch in der Lage ist, den Minister von sich aus zu stürzen. Es wird oft übersehen, daß es sich dabei um zwei grundverschiedene Dinge handelt. Wenn auch die Bundesminister nicht vom Bundestag gestürzt werden können, so sind sie doch dem Bundestag verantwortlich. Das hat Bedeutung für die Frage der Mißbilligungsvoten. Sie erinnern sich an die Debatte im Bundestag über das Telegramm des Justizministers Dehler an die Mannheimer Juristen betreffend den PlenarbeschluB des Bundesverfassungsgerichts und an den Mißbilligungsantrag der SPD. Die CDU wrüte genau, daB es eine ganz faule Sache war. Sie konnte schlecht aus sachlichen Gründen dagegen stimmen, also klammerte man sich an das Argument: Mißbilligungsvoten sind verfassungsrechtlich überhaupt nicht zulässig. Nach meiner Meinung sind solche Mißbilligungsvoten, Tadelsvoten $u$. dgl. durchaus zulässig, und es muß darüber abgestimmt werden. Welche Folgen sie haben, ist eine andere Frage. Aber lesen Sie einmal die Debatten im bayerischen Landtag über das Verhalten des Justizministers Müller in der Auerbach-Affäre nach. Im Ergebnis haben sie doch dazu geführt, daß der Ministerpräsident ihn entlassen mußte, weil das Parlament erklärte: mit ihm arbeiten wir nicht mehr zusammen.

Was Herr Pfeifer über das österreichische Beispiel gesagt hat, hat natürlich seine praktischen Erfahrungen als österreichischer Oppositions-Parlamentarier für sich. Aber ich fühle mich nicht ganz widerlegt. Ich meine, daß in dem österreichischen Koalitions-Regime doch nicht eigentlich die Verfassung aufgehoben ist, sondern es scheint mir, daß dort eben die Mehrheitsparteien eine neue Methode entwickelt haben, den Mehrheitswillen festzustellen. Auch in Osterreich dürfte doch niemals ein Abgeordneter deshalb sein Mandat verlieren, weil er dem Koalitionspakt entgegengehandelt hat, nur ist vielleicht dort der Druck etwas größer als bei uns. Es scheint mir nur ein gradueller Unterschied zu sein, aber das hebt nicht auf, daß dieses österreichische Beispiel doch eminent interessant ist dafür, wie man versucht, eine gemeinsame Regie- 
rung über bestehen bleibende Gegensätze hinweg zu bilden. Man muß dabei auch an die großen Koalitionen denken. Vielleicht ist die österreichische Regierung mehr große Koalition als Allparteienregierung; sie liegt gerade an der Grenze. Die Bildung der großen Koalitionen, diese Verständigung auf einen gewissen Bereich unter Freihaltung anderer Bereiche, scheint mir eine für die heutige Lage - Parlament und Regierung im modernen Staat - außerondentlich wichtige Angelegenheit zu sein.

Was die Stellung des Bundespräsidenten angeht, die ja von mehreren Diskussionsrednern angesprochen wonden ist, so darf ich zunächst Herrn Hans Schneider sagen, daß mich das Argument aus dem Wortlaut nicht sehr überzeugt. Gerade Bestimmungen einer Verfassung, die politisches Recht ist, müssen stärker aus dem Gesamtzusammenhang heraus interpretiert werden als aus dem bloßen Wortlaut. Aus dem System der Verfassung, aus der Ausgestaltung der einzelnen Verfassungsorgane und ihrer Zuordnung zueinander kann sich unter Umständen ergeben, daß das Wort „kann“ ein politisches „muß“ verschleiert. Ich darf daran erinnern, daß zu der umstrittenen Frage der Ernennung und Entlassung der Minister Walter Jellinek schon auf der Heidelbenger Tagung gesagt hat, daß er gar keinen Zweifel habe, daß der Bundespräsident dem Ersuchen des Bundeskanzlers folgen müsse. Nach dem Grundgesetz wird der Bundeskanzler grundsätzlich von der Mehrheit der Mitglieder des Bundestags gewählt, und zwar letztlich ohne Rücksicht auf einen Vorschlag des: Bundespräsidenten. Der Bundeskanzler ist die Zentralfigur der Bundesregierung; er bestimmt die Richtlinien der Politik; ihm allein kann das Mißtrauen ausgesprochen werden. Der Bundespräsident ist bewußt schwach gehalten worden. Dann kann es nicht dem System des Grundgesetzes entsprechen, daß der Bundespräsident Einfluß auf den personalen Bestand der Bundesregierung nehmen und den Bundeskanzler daran hindern darf, die Regierung so zusammenzusetzen, wie er es nach Verständigung mit den politischen Parteien wünscht.

Herr Schneider hat nun vor allen Dingen noch die Funktion des Bundespräsidenten als pouvoir neutre hervorgehoben. Aber dazu möchte ich sagen, daß doch jene Aufwertung des Reichspräsidenten der Weimarer Reichsverfassung mit Hilfe des Begriffs des pouvoir neutre verfassungsrechtlich nur deshalb gerechtfertigt war, weil auch er aus allgemeiner Vollkswahl hervorgegangen war wie das Parlament. Gehen wir doch auf die Grundlagen zurück: Weimar hatte den Reichspräsidenten aus allgemeiner Volkswwahl, hatte das sozusagen 
unbeschränkte Auflösungsrecht, hatte die Möglichkeit, daß der Reichspräsident nach seinem Ermessen den Reichskanzler ernennen und entlassen, ja ausgesprochene Kampfregierungen bilden konnte. Alles das gilt nicht für den Bundespräsidenten nach dem Grundgesetz. Darum glaube ich nicht, daß dieser eine solche Funktion haben kann, wie sie dem Weimarer Reichspräsidenten zukam. Ich habe üibrigens in meinem Referat darauf hingewiesen, da $\mathrm{B}$ das Nominationsrecht im politischen Raum eine gewisse Einflußmöglichkeit gibt, daß der Bundespräsident vorher sondieren, daB er die Parteiführer zu sich bestellen und damit unter Umständen der Regierungsbildung eine gewisse Richtung geben kann. Aber ich bestreite, daß nach dem System des Grundgesetzes dem Bundespräsidenten ein wirklich entscheidender Einfluß auf Bildung und Bestand unserer Bundesregierung zukommen kann.

$\mathrm{DaB}$ meine These über das Prüfungsrecht des Bundespräsidenten auf heftigen Widerspruch stoßen würde, war mir klar. Ich stehe da ja mit Herm Peters ziemlich isoliert. Trotzdem halte ich daran fest. Sie erinnern sich, daB hier in diesem Raum vor 35 Jahren Richard Thoma seinen Vortrag über das richterliche Prüfungsrecht gehalten und damals gesagt hat, wir brauchten kein richterliches Prüfungsrecht, weil wir genügend andere Kontrollen eingebaut hätten. In diesem $\mathrm{Zu}-$ sammenhang erwähnte er auch das nach seiner Auffassung bestehende materielle Prüfungsrecht des Reichspräsidenten. Nun ist heute das richterliche Prüfungsrecht verfassungsrechtlich anerkannt, und zwar in der extremen Form, daß die Verwerfungskompetenz beim Bundesverfassungsgericht konzentriert ist. Dann scheint es mir aber nicht mehr konsequent zu sein, trotzdem noch dem Bundespräsidenten mit seiner dem Parlament gegenüber doch schwächeren politischen Grundlage das Recht zu geben, vom Parlament beschlossene Gesetze zu verwerfen. Nach den Grundlagen unserer Verfassung muß, wenn das Parlament ein Gesetz beschlossen hat, dieses Gesetz auch verkündet werden, und nur dem Bundesverfassungsgericht steht es zu, seine etwaige Verfassungswidrigkeit festzustellen. Am Rande: Sie wissen, daß in Berlin der Präsident des Abgeordnetenhauses die Gesetze ausfertigt, und in Frankreich ist es so, daß, wenn der Staatspräsident die Gesetze nicht binnen der bestimmten Fristen ausfertigt, der Präsident der Nationalversammlung die Gesetze ausfertigt und verkündet. Das ist meiner Meinung nach absolut konsequent. Für das materielle Prüfungsrecht des Bundespräsidenten wird nun auf den Wortlaut des Grundgesetzes verwiesen: Der Bundespräsident habe "die nach den Vorschriften dieses Grund- 
gesetzes zustande gekommenen Gesetze" zu verkünden. Zur Weimarer Zeit hieß es: Wenn der Reichspräsident die Gesetze verkünden muB, die verfassungsmäßig zustande gekommen sind, dann könne die Prüfung micht beschränkt sein auf das formelle Zustandekommen der Gesetze, weil die Form davon abhängig sei, ob die Gesetze mit der Verfassung inhaltlich in Einklang stünden. Dieses Argument konnte frühher allenfalls durchgehen, weil die Technik der Verfassungsdurchbrechung mit verfassungsändernder Mehrheit anerkannt war. Heute aber haben wir ein spezielles Gesetzgebungsverfahren für verfassungsändernde Gesetze. Und nach meiner Meinung heißt heute prüfen, $a b$ ein Gesetz verfassungsmäßig zustande gekommen ist, nur prüfen, ob der eine oder der andere von diesen beiden Wegen eingehalten worden ist. Das kann aber nicht bedeuten, da $B$ der Bundespräsident oder die gegenzeichnende Bundesregierung erklären dürfen, ein Gesetz, das im einfachen Weg beschlossen worden ist, sei deshalb nicht gültig, weil eine Verfassungsänderung vorausgehen mußte. Aber hier - weiß ich - kämpfe ich ziemlich allein auf weiter Flur.

Ich muß damit meine Bemerkungen abschließen. Die Diskussion hat noch viele andere Anregungen gebracht, auf die ich aus Zeitmangel nicht mehr eingehen kann. Ich hoffe, mich darüber an anderer Stelle noch äußern zu können. 